\title{
The Code Decoded
}

\author{
A user's guide to the \\ International Code of Nomenclature \\ for algae, fungi, and plants
}


In memory of my mother,

Eileen Turland, née Simms (1938-2014) 


\title{
The Code Decoded
}

\author{
A user's guide to the \\ International Code of Nomenclature \\ for algae, fungi, and plants
}

\section{Second edition}

\section{Nicholas Turland}

Nicholas Turland

Botanischer Garten und Botanisches Museum Berlin, Freie Universität Berlin, Königin-Luise Str. 6-8, 14195 Berlin, Germany; n.turland@bgbm.org 


\section{The Code Decoded}

A user's guide to the International Code of Nomenclature for algae, fungi, and plants Second edition

Author: Nicholas Turland

Cover image: Kautsar Aritona

ISBN 978-954-642-963-6 (Paperback)

ISBN 978-954-642-964-3 (E-book)

Sofia, 2019

Pensoft Publishers PENSOr.

12, Prof. Georgi Zlatarski Str.

1111 Sofia, Bulgaria

e-mail: info@pensoft.net

www.pensoft.net 


\section{CONTENTS}

$\begin{array}{ll}\text { PREFACE } & 7\end{array}$

ACKNOWLEDGEMENTS 9

$\begin{array}{lr}\text { CHAPTER } 1 & 10\end{array}$

Introduction

CHAPTER 2

15

Basic concepts and terms

CHAPTER 3

23

Structure and organization of the Code

CHAPTER 4

25

Media for publication

CHAPTER 5

30

How to publish a new name

CHAPTER 6

55

How to find the correct name for a taxon

CHAPTER 7

65

How to designate a type

CHAPTER 8

Conservation, protection, rejection, suppressed works, and binding decisions

CHAPTER 9

How to cite authors of names

CHAPTER 10

100

How to spell names

CHAPTER 11

112

Names of algae, fungi, fossils, and hybrids, and of groups not covered by the Code

CHAPTER 12

Important dates in the Code 
CHAPTER 13

137

How to change the Code

CHAPTER 14

146

A very brief history of the Code

CHAPTER 15

150

Resources for biological nomenclature

REFERENCES

156

ABBREVIATIONS, ACRONYMS, SYMBOLS, AND LATIN WORDS

166

INDEX TO SUBJECTS

174 


\section{PREFACE}

The purpose of this second edition of The Code Decoded is to serve as a user's guide to the International Code of Nomenclature for algae, fungi, and plants ("Code"), specifically the Shenzhen Code (Turland \& al., 2018). My objective, as for the first edition (Turland, 2013), has been to create a text that is reasonably clear and simple, which inevitably means it will fail to cover every rule and explain every circumstance that you, the user, will encounter. A very simple guide would be forced to gloss over so many important details that I fear it would be of limited use, whereas a truly comprehensive guide would be even more complex and intimidating than the Code itself. These two hypothetical guides would seem to defeat the objective, so instead I offer what I hope is a middle path, neither oversimplified nor unnecessarily complicated. While I realize the futility of trying to satisfy all potential users, I hope that this guide will be useful to those who are new to the Code as well as to veterans who nevertheless are not familiar with every arcane detail. The chapters are arranged so that the guide may be used for quick reference, e.g. important dates for certain rules, how to publish a new name, how to find the correct name for a taxon, how to designate a type, or even how to try to change the Code itself. Again with quick reference in mind I have employed subheadings, boxes, bulleted lists, tables, and key words in boldface. I have tried to explain the text of the Code in plain language, although it is necessary to know some technical terms in order to follow this guide (and for those, see Chapter 2).

In preparing this second edition, my aims were as follows: (1) update the guide according to the Shenzhen Code; (2) correct any errors discovered in the first edition; (3) delete any obsolete content in the first edition; (4) add new content that would improve the guide; and (5) try to improve clarity and precision without adding too much complexity.

Some readers will be aware of other guides to biological nomenclature, in various languages. I do not attempt to list them all here, but will mention three English-language examples. Biological nomenclature (Jeffrey, 1989), in its third edition, is quite broad in its scope, dealing with issues of biological nomenclature in general and discussing the contemporary botanical, zoological, and bacteriological codes. Plant names: A guide to botanical nomenclature (Spencer \& al., 2007), in its third edition, deals with botanical nomenclature (i.e. plants, not algae or fungi) and cultivated plant nomenclature. The names of plants (Gledhill, 2008), in its fourth edition, deals with the nomenclature of algae, fungi, and plants and includes an extensive (381-page) glossary of generic names, epithets, and word particles together with their meanings.

You may be curious as to how I became involved with biological nomenclature, in which case the short autobiographical sketch that follows may be of interest. In 1993 I was working on floristic projects in the Department of Botany at the Natural History Museum, London, mostly as a volunteer. Then a position became available working on the 
Linnaean Plant Name Typification Project, headed by Charlie Jarvis. I applied for the job and was granted an interview, where I managed to convince the panel that I had grasped the rudiments of nomenclature and was familiar with databases, such that I was offered the job. I happily accepted and spent the next few days reading the Code, then the Berlin Code, from cover to cover (details of all editions of the Code, and of the International Botanical Congresses referred to in this guide, can be found in Chapter 14). This proved to be a good move, because the baptism of fire that followed immersed me in Linnaeus's 18th-century world, or rather a late 20th-century interpretation of it. Original material, Linnaean annotation, lectotypes, neotypes, epitypes, current usage, effective typification, conservation, and rejection all became everyday words. But alas all good things must come to an end, and my fixed-term contract terminated in 1997, when I moved to a new position working on the Flora of China at the Missouri Botanical Garden, Saint Louis.

In 1999, Saint Louis was the venue for the XVI International Botanical Congress. I attended the Nomenclature Section there with keen interest, and was delighted to be invited by the then Rapporteur-général, Werner Greuter, to serve on the Editorial Committee for the Saint Louis Code. There followed much work verifying proposed corrections to Appendix IIB (of conserved family names) for the Saint Louis Code, and then further work on the Special Committee on Suprageneric Names, which reported to the Vienna Congress of 2005. In 2003, the Rapporteur-général for the Vienna Congress, John McNeill, proposed that I be Vice-rapporteur. This entailed my working closely with him to co-edit the Proposals to Amend the Code column in Taxon, prepare the synopsis of proposals prior to the Vienna Congress of 2005, assist at the Nomenclature Section in Vienna, and serve again on the Editorial Committee to produce the Vienna Code. In the years leading up to the Melbourne Congress, I participated in the Special Committee for Electronic Publication, which developed the rules that now permit electronic material to be effectively published, and was I served again as Vice-rapporteur at the Melbourne Congress of 2011 and on the Editorial Committee for the Melbourne Code. At the Melbourne Congress, John McNeill had decided not to seek re-election as Rapporteur-général for the Shenzhen Congress of 2017, and I was nominated, and elected, as his successor. While the Melbourne Code was in production, I worked on the user's guide to the Code that was the first edition of The Code Decoded, published in 2013, when I also moved from Saint Louis to Berlin to start a new position as head of publishing at the Botanischer Garten und Botanisches Museum Berlin. In the years leading up to the Shenzhen Congress, I worked with the new Vice-rapporteur, John Wiersema, to edit the 397 proposals to amend the Code and publish the synopsis of proposals. I also served on the Special Committee on By-laws for the Nomenclature Section and the Special Subcommittee on Governance of the Code with respect to Fungi. These committees wrote the rules that became Division III (Provisions for governance of the Code), and the latter committee was instrumental in establishing Chapter F (Names of organisms treated as fungi). At the Shenzhen Congress, I was re-elected as Rapporteur-général for the Rio de Janeiro Congress of 2023. The Shenzhen Code was published in June 2018 only 11 months after the Congress, thanks to the efficient work of an excellent Editorial Committee. Serving as Rapporteur has been immensely satisfying, and I look forward to continuing to serve during the coming years. 


\section{ACKNOWLEDGEMENTS}

I thank everyone who has contributed, directly or indirectly, to both editions of this guide. I am deeply indebted to Charlie Jarvis (Natural History Museum, London), who patiently helped me develop a thorough basic knowledge of the nomenclature of algae, fungi, and plants during my time on the Linnaean Plant Name Typification Project (1994-1997), and John McNeill (Royal Botanic Garden Edinburgh), who took that initial training to a higher level, continuously sharing his profound knowledge and decades of experience during the time I assisted him as Vice-rapporteur (2003-2012), and who also reviewed an earlier draft of this book. I also warmly thank Sandy Knapp (Natural History Museum, London) and John Wiersema (United States Department of Agriculture) for their hard work, good humour, and support as President of the Nomenclature Section and Vice-rapporteur, respectively, for the Shenzhen Congress of 2017; and it was Sandy Knapp who convinced me to write this second edition. Maria Vorontsova (Royal Botanic Gardens, Kew) thoroughly reviewed the manuscript of the first edition of this guide, making many excellent suggestions. Robbert Gradstein and Franz Stadler (Editor-in-chief and Production Editor, respectively) and two anonymous reviewers also provided helpful comments and guidance for the first edition. I thank Lyubomir Penev, Teodor Georgiev, and Slavena Peneva, all at Pensoft Publishers, for the design, layout, and publication of the second edition. I am also grateful to the following (listed in alphabetical order), for advice, encouragement, suggestions, information, and comments: Konstanze Bensch (MycoBank, Utrecht/München), Maarten Christenhusz (Plant Gateway), Vincent Demoulin (Université de Liège), Adam Halamski (Institute of Paleobiology Polish Academy of Sciences), Patrick Herendeen (Chicago Botanic Garden), Heather Lindon (Royal Botanic Gardens, Kew), Karol Marhold (Institute of Botany, Slovak Academy of Sciences, Bratislava; Charles University in Prague), Bruce Maslin (Western Australian Herbarium), Tom May (Royal Botanic Gardens Victoria), Ulrich Meve (Universität Bayreuth), Lyubomir Penev (Pensoft), Rudolf Schmid (University of California, Berkeley), Kevin Thiele (Western Australian Herbarium), the following at the Botanischer Garten und Botanisches Museum Berlin (BGBM), Freie Universität Berlin: Thomas Borsch, Werner Greuter, Wolf-Henning Kusber, and Hans Walter Lack. The following kindly provided and/or granted permission to reproduce published material, images of herbarium specimens, or photographs: American Society of Plant Taxonomists, BGBM Press, Conservatoire et Jardin botaniques de la Ville de Genève, Czech Scientific Society for Mycology, Li Zhang (Fairy Lake Botanical Garden), Linnean Society of London, Missouri Botanical Garden Press, Museo Nacional de Historia Natural (Chile), and Robert Lücking (BGBM). The International Association for Plant Taxonomy, publishers and copyright holders of the first edition, granted permission to publish this second edition and funded its open-access publication. Finally, and once again, I warmly thank my wife, Christine, for continuing to tolerate my many hours devoted to nomenclatural matters. 


\section{CHAPTER 1 | INTRODUCTION}

\section{SCIENTIFIC NAMES VERSUS COMMON NAMES}

The purpose of naming organisms is to provide a means of reference to facilitate communication about those organisms. A universally understood, precise, and stable system of naming is essential for effective scientific communication. A simple system of naming is also desirable, but simplicity and precision are unfortunately not always compatible.

Humans around the world have been naming plants, and probably fungi and algae too, for millennia. A culture that utilizes these organisms for food, medicine, wood, fibre, mind alteration, etc., needs a means of referring to particular organisms, and common names (also called vernacular names) probably exist in every language.

Many of these common names refer to some physical aspect of the plant. The name bluebell derives from blue, bell-shaped flowers. The name cuckoo pint derives not from the bird and a unit of capacity, but from Old English cuic and pintel, meaning "lively" (quick) and "penis", respectively, referring to the erect, cylindric, fleshy appendix of the inflorescence. Sometimes plant uses are the basis of the name, e.g. medicine in self-heal and woundwort; parasite-control in fleabane; bedding material in bedstraw. Frequently folk taxonomy is also implicit in the name, and this may coincide with a modern scientific classification of a group, e.g. trees and shrubs named as various kinds of oak or Eiche in English and German, respectively, are scientifically named Quercus, thus durmast oak or Traubeneiche is Q. petraea; holm oak or Steineiche is Q. ilex; white oak or Flaumeiche is $Q$. pubescens (in Europe, whereas the North American white oak is $Q$. alba). However, the name oak can be used for phylogenetically quite unrelated plants, e.g. poison oak in western North America is Toxicodendron diversilobum, which is not closely related to Quercus. Similarly, white bryony and black bryony in Britain are, respectively, Bryonia cretica and Dioscorea communis (or Tamus communis); both are climbing, non-woody vines, but again they are not at all closely related.

There is, however, a problem with common names: while they may provide a popular "handle" for discussing organisms, they are frequently ambiguous, often with multiple names in common use for the same organism, and with several examples of the same name, in one or more languages, applied to different organisms in different geographical regions. In Britain, the name cuckoo-flower has been applied to seventeen species in ten families (Watts, 2000). One of those species probably has more British common names than any other plant, including lords-and-ladies, parson-in-the-pulpit, cuckoo-pint, and some names used only regionally, e.g. ram's-horn (Sussex) and adder's-tongue (Cornwall and Somerset). The name bluebell is applied to three quite different species in England, Scotland, and North America, and the Scottish bluebell is the harebell in England. 
When the scientific naming of organisms was developing in the 16th to 18th centuries, the universal language of science was Latin. That is why the names use the Latin language. Greek-derived words are also used, and indeed words from many other languages, but they are all treated as being Latin. The basic principle is that scientific names, which are often called Latin names, are used worldwide, enabling scientists speaking different languages to communicate readily with one another. In the examples given above, the species that is variously called lords-and-ladies, parson-in-the-pulpit, cuckoo-flower, cuckoo-pint, ram's-horn, and adder's-tongue is Arum maculatum, not only in Britain but everywhere else in the world. English bluebell is everywhere Hyacinthoides non-scripta; North American bluebell is Mertensia virginica; Scottish bluebell and English harebell are Campanula rotundifolia; English toothwort and German Schuppenwurz are Lathraea squamaria; North American toothwort and English bittercress are species of Cardamine, and another species of English cuckoo-flower is Cardamine pratensis. In a global context, therefore, using common names can be ambiguous and highly confusing, whereas using scientific names enables more precise communication.

The current system of biological nomenclature dates back to the mid-18th-century, when Swedish naturalist Carolus Linnaeus (Carl von Linné) published his Species plantarum and Systema naturae (Linnaeus, 1753, 1758), in which a binomial, sometimes called binominal or binary, i.e. "two-name", system was introduced. A binomial is the name of a species (where a species is considered to be the basic taxonomic unit comprising a group of individual organisms). A binomial consists of the name of a genus, e.g. Quercus, followed by what Linnaeus called a nomen triviale (trivial name), which is now called a specific epithet, e.g. robur, hence Quercus robur. This is a very user-friendly method for naming millions of species of organisms, because even if you know a species only by its name, you already know to which genus it belongs. It is much easier to remember the names and taxonomic placement of a relatively small number of genera than it is a very large number of species.

\section{TAXONOMY AND NOMENCLATURE ARE DIFFERENT THINGS}

Taxonomy (or systematics) is the science that deals with circumscribing and classifying organisms in a system. Nomenclature is the provision of means of reference, i.e. names, for those organisms. Classifications are in a constant state of change as new data come to light, especially with regard to evolutionary relationships inferred from molecular studies. To pretend that any particular classification ought to be fixed as the final word on a group of organisms would be grossly unscientific. Because of the nature of the current nomenclatural system, this perpetual process of taxonomic reappraisal inevitably causes a certain degree of nomenclatural change. Changing a family to a subfamily results in a name change, e.g. Pyrolaceae becomes Pyroloideae. Moving a genus from one family to another does not result in a name change. Moving a species from one genus to another necessarily causes a name change because under the binomial system the accepted generic name is part of the species name, e.g. when the species originally described as $H y$ - 
acinthus non-scriptus was moved from the genus Hyacinthus to the genus Hyacinthoides, its name had to be changed to Hyacinthoides non-scripta. Likewise moving a variety from one species to another causes a name change. Names below the rank of genus include an inherent classification: a species named Hyacinthoides non-scripta belongs to the genus Hyacinthoides, but a genus named Hyacinthoides can belong to any family, e.g. to Asparagaceae, Hyacinthaceae, or Liliaceae. This does not mean that nomenclature mandates a particular classification. Taxonomy and nomenclature are quite different things. The taxonomist uses evidence from research to arrive at a particular classification and then uses the rules of nomenclature to apply the correct name to the taxa recognized.

\section{RULES FOR BIOLOGICAL NOMENCLATURE}

The purpose of having rules for biological nomenclature is to provide a stable method of naming organisms, avoiding and rejecting the use of names that may cause error, ambiguity, or confusion. The current rules for the scientific nomenclature of plants, as well as for fungi and algae, are contained in the International Code of Nomenclature for algae, fungi, and plants (Shenzhen Code; Turland \& al., 2018). Unless otherwise qualified, "Code" in this guide refers to the Shenzhen Code. The title was formally changed at the XVIII International Botanical Congress in Melbourne in 2011, whereas previously it was the International Code of Botanical Nomenclature, or ICBN. The acronym "ICN", standing for "International Code of Nomenclature", is best avoided because it could refer to any one of five biological codes, of which more below. Note that the current edition of the Code supersedes all previous editions. Using a previous edition is therefore very risky because you could follow rules that have been changed or fail to follow new rules.

The Code governs the nomenclature of all organisms traditionally treated as algae, fungi, or plants, whether fossil or non-fossil, including blue-green algae (Cyanobacteria), chytrids, oomycetes, slime moulds, and photosynthetic protists with their taxonomically related non-photosynthetic groups (but excluding Microsporidia). The nomenclature of hybrids is also covered, but that of cultivated plants is dealt with separately by the International Code of Nomenclature for Cultivated Plants (ICNCP or Cultivated Plant Code), prepared under the authority of the International Commission for the Nomenclature of Cultivated Plants and now in its 9th edition (Brickell \& al., 2016). Three additional codes govern the nomenclature of animals, prokaryotes (bacteria etc.), and viruses. They are, respectively, the International Code of Zoological Nomenclature (ICZN or Zoological Code; International Commission on Zoological Nomenclature, 1999); the International Code of Nomenclature of Prokaryotes (Parker \& al., 2019); and the International Code of Virus Classification and Nomenclature (International Committee on Taxonomy of Viruses, 2018).

Unlike most modern sciences, e.g. ecology, the nomenclature of algae, fungi, and plants still makes full use of literature dating back to 1753 , and in this respect it seems more like history than science. This strong historical element persists because the rules of the Code, except where expressly limited, are retroactive to 1753 . Retroactive means that they 
function as if they had been in the Code in 1753, and indeed as if the Code had existed in 1753. In reality, the Code did not exist until Alphonse de Candolle published his Lois de la Nomenclature Botanique in 1867 (Candolle, 1867), and much of the content of the Code today was added since 1867.

Novice and veteran users of the Code alike would agree that it is a very complex document. This complexity has evolved over 17 editions beginning with Candolle's Lois. Throughout this more than 150-year history, diverse issues have arisen prompting scientists to refine the rules every few years at an International Botanical Congress, and since 2018 also at an International Mycological Congress, each time making the Code a little more precise but at the same time a little more complex. Some rules are of fundamental importance, whereas others exist only to govern rare cases. The fundamental rules are sometimes quite simple, whereas the rare-case ones are sometimes formidably complex, and vice versa. It is not necessary to learn and understand every rule in the Code in order achieve competence in nomenclature. This guide aims to highlight the most important rules.

The rules of the Code are not law but are voluntarily followed with an international consensus, i.e. the majority of botanists, mycologists, and phycologists worldwide have agreed to follow the rules. Scientific names published in compliance with these rules can achieve international acceptance. Names published under alternative sets of rules might gain acceptance among the particular groups of scientists who follow those particular rules, but they will not be generally accepted by the international scientific community.

\section{THE DRAFT BIOCODE}

Over the last few decades, efforts have been made to harmonize the terminology and rules of the current separate biological codes into a single set of rules for biological nomenclature, which came to be called the Draft BioCode (Greuter \& al., 1998, 2011). The current codes, while they have a great deal in common, have quite different rules for some situations. For example, the Code for algae, fungi, and plants rules that a tautonym, in which the specific epithet exactly repeats the generic name, cannot be validly published, whereas tautonyms such as Glis glis and Rattus rattus are permitted by the ICZN. There is also a problem with homonyms, i.e. two or more names spelled exactly alike but applying (usually) to different organisms. While a later (or junior) homonym cannot be legitimate under the Code for algae, fungi, and plants, or potentially valid under the ICZN, these rules apply mostly within their respective codes, rarely across them, so that, e.g., Pieris applying to a woody plant and Pieris applying to a butterfly are both legitimate/potentially valid names. There is also a problem with terminology between the codes, in which different terms are used for the same concept and the same term is used for different concepts. This is illustrated by the examples in Table 1 (p. 14).

The Draft BioCode, developed by the International Committee on Bionomenclature (http://www.bionomenclature.net/), was intended to solve these problems through 
its eventual adoption by the various disciplines of the biological community. The relative simplicity of the Draft BioCode derived from its dealing only with the names of the present and future; it did not attempt to rule on the nomenclature of the past ca. 250 years. Because of this, it could only be implemented effectively after the separate codes had agreed to introduce mandatory registration of new names and to adopt lists of protected names (called "Names in Current Use" [NCU] lists). However, enthusiasm for the Draft BioCode was significantly lacking in at least the botanical and zoological communities, such that, in 2012, the International Committee on Bionomenclature decided not seek its implementation but rather to use it as a framework for facilitating communication between the different biological disciplines and nomenclatural codes, and to maintain its availability should it be required at some future date. For a discussion of the challenges facing the codes of biological nomenclature see Knapp \& al. (2004).

Table 1. Comparison of terms used for three statuses of names across five codes of biological nomenclature (for additional terms, and for those recommended for use in biological nomenclature, see David \& al., 2012).

\begin{tabular}{|l|l|l|l|l|}
\hline \multicolumn{4}{|l|}{ International Code of } \\
\hline $\begin{array}{l}\text { Nomenclature } \\
\text { for algae, fungi, } \\
\text { and plants }\end{array}$ & $\begin{array}{l}\text { Zoological } \\
\text { Nomenclature }\end{array}$ & $\begin{array}{l}\text { Nomenclature } \\
\text { of Prokaryotes }\end{array}$ & $\begin{array}{l}\text { Virus } \\
\text { Classification and } \\
\text { Nomenclature }\end{array}$ & $\begin{array}{l}\text { Nomenclature } \\
\text { for Cultivated } \\
\text { Plants }\end{array}$ \\
\hline $\begin{array}{l}\text { validly } \\
\text { published }\end{array}$ & available & $\begin{array}{l}\text { validly } \\
\text { published }\end{array}$ & established & established \\
\hline legitimate & potentially valid & legitimate & valid & acceptable \\
\hline correct & valid & correct & accepted & accepted \\
\hline
\end{tabular}

\section{THE PHYLOCODE}

One of the criticisms aimed at the Code today is that modern phylogenetics are incompatible with a "Linnaean", rank-based, hierarchical system of nomenclature, although it has been argued that there is no inherent obstacle to naming clades under the Code for algae, fungi, and plants (Barkley \& al., 2004). An alternative system has been under development in recent years, namely the International Code of Phylogenetic Nomenclature or PhyloCode (Cantino \& Queiroz, 2010), which provides rules for naming all clades of organisms, whether extant or extinct. The PhyloCode may be used concurrently with what it calls the "rank-based codes", i.e. the four traditional codes for algae/fungi/plants, animals, prokaryotes, and viruses. The PhyloCode relies on the rank-based codes to determine the acceptability of pre-existing names, but it governs the application of those names independently. It is still a draft, under revision, and will take effect, non-retroactively upon publication of Phylonyms: a Companion to the PhyloCode. 


\section{CHAPTER 2|BASICCONCEPTSANDTERMS}

Before embarking on the chapters devoted to particular topics covered by the Code, it is necessary to consider some of the basic concepts and terms used in the nomenclature of algae, fungi, and plants. The key words are highlighted in boldface. References to the relevant definitions in the Code are provided.

The Code is divided into numbered paragraphs. Articles (Art.) are mandatory rules, whereas Recommendations (Rec.) are optional guidelines. Notes explain an aspect of the rules that may not be readily apparent but is covered explicitly or implicitly elsewhere in the Code; thus a Note has binding effect. Examples (Ex.) are provided to illustrate the Articles and Recommendations.

The Code defines a taxon (plural: taxa) as any taxonomic group at any rank (Art. 1.1), e.g. variety, species, genus, family, kingdom, where a taxonomic group is a group of organisms in a classification. The terminal points of any clade can be treated individually as taxa and collectively as a higher-ranked taxon. Taxa below the rank of species are termed infraspecific taxa, while those above the rank of genus (plural: genera) are suprageneric taxa. Note that "infrageneric taxon" as a term for a taxon between the ranks of genus and species should be avoided, because strictly speaking it would mean a taxon at any rank below genus, i.e. including species and infraspecific taxa. A better term is subdivision of a genus. Similarly, subdivision of a family is preferable to "infrafamilial taxon". Note that this correct usage of taxa is much broader than the informal (and incorrect) usage meaning "species and infraspecific taxa" often seen in the context of biodiversity inventory, e.g. "there are $x$ taxa in this region".

\section{Name versus taxon}

A name is a quite different concept to a taxon. Whereas a taxon is an actual group of organisms, a name is the label applied to that group as a means of reference. A taxon is described, whereas a name is published and applied to a taxon. For a name to have any status under the Code it must be validly published (see p. 18).

A fossil-taxon is defined as a taxon the name of which is based on a fossil type (Art. 1.2). A fossil-taxon consists of the remains of one or more parts of the parent organism, or one or more of their life history stages, preserved in one or more preservational states. The converse is a non-fossil taxon, the name of which is based on a non-fossil type. Note that diatoms, even if they are found in a fossil context, are treated as non-fossil taxa under the Code. Note the hyphenation of the term fossil-taxon; when 
a fossil-taxon is a genus, species, or variety it is called a fossil-genus, fossil-species, or fossil-variety, respectively; a fossil-variety is an infraspecific fossil-taxon.

Hybrids are given special provisions in Chapter $\mathrm{H}$ of the Code. A hybrid taxon is termed a nothotaxon (from Greek vóOos, nothos, hybrid). Hence a nothospecies is a hybrid between two or more species, a nothogenus a hybrid between two or more genera, etc. A hybrid taxon may be given a name, e.g. Salix $\times$ capreola, or it may be expressed as a hybrid formula, e.g. Salix aurita $\times$ S. caprea. The multiplication sign $(x)$ indicates a hybrid (see pp. 125-127).

The Code permits an indefinite number of taxa at consecutively subordinate ranks, treats the species as the basic rank (Art. 2), and names a number of ranks both above and below species (Art. 3 and 4). Taxa are certainly not limited to these named ranks. Additional ones may be inserted by prefixing "sub-" to a rank, e.g. subspecies, subgenus, subfamily, etc. If more ranks are needed (which may well be necessary when naming taxa representing clades in a large phylogenetic tree), any quantity of ranks may be inserted as needed, e.g. by prefixing "super-" to a rank, as in superorder or superspecies, provided that no confusion or error is thereby introduced (Art. 4.3). For example, subspecies would be inserted immediately below species, whereas superspecies would be inserted immediately above species.

The named ranks of taxa are given in Table 2 (p. 17). The rank-denoting terms are in Latin, but modern-language forms are frequently and correctly used, as in the English equivalents provided here (note that phylum, genus, series, and species are the same in Latin and English). It is important to remember that the relative order of these named ranks cannot be altered (Art. 5.1). The Code also recommends standard abbreviations for most of these ranks (Rec. 5A), as shown in Table 2 (p. 17). Note that subgenus is abbreviated to "subg.", even though logically it ought to be "subgen."

A gathering is the term used for a collection presumed to be of a single taxon made by the same collector(s) at the same time from a single locality (Art. 8.2 footnote). A specimen is either a whole gathering, or a part of a gathering, of a single species or infraspecific taxon, disregarding admixtures, mounted either as a single preparation (e.g. a herbarium sheet, box, spirit jar, or microscope slide) or as more than one preparation with the parts clearly labelled as being part of the same specimen or bearing a single, original label in common (Art. 8.2 and 8.3). Two or more specimens that belong to the same gathering are duplicates (Art. 8.3 and footnote). A single specimen can be a part, several parts, or the whole of one or several organisms and can include, e.g., flowering and fruiting or male and female material, provided that all the material belongs to the same gathering as defined above.

The application of the name of a taxon is determined by a nomenclatural type (Art. 7.1). A type is a specimen, or in some cases an illustration, to which the name of a taxon is permanently attached (Art. 7.2). A name, therefore, has a type, and a type belongs 
Table 2. Named ranks of taxa, in descending sequence.

\begin{tabular}{|l|l|l|}
\hline Latin rank-denoting term & English equivalent term & Recommended abbreviation \\
\hline regnum & kingdom & - \\
\hline subregnum & subkingdom & - \\
\hline divisio or phylum & division or phylum & - \\
\hline subdivisio or subphylum & subdivision or subphylum & - \\
\hline classis & class & cl. \\
\hline subclassis & subclass & subcl. \\
\hline ordo & order & ord. \\
\hline subordo & suborder & subord. \\
\hline familia & family & fam. \\
\hline subfamilia & subfamily & subfam. \\
\hline tribus & tribe & tr. \\
\hline subtribus & subtribe & subtr. \\
\hline genus & genus & gen. \\
\hline subgenus & subgenus & subg. \\
\hline sectio & section & sect. \\
\hline subsectio & subsection & subsect. \\
\hline series & series & ser. \\
\hline subseries & subseries & subser. \\
\hline species & species & sp. \\
\hline subspecies & subspecies & subsp. \\
\hline varietas & variety & var. \\
\hline subvarietas & subvariety & subvar. \\
\hline forma & form & f. \\
\hline subforma & subform & subf. \\
\hline & & \\
\hline
\end{tabular}

to a taxon, thus a taxon does not have a type but may include one. Be aware that a type is not necessarily the most typical (i.e. normal) or adequate example of a taxon, even though ideally it should be if it is to provide the link between name and taxon. On 1 January 1958, it became mandatory to indicate the type when publishing a name of a new taxon at the rank of genus or below. A name of a new taxon published before 1958, therefore, does not necessarily have a type, which often results in ambiguity in its application and necessitates later selection of a type, e.g. a lectotype (see Chapter 7).

Before a new name, new type designation, or other nomenclatural act can have any status under the Code, the publication in which it appears must be effectively published 
(Art. 29-31; Fig. 1, p. 20). Simply publishing something does not necessarily make it effectively published; it depends how it is published. Up until the end of 2011, only printed matter distributed to institutions with libraries accessible to scientists generally was effectively published. From 1 January 2012, electronic material, under certain conditions, may be effectively published in addition to printed matter. Effective publication is dealt with in Chapter 4.

For a name to have any status under the Code it must be validly published (Art. 6.3 and 12.1; Fig. 1, p. 20). Valid publication is publication in accordance with the rules of Art. 32-45, the first condition of which is effective publication. Complying with all the rules of 14 Articles may seem daunting, but you will be unlikely to encounter problems if you remember the key rules, which are dealt with in Chapter 5. Following the editorial style required by your publisher (guidelines for submitting manuscripts) will automatically comply with many of the rules, while others apply only in special cases or to particular taxonomic groups, e.g. algae, fungi, and fossils.

If the Code is strictly followed, a name that is not validly published should not be called a "name" at all but rather a designation. The Code does not use the terms "valid name" or "invalid name" (even though the latter often appears in works as "nomen invalidum" or "nom. inval."), but rather "validly published name" and "name [or, better, designation] not validly published". Perhaps the commonest reason for a name not to have been validly published is because it was not accompanied by a description or diagnosis or reference to a previously published one. Such a designation is called a nomen nudum ("naked name").

A description is a statement of a feature or features of a taxon, whereas a diagnosis is a statement of that which distinguishes a taxon from other taxa (in the opinion of the author of the taxon; Art. 38.2). For example, "petals white, 2-3 × 0.5-1 cm, emarginate at apex" is a description, whereas "differing from species $x$ by having petals white, $2-3 \times 0.5-1 \mathrm{~cm}$, and emarginate at apex" or "distinguished from other species in the genus by having ..." are diagnoses.

The term protologue means everything associated with a name at its valid publication, e.g. description, diagnosis, illustrations, references, synonymy, geographical data, citation of specimens, discussion, and comments (from Greek $\pi \varrho \dot{\tau} \tau \circ \varsigma$, protos, first, and $\lambda$ óyos, logos, discourse; Art. 6.13 footnote).

An illegitimate name (Art. 6.4) is either (1) a later homonym (Art. 53 and 54), (2) a name that was nomenclaturally superfluous when published (Art. 52), or, much more rarely, (3) a name of a family or subdivision of a family based on an illegitimate generic name (Art. 18.3 and 19.6).

Homonyms are names spelled exactly the same but based on different types (same name, different type), e.g. Vicia gigantea Hook. 1831 and Vicia gigantea Bunge 1833. 
A name is nomenclaturally superfluous when a different name should have been used instead, and under Art. 7.5 the superfluous name often has the same type as the name that should have been used (different name, often same type). For example, Agapanthus umbellatus L'Hér. 1789 based on Crinum africanum L. 1753 was nomenclaturally superfluous because L'Héritier should instead have published the new combination Agapanthus africanus because C. africanum has priority.

Priority of publication is a fundamental principle of the Code. The nomenclature of a taxonomic group is based upon priority of publication (Principle III). In very simple terms, if you have a choice between multiple names for a particular taxon, you must use the name that was published first. More precisely, if two or more names apply to the same taxon (i.e. with the same circumscription) at the same rank, the earliest published, legitimate name has priority and is the correct name if there is no obstacle under the rules (or, if its position is different, it provides the final epithet of the correct name).

Circumscription means what is included in the taxon; how broadly or narrowly it is defined.

Position means placement of the taxon within a particular genus or species.

A legitimate name (Art. 6.5; Fig. 1, p. 20) is a name that is in accordance with the rules. Quite simply it is a name that is not illegitimate as defined above (p. 18). A useful rule to remember is that names are "born" either legitimate or illegitimate upon their valid publication. An illegitimate name can become legitimate only through conservation, protection, or sanctioning (see Chapter 8 and pp. 119-120).

The correct name (Art. 6.6; Fig. 1, p. 20) is the legitimate name that applies to a taxon with a particular circumscription, position, and rank that must be adopted under the rules. The rules are mainly those of priority in Art. 11, and in particular Art. 11.3 (ranks of family to genus inclusive) and Art. 11.4 (below the rank of genus). At the rank of family or below, a taxon can have only one correct name (with a few special exceptions; Art. 11.1). Above the rank of family a taxon can have more than one correct name because the principle of priority does not apply at those ranks (Art. 11.10).

A combination (Art. 6.7) is a name below the rank of genus. All names below the rank of genus are combinations. A combination consists of a generic name combined with one or two epithets, e.g. Poa subg. Stenopoa, Poa trivialis, Poa trivialis subsp. sylvicola.

An epithet is one of the words in a combination other than the generic name and any rank-denoting term (a hyphenated word is here equivalent to a single word). The name of a subdivision of a genus has one epithet, called a subdivisional epithet, Stenopoa above. The name of a species is a binary combination (or binomial) and also has one epithet, called a specific epithet, trivialis above. The name of an infraspecific taxon has both a specific epithet and an infraspecific epithet, trivialis and sylvicola above. When 


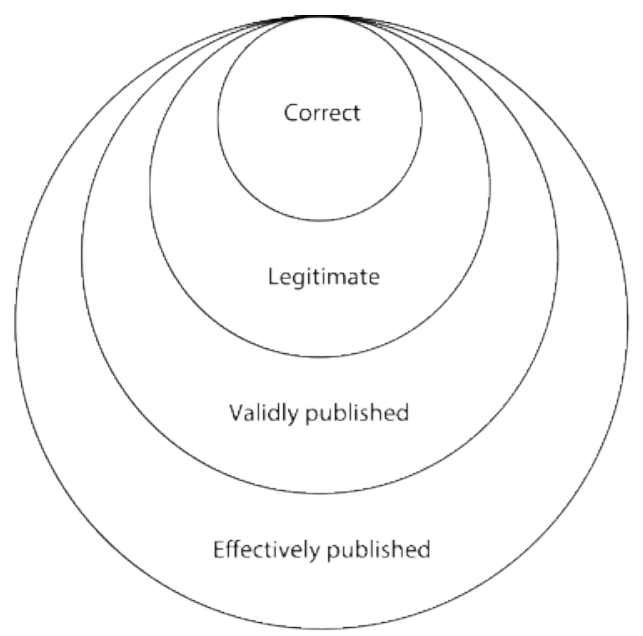

Fig. 1. Effectively published, validly published, legitimate, and correct as subsets of all possible names and designations. (Not to scale: sizes of sets are not intended to reflect actual numbers of names and designations.)

\section{Do not confuse (il)legitimate with (in)valid}

It is a common mistake to confuse legitimate with "valid", i.e. validly published, and illegitimate with "invalid", i.e. not validly published. In fact, a name must be validly published in order to be either legitimate or illegitimate; a name that is either legitimate or illegitimate is by definition validly published. If a name is not validly published, it has no status under the Code and is therefore neither legitimate nor illegitimate. Further confusion is caused when "valid name" is used to mean correct name, influenced by zoological practice (see Table 1, p. 14), or when "valid species" is used to mean a taxonomically accepted species, i.e. one considered distinct and not to be united with another.

the combination is not the name of a species, a rank-denoting term is used, "sect." and "subsp." above. Note that the rank-denoting term is not part of the name (Art. 32 Note 1), therefore Poa subg. Stenopoa and Poa sect. Stenopoa are the same combination, indeed the same name, but that name at different ranks; likewise Poa trivialis subsp. sylvicola and Poa trivialis var. sylvicola.

An autonym (Art. 6.8) is a special kind of combination that is established automatically (Art. 22.3 and 26.3), even if it does not actually appear in the publication where it is established. It is always the name of a subdivision of a genus or an infraspecific taxon; autonyms do not exist above the rank of genus. Either the subdivisional epithet repeats the generic name exactly, e.g. Poa subg. Poa, or the infraspecific epithet repeats 
the specific epithet exactly, e.g. P. trivialis subsp. trivialis. An autonym always applies to the subordinate taxon that includes the type of the genus or species: thus $P$. subg. Poa includes the type of Poa and $P$. trivialis subsp. trivialis includes the type of $P$. trivialis.

When the same name based on the same type has been published independently at different times perhaps by different authors, these are not homonyms but isonyms (Art. 6 Note 2). For example, an author might publish a new combination unaware that it had already been published. When isonyms exist, only the earliest among them has any nomenclatural status, and all later isonyms may be disregarded. However, the places of publication cited for conserved names of families in Appendix IIB are treated as correct in all circumstances, even when otherwise such a name is a later isonym.

A name of a new taxon (Art. 6.9) is a name validly published in its own right. It is not a name based on a previously validly published name, i.e. a new combination, a name at new rank, or a replacement name. For example, the name of a new species (species nova, sp. nov.) is the name of a new taxon.

A new combination or a name at new rank (Art. 6.10) is a new name based on a legitimate, previously published name, which is its basionym. Essentially this is renaming a taxon without publishing a name of a new taxon, so that the protologue and type of an existing name-the basionym - apply also to the new name. Such a renaming is needed when an already-named taxon is assigned to a different genus or species or when it is changed in rank. The basionym provides the final epithet, name, or stem of the new combination or name at new rank. For example, Centaurea benedicta (L.) L. 1763 is a new combination based on the basionym Cnicus benedictus L. 1753; Crupina (Pers.) DC. 1810 is a name at new rank based on the basionym Centaurea subg. Crupina Pers. 1807. In a protologue, a new combination is indicated by "comb. nov." (combinatio nova) and a name at new rank by "stat. nov." (status novus, new status, i.e. new rank). It is possible for a new combination to be at the same time a name at new rank (indicated by "comb. \& stat. nov." or "comb. et stat. nov.", combinatio et status novi).

A replacement name (Art. 6.11) is a new name published as an explicit substitute for a legitimate or illegitimate, previously published name, which is its replaced synonym. The principle is parallel to that of a new combination or a name at new rank, except that the replaced synonym, when legitimate, does not provide the final epithet, name, or stem of the replacement name. For example, Trifolium infamia-ponertii Greuter 1976 is a replacement name based on the replaced synonym T. intermedium Guss. 1821, which is illegitimate because it is a later homonym of T. intermedium Lapeyr. 1818. Centaurea chartolepis Greuter 2003 is a replacement name based on the replaced synonym Chartolepis intermedia Boiss. 1856. In this case, the replaced synonym is legitimate, but its epithet intermedia cannot be used in combination with Centaurea because of the pre-existing Centaurea intermedia Mutel 1846, i.e. to publish a new combination "Centaurea intermedia (Boiss.) ..." would create a later homonym, which would be illegitimate. In a protologue, a replacement name is indicated by "nom. nov.", 
an abbreviation of nomen novum, which is an alternative term for replacement name (another, former term was "avowed substitute").

Another situation where a replacement name may be published is to avoid creating a tautonym, a designation in which the specific epithet exactly repeats the generic name; a tautonym cannot be validly published (Art. 23.4). For example, Cyanus segetum Hill 1762 is a necessary replacement name in Cyanus for the legitimate Centaurea cyanus L. 1753, because a new combination "Cyanus cyanus" could not be validly published.

\section{A basionym must be legitimate}

Remember that a basionym must be legitimate. If it is not legitimate, it is not a basionym and what might seem like a new combination or a name at new rank is in fact a replacement name based on a replaced synonym. For example, Calandrinia polyandra Benth. 1863 may seem like a new combination based on Talinum polyandrum Hook. 1855. However, the latter name is illegitimate because it is a later homonym of Talinum polyandrum Ruiz \& Pav. 1798. Therefore, C. polyandra is a replacement name based on the replaced synonym T. polyandrum Hook. In this case, the specific epithet has been reused, a practice permitted under Art. 58.1.

A synonym is simply one of two or more names that apply to the same taxon. There are two kinds of synonyms: homotypic synonyms, which have the same type, and heterotypic synonyms, which have different types; these are also called nomenclatural synonyms and taxonomic synonyms, respectively. Quite simply, homotypic synonyms are different names based on the same type, and they must therefore apply to the same taxon, whereas heterotypic synonyms are names based on different types that are considered to belong to the same taxon (see Fig. 10, p. 58). Homotypic synonyms are synonyms as a matter of fact, whereas heterotypic synonyms are synonyms as a matter of taxonomic opinion. A new combination or name at new rank and its basionym are always homotypic synonyms; likewise a replacement name and its replaced synonym. Synonyms are often denoted by the equality sign $(=)$, but if you wish to differentiate the two kinds, use the identity sign (三) for homotypic synonyms and reserve "=" for heterotypic synonyms. The term synonym is commonly used for a name that applies to a taxon but is not the accepted name, e.g. it could be the basionym (homotypic) or a later name (heterotypic) that does not have priority.

The term nomenclatural novelty is often encountered. This is defined in the Code as any or all of the categories name of a new taxon, new combination, name at new rank, and replacement name (Art. 6 Note 4). A nomenclatural novelty results from a nomenclatural act, which is an act requiring effective publication. Nomenclatural acts may also affect aspects of names such as typification, priority, orthography, or gender (Art. 34.1 footnote). 


\section{CHAPTER 3 | STRUCTURE AND ORGANI- ZATION OF THE CODE}

This brief chapter outlines the structure of the Code and describes how the rules and recommendations, Appendices, and other included material are organized.

The Shenzhen Code contains a Preface, which summarizes the main changes to the Code since the previous edition. There follows a key to the renumbering of Articles since the previous edition and a list of dates on which various rules became effective. Then there is the main text, comprising a Preamble (abbreviated to Pre.) and three Divisions (Div.), followed by a Glossary and two indexes.

The main rules of the Code form Div. II, while the rules by which the rules are created, modified, or deleted form Div. III (Provisions for governance of the Code). The reasons for the very existence of the rules are stated in the Preamble and Div. I (Principles). The Glossary lists and defines the terms used in the Code, followed by an index of scientific names and a subject index.

The Code also includes seven Appendices (App.). The first (App. I) lists suppressed works; the next four (App. II-V) list conserved, protected, and rejected names; App. VI lists binding decisions on whether or not to treat certain names as validly published; and App. VII lists binding decisions on whether or not to treat certain names as homonyms. These Appendices were published in the same volume as the rest of the Code until the Melbourne Code, when they appeared as a separate volume (Wiersema $\&$ al., 2015a). They are now freely available online in a searchable database (https:// naturalhistory2.si.edu/botany/codes-proposals/), which is continuously updated.

The mandatory rules of the Code are called Articles (Art.) in Div. II, numbered Art. 1-62, F.1-F.10 (in Chapter F, Names of organisms treated as fungi), and H.1-H.12 (Chapter $\mathrm{H}, \mathrm{Names}$ of hybrids). The rules in Div. III are called Provisions (Prov.), numbered Prov. 1-8. Paragraphs are individually numbered within each Article or Provision (e.g. Art. 1.1, 1.2). The rules of Chapter $F$ apply only to names of fungi, but it is important to remember that most of the other rules of the Code apply to fungi as well as to algae and plants. Notes explain aspects of the Articles that may not be readily apparent but are covered explicitly or implicitly elsewhere in the Code; thus a Note has binding effect. Notes are placed within Articles following the rules they explain and are consecutively numbered (e.g. Art. 4 Note 1, 2, 3, 4). The optional guidelines are called Recommendations (Rec.). Recommendations follow some of the Articles and bear the Article number plus a letter (e.g. Rec. 8A, 8B), with individually numbered paragraphs (e.g. Rec. 8B.1, 8B.2, 8B.3). There are also three Recommendations in Div. III, numbered differently (Prov. 4 Rec. 1, Prov. 7 Rec. 1 and 2). This numbering system is used when referring to items in the Code and for cross-referencing within the Code. The actual page numbers in the Code are rarely cited. 
The Articles, Notes, and Recommendations are copiously illustrated by Examples (Ex.), which are also numbered consecutively within Articles and Recommendations (Art. 1 Ex. 1, 2,3). The Examples are taken from real cases of correct or incorrect nomenclature. Some are simple and easily understood, while others are extremely complicated. An Example prefixed by an asterisk ( ${ }^{*} \mathrm{Ex}$.) denotes what is termed a voted Example, i.e. one accepted by an International Botanical Congress in order to govern nomenclatural practice when the corresponding Article of the Code is open to divergent interpretation or does not adequately cover the matter (Art. $7^{*}$ Ex. 16 footnote).

The Code tries to present content in a logical sequence, and this is often based on rank. For example, the rules on the formation of names (Art. 16-27) begin with names of taxa above the rank of family and, through a descending sequence, end with names of infraspecific taxa. The rules on typification begin with general rules (Art. 7), followed by rules on typification of names of species and infraspecific taxa (Art. 8 on what constitutes a type and Art. 9 on different kinds of types), followed by rules on typification of names above the rank of species (Art. 10). Individual Articles, Recommendations, and Examples may follow such a sequence. Lists of names have a logical sequence, generally sorted by rank, date, or alphabetically. The Code also tries to present rules in a practical sequence, in which key rules, on which others depend, appear first. However, be aware that rules that apply only in rare cases may appear ahead of rules that apply widely, so never think you need to read only the first rule or first few rules of a particular Article. Fortunately, the rules of the Code are copiously cross-referenced to other Articles, Notes, Recommendations, etc. These are often prefixed by "see", or "see also" (when the referenced item also applies to the case), or "but see" (when the referenced item contains an exception to the case). 


\section{CHAPTER 4 | MEDIA FOR PUBLICATION}

The Code recognizes only certain types of publications as effective (Art. 29-31). Before there is any possibility of a new name being validly published, or a type designation being effective, the publication in which it appears must be effectively published. Almost all printed books and journals are effectively published, but some printed matter is excluded, e.g. non-scientific newspapers. From 2012 onward, electronic material can also be effectively published under certain conditions.

Effective publication is achieved by two methods. The first method requires distribution of printed matter (through sale, exchange, or gift) to the general public or at least to scientific institutions with generally accessible libraries (Art. 29.1). Note the words "at least to scientific institutions", i.e. plural institutions, which means that, at the barest minimum, two copies must be distributed, one to each of two scientific institutions, although such a tiny distribution would be extremely poor practice.

The second method became possible through a decision of the XVIII International Botanical Congress, held in Melbourne in 2011, which expanded the rules on effective publication so that certain kinds of electronic material distributed on or after 1 January 2012 could be effectively published. Thus now publication is also effected by distribution on or after 1 January 2012 of electronic material in Portable Document Format (PDF) in an online publication with an International Standard Serial Number (ISSN) or an International Standard Book Number (ISBN) (Art. 29.1). The term "online" is defined as accessible electronically via the World Wide Web (Art. 29.2). Should PDF ever be succeeded, Art. 29.3 permits use of a successor international standard format communicated by the General Committee (see pp. 143-145).

Further conditions are attached to electronic material constituting effective publication. If there is evidence within or associated with the publication that its content is merely preliminary and was, or is to be, replaced by a content that the publisher considers final, then only the version with that final content is effectively published (Art. 30.2). Moreover, the content of a particular electronic publication must not be altered after it is effectively published (Art. 30.4). Any such alterations are not themselves effectively published. Corrections or revisions must be issued separately to be effectively published. Note that content explicitly excludes volume, issue, article (paper), and page numbers (Art. 30.3). Therefore, when a final version of a paper is published online with preliminary pagination ahead of its final, paginated placement in a journal, that preliminary pagination does not prevent effective publication. 


\section{SUMMARY OF WHAT IS EFFECTIVE PUBLICATION}

\section{Printed matter}

- Distribution to the general public or at least to scientific institutions with generally accessible libraries (Art. 29.1).

\section{Electronic material}

- Published on or after 1 January 2012 in Portable Document Format (PDF) in an online publication with an International Standard Serial Number (ISSN) or an International Standard Book Number (ISBN) (Art. 29.1).

\section{SUMMARY OF WHAT IS NOT EFFECTIVE PUBLICATION}

The following methods of disseminating information do not constitute effective publication, with some rules taking effect only after certain dates:

\section{Printed matter}

- Printed matter that is not distributed, or that is distributed to scientific institutions without generally accessible libraries, or when only one copy is produced and "distributed" (and thereby failing to satisfy the minimum requirements of Art. 29.1).

- $\quad$ Trade catalogues and non-scientific newspapers, except before 1953 (Art. 30.7).

- $\quad$ Seed-exchange lists, except before 1973 (Art. 30.7).

- $\quad$ Printed matter accompanying specimens (e.g. printed labels), except before 1953 or when distributed independently of the specimens (Art. 30.8 and Note 2).

- University or college degree theses, with three exceptions: those before 1953; those in serial publications (e.g. Dissertationes Botanicae), and those that include an explicit statement or other evidence that the author or publisher considered the thesis to be effectively published under the Code (Art. 30.9). "Other evidence" could be an ISBN or the name of the printer, publisher, or distributor.

\section{Electronic material}

- Any kind of electronic material other than that specified in Art. 29, e.g. material distributed before 1 January 2012, material in format other than PDF, material not online, or material with neither an ISSN nor an ISBN (Art. 30.1). 
- Content that is evidently merely preliminary and was, or is to be, replaced by content that the publisher considers final (Art. 30.2).

- Alteration of the content of a particular electronic publication that is already effectively published, unless such corrections or revisions are issued as a separate publication (e.g. a corrigendum, erratum, supplement, or new edition) (Art. 30.4).

\section{Other media}

- Communication of nomenclatural novelties at a public meeting (Art. 30.1), e.g. verbally delivering material during a lecture, or displaying material in a PowerPoint presentation.

- Placing of names in collections or gardens open to the public (Art. 30.1), e.g. placing material on signs and labels.

- Issue of microfilm made from manuscripts or typescripts or other unpublished material (Art. 30.1).

- Hand-written material, although indelible autograph is permitted before 1953 (Art. 30.5); indelible autograph is defined as hand-written material reproduced by some mechanical or graphic process, such as lithography, offset, or metallic etching (Art. 30.6).

\section{Best practice - publishing effectively}

These suggestions are based on Recommendations in the Code (Rec. 29A, 30A, and 31B). Some of these recommendations are aimed at publishers and editors as well as authors, and indeed some may be beyond the control of authors.

- Give preference to journals that regularly publish taxonomic papers, and avoid publishing in non-scientific journals.

- Even better, publish your work in the kinds of journals where the content is automatically indexed and integrated into diverse databases. Such journals may provide information on where they are indexed.

- If you are worried that the taxonomic community may not notice your publication (printed or electronic), at least send a copy to an indexing centre appropriate to the taxonomic group, e.g. the International Plant Names Index (IPNI; https://www.jpni.org/) for vascular plants. 
- Avoid publishing in ephemeral printed matter of any kind (e.g. corrigenda or errata slips), and in particular printed matter that is produced in small numbers. Printed matter should be deposited in at least ten generally accessible libraries throughout the world, but preferably more (ideally hundreds). Distributing two photocopies to two libraries-the barest minimum-is simply an abuse of the system!

- When publishing electronically, give preference to publications that are archived and curated (for details, see Rec. 29A.2) and that comply with the PDF/A archival standard (ISO 19005).

- Mention the nomenclatural novelties in your publication in the summary or abstract, or list them in an index (some journals as a matter of routine include a list of the nomenclatural novelties published in each issue).

- Clearly indicate versions of the same electronic publication as either preliminary or final upon first issuing them. The phrase "Version of Record" should only be used to indicate a final version in which the content will not change.

- The final version of an electronic publication should also be "citation ready", i.e. the pagination should be final, not preliminary. This applies especially to papers published in journals in advance of an issue or volume being completed.

- Clearly cite the precise date of publication on the printer matter. For electronic publications, cite the precise date of publication and the ISSN or ISBN on a page of the PDF, not merely on the web page that links to the PDF nor merely in the metadata ("document properties") of the PDF; likewise the journal name and volume/issue/article number if applicable.

\section{DATE OF EFFECTIVE PUBLICATION}

It is important to know the date of effective publication whenever names or other nomenclatural acts, such as designations of type, are competing for priority. When two competing names were published in the same year, the exact date is needed. Article 31.1 rules on how to determine the date of effective publication. Put simply, it is the date on which the printed matter or electronic material became available as defined in Art. 29 and 30. Electronic material becomes available as soon as it is accessible electronically via the World Wide Web. But at what point does printed matter become available? Recommendation $31 \mathrm{~A}$ helps here by advising that the date on which the 
publisher or publisher's agent delivers printed matter to one of the usual carriers for distribution to the public should be accepted as its date of effective publication.

For many older works, Taxonomic literature, ed. 2 (TL-2; see pp. 151 and 154) is a very important source of meticulously researched information on dates of effective publication. The dates given by TL-2 often differ from what is printed on the title pages of the books. Sometimes the title-page date represents the completion of a multi-part work, whereas the individual parts were published on different, earlier dates. Sometimes a title-page date is simply wrong. Sometimes there is no evidence beyond the date that appears in the printed matter or electronic material, and in that case that date must be accepted as correct (Art. 31.1).

Be careful when determining the dates of papers in journals. Firstly, when separately issued parts of a journal volume have been bound together, you should not trust the date that appears on the cover, because it could be a book-binder's error. Instead look at the individual front and back covers of the relevant separate part, if the covers have been retained upon binding; or sometimes the date may be on the title page(s), preliminary pages, or the first or last text pages of the part. Some journals issue separate covers and title pages for the whole volume and for each part, with a later date appearing on those for the whole volume. Sometimes a volume may have been issued in parts without covers or title pages. There may be a list of page ranges with corresponding dates on one of the preliminary pages of the volume, or dates may be printed on the first or last page of each part, in which case you have to search for them. Some journals print the date of publication of a particular part not in that part but in the following part.

For electronic material, look for a statement of date in the text of the PDF document itself; only if no date is given there should you look on the web page(s) from which the document is served. Bear in mind that the date given on the web page could be, e.g., the general date of an issue of a journal, not of the individual papers therein. Do not use the "created" or "modified" dates in the "document properties" (i.e. the metadata); the document may have been issued online days after its creation or last modification, or these dates could merely reflect the date of your download.

If a publication exists in parallel printed and electronic versions, do not assume they were necessarily published simultaneously. Look for evidence of date for both versions. If there is no evidence that they were published on different dates, they must be treated as effectively published on the same date (Art. 31.2). 


\section{CHAPTER 5 | HOW TO PUBLISH A NEW NAME}

Valid publication has great importance because a name that has not been validly published has no status-is not even a name-under the Code. If you made a mistake when attempting to publish a new name, it might not be validly published. This could be time-consuming for you, not to mention embarrassing, if your new name had no status and required a second attempt at publication before it could be used. The following "how to" lists are based on the rules on valid publication (Art. 32-45), with references provided to the relevant Articles.

\section{HOW TO PUBLISH THE NAME OF A NEW TAXON}

Suppose you wish to publish the name of a new taxon. What do you need to do in order for it to be validly published? The main requirements to remember are itemized below and illustrated by Figs. 2, 3, and 4 (pp. 32-36; while Figs. 5 and 6, pp. 37-38 show historical protologues for comparison).

- The name must be effectively published (Art. 32.1(a)), as explained in Chapter 4.

- The name must have a form that complies with Art. 16-27 (Art. 32.1(c)). See Rules on the formation of names, pp. 48-54.

- For the name of a taxon below the rank of genus, the name of the genus or species to which it is assigned must be validly published either previously or at the same time (Art. 35.1).

- The protologue must include either a description or a diagnosis that is in either Latin or English (Art. 38.1(a) and 39.2). Optionally, you may include both a description and a diagnosis, and you may provide an additional description and/or diagnosis in a language other than Latin or English; such optional additions are not prohibited by the Code and will not affect valid publication, although editors of journals and books may have their own guidelines on what you can include. A description gives the physical properties of the taxon, e.g. morphology, colour, odour, flowering time, chromosomes, chemical properties, or DNA sequence data. A diagnosis of a taxon is a statement of that which distinguishes the taxon from other taxa in the opinion of the author of the taxon (Art. 38.2).

- For the name of taxon at the rank of genus or below, you must designate the type of the name in the protologue (Art. 40.1), using the word "typus" or "bolotypus", or 
its abbreviation (e.g. holo.), or its equivalent in a modern language (e.g. holotipo, holotype, tipo, type) (Art. 40.6).

- For the name of a species or infraspecific taxon, you must designate a specimen (Art. 40.4) as the holotype, although for non-fossil microscopic algae and non-fossil microfungi an effectively published illustration is permitted as the holotype under certain circumstances (see Art. 40.5).

- For the name of a species or infraspecific taxon, when the holotype is a specimen (which it almost always will be), you must specify in the protologue the single herbarium, collection, or institution in which it is conserved (Art. 40.7).

- Additional, special rules exist for the names of algae (Art. 40.8 and 44), fungi (Art. 40.8 and F.5), fossils (Art. 43), and hybrids (Chapter H), for which see Chapter 11. 
Zyrphelis ecklonis (DC.) Kuntze subsp. oligocephala Zinnecker-Wiegand, subsp. nov.

A subspecie typica differt foliis falcatis numquam glandulosis, aut glabris aut \pm longe setosis, capitulis minoribus numerosis.

Typus: [South Africa, Western Cape province, Clanwilliam Distr.] Cedarberg Mts., Middelberg, 14. 12. 1941, Esterhuysen 7250 (holotypus, BOL!).

Zyrphelis ecklonis (DC.) Kuntze subsp. strictifolia ZinneckerWiegand, subsp. nov.

A subspecie typica differt foliis $(4-) 5 \times 2 \mathrm{~mm}$ usque ad $11.0 \times 2.5 \mathrm{~mm}$, rigidis glabris vel interdum subtus hirsutis, coriaceis et cauli adpressis.

Typus: [South Africa, Western Cape province, Clanwilliam Distr.] Rocky hill behind the homestead of Krommerivier, in the Cederberge, 27.9. 1934, Acocks 3136 (holotypus, S!).

1. Merianthera bullata R. Goldenb., Fraga \& A.P. Fontana, sp. nov. - Type: BRAZIL. Espírito Santo: Santa Teresa, Distrito de 25 de Julho, Loc. Bela Vista, Propr. José Zucolotto, 29 Apr 2005 (fl), A.P. Fontana \& al. 1404 (holotype: MBML; isotype: UPCB). - Figure 5.

Shrubs $0.5-2.5 \mathrm{~m}$. Petioles 7-26 mm long; blade 4.1-18 $\times 4.4-20 \mathrm{~cm}$, orbicular to broadly orbicular, base truncate to broadly cordate, apex broadly rounded, truncate to broadly emarginate, coriaceous, slightly discolorous when dried, acrodromous nerves $5-7$, plus a faint submarginal pair, shortly 
Fig. 2. Three modern protologues of names of new plant taxa: Zyrphelis ecklonis subsp. oligocephala Zinnecker and Zyrphelis ecklonis subsp. strictifolia Zinnecker, from a paper in volume 60 of the journal Taxon by Ortiz \& Zinnecker-Wiegand (2011: 1196), and Merianthera bullata R. Goldenb., Fraga \& A.P. Fontana, from a paper in volume 61 of Taxon by Goldenberg \& al. (2012: 1047). Reproduced by permission of the International Association for Plant Taxonomy. Components of the protologues are as follows:

- Names cited in full (generic name not abbreviated), authorship explicitly cited, and novel status indicated ("subsp. nov." or "sp. nov."); all three items are best practice and should certainly be followed (even if strictly they are not requirements for valid publication under the Code).

- Latin validating description or diagnosis for the names in Zyrphelis (here diagnoses), as required for names published between 1935 and 2011, inclusive (Art. 39.1).

- Latin or English validating description or diagnosis for Merianthera bullata (here an English description), as required for names published from 2012 onward (Art. 39.2).

- $\quad$ Citation of type (Art. 40.1), which is a specimen (Art. 40.4), using one of the words "typus" or "holotypus", or its abbreviation, or its modern-language equivalent (here both words in Latin or English; Art. 40.6), specifying the single herbarium where the type is conserved (BOL, S, or MBML; Art. 40.7), and citing a duplicate, i.e. an isotype, in the herbarium UPCB. The exclamation mark (!) placed after the herbarium code in the Zyrphelis protologues indicates that the cited specimen has been seen by the author(s). No meaning should be inferred from the absence of exclamation marks in the Merianthera protologue because the authors did not use exclamation marks at all in their paper. 
1b. Orychophragmus violaceus var. odontopetalus Ling Wang \& Chuan P. Yang, var. nov. TYPE: China. Heilongjiang: Harbin, cultivated on campus of Northeast Forestry University (NEFU), 20 May 2009, X. J. Ma, L. Wang \& C. P. Yang 09009 (holotype, NEFI). Figure 1.

Haec varietas ab Orychophragmo violaceo (L.) O. E. Schulz var. violaceo petalis ad vel supra medium dentibus obtusis 5 vel plus praeditis, petalorum unguibus longioribus (10-13 mm longis) atque caulibus et pedicellis puberulis differt.

Herbs, annual or biennial, $10-50 \mathrm{~cm}$ tall; stems puberulent. Basal and lower leaves lyrate; petiole $2-4$ cm; uppermost leaves often undivided, elliptic, 5-7 $\times$ 3-4 cm; apex acute, base auriculate, semi-amplexicaule, margin regularly serrate or rarely pinnatifid, lobes with few teeth. Flowers purple, 2-4 cm diam., pedicels $10-15 \mathrm{~mm}$, puberulent; calyx tube purplish; petals 4 , broadly obovate, with 5 or more obtuse teeth on expanded apical blade, expanded petal $10-13 \mathrm{~mm}$ long. Silique linear, $8-10 \mathrm{~cm}$, quadrangular; seeds ovoid to oblong, $2 \mathrm{~mm}$, black-brown.

Habitat and distribution. The plants were derived from naturally growing specimens from the Beijing Botanical Garden. The plants are common in Hebei, Liaoning, Shandong, Shanxi, Shaanxi, and Jiangsu provinces but do not grow in the wild in the Harbin area, Heilongjiang Province (Fu, 2003). However, the plants have been established as ornamental species throughout the Harbin metropolitan area.

IUCN Red List category. Because this is a widespread taxon in the above named provinces, the new variety is determined as of Least Concern (LC), according to IUCN Red List categories and criteria (IUCN, 2001).

Paratypes. CHINA. Beijing: Xiangshan, Beijing Botanical Garden, under trees, 22 Apr. 2006, L. Wang 21012 (NEFI). Heilongjiang: Harbin, cult., residential area of NEFU, 20 May 2009, L. Wang, X. J. Ma \& Y. J. Bao 9014 (NEFI); Harbin Forest Farm of NEFU, forest edge, 18 May 2008, L. Wang \& X. Z. Zhang 8012 (NEFI). Liaoning: near town of Beizhen, roadsides, 6 May 2005, L. Wang \& C. P. Yang 4083 (NEFI). 
Fig. 3. A modern protologue of the name of a new plant taxon: Orychophragmus violaceus var. odontopetalus Ling Wang \& Chuan P. Yang, from a paper in volume 22 of the journal Novon by Wang \& al. (2012: 110). Reproduced by permission of Missouri Botanical Garden Press. Components of the protologue are as follows:

- Name cited in full (generic name not abbreviated), authorship explicitly cited, and novel status indicated ("var. nov."); all three items are best practice and should certainly be followed (even if strictly they are not requirements for valid publication under the Code).

- $\quad$ Citation of type (Art. 40.1), which is a specimen (X.J. Ma, L. Wang \& C.P. Yang 09009; Art. 40.4), using one of the words "typus" or "holotypus", or its abbreviation, or its modern-language equivalent (here both words in English; Art. 40.6), and specifying the single herbarium where it is conserved (NEFl; Art. 40.7).

- Latin or English validating description or diagnosis (here a Latin diagnosis and an English description), as required for names published from 2012 onward (Art. 39.2).

- Notes on habitat and distribution, IUCN Red List category, and citation of paratypes (Art. 9.7). 
Halegrapha paulseniana Luch \& Lücking, sp. nov. MycoBank MB 828103. - Fig. 1D-F.

Holotype: U.S.A., Hawaii, Maui, East Maui, Haleakalā Volcano, lower Waikamoi Preserve (The Nature Conservancy), $5 \mathrm{~km} \mathrm{SE}$ of Pukalani and $18 \mathrm{~km} \mathrm{SE}$ of Kahului, lower access trail to preserve off Olinda Road, $20^{\circ} 48^{\prime} 23^{\prime \prime} \mathrm{N}, 156^{\circ} 15^{\prime} 19^{\prime \prime} \mathrm{E}, 1200-1300 \mathrm{~m}$, disturbed primary forest dominated by Acacia koa and Cатрапиlaceae, with invasive Hedychium gardnerianum in lower portions, 11 Jun 2013, R. Lücking, B. Moncada \& P. Bily 35834 (BISH; isotypes: B, F).

Diagnosis - Differing from Halegrapha mexicana A. B. Peña \& Lücking in the much larger lirellae featuring an apically complete, thin thalline margin, and from all other species in the genus in its laterally mostly uncarbonized excipulum.

Fig. 4. A modern protologue of the name of a new fungal taxon: Halegrapha paulseniana Luch \& Lücking, from a paper in volume 48 of the journal Willdenowia by Luch \& Lücking (2018: 416). Reproduced by permission of the authors and the Botanischer Garten und Botanisches Museum Berlin. Components of the protologue are as follows:

- Name cited in full (generic name not abbreviated), authorship explicitly cited, and novel status indicated ("sp. nov."); all three items are best practice and should certainly be followed (even if strictly they are not requirements for valid publication under the Code).

- Citation of the identifier issued for the name by a recognized repository ("MycoBank MB $\left.828103^{\prime \prime}\right)$, as required for new names of fungi published from 2013 onward (Art. F.5.1).

- Citation of type (Art. 40.1), which is a specimen (R. Lücking, B. Moncada \& P. Bily 35834; Art. 40.4), using one of the words "typus" or "holotypus", its abbreviation, or its modern-language equivalent (here in English, "holotype"; Art. 40.6), specifying the single herbarium where it is conserved (BISH; Art. 40.7), and citing two duplicates, i.e. isotypes, in the herbaria B and F. Additional collecting details of the type are also cited (locality with coordinates, altitude, habitat, and date).

- Latin or English validating description or diagnosis (here an English diagnosis; also an English description, not shown in this figure), as required for names published from 2012 onward (Art. 39.2).

- Also provided, but not shown in this figure, are remarks on the new species, including distribution, ecology, derivation of the specific epithet, and comparison with other taxa, as well as illustrations of the organism and its habitat. 


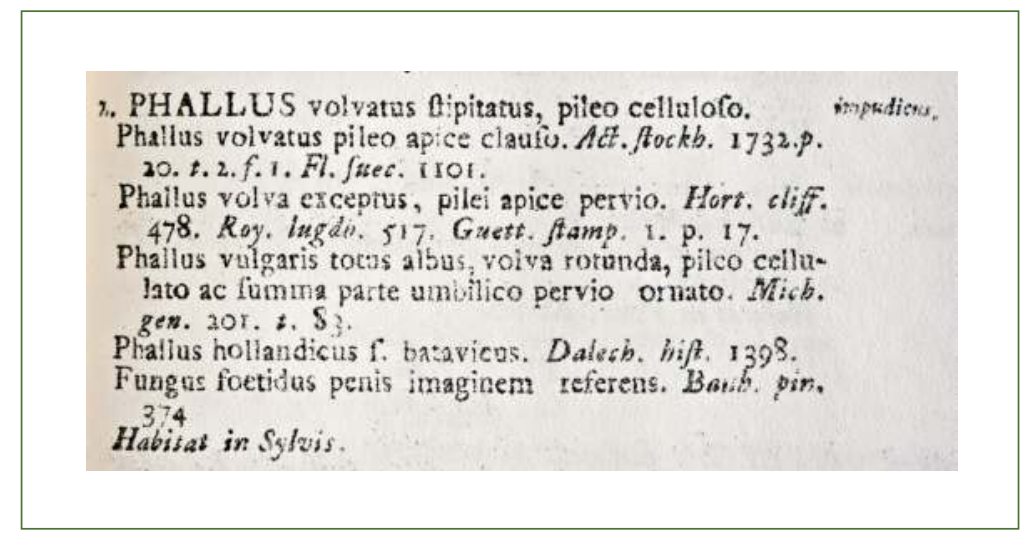

- Fig. 5. An 18th-century protologue of the name of a new fungal taxon: Phallus impudicus L. Part of page 1179 of volume 2 of the 1st edition of Linnaeus's Species plantarum (Linnaeus, 1753: 1179). The components of the protologue are as follows:

- $\quad$ Sequential species number within the genus Phallus: "2."

- Diagnostic phrase name (polynomial): "Phallus volvatus stipitatus, pileo celluloso." (Phallus volvate, stipitate, with a cellular cap). This is Linnaeus's nomen specificum legitimum (lawful specific name), in Latin, serving as the validating diagnosis of the species name.

- $\quad$ Specific epithet, in the margin: "impudicus." (immodest). This is Linnaeus's nomen triviale (trivial name), directly associated with the generic name (at the start of the phrase name and in the heading of the genus) to form the combination Phallus impudicus.

- Synonyms: five pre-starting-point phrase names are cited in synonymy; the illustration cited with the third synonym (Micheli, 1729: 201, t. 83) has been designated as the lectotype of $P$. impudicus (see Fig. 18, p. 77).

- $\quad$ Statement of provenance: "Habitat in Sylvis." (It inhabits the woods). 
11. T. graвRuM, ex omni parte glaberrimum, foliis elliptico-oblongis longè in petiolum attennatis nunc. integerrimis nunc parcè subsinnato-dentatis, scapo foliis panlò longiore, invol. sqnamis exter. patalis immarginatis ovato-lanceolatis apice callosis, achænii lævis rostro abbreviato. $\mathcal{H}$ in humidis montanis Dahnriæ ad Nuchu-Doban legit el. Turczaninow. Hieracium glabrum, et postea Leontodon nov. sp. Tnrcz.! in litt. Affine T. glancantho, sed nt videtur diversum invol. nigricantibus non ant vix corniculatis, achænii (equidem immaturi) rostro brevi, scapo etiam apice glaberrimo. (v. s. comm. à cl. inv.)

Fig. 6. A 19th-century protologue of the name of a new plant taxon: Taraxacum glabrum DC. Part of page 147 of part 1 of volume 7 of Candolle's Prodromus systematis naturalis regni vegetabilis (Candolle, 1838: 147). Components of the protologue are as follows, with abbreviations in the original Latin expanded here using square brackets:

- Sequential species number within the genus Taraxacum: "11."

- Binomial: "T[araxacum]. glabrum" (specific epithet: glabrous).

- $\quad$ Validating diagnosis, in Latin: "T[araxacum]. glabrum, ex omni parte glaberrimum [...] rostro abbreviato." (Taraxacum glabrum, in every part very glabrous [...] with beak shortened).

- Symbol meaning perennial: “2|".

- $\quad$ Statement of provenance and collector's name: "in humidis montanis Dahuriae ad Nuchu-Doban legit cl[arissimo]. Turczaninow." (in damp montane [places] of Dahuria at Nuchu-Doban gathered by the most illustrious Turczaninow).

- Unpublished synonyms cited from Candolle's correspondence with Turczaninow: "Hieracium glabrum, et postea Leontodon nov[a]. sp[ecies]. Turcz[aninow]. ! in litt[eris]." (Hieracium glabrum, and afterwards Leontodon new species. Turczaninow ! [I have seen] in letters/correspondence).

- Comparison with a supposedly related species: "Affine T. glaucantho, sed [...]" (Akin to T. glaucanthum, but ...).

- Indication that a specimen has been seen by Candolle: "(v[idi]. s[iccam]. comm[unicatam]. à cl[arissimo]. inv[entore].)" (I have seen a dry [plant, i.e. specimen] communicated by the most illustrious discoverer [i.e. Turczaninow]). 


\section{HOW TO PUBLISH A NEW COMBINATION, NAME AT NEW RANK, OR REPLACEMENT NAME}

Suppose you wish to rename a taxon that has been named previously. You wish to publish a new combination, a name at new rank, or a replacement name (see Chapter 2 for definitions of those terms). What do you need to do in order for such a new name to be validly published? The main requirements to remember are itemized below and illustrated by Fig. 7 (p. 40; while Fig. 8, p. 41 shows a historical protologue for comparison).

- The new name must be effectively published (Art. 32.1(a)), as explained in Chapter 4.

- The new name must have a form that complies with Art. 16-27 (Art. 32.1(c)). See Rules on the formation of names, pp. 48-54.

- For the new name of a taxon below the rank of genus, the name of the genus or species to which the taxon is assigned must be validly published either previously or at the same time (Art. 35.1).

- You must cite the basionym or replaced synonym in the protologue together with a full and direct reference to its author and place of valid publication, with page or plate reference and date (Art. 41.5). "Direct" means citing the actual author and place of publication, not a different publication that in turn refers to the actual one, while "full" means all necessary details. Page or plate reference means the page or pages on which the basionym or replaced synonym was validly published or on which the protologue appears, not the pagination of the whole publication unless it is coextensive with that of the protologue (Art. 41 Note 1). If the publication is unpaginated, cite the page number in square brackets, e.g. "[42]" or use another unambiguous method (e.g. generic name plus species number for Miller's The gardeners dictionary; Miller, 1768). If you need to cite an online publication that is the final version (e.g. the "Version of Record") but still has preliminary pagination, you can note its online status and cite the preliminary page number in square brackets. Some journals require the full and direct reference to be given in the format "Author(s) (year: page/plate number(s))", with the full bibliographic details of the publication given in the references section. Such a reference is still full and direct, even though it is split between two places in the publication, and it therefore complies with Art. 41.5, but the Code explicitly recommends against this method (see Rec. 41A.1). 
1. Polyalthia fruticosa (Jessup) B. Xue \& R.M.K. Saunders, comb. nov. $\equiv$ Haplostichanthus fruticosus Jessup, Fl. Australia 2: 41, 449, fig. 9A-D. 2007 - Type: Australia, Queensland, Williams Spring, $22.4 \mathrm{~km}$ NE of Bamaga, 17 Feb. 1994, D.G. Fell, J.P. Stanton \& C. Roberts DGF3784 (holotype: BRI).

2. Polyalthia hispida B. Xue \& R.M.K. Saunders, nom. nov. $\equiv$ Haplostichanthus rufescens Jessup, Fl. Australia 2: 41-42, 449, fig. 9Q-S. 2007 - Type: Australia, Queensland, N Johnstone River, Palmerston National Park, Crawford's Lookout to Tchupalla Falls Track, 15 Feb. 1982, L.W. Jessup \& J.G. Tracey 471 (holotype: BRI).

The combination Polyalthia rufescens is already occupied (P. rufescens Hook. f. \& Thomson), and a new name is therefore proposed. The new specific epithet describes the hispid leaves, flowers and fruits.

3. Polyalthia johnsonii (F. Muell.) B. Xue \& R.M.K. Saunders, comb. nov. $\equiv$ Haplostichanthus johnsonii F. Muell. in Vict. Naturalist 7: 180. 1891 - Type: Australia, Queensland, Mt Bartle Frere, 1891, S. Johnson s.n. (holotype: MEL; isotypes: BRI, K, NSW).

Fig. 7. Two modern new combinations and a replacement name: Polyalthia fruticosa (Jessup) B. Xue \& R.M.K. Saunders, P. hispida B. Xue \& R.M.K. Saunders, and P. johnsonii (F. Muell.) B. Xue \& R.M.K. Saunders, all from a paper in volume 61 of the journal Taxon by Xue \& al. (2012: 1034). Reproduced by permission of the International Association for Plant Taxonomy. Components of the protologues are as follows:

- Names cited in full (generic name not abbreviated), authorship explicitly cited, and novel status indicated ("comb. nov." or "nom. nov."); all three items are best practice and should certainly be followed (even if strictly they are not requirements for valid publication under the Code).

- Basionym or replaced synonym indicated (" $\equiv$ " indicates homotypic synonymy) together with a full bibliographic reference to its place of valid publication, as required for names published from 1953 onward (Art. 41.5); the basionym or replaced synonym is also cited (indicated does not necessarily mean cited), as required for names published from 2007 onward (Art. 41.5). Instead of the symbol "三", the word "basionym", or its abbreviation (e.g. "basio."), or its equivalent in another language may be used.

- Citation of type: again, this is good practice, although the Code does not require it for valid publication of a new combination, name at new rank, or replacement name. 
A. Heterochaeta Bth. = Heterochaeta asteroides DC. = A. asterodes OK.

Big. paniculata Asa Gray non Aster p. Lam. = A. Asae OK.

Fig. 8. A 19th-century new combination and a replacement name, both from page 315 of part 1 of Kuntze's Revisio generum plantarum (Kuntze, 1891: 315). Each name was validly published with a reference to the basionym or replaced synonym (Art. 41.1), although it was not a full reference, which was not required until 1953 (Art. 41.5). Components of these two protologues are as follows, with abbreviations in the original Latin expanded here using square brackets:

Aster asteroides (DC.) Kuntze:

- Homotypic synonym: "A[ster]. Heterochaeta Bth.", i.e. A. heterochaeta Benth. ex C.B. Clarke 1876, a replacement name for Heterochaeta asteroides DC. Aster heterochaeta was nomenclaturally superfluous when published, and is therefore illegitimate under Art. 52.1, because Clarke should have used A. asteroides instead.

- Basionym: "Heterochaeta asteroides DC." 1836.

- $\quad$ New combination: "A[ster]. asterodes [sic!] OK.", i.e. A. asteroides (DC.) Kuntze. Kuntze's spelling of the epithet is correctable to the original spelling of the basionym (Art. 60.1 and 60.2).

Aster asae Kuntze:

- Replaced synonym: "Big[elowia]. paniculata Asa Gray non Aster p[aniculatus]. Lam.", i.e. Bigelowia paniculata A. Gray 1873 non Aster paniculatus Lam. 1783 nec A. paniculatus Mill. 1768.

- $\quad$ Replacement name: "A[ster]. Asae OK.", i.e. A. asae Kuntze.

The generic names Aster and Bigelowia are spelled out above the entries on the same page. Kuntze abbreviated his own name as "OK" (Otto Kuntze). Notice the obsolete practice of using an initial capital letter in epithets of species names when they are proper nouns (see Rec. 60F.1): "Heterochaeta", a generic name in apposition (nominative), and "Asae", the genitive of Asa. 


\section{Best practice - publishing new names}

Some of these suggestions are based on Recommendations in the Code. See especially those on formation of generic names (Rec. 20A) and specific epithets (Rec. $23 \mathrm{~A}$, applying equally to infraspecific epithets), those on valid publication (Rec. $32 \mathrm{~A}-44 \mathrm{~A})$, and those on orthography (Rec. $60 \mathrm{~A}-60 \mathrm{H}$ ).

- Give an adequate description and diagnosis. When publishing the name of a new taxon, it may be a matter of editorial policy whether you include a description or a diagnosis, or both, and whether you use Latin or English, or both. But in any event, the more relevant information you can provide, the better. Simply writing "Like other species in the genus [or species $x$ ] but with lanceolate leaves, caducous sepals, and white petals 5-8 mm long" and no other details is not very useful.

- Check the relevant name index(es) when publishing any new name, e.g. the International Plant Names Index (https://www.ipni.org/), in case the name already exists. You would not want to publish a later isonym (which would have no nomenclatural status) or a later homonym (which would be illegitimate).

- Check that your intended basionym or replaced synonym is already validly published when you publish a new combination, name at new rank, or replacement name. When publishing a replacement name for a later homonym (or to avoid creating a later homonym), check that the earlier homonym (or the blocking name, i.e. the name that would be an earlier homonym if you were to create a later one) was indeed validly published, because there are many entries in older lists, e.g. Index kewensis (see p. 151), that are not in fact validly published names.

- Indicate as such the name of a new taxon, e.g. species nova or genus novum or ordo novus. These Latin terms are normally abbreviated to sp. nov., gen. nov., ord. nov., etc., which neatly avoids ensuring that the adjective novus, $-a,-u m$ (new) agrees in gender with the noun that is the rank-denoting term.

- Indicate as such a new combination, name at new rank, or replacement name. The common abbreviations are "comb. nov." (combinatio nova), "stat. nov." (status novus), and "nom. nov." (nomen novum), respectively. When a new combination is also a name at new rank, you can write "comb. \& stat. nov." or "comb. et stat. nov."

- Make the type obvious. When designating the type of the name of a new taxon, you are required to use the word "typus" or "holotypus", or its abbreviation, or its equivalent in a modern language. To make your designation of type obvious to the widest international audience, use one of the Latin words or a modern-language equivalent that uses the Latin alphabet and is cognate with the Latin, e.g. holotipo (Spanish) or holotype (English). 
- Specify the herbarium clearly. When designating a specimen as the holotype, you are required to specify the single herbarium, collection, or institution in which it is conserved. The standard method, which should be readily understood internationally, is to cite the herbarium code given in Index Herbariorum (http://sweetgum.nybg.org/science/ih/), e.g. NY for the New York Botanical Garden.

- $\quad$ Refer unambiguously to a single specimen (see Art. 8.2 and 8.3) when designating the holotype, e.g. by citing a herbarium barcode or other number that permanently identifies the specimen. If the specimen can be viewed online via a permanent link, cite the link also. Citing a single gathering may be sufficient to indicate a type (Art. 40.2), but if there is more than one specimen of that gathering in the single specified herbarium, those specimens will be syntypes (Art. 40 Note 1) and there will be no holotype; this is the only way syntypes can still come into being and it is not best practice.

- Cite the collection details of the holotype, i.e. full locality, date of collection, name(s) of collector(s), and any collecting number. Even though merely citing a unique specimen identifier and a herbarium code can be enough for valid publication, it is helpful to give more information about the type, especially if the specimen cannot be viewed online with open access. Precise locality details should be withheld only if there is a real threat of overcollecting.

- Clearly annotate the holotype specimen as such, labelling it at least with the name that it typifies, and your name, and ensure that it is available for examination in the herbarium specified in the protologue. A holotype should not be an unmounted specimen languishing indefinitely in a pile of newspaper in your office (or, even worse, your home).

- You have great freedom in choosing the name of a new taxon (or a replacement name), and there is potential for much creativity, provided that you follow the rules on formation of names (see pp. 48-54). Do choose a name that is somehow relevant to the organism. Naming taxa after their most distinctive morphological features, geographical locations, and habitat preferences is common. But beware of local geographical names: while a new taxon might be a local endemic when first described, it could be found in other places later.

- On the other hand, do not honour yourself in the name of a new taxon or a replacement name. Many would regard such an act as appallingly egocentric. However, there is nothing wrong with publishing a new combination or name at new rank for which the basionym, already published by someone else, honours you. 


\section{RULES ON VALID PUBLICATION ACCORDING TO DATE}

Some rules on valid publication are limited by date, meaning that they apply on or after a particular date but do not apply before that date. When rules are not limited by date, they apply from the nomenclatural starting-point of the taxonomic group concerned (e.g. 1 May 1753 for Spermatophyta; see Art. 13.1 and F.1). The most commonly encountered rules are summarized here, arranged by the date upon which, under the current Code, they become effective. Additional rules and dates apply to the names of algae (Art. 44), fungi (Art. F.5), fossils (Art. 43), and hybrids (Chapter H), for which see Chapter 11.

\section{May 1753}

- This is the nomenclatural starting-point for vascular plants, Sphagnum mosses, liverworts (Marchantiophyta), hornworts (Anthocerotophyta), fungi, and most algae, i.e. Species plantarum, ed. 1 (Linnaeus, 1753) (Art. 13.1 and F.1); later starting-points apply to all other mosses, some algae, all fossils, and suprageneric names of vascular plants and bryophytes (Art. 13.1; pp. 130-131 and Chapter 11). No validly published name can exist before the starting-point of the respective group (Art. 32.1(a)).

- The name must be effectively published (Art. 32.1(a)).

- The name must have a form that complies with Art. 16-27 (Art. 32.1(c)). See Rules on the formation of names, pp. 48-54.

- The name of the genus or species to which the name is assigned must be validly published either previously or at the same time (Art. 35.1).

- In a combination, the author must definitely associate the final epithet with the name of the genus or species, or with its abbreviation (Art. 35.2). For example, merely listing Cnidium peucedanoides under Eulophus would not validly publish the combination Eulophus peucedanoides; it would be necessary to cite that combination either in full or in abbreviated form, e.g. "E. peucedanoides".

- The name must be accepted by the author in the original publication, e.g. it must not be a provisional name or merely cited as a synonym (Art. 36.1). A name published provisionally (nomen provisorium, nom. prov.) or as a synonym (pro synonymo, pro syn.) is not validly published. However, if an author accepts a new name but cites it with a question mark or some other indication of taxonomic doubt (not an uncommon practice in older botanical literature), this does not prevent valid publication, e.g. "Sersalisia ? acuminata" (see Art. 36 Ex. 1).

- The relative order of ranks specified in Art. 3 and 4 (see Table 2, p. 17), enforced by Art. 5, must be followed (Art. 37.6). Misplaced ranks include, e.g., forms divided into varieties, species containing genera, and genera containing families or tribes. 
- The name of a new taxon must be accompanied by a description or diagnosis, or by a reference to one that was previously and effectively published (Art. 38.1(a)). A name, or rather a designation, that has neither a description nor a diagnosis nor a reference to one is called a nomen nudum (nom. nud., naked name) and is not validly published.

- A new combination, name at new rank, or replacement name must be accompanied by a reference to the basionym or replaced synonym (Art. 41.1). There are limitations on rank, e.g. a family name cannot be based on a generic name, and a generic name cannot be based on a species name (see Art. 41.2 for details). The reference may be indirect before 1 January 1953 (see there).

\section{January 1908}

- For the name of a new taxon at generic or lower rank, an illustration with analysis is no longer acceptable in place of a validating description or diagnosis (Art. 38.7 and 38.8; for the definition of analysis see Art. 38.9 and 38.10).

\section{January 1912}

- The name of a new genus may no longer coincide with a Latin technical term in use in morphology at the time of publication (Art. 20.2). Such a name may be validly published before 1912 provided that it was accompanied by a binomial species name.

\section{January 1935-31 December 2011}

- For the name of a new taxon of plants or fungi (except fossils), the validating description or diagnosis must be in Latin (Art. 39.1). For a name published before 1935, the validating description or diagnosis may be in any language.

\section{January 1953}

- Alternative names are no longer validly published (Art. 36.3). In this sense, alternative names are two or more different names based on the same type and accepted as alternatives simultaneously for the same taxon by the same author in the same publication. This is a different sense to the alternative family names authorized by Art. 18.6.

- There must be a clear indication of the rank of the taxon concerned (Art. 37.1). The termination (ending) of a suprageneric name is acceptable as an indication of the rank (e.g. -aceae indicates the rank of family) (Art. 37.2 and footnote). Before 1953 , a name may be validly published without a clear indication of rank. 
- For the name of a new taxon, a reference to a previously and effectively published description or diagnosis (when a description or diagnosis is not included in the protologue) must be full and direct. For the name of a new taxon published before 1953 such a reference may be indirect or even cryptic (Art. 38.13).

- For a new combination, name at new rank, or replacement name, the reference to the basionym or replaced synonym must be full and direct. For such names published before 1953 there still must be a reference, but it may be indirect (e.g. via another name) or even cryptic (e.g. merely an author citation) (Art. 41.3 and 41.5).

\section{January 1958}

- For the name of a new taxon at generic or lower rank, the type must be indicated (Art. 40.1). Before 1958, a name may be validly published without indicating a type.

\section{January 1958-31 December 2011}

- For the name of a new taxon of algae (except fossils), the validating description or diagnosis must be in Latin (Art. 44.1). For a name published before 1958, the validating description or diagnosis may be in any language.

\section{January 1973}

- For a name to be validly published without simultaneous fulfilment of all the relevant requirements of the Code for valid publication, full and direct reference must be given to the place(s) where these requirements were previously fulfilled (Art. 33.1). Before 1973, such a name is validly published when the last of these requirements is fulfilled.

\section{January 1990}

- For the name of a new taxon at generic or lower rank, the type must be indicated using the word "typus" or "holotypus", or its abbreviation, or its equivalent in a modern language (Art. 40.6).

- For the name of a new taxon at specific or lower rank, the single herbarium, collection, or institution in which the type is conserved must be specified if the type is a specimen or an unpublished illustration (Art. 40.7).

\section{January 1996}

- For the name of a new taxon of fossils, the validating description or diagnosis must be in Latin or English (Art. 43.1). For a name published before 1996, the validating description or diagnosis may be in any language. 


\section{January 2007}

- For the name of a new taxon at specific or lower rank, the type may no longer be an illustration and must be a specimen (Art. 40.4). An exception is made in certain cases for non-fossil microscopic algae and non-fossil microfungi (Art. 40.5).

- For a new combination, name at new rank, or replacement name, the basionym or replaced synonym must be cited (Art. 41.5). It is no longer permitted to indicate the basionym or replaced synonym without actually citing it. (To indicate does not necessarily mean to cite.)

\section{January 2012}

- For the name of a new taxon in all groups, the validating description or diagnosis must be in either Latin or English (Art. 39.2).

\section{January 2019}

- For the name of a new taxon of algae or fungi at specific or lower rank, when the type is a culture preserved in a metabolically inactive state (Art. 8.4), the protologue must include a statement that the culture is preserved in such a state (Art. 40.8).

\section{Registration of algal and plant names}

At the Shenzhen Congress of 2017, a framework of rules entered the Code for the future registration of new names and/or nomenclatural acts of algae and plants, including fossil algae and fossil plants. For fungi and fossil fungi, registration of new names has been mandatory since 1 January 2013 and that of type designations since 1 January 2019 (Art. F.5; see pp. 118-119). Recognized nomenclatural repositories are responsible for registering names and/or nomenclatural acts. For organisms other than fungi, the procedure can be summarized as follows:

- An institution may apply to the General Committee (see pp. 143-145) to become a recognized nomenclatural repository. The General Committee refers the application to the Registration Committee.

- Details of the proposed system must be developed in consultation between the applicant, the Registration Committee, and the Nomenclature Committee(s) for Vascular Plants, Bryophytes, Algae, and/or Fossils. The details must be widely publicized and a public trial run of at least one year must have shown that the system functions efficiently and sustainably. 
- Registration may occur before (as with fungi), simultaneously with, and/or after publication of a name or nomenclatural act.

- The Registration Committee makes a recommendation to the General Committee, which acts on that Recommendation, either recognizing the repository or not.

- The General Committee has the power to suspend or revoke recognition of a repository.

- Nothing in the Code currently allows registration of algal or plant names to become mandatory. Nor does the General Committee have that power. A proposal to amend the Code must be submitted to and accepted by a future International Botanical Congress.

Whether registration for algae, plants, or their fossils becomes mandatory at the next International Botanical Congress in 2023 will depend on whether a functional system exists by then. Between the Melbourne and Shenzhen Congresses, the International Plant Names Index (https://www.ipni.org/) conducted a trial run of a registration system for names of vascular plants, and the practicalities of establishing a sustainable system are still being explored. During the same period, two registration systems for names and types of fossil-taxa were launched: the Plant Fossil Names Registry (https:// www.fossilplantnames.org/), for fossil plants, and the International Fossil Plant Names Index (https://fossilplants.info/), for all fossil-taxa covered by the Code. In 2017, after the Shenzhen Congress, a registration system for algal names and types was launched: PhycoBank (https://www.phycobank.org/). Public trial runs of these systems are currently available, although at the time of writing (January 2019) none has applied to the General Committee to become a recognized repository.

\section{RULES ON THE FORMATION OF NAMES}

The remaining requirements for valid publication, not yet discussed, concern the actual form of scientific names. Under these rules, valid publication of a name depends on its having the required form, unlike the rules on orthography and gender (see Chapter 10), which are independent of valid publication and permit correction of errors in spelling and grammar.

The core rule on valid publication is Art. 32.1, which requires a name to be composed only of letters of the Latin alphabet and to have a form that complies with the provisions of Art. 16-27. Those provisions apply to names of taxa at different ranks, and are organized in a descending sequence from taxa above the rank of family to infraspecific taxa. They are described below. 


\section{Names of suprageneric taxa}

Names above the rank of family (Art. 16.1) may be either automatically typified names formed from the name of an included genus, such as Magnoliophyta (from Magnolia), Pinopsida (from Pinus), and Poales (from Poa), or descriptive names, such as Angiospermae, Fungi, Gymnospermae, Monocotyledones, Spermatophyta, and Tracheophyta. An automatically typified name is so called because it automatically has the same type as the name of the genus from which it is formed. These names are formed by adding a termination (ending) appropriate to the rank of the name (Art. 16.3 and 17.1; see Table 5, p. 51) to the stem of the genitive of the generic name, with the connecting vowel $-o$ - if the termination begins with a consonant. For example, Magnoliophyta is formed from Magnoli- (the stem of Magnoliae, the genitive of Magnolia) plus the connecting vowel -o-plus -phyta (the termination for a division or phylum of algae or plants); Poales is formed from Po- (the stem of Poae, the genitive of Poa) plus -ales (the termination for an order).

The name of a family or a subdivision of a family is formed in the same way (see Table 3, p. 50) but with a different termination: -aceae for family, -oideae for subfamily, -eae for tribe, and -inae for subtribe (Art. 18.1, 19.1, and 19.3; see Table 5, p. 51).

Names of families or subdivisions of families cannot be descriptive names, except for those listed in Art. 18.5, the traditional family names, e.g. Compositae, for which Art. 18.6 permits the use of an alternative family name (nomen alternativum, nom. alt.) formed from a generic name, which provides the type. These names are listed in Table 4 (p. 50).

Note that when the Papilionaceae are regarded as a family distinct from the remainder of the Leguminosae, the name Papilionaceae is conserved (see Chapter 8) against Leguminosae; otherwise Leguminosae Juss. 1789 has priority over Papilionaceae Giseke 1792. In addition, Art. 19.8 permits the use of Papilionoideae as an alternative to Faboideae when the Papilionaceae are included in the Leguminosae as a subfamily.

The rank-denoting terminations prescribed in Art. 16-19 (and summarized in Art. 37.2 footnote) must be used, and at the ranks of phylum to subclass, inclusive, different terminations are used for names of algae, fungi, and plants (see Table 5, p. 51). If additional ranks not mentioned in Art. 16-19 are inserted, e.g. to allow naming of clades in a large phylogenetic tree, then it is not mandatory to use a particular termination for the names in those additional ranks.

Note that suprageneric names are treated as plural nouns, hence it is grammatically better to write "the Orchidaceae are" than "the Orchidaceae is". They are also written with an initial capital letter. Whether or not they should be italicized is a matter of editorial style and tradition, not of nomenclature. The Code neither rules nor recommends on the matter, but consistently italicizes all scientific names under its jurisdiction. Note that for zoological names, the International Code of Zoological Nomenclature (Appendix 
B: Gen. Rec. 6) recommends against italicizing names of taxa higher than genus-group and actually writes such names in capital letters.

Table 3. Formation of automatically typified suprageneric names, using family names as an example (see Art. 18.1).

\begin{tabular}{|l|l|l|l|}
\hline Generic name & Genitive singular & Stem & Family name (add -aceae) \\
\hline Aextoxicon & Aextoxicou & Aextoxic- & Aextoxicaceae \\
\hline Aster & Asteris & Aster- & Asteraceae \\
\hline Capparis & Capparis/-os & Cappar- & Capparaceae \\
\hline Cycas & Cycadis & Cycad- & Cycadaceae \\
\hline Dryopteris & Dryopteridis/-os & Dryopterid- & Dryopteridaceae \\
\hline Juglans & Juglandis & Jugland- & Juglandaceae \\
\hline Lilium & Lilii & Lili- & Liliaceae \\
\hline Magnolia & Magnoliae & Magnoli- & Magnoliaceae \\
\hline Melastoma & Melastomatis/-os & Melastomat- & Melastomataceae \\
\hline Pinus & Pini & Pin- & Pinaceae \\
\hline Plantago & Plantaginis & Plantagin- & Plantaginaceae \\
\hline Poa & Poae & Po- & Poaceae \\
\hline Potamogeton & Potamogetonis/-os & Potamogeton- & Potamogetonaceae \\
\hline Salix & Salicis & Salic- & Salicaceae \\
\hline Smilax & Smilacis & Smilac- & Smilacaceae \\
\hline Vitis & Vitis & Vit- & Vitaceae \\
\hline
\end{tabular}

Table 4. Traditional and alternative family names and their types.

\begin{tabular}{|l|l|l|}
\hline $\begin{array}{l}\text { Traditional family } \\
\text { name }\end{array}$ & $\begin{array}{l}\text { Alternative family name (nomen } \\
\text { alternativum) }\end{array}$ & Type \\
\hline Compositae & Asteraceae & Aster $\mathrm{L}$. \\
\hline Cruciferae & Brassicaceae & Brassica L. \\
\hline Gramineae & Poaceae & Poa L. \\
\hline Guttiferae & Clusiaceae & Clusia L. \\
\hline Labiatae & Lamiaceae & Lamium L. \\
\hline Leguminosae & Fabaceae & Faba Mill. [= Vicia L.] \\
\hline Palmae & Arecaceae & Areca L. \\
\hline Papilionaceae* & Fabaceae & Faba Mill. \\
\hline Umbelliferae & Apiaceae & Apium L. \\
\hline *Conserved (see Chapter 8 ) against Leguminosae when the Papilionaceae are treated as \\
a family distinct from the remainder of the Leguminosae.
\end{tabular}


Table 5. Mandatory terminations (endings) of suprageneric names according to rank and organismal group.

\begin{tabular}{|l|l|l|l|l|}
\multirow{2}{*}{ Rank } & \multicolumn{2}{l}{ Termination } & Article \\
\cline { 2 - 5 } & Algae & Fungi & Plants & \\
\hline division or phylum & -phyta & -mycota & -phyta & 16.3 \\
\hline subdivision or subphylum & -phytina & -mycotina & -phytina & 16.3 \\
\hline class & -phyceae & -mycetes & -opsida & 16.3 \\
\hline subclass & -phycidae & -mycetidae & -idae & 16.3 \\
\hline order & -ales & & 17.1 \\
\hline suborder & -ineae & & 17.1 \\
\hline family & -aceae & & 18.1 \\
\hline subfamily & -oideae & 19.1 \\
\hline tribe & -eae & 19.3 \\
\hline subtribe & -inae & 19.3 \\
\hline
\end{tabular}

\section{Names of genera}

The name of a genus is a nominative singular noun, or a different kind of word treated as such, and is written with an initial capital letter (Art. 20.1). The name can be formed quite arbitrarily and does not necessarily have to mean anything in Latin or Greek. For example, Daucus from Greek $\delta$ ¿่xoৎ, daukos, a carrot-like plant from Crete used in medicine, Ginkgo from the Japanese name of the tree, Magnolia named in honour of Pierre Magnol, Quercus from the Latin quercus (oak), Wollemia from the Wollemi National Park, the place of discovery of the tree. A generic name may consist of two words so long as they are hyphenated (Art. 20.3), e.g. Solms-laubachia, commemorating Hermann Maximilian Carl Ludwig Friedrich zu Solms-Laubach (1842-1915).

The name of a genus published before 1912 may coincide with a Latin technical term in use in morphology at the time of publication, provided that it was accompanied by a binomial species name (Art. 20.2). For example, Tuber F.H. Wigg. 1780 was validly published because it was accompanied by the binomial species name T. gulosorum F.H. Wigg. On or after 1 January 1912, however, such names are not validly published.

\section{Names of subdivisions of genera}

The name of a subdivision of a genus is a combination of the name of a genus and a subdivisional epithet (Art. 21.1), between which is inserted a rank-denoting term (e.g. subgenus, section, series, usually abbreviated as subg., sect., ser.). The subdivisional epithet (Art. 21.2) is written with an initial capital letter and can take three forms: (1) the same form as a generic name (a nominative singular noun or a word treated as such), 
e.g. Poa subg. Stenopoa ("narrow Poa"); (2) a genitive plural noun, e.g. Pleione subg. Scopulorum ("of the rocks"); or (3) a plural adjective agreeing in gender with the generic name, e.g. Salix sect. Argenteae ("silvery”, feminine plural, Salix is feminine). A name in which the subdivisional epithet is formed from the prefix Eu-followed by the name of the genus is not validly published (Art. 21.3), e.g. Carex sect. "Eucarex".

\section{Names of species}

The name of a species is a combination of the name of a genus and a specific epithet (Art. 23.1). The specific epithet can be derived from any source whatever (Art. 23.2) and is either an adjective agreeing in gender with the generic name, a genitive noun, a nominative noun or a word treated as such, or two or more united or hyphenated words (see Table 6, pp. 52-53). The specific epithet may not exactly repeat the generic name, e.g. "Linaria linaria"; such a designation is a tautonym and, while permitted in zoological nomenclature, cannot be validly published under the Code (Art. 23.4).

Note that specific epithets (and names in general) are not necessarily appropriate to the organism, and the Code does not require them to be appropriate, although when naming a new taxon you might want to choose an appropriate epithet. For example, Orobanche alba Stephan ex Willd. ("white") is usually purplish red. Acer sempervirens L. ("evergreen") is usually deciduous. Sedum anglicum Huds. ("English") is widespread in western Europe and does not only occur in England. Sideritis cretica L. ("of or pertaining to Crete") does not occur in Crete but in the Canary Islands.

Table 6. Examples of specific epithets. Thousands more examples can be found in Gledhill (2008).

\begin{tabular}{|l|l|l|l|}
\hline Generic name & Specific epithet & $\begin{array}{l}\text { Specific epithet: } \\
\text { kind of word }\end{array}$ & $\begin{array}{l}\text { Specific epithet: } \\
\text { English meaning }\end{array}$ \\
\hline Helianthus & annuus & $\begin{array}{l}\text { adjective, } \\
\text { masculine }\end{array}$ & annual \\
\hline Rhododendron & alba & $\begin{array}{l}\text { adjective, } \\
\text { feminine }\end{array}$ & white \\
\hline Magnolia & grandiflora & $\begin{array}{l}\text { adjective, } \\
\text { neuter }\end{array}$ & $\begin{array}{l}\text { compound of } \\
\text { adjective+adjective, } \\
\text { feminine }\end{array}$ \\
\hline Thalictrum & aquilegiifolium & $\begin{array}{l}\text { compound of } \\
\text { noun+adjective, } \\
\text { neuter }\end{array}$ & Aquilegia-leaved \\
\hline
\end{tabular}




\begin{tabular}{|c|c|c|c|}
\hline Generic name & Specific epithet & $\begin{array}{l}\text { Specific epithet: } \\
\text { kind of word }\end{array}$ & $\begin{array}{l}\text { Specific epithet: } \\
\text { English meaning }\end{array}$ \\
\hline Quercus & griffithii & $\begin{array}{l}\text { genitive noun, } \\
\text { masculine singular }\end{array}$ & Griffith's \\
\hline Ballota & deserti & $\begin{array}{l}\text { genitive noun, } \\
\text { masculine singular }\end{array}$ & of the desert \\
\hline Strelitzia & reginae & $\begin{array}{l}\text { genitive noun, } \\
\text { feminine singular }\end{array}$ & the queen's \\
\hline Gladiolus & masoniorum & $\begin{array}{l}\text { genitive noun, } \\
\text { masculine plural }\end{array}$ & the Masons' \\
\hline Coix & puellarum & $\begin{array}{l}\text { genitive noun, } \\
\text { feminine plural }\end{array}$ & the girls' \\
\hline Glebionis & segetum & $\begin{array}{l}\text { genitive noun, } \\
\text { feminine plural }\end{array}$ & of the cornfields \\
\hline Quercus & suber & nominative noun & cork tree \\
\hline Nymphaea & lotus & nominative noun & lotus \\
\hline Zea & mays & $\begin{array}{l}\text { word treated as } \\
\text { nominative noun }\end{array}$ & maize \\
\hline Disa & longicornu & $\begin{array}{l}\text { compound of } \\
\text { adjective+nominative } \\
\text { noun }\end{array}$ & long horn \\
\hline Anthyllis & barba-jovis & $\begin{array}{l}\text { hyphenated words, } \\
\text { nominative noun- } \\
\text { genitive noun }\end{array}$ & Jupiter's beard \\
\hline Aster & novae-angliae & $\begin{array}{l}\text { hyphenated words, } \\
\text { genitive adjective- } \\
\text { genitive noun }\end{array}$ & of New England \\
\hline Galanthus & reginae-olgae & $\begin{array}{l}\text { hyphenated words, } \\
\text { genitive noun- } \\
\text { genitive noun }\end{array}$ & Queen Olga's \\
\hline Impatiens & noli-tangere & $\begin{array}{l}\text { hyphenated words, } \\
\text { verb-verb }\end{array}$ & do not touch \\
\hline
\end{tabular}

\section{Names of infraspecific taxa}

The name of an infraspecific taxon is a combination of a generic name, a specific epithet, and an infraspecific epithet (Art. 24.1). The infraspecific epithet is formed in the same way as a specific epithet (Art. 24.2). A rank-denoting term (e.g. subspecies, 
variety, form, usually abbreviated as subsp., var., f.) is placed immediately before the infraspecific epithet but, as with the name of a subdivision of a genus (see pp. 51-52), it is not part of the name itself. For example, Poa trivialis subsp. sylvicola and P. trivialis var. sylvicola are the same combination but at different ranks.

\section{Autonyms}

The name of a subdivision of a genus that includes the type of the generic name must repeat the generic name unaltered as its subdivisional epithet (Art. 22.1 and 22.2), e.g. Rhododendron subg. Rhododendron. Such names are autonyms and, as the term implies, they are automatically established when the name of a subdivision of a genus at a particular rank is first validly published (Art. 22.3), even if no autonym is explicitly cited in the publication (Art. 6.8 and 32.3), which was usually the case in older literature. However, if the generic name is illegitimate, no autonym is established (Art. 22.5).

Similarly, the name of an infraspecific taxon that includes the type of the species name must repeat the specific epithet unaltered as its infraspecific epithet (Art. 26.1 and 26.2), e.g. Poa trivialis subsp. trivialis. These names are also autonyms and are established by the first valid publication of an infraspecific name at a particular rank (Art. 26.3), although, if the species name is illegitimate, no autonym is established (Art. 27.2).

Note that autonyms exist only for those subordinate taxa that include the type of the adopted name of the genus or species (Art. 22 Note 1 and Art. 26 Note 1); nor do they exist above the rank of genus. For example, if tribes are recognized within Poaceae, the name Poeae is not an autonym. Similarly, if sections are recognized within Poa subg. Stenopoa, the name $P$. sect. Stenopoa is not an autonym; and if varieties are recognized within $P$. trivialis subsp. sylvicola, the name $P$. trivialis var. sylvicola is not an autonym.

Even though autonyms exist only as defined above, there are names at other ranks that resemble autonyms. Note that these names are not automatically generated but each must be validly published with its own nomenclatural act. Here are some examples. A tribe assigned to a family called Poaceae must be called Poeae if it includes type of the family name (Art. 19.4). Above the rank of family, a suborder assigned to an order called Poales must be called Poineae if it includes type of the family name (Art. 16.2). Below the rank of genus, a section assigned to a subgenus called $P$. subg. Stenopoa should (not must) be called $P$. sect. Stenopoa if it includes the type of that subgeneric name and when there is no obstacle to so naming it under the rules (Rec. 22A.1). Similarly a variety assigned to a subspecies called $P$. trivialis subsp. sylvicola should (not must) be called $P$. trivialis var. sylvicola if it includes the type of that subspecific name and again when there is no obstacle to so naming it under the rules (Rec. 26A.1).

Note also that, for nomenclatural purposes, a species is regarded as the sum of its subordinate taxa (Art. 25.1). Because, e.g., Poa trivialis includes both subsp. trivialis and subsp. sylvicola, use the species name for subsp. trivialis alone may lead to confusion. 


\section{CHAPTER 6 | HOW TO FIND THE CORRECT NAME FOR ATAXON}

\section{PRIORITY}

The principle of priority is fundamental in determining the correct name for a taxon at the rank of family and below. Above the rank of family, priority does not apply. Priority means that if two or more names apply to the same taxon at the same rank, the earliest published, legitimate name (or its final epithet) must be used unless other rules prevent such use. Although several validly published names may apply to a taxon, there can be only one correct name for that taxon with a particular circumscription, position, and rank (Art. 11.1); the other names are synonyms.

Finding the correct name for a taxon can be a lengthy process involving specialist literature. Fortunately, a large body of older literature is now scanned and online, making it available to anyone with a computer and an internet connection. Checking such literature online is generally much faster than visiting a library and consulting the physical books.

Assume you have defined a taxon with a particular circumscription (what it includes), position (for nomenclatural purposes, to what genus or species it is assigned), and rank. This much is taxonomy, but it has nomenclatural consequences. You are faced with a list of names, or apparent names, that potentially apply to the taxon. From among these, how do you determine the correct name?

You can begin (see Fig. 9, p. 57) by disregarding any names or, rather, designations that are not effectively or not validly published. Then you can check the types of the validly published names and exclude any that do not refer to the taxon as circumscribed (typification is dealt with in detail in Chapter 7). Then you can relegate to synonymy any names that are illegitimate (Art. 6.4).

It is very important to remember that names compete for priority only against names at the same rank (Art. 11.2), e.g. an earlier name of a variety cannot have priority over the later name of a species. For example, when Magnolia virginiana var. foetida L. 1753 is raised to specific rank, it is called M. grandiflora L. 1759, not M. foetida (L.) Sarg. 1889. Even though $M$. virginiana var. foetida is the earliest name, it cannot compete against names of species.

For taxa at the rank of family to genus, inclusive, the correct name is simply the earliest legitimate name at the same rank (Art. 11.3). For example, when Aesculus L. 1753, Pavia Mill. 1754, Calothyrsus Spach 1834, and Macrothyrsus Spach 1834 are referred to a single genus, its correct name is Aesculus, which is the earliest legitimate name at 


\section{Dealing with designations (names not validly published)}

Even though you may disregard designations that are not validly published names, because they have no status under the Code (Art. 6.3 and 12.1), it is often useful to cite them in synonymy or in comments and explain why they are not validly published by citing the relevant Article(s). This is helpful to other workers, who will then not need to repeat the research that you conducted. The Code is consistent in citing designations within double quotation marks, e.g. "Aster angustifolius", a nomen nudum published by Royle (1835: 251, t. 58, f. 1).

You can also cite any specimens or illustrations upon which such a designation was based, but do not refer to them as types, because types are attached to and determine the application of names (Art. 7.1 and 7.2), and names must by definition be validly published (Art. 6.3 and 12.1). This is why the third step in the Nomenclatural Filter in Fig. 9 (p. 57), i.e. typification, is placed after effective and valid publication.

Another kind of designation is the misapplied name, i.e. when an author uses an existing name in a sense different to its original usage, or, more precisely, in a sense not including its type. Unless the author explicitly excluded the type (in which case a later homonym is published; see Art. 48.1), the misapplied name has no nomenclatural status separate from the name as correctly applied. You may simply disregard it, but it is sometimes useful to cite it as a misapplied name, e.g. Solanum pyracanthos sensu Jacq. non Lam., where sensu means "in the sense (or opinion) of" the author whose name immediately follows, and non means "not", hence S. pyracanthos in the sense of Jacquin (1804: 36), not of Lamarck, the original author. If a name was more widely misapplied, you might see a citation such as Polygala chinensis auct. non L., where "auct." is an abbreviation of auctorum, meaning "of authors". Unfortunately, the botanical literature is rich in misapplied names, and they are often cited as if they are validly published in their own right and are therefore easily mistaken for later homonyms. The International Plant Names Index (https://www.ipni.org/), for example, has many records of misapplied names that resemble later homonyms, although these records are gradually being resolved.

generic rank, and the other names are synonyms. Of course, the only validly published names applicable to your taxon could all be at other ranks, or they could all be illegitimate, or both. In that case you would need to publish the name of a new taxon, a name at new rank, or a replacement name.

Below the rank of genus, determining the correct name can be more complicated. It is not necessarily the earliest legitimate combination at the same rank and subordinate to the same genus or species, but rather the combination of the final epithet of the earliest 


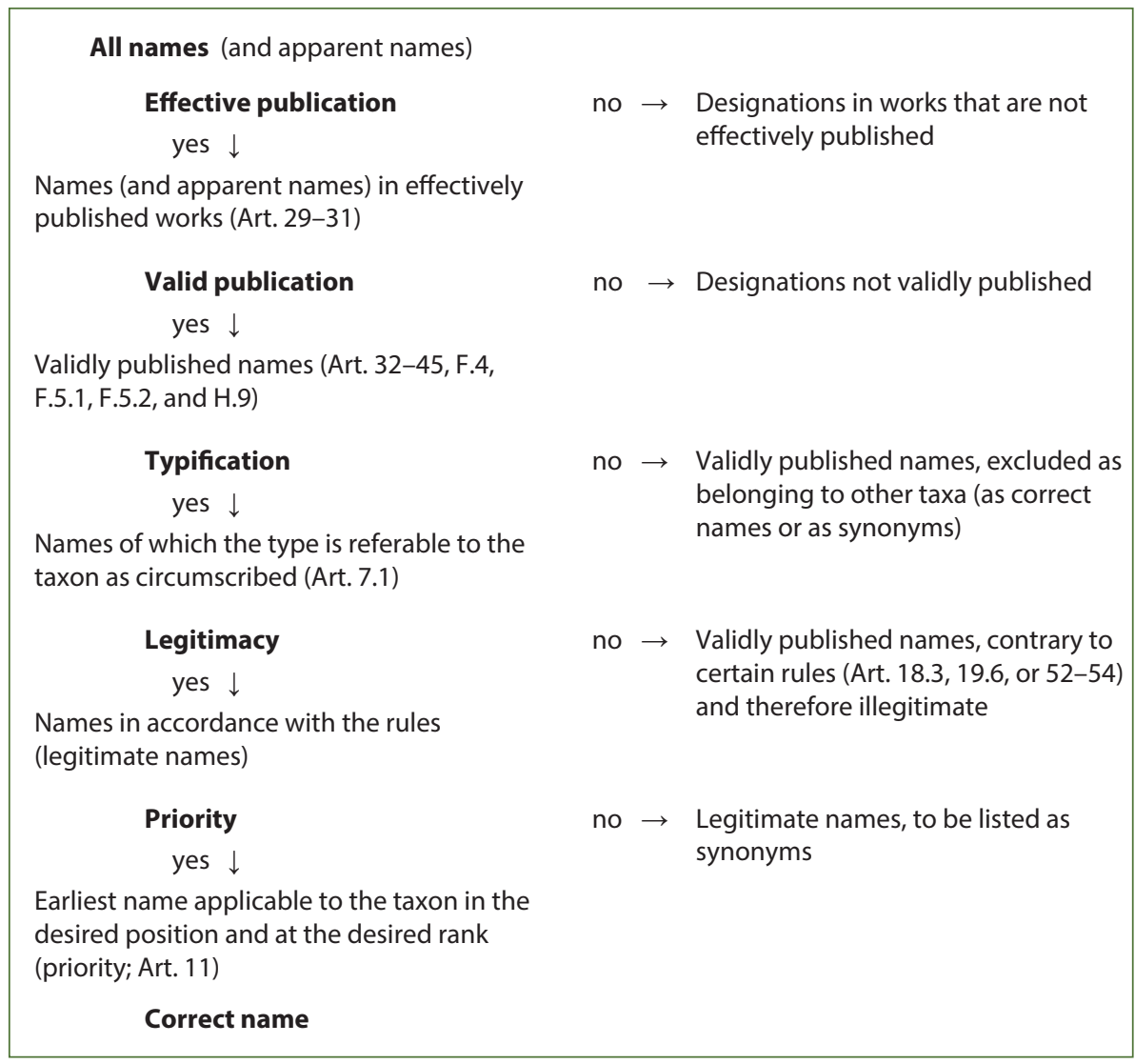

Fig. 9. The Nomenclatural Filter. Illustrating the steps to be taken in determining the correct name for a taxon. Based on a modification by David Hawksworth and John McNeill of a similar figure by Jeffrey (1989: 19).

legitimate name of the taxon at the same rank, with the correct name of the genus or species to which it is assigned (Art. 11.4; see Fig. 10, p. 58).

Note that the earliest legitimate name of the taxon at the same rank may be in a different position to the one desired, i.e. the name of a subdivision of a genus or a species name combined under a different generic name, or the name of an infraspecific taxon combined under a different species name. In such a case, it is possible that the correct name has not yet been published, and it may be necessary to publish a new combination based on that earliest name.

If the combination resulting from this procedure would form a tautonym, which could not be validly published (e.g. "Cyanus cyanus"), or if it would be a later homonym, which would be illegitimate, the final epithet of the next earliest legitimate name at the 
same rank is to be used instead. If there is no final epithet available for use, a replacement name or the name of a new taxon may be published.

For example, Wei \& Pedley (2010) recognized a taxon with a circumscription that included the types of the species names Millettia unijuga Gagnep. 1913 and Craspedolobium schochii Harms 1921; they considered the appropriate position to be subordinate to Craspedolobium and the appropriate rank to be species. The two names are legitimate and at the same rank and therefore compete for priority. Millettia unijuga is earlier, and so the correct name is the combination of its final epithet, unijuga, with Craspedolobium, i.e. C. unijugum (Gagnep.) Z. Wei \& Pedley 2010, which had to be published as a new combination. Note also that, because unijuga is an adjective, its feminine ending, which agrees with the gender of Millettia, must be changed to unijugum to agree with the neuter gender of Craspedolobium (Art. 23.5).

7. Solanum chilense (Dunal) Reiche, Anales Univ. Santiago 124: 742. 1909. Lycopersicon chilense Dunal in A. DC., Prodr. 13(1): 24. 1852.-TYPE: CHILE. Region II (Antofagasta): Cobija, 1839, Gaudichaud s.n. (holotype: G-DC! [F neg. 6761: F! GH! WIS!]]; isotypes: B [destroyed, F neg. 2726: F! GH! WIS!], F-fragment! G! [F neg. 2726: F! GH! WIS!], MPU-fragment! P! WIR!).

Lycopersicon atacamense Philippi, Fl. Atacam. 42. 1860.-TYPE: CHILE. "Paposo, Diciembre 1853, Tilopozo," Philippi s.n. (lectotype, here designated: SGO055593! [Departmento de Investigaciones Agrícolas neg. s.n.: F! GH!]).

Lycopersicon bipinnatifidum Philippi, Anales Mus. Nac. Santiago de Chile, Bot. 1891: 63. 1891.-TYPE: CHILE. Region I (Tarapacá): Chacarillas, Mar 1885, Rahmer s.n. (lectotype, here designated: SGO-055599!; isolectotype: SGO042822! Departmento de Investigaciones Agrícolas neg. s.n.: F! GH!]).

Lycopersicon puberulum Philippi, Anales Mus. Nac. Santiago de Chile, Bot. 1891: 64. 1891. Lycopersicon peruvianum subsp. puberulum (Philippi) Luckwill, Univ. Aberdeen Studies 120: 30. 1943.-TYPE: PERU. "Tacna e seminibus e P. Ortega communicat culta Santiago," Dec 1887, Philippi s.n. (lectotype, here designated: SGO-042824!; isolectotype: WU!).

Robust perennial herbs, erect becoming decumbent, woody at the base, to $1 \mathrm{~m}$ tall, to $1 \mathrm{~m}$ in diameter, occasionally spreading in rocky habitats. Stems $8-12 \mathrm{~mm}$ in diameter at base, grayish, densely velvety-pubescent with simple uniseriate eglandular white trichomes to $0.5 \mathrm{~mm}$ long (with a unicellular base and bent at the tip), much more abundant on young stems, and scattered short, uniseriate glandular trichomes with 4-celled heads and 8-celled heads amongst the eglandular trichomes. Sympodial units 2- (rarely 3-) foliate; internodes 
Fig. 10. Taxonomic treatment of Solanum chilense (Dunal) Reiche, from page 89 of a monograph in volume 84 of Systematic Botany Monographs by Peralta \& al. (2008: 89). Reproduced by permission of the American Society of Plant Taxonomists. Components of this treatment are as follows:

- $\quad$ Accepted name: Solanum chilense; homotypic synonym: Lycopersicon chilense; citation of holotype at herbarium G-DC (Fig. 13, p. 66) and isotypes at B (destroyed), F (fragment), G, MPU (fragment), P, and WIR. The exclamation mark (!) placed after a herbarium code indicates that the cited specimen has been seen by the author(s). Herbarium codes follow Index Herbariorum (http://sweetgum.nybg.org/science/ih/).

- Heterotypic synonym: Lycopersicon atacamense; designation of lectotype at herbarium SGO.

- Heterotypic synonym: Lycopersicon bipinnatifidum; designation of lectotype at SGO (Fig. 14, p. 67) and citation of isolectotype at SGO.

- Heterotypic synonym: Lycopersicon puberulum; homotypic synonym: Lycopersicon peruvianum subsp. puberulum; designation of lectotype at SGO (Fig. 15, p. 68) and citation of isolectotype at WU.

- The homotypic synonyms (Lycopersicon chilense and Solanum chilense; L. puberulum and $L$. peruvianum subsp. puberulum) have the same types and therefore apply to the same taxa as a matter of fact. On the other hand, the heterotypic synonyms (Lycopersicon atacamense, L. bipinatifidum, L. chilense, and L. puberulum) have different types, and the authors of this monograph have made the taxonomic decision (a matter of opinion) that they all belong to the same species and to the genus Solanum. The earliest legitimate name for the taxon at specific rank is Lycopersicon chilense Dunal 1852; the combination of its final epithet, chilense, with Solanum, i.e. Solanum chilense, is therefore the correct name for the species.

Occasionally, simultaneously published names at the same rank will compete for priority. In such cases, the correct name is decided by a nomenclatural act, i.e. the first author to accept one name and relegate the others to synonymy in an effectively published work (Art. 11.5). For example, when Dentaria L. 1753 and Cardamine L. 1753 are united, the combined genus is called Cardamine because that name was accepted by Crantz (1769: 126-127, [142]), who first united the two, treating Dentaria as a synonym.

On the subject of simultaneously published names at the same rank, note that an autonym always has priority over the name(s) that established it (Art. 11.6). For example, Heracleum sibiricum includes two subspecies, named $H$. sibiricum subsp. lecokii and $H$. sibiricum subsp. sibiricum, the latter name automatically established upon valid publication of the former. When $H$. sibiricum, including both subspecies, is included in $H$. 


\section{Choosing between names of equal priority}

Determining the earliest published choice between names of equal priority is notoriously difficult. These nomenclatural acts are not indexed, and the apparent earliest choice that you traced could quite possibly be preceded by a different choice that you did not trace. This potential problem is worse for widespread taxa, where the literature can be extensive.

sphondylium as a single subspecies, the correct name of that subspecies is $H$. sphondylium subsp. sibiricum, not " $H$. sphondylium subsp. lecokii". Note also that the basionym of $H$. sphondylium subsp. sibiricum is $H$. sibiricum, not $H$. sibiricum subsp. sibiricum.

There are exceptional circumstances under which a taxon can have more than one correct name in a particular circumscription, position, and rank. Eight automatically typified family names are permitted as alternatives to descriptive family names of long usage, e.g. Asteraceae is permitted as an alternative to Compositae (Art. 18.6; see Table 4, p. 50). There is also one subfamily name, Papilionoideae, permitted as an alternative to Faboideae when the Papilionaceae are included in the family Leguminosae as a subfamily (Art. 19.8).

\section{CIRCUMSCRIPTION, POSITION, AND RANK}

Circumscription is an indication of the elements (e.g. subordinate taxa, synonyms, specimens, illustrations) that are included in a taxon. The names Tulipa saxatilis Sieber ex Spreng. 1825 and T. bakeri A.D. Hall 1938 can be applied to one broadly circumscribed species or to two narrowly circumscribed species; in the former case, T. saxatilis is accepted and T. bakeri is a synonym; in the latter case, both names are accepted. The name Taraxacum officinale W.W. Weber ex F.H. Wigg. can be applied to a very broadly circumscribed species that includes a huge range of segregate taxa, all the names of which (except T. officinale) are then synonyms. Alternatively, T. officinale and the numerous other names can be applied to very narrowly circumscribed segregate species, each of which then has an accepted name. When the same name is commonly used with such disparate circumscriptions, the terms sensu lato (in a broad/wide sense) and sensu stricto (in a strict/narrow sense) are often used, optionally abbreviated, e.g. T. officinale s.str. and T. officinale s.l.

Position means the placement of a taxon relative to other taxa in a classification, and for nomenclatural purposes this means its placement subordinate to a particular genus or species. The names Geranium zonale L. and Pelargonium zonale (L.) L'Hér. apply to the same species in different positions. If the name $G$. zonale is accepted, $P$. zonale is a synonym, and vice versa.

Rank means the position of the taxon in a hierarchy of consecutively subordinate ranks, e.g. genus, subgenus, section; or species, subspecies, variety (see Art. 3-4). The 
names Pinus brutia Ten. and P. halepensis subsp. brutia (Ten.) Holmboe apply to the same taxon at different ranks. If the name $P$. brutia is accepted, $P$. halepensis subsp. brutia is a synonym, and vice versa.

\section{LEGITIMACY AND ILLEGITIMACY}

While legitimacy and illegitimacy were briefly discussed under basic concepts and terms (pp. 18-19), the present section examines in more detail the three ways in which a name can be illegitimate:

- When the name is a later homonym (Art. 53.1-53.3 and F.6.1)

- When the name was nomenclaturally superfluous when published (Art. 52.1)

- When the name is that of a family or subdivision of a family and it is based on an illegitimate generic name (Art. 18.3 and 19.6)

\section{Born illegitimate}

When a name is validly published it is either legitimate or illegitimate. Names are thus "born" either legitimate or illegitimate and remain so in the absence of special intervention. An illegitimate name cannot be correctly used, but it can serve as the replaced synonym of a replacement name, providing the type of that replacement name. The only way in which an illegitimate name can become legitimate is through conservation or, for fungal names, protection (Art. 14 or Art. F.2; see Chapter 8) or, also for fungal names, through sanctioning (Art. F.3; see pp. 119-120).

Note that an illegitimate name does not pass on its illegitimacy to names of subordinate taxa. Thus an infraspecific name may be legitimate even if it was published under an illegitimate species name (Art. 55.2), or a name of a species or subdivision of a genus may be legitimate even if it was published under an illegitimate generic name (Art. 55.1). This is not to be confused with names that are not validly published, e.g. a species name cannot be validly published under a generic designation that is not validly published (Art. 35.1).

A name of a family, genus, or taxon below the rank of genus, unless conserved, protected, or sanctioned, is illegitimate if it is a later homonym (Fig. 11, p. 62). Homonyms are two or more names with exactly the same spelling (disregarding any rank-denoting term, e.g. sect., var.) but based on different types. They usually apply to different taxa, e.g. Vicia gigantea Hook. 1831, described from western North America, and Vicia gigantea Bunge 1833, a different species described from China. Bunge's name was pub- 
lished two years later and is a later homonym and therefore illegitimate. It makes no difference if the earlier homonym is itself illegitimate, a name rejected under Art. 56.1 (see Chapter 8), or otherwise generally treated as a synonym, provided that it is validly published. If a supposed earlier homonym is not validly published, it has no status under the Code and the later name is not a homonym. So-called "parahomonyms", names based on different types and spelled so similarly that they are likely to be confused, are to be treated as homonyms (Art. 53.2 and 53.3) and, in cases of doubt, a binding

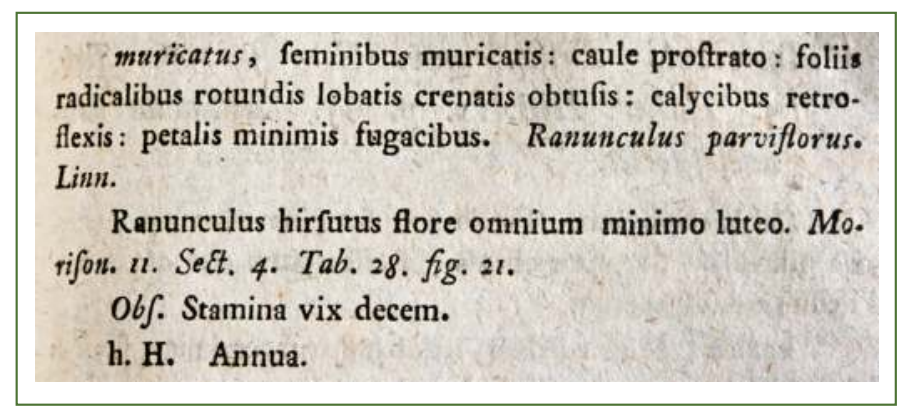

Fig. 11. A name that is illegitimate because it is a later homonym (Art. 53.1): Ranunculus muricatus Moench 1794 non L. 1753. Part of page 215 of Moench's Methodus plantas horti botanici et agri Marburgensis (Moench, 1794: 215). This name is doubly illegitimate because it was also nomenclaturally superfluous when published (Art. 52.1). Components of the protologue are as follows:

- Specific epithet: "muricatus" (muricate), thus a later homonym of R. muricatus L. 1753 and therefore illegitimate under Art. 53.1.

- Diagnostic phrase name (polynomial): "[Ranunculus] muricatus, caule prostrato [...] petalis minimis fugacibus." (Ranunculus muricatus with prostrate stem [...] petals very small, fleeting).

- $\quad$ Synonym: "Ranunculus parviflorus. Linn." 1759. An earlier, validly published name at the same rank; citing it made $R$. muricatus Moench nomenclaturally superfluous when published, and therefore illegitimate under Art. 52.1, because Moench should have used R. parviflorus L. instead.

- Synonym: "Ranunculus hirsutus flore omnium minimo luteo." A pre-starting-point phrase name referring to an illustration (Morison, 1680: sect. 4, t. 28, fig. 21).

- "Obs[ervatio]. Stamina vix decem." (Observation. Stamens hardly ten).

- "h[abitat]. [in] H[orto]. Annua." (It inhabits the garden [the botanic garden at Marburg, Germany]. Annual). 
decision can be requested (Art. 53.4; see pp. 90-91). In rare cases, homonyms can be legitimate if they were published simultaneously and no earlier homonym exists (Art. 53 Note 1), but only one of them can be available for use (see Art. 53.5).

A name is illegitimate if it was nomenclaturally superfluous when it was published (Fig. 12, p. 63, see also Fig. 11, p. 62), unless it is conserved, protected, or sanctioned (see Chapter 8). Nomenclaturally superfluous when published means that the taxon to which it was applied, as circumscribed by its author, definitely included the type of a name that ought to have been adopted, or of which the epithet ought to have been

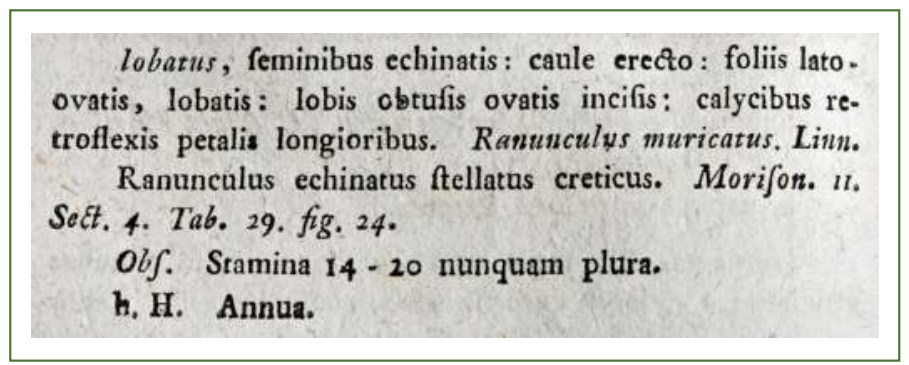

Fig. 12. A name that is illegitimate because it was nomenclaturally superfluous when published (Art. 52.1): Ranunculus lobatus Moench. Part of page 214 of Moench's Methodus plantas horti botanici et agri Marburgensis (Moench, 1794: 214). Components of the protologue are as follows:

- Specific epithet: "lobatus" (lobed).

- Diagnostic phrase name (polynomial): "[Ranunculus] lobatus, seminibus echinatis [...] calycibus retroflexis petalis longioribus." (Ranunculus lobatus with prickly seeds [...] calyces bent backward, longer than petals).

- Synonym: "Ranunculus muricatus. Linn." 1753. An earlier, validly published name at the same rank; citing it made $R$. lobatus nomenclaturally superfluous when published, and therefore illegitimate under Art. 52.1, because Moench should have used R. muricatus L. instead.

- Synonym: "Ranunculus echinatus stellatus creticus." A pre-starting-point phrase name referring to an illustration (Morison, 1680: sect. 4, t. 29, fig. 24).

- "Obs[ervatio]. Stamina 14-20 nunquam plura." (Observation. Stamens 14-20 never more).

- " "h[abitat]. [in] H[orto]. Annua." (It inhabits the garden [the botanic garden at Marburg, Germany]. Annual). 
adopted. The rules on priority (Art. 11.3 and 11.4) decide which name or epithet ought to have been adopted. Wintera Murray 1784 was nomenclaturally superfluous when published, and is therefore illegitimate, because Murray cited Drimys J.R. Forst. \& G. Forst. 1775 as a synonym; Ranunculus lobatus Moench 1794 is illegitimate because Moench cited R. muricatus L. 1753 as a synonym (Fig. 12, p. 63). Both authors definitely included the type of the name that ought to have been adopted (by citing that name as a synonym; see Art. 52.2(e)).

A name that was nomenclaturally superfluous when published is not illegitimate if it has a basionym (which is necessarily legitimate) or if it is formed from a legitimate generic name (Art. 52.4); it was still nomenclaturally superfluous (and therefore incorrect) when published, but it may become correct upon later use that excludes the element that caused the superfluity. Chloris radiata (L.) Sw. 1788 was nomenclaturally superfluous when published because Swartz cited the legitimate Andropogon fasciculatus L. 1753 as a synonym. However, it is not illegitimate since it has a basionym, Agrostis radiata L. 1759. Chloris radiata can be a correct name if Andropogon fasciculatus is treated as a different species. Carpinaceae Vest 1818 was nomenclaturally superfluous when published because Vest included Salix L., the type of Salicaceae Mirb. 1815, but it is not illegitimate because it is formed from Carpinus L., a legitimate generic name. If Salix is excluded, Carpinaceae can be a correct name.

Much rarer than the other two cases, a name of a family or subdivision of a family is illegitimate if it is based on an illegitimate generic name. For example, both Caryophyllaceae and Caryophylloideae are formed from the illegitimate name Caryophyllus Mill. 1754 non L. 1753, but because Caryophyllaceae has been conserved (see App. IIB), neither it nor Caryophylloideae is now illegitimate. 


\section{CHAPTER 7 |HOW TO DESIGNATE A TYPE}

The application of names of taxa at the rank of family and below is determined by means of nomenclatural types (Art. 7.1). A nomenclatural type is a specimen or illustration to which the name of a taxon is permanently attached, whether that name is the correct name or a synonym (Art. 7.2). The type is not necessarily a high-quality specimen, a well-drawn illustration, or even a typical (i.e. normal) example of a taxon (see Figs. 13-15, pp. 66-68), although when you indicate or designate a type, you should as far as possible select a specimen or illustration that does satisfy these criteria.

There are two quite distinct circumstances in which you might indicate or designate a type. The first is when you describe the name of a new taxon, when you must indicate the type in the protologue in order for the name to be validly published (Art. 40.1). This requirement is dealt with in Chapter 5 . The second circumstance-and the subject of the present chapter-is when you designate a type for an existing name that does not already have a type. This could be a name from the period 1753-1957, when it was not a requirement of valid publication to indicate the type in the protologue. Such names frequently do not have types, or they may have multiple types (syntypes) or multiple elements (specimens and/or illustrations) of original material, from which you need to choose one type (a lectotype); or they may have no original material at all, in which case you need to choose a completely new type (a neotype). Alternatively a name may have had a type that was lost or destroyed and now needs to be replaced (with a lectotype or neotype), or sometimes a name cannot be precisely applied because its existing type is so ambiguous, in which case you can designate an unambiguous supporting type (an epitype).

Why should you go to the trouble of designating a lectotype, neotype, or epitype when it is not mandatory to do so? A validly published name remains validly published without such typification. However, such a name without a type-usually from before 1958 can be uncertain or unstable in its application. For example, a name may be based on several syntypes or other elements of original material that represent more than one taxon, or there may be no original material whatsoever. In either case, it is merely tradition, not the type, that is determining the application of the name. This is an unstable nomenclatural situation. Traditions may stray over time. Moreover, one careless lectotypification or neotypification, designating an element that does not agree with current usage of the name, and the application of the name would be changed. This was the fundamental principle behind the Linnaean Plant Name Typification Project that was based at the Natural History Museum, London. In the absence of types it was tradition that determined the application of thousands of Linnaean names. This was not a stable basis for naming some of the world's best-known plants (and algae and fungi). Of course, the principle is not restricted to Linnaean names; it potentially applies to tens of thousands of names. 
A name may have syntypes or other original material that all correspond with current usage of the name but are of widely disparate quality, e.g. an excellent specimen with all parts clearly present, a very poor specimen comprising little more than a bare twig, and an illustration. In this case, obviously the excellent specimen would make the best lectotype. A lectotypification on the twig or illustration could make it difficult to apply the name with precision, particularly if there were closely related taxa that could only be distinguished by features that were missing from the twig and illustration. Moreover, it would not be possible to extract DNA from the illustration.

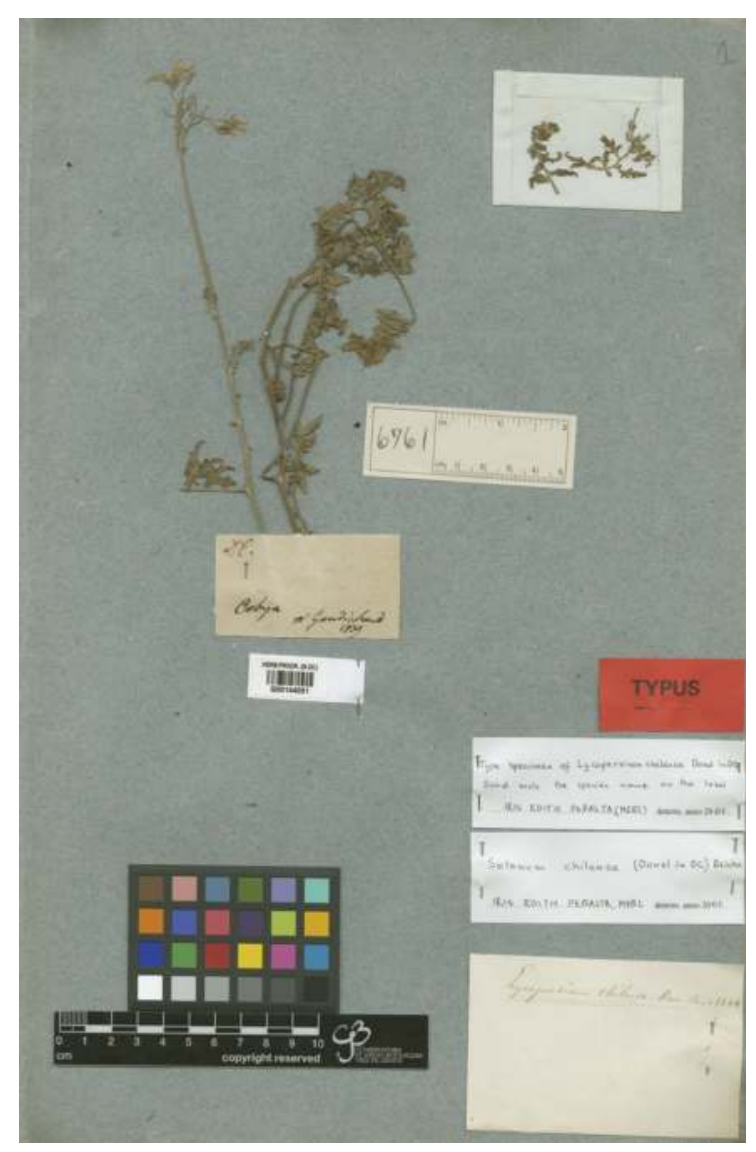

Fig. 13. The holotype of Lycopersicon chilense Dunal:the specimen Gaudichaud-Beaupré s.n. in herbarium G-DC (specimen barcode G00144031). Lycopersicon chilense is the basionym of Solanum chilense (Dunal) Reiche (Fig. 10, p. 58), and the two names are therefore homotypic synonyms. They have the same type, and they apply to the same taxon as a matter of fact, not as a matter of taxonomic opinion. This also shows that a type specimen is not necessarily a high-quality specimen. - Reproduced by permission of Conservatoire et Jardin botaniques de la Ville de Genève. 
Suppose it is clear from the protologue of a name that no holotype exists, how do you know whether or not someone has already designated a lectotype or neotype? Unfortunately, you can rarely be sure. If the name is a Linnaean one, you can check Order out of chaos (Jarvis, 2007). For generic names, you can check Index Nominum Genericorum (https:// naturalhistory2.si.edu/botany/ing/), which cites the type (“T.: ...”), or a homotypic name (“三..."), or "T.: non designatus" (type not designated). You can check other nomenclatural databases that contain typifications, e.g. Tropicos (http://www.tropicos.org/). Otherwise, you should check monographs for the relevant group, and also relevant Floras that include

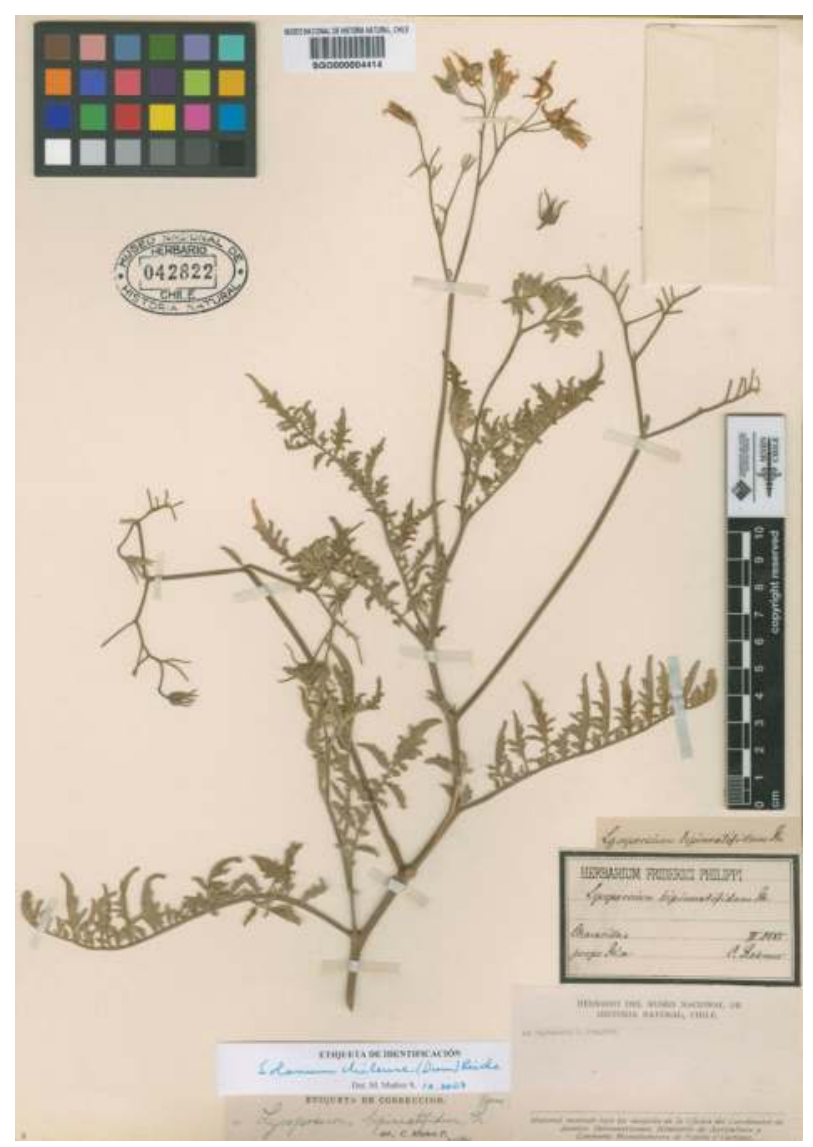

Fig. 14. The lectotype of Lycopersicon bipinnatifidum Phil.: the specimen Rahmer s.n. in herbarium SGO (specimen accession no. 042822, barcode SGO000004414), showing longer leaves with more complex lobing than those of L. puberulum Phil. (Fig. 15, p. 68). Lycopersicon bipinnatifidum is a heterotypic synonym of both L. chilense Dunal (Fig. 13, p. 66) and L. puberulum. All three names have quite different-looking type specimens and they were originally applied to separate species. Despite these differences they are now considered to belong to the same variable species as a matter of taxonomic opinion. - Reproduced by permission of Museo Nacional de Historia Natural, Chile. 
typifications. If you find a typification, do not stop until you have checked all the likely publications. There may be an earlier typification. Remember that priority applies to typifications as well as to names, so that the earliest typification must be followed. Finally, after a thorough search of the literature, if you have found nothing, you can proceed and (probably) be the first person to typify the name.

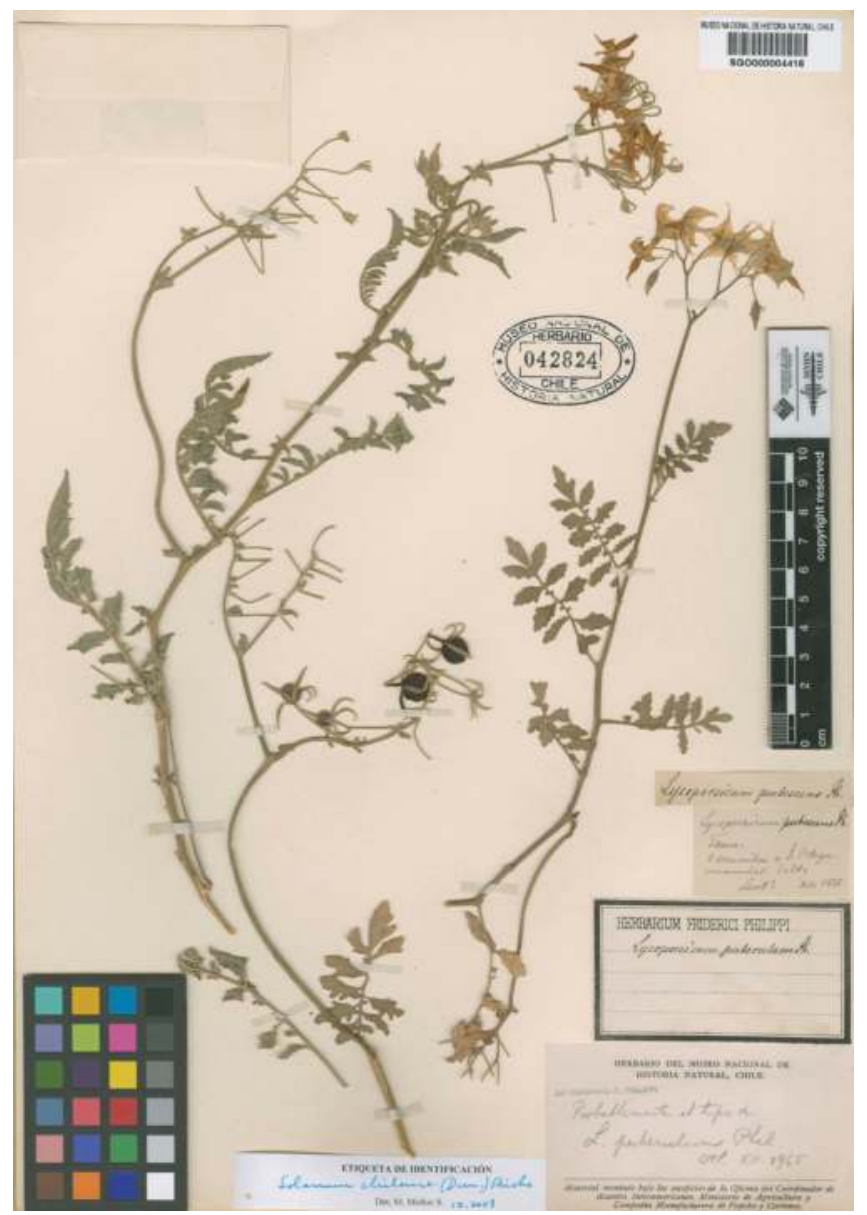

Fig. 15. The lectotype of Lycopersicon puberulum Phil.: the specimen Philippi s.n. in herbarium SGO (specimen accession no. 042824, barcode SGO000004416), showing shorter leaves with less complex lobing than those of L. bipinnatifidum Phil. (Fig. 14, p. 67). Lycopersicon puberulum is a heterotypic synonym of both L. chilense Dunal (Fig. 13, p. 66) and L. bipinnatifidum. All three names have quite different-looking type specimens and they were originally applied to separate species. Despite these differences they are now considered to belong to the same variable species as a matter of taxonomic opinion. Reproduced by permission of Museo Nacional de Historia Natural, Chile. 
Be sceptical about the type status of herbarium specimens annotated or labelled as "holotype", "isotype", "lectotype", etc., for example in the online database JSTOR Global Plants (https://plants.jstor.org/). The alleged type status is not necessarily correct and a specimen could be another category of type (see kinds of types, p. 70-72), or uncited original material. You should always check the protologue of the name as well as any publication cited as a typification of the name. Also bear in mind that lectotypes, neotypes, and epitypes must be designated by effective publication (see Chapter 4), which is not achieved by annotating herbarium specimens.

\section{BASIC RULES FOR TYPES}

As mentioned under valid publication (Chapter 5), since 1 January 1958 when publishing the name of a new taxon at the rank of genus or below, it has been necessary to indicate the type, normally by designating it as such, otherwise the name is not validly published (Art. 40.1). Names that were published before 1958 without a type may be validly published, and a type can be subsequently designated for them. To indicate or designate the type of a name is to typify the name. A typified name has a type.

The holotype, lectotype, or neotype of a name of a species or infraspecific taxon is either a single specimen conserved in a single herbarium or it is an illustration (Art. 8.1), although for fossil-taxa it is always a specimen (Art. 8.5). The holotype of the name of a new taxon (non-fossil) published before 1 January 2007 can be a specimen or an illustration; when such a name is published on or after that date, the holotype must be a specimen (Art. 40.4), although an illustration is permitted as the holotype for names of microscopic algae and microfungi if preservation is difficult or impossible (Art. 40.5; see pp. 113 and 118). Note that this ban on illustrations as types applies only to holotypes of names of new taxa published on or after 1 January 2007. It does not apply to designating a lectotype, neotype, or epitype under Art. 9 for an already validly published name. Nor does it apply to a new combination, name at new rank, or replacement name.

A new combination, name at new rank, or replacement name is automatically typified by the type of its basionym or replaced synonym (Art. 7.3 and 7.4), e.g. Picea abies (L.) H. Karst. has the same type as its basionym, Pinus abies L.; Cedrus libani A. Rich. has the same type as its replaced synonym, Pinus cedrus $\mathrm{L}$. The type of an autonym is that of the name from which it is derived (Art. 7.7), e.g. Poa L. subg. Poa has the same type as Poa L.; P. trivialis L. subsp. trivialis has the same type as P. trivialis L.

The type of the name of a genus or subdivision of a genus is in almost all cases the type of the name of a species (Art. 10.1), e.g. the type of Poa L. is the type of P. pratensis L.; the type of $P$. subg. Arctopoa (Griseb.) Probatova is the type of P. eminens C. Presl. For purposes of designation or citation of a type, it is sufficient to cite the species name alone, rather than its type specimen or illustration, e.g. the type of Poa can be cited simply as $P$. pratensis L., rather than the specimen Tzvelev N-257 (BM). 
A name of a family or subdivision of a family is automatically typified by the type of the generic name from which it is formed (Art. 10.6). Thus the type of Poaceae is the type of Poa, i.e. the type of P. pratensis, i.e. the specimen Tzvelev N-257 (BM). The specially permitted descriptive family names of long usage are typified by the type of the corresponding alternative name, e.g. Gramineae has the same type as Poaceae. For purposes of designation or citation of a type, it is sufficient to cite the generic name alone.

This does not mean that the type of the name of a genus is a species or the type of the name of a family is a genus - that would be an oversimplification - so the terms "type species" and "type genus", although sometimes used, are incorrect and should be avoided.

Note that the principle of typification does not apply above the rank of family, except that names formed from generic names (e.g. Magnoliophyta) are automatically typified by the same type as that of the generic name (Art. 10.10).

A specimen is defined as a gathering, or part of a gathering, of a single species or infraspecific taxon. Admixtures are disregarded, e.g. microscopic algae or fungi in environmental samples, inseparably mingled bryophytes, epiphytes or their substrate plants, parasites or their hosts. A gathering is defined as a collection presumed to be of a single taxon made by the same collector(s) at the same time from a single locality (and collecting numbers alone do not necessarily denote different gatherings). To be eligible as a type, a specimen must be preserved permanently and may not be a living organism or a culture, although fungi and algae may be preserved in a metabolically inactive state. A specimen can consist of a single organism, parts of one or several organisms, or of multiple small organisms. A specimen is usually mounted on a single herbarium sheet or in an equivalent preparation, such as a box, packet, jar, or microscope slide; it may be mounted on more than one sheet, slide, etc. so long as these parts are all clearly labelled as belonging to one specimen, or bear a single original label in common (e.g. the specimen folders in the Geneva herbaria), otherwise the parts are duplicate specimens belonging to the same gathering. It is also possible for two or more specimens belonging to different gatherings to be mounted, labelled accordingly, on a single herbarium sheet (e.g. numerous 19 th century specimens in BM). The definitions of gathering, specimen, and duplicate are in Art. 8.2, 8.3, their footnotes, and 8.4.

\section{KINDS OF TYPES}

The Code defines several different kinds of types, all belonging to names of species or infraspecific taxa. There is also the term original material, which can include some of these kinds of types. These terms are defined as follows:

- A holotype (Art. 9.1) is the one specimen (Fig. 13, p. 66) or illustration either indicated by the author as the nomenclatural type or used by the author when no type was indicated. As long as it exists, it fixes the application of the name concerned. 
- An isotype (Art. 9.5) is any duplicate of the holotype and is always a specimen. If the holotype is an illustration there cannot be any isotypes.

- A syntype (Art. 9.6) is also always a specimen. It is any specimen cited in the protologue when there is no holotype, or any one of two or more specimens simultaneously designated in the protologue as types. Citation of a gathering, or part of a gathering, is considered to be citation of the included specimens, which are therefore syntypes.

- An isosyntype (Art. 9.4 footnote) is a duplicate of a syntype.

- A paratype (Art. 9.7) is any specimen cited in the protologue that is neither the holotype nor an isotype, nor one of the syntypes if in the protologue two or more specimens were simultaneously designated as types. Note that there is no such term "isoparatype" for a duplicate of a paratype.

- Original material (Art. 9.4) is defined by the Code as the holotype, isotypes, syntypes, isosyntypes, and paratypes of a name (either seen or not seen by the author), any illustrations published as part of the protologue, and any other specimens and published or unpublished illustrations that the author associated with the taxon and that were available to the author no later than the preparation of the validating description or diagnosis. Thus it is possible for uncited specimens and uncited illustrations to be part of the original material.

- A lectotype (Art. 9.3) is a specimen (Figs. 14, 15, and 17, pp. 67, 68, and 76) or illustration (Fig. 18, p. 77) designated from the original material as the nomenclatural type if the name was published without a holotype, or if the holotype is lost or destroyed, or if a type is found to belong to more than one taxon.

- An isolectotype (Art. 9.4 footnote) is a duplicate of the lectotype.

- A neotype (Art. 9.8) is a specimen or illustration selected to serve as nomenclatural type if no original material is extant, or as long as it is missing.

- An isoneotype (Art. 9.4 footnote) is a duplicate of the neotype.

- An epitype (Art. 9.9) is a specimen or illustration selected to serve as an interpretative type when the holotype, lectotype, or previously designated neotype, or all original material associated with a validly published name, is demonstrably ambiguous and cannot be critically identified for purposes of the precise application of the name to a taxon. The epitype concept was new to the Code in the Tokyo Code (Greuter \& al., 1994).

- An isoepitype (Art. 9.4 footnote) is a duplicate of the epitype. 
If one of the terms holotype, isotype, syntype, paratype, lectotype, neotype, or epitype is incorrectly used, i.e. in a sense that differs from its definition in the Code, that use is treated as an error to be corrected (Art. 9.10). For example, if a specimen is designated as a "lectotype" when it is not part of the original material, and in fact there is no extant original material, the incorrect use of the term "lectotype" is corrected to "neotype". If a "paratype" is designated with a statement that it supports an ambiguous lectotype, the term "paratype" is corrected to "epitype". A correction under Art. 9.10 does not have to be separately published, nor is the date of the original type designation affected, but that original designation must satisfy the rules for the relevant kind of type. For example, if a term used in a type designation published on or after 1 January 2001 is to be corrected to "lectotype", "neotype", or "epitype", the designation must include the phrase "designated here" or an equivalent (Art. 7.11). If a term used in the protologue of the name of a new taxon is to be corrected to "holotype", remember that such a name published on or after 1 January 1990 is not validly published if the type is not indicated using the word "typus" or "holotypus" or its abbreviation or its equivalent in a modern language (Art. 40.6). A name must be validly published in order to have any status under the Code and therefore to have a type; if it is not validly published, Art. 9.10 does not apply because there is nothing to correct.

Other terms you may encounter are "cotype", an obsolete term meaning syntype (or sometimes isotype or paratype); "iconotype", an unofficial term meaning either a holotype illustration or a "typotype", the latter an unofficial term for a specimen that is the basis of a type illustration and that was not seen by the author of the name thus typified; "topotype", an unofficial term meaning a specimen (which could be a neotype of epitype) collected from the original type locality; and "kleptotype", an unofficial term meaning a type or a fragment of a type that should not be in its current location (because it was deliberately stolen, borrowed and not returned, etc.).

Paralectotype is an official term in the International Code of Zoological Nomenclature (Art. 73.2.2) for specimens that were syntypes prior to the designation of a lectotype; the paralectotypes cease to be syntypes, have no name-bearing function, and do not regain status as syntypes if the lectotype is lost or destroyed. The term is sometimes used unofficially in a similar sense in the nomenclature of algae, fungi, and plants, i.e. for the remaining syntypes after designation of a lectotype, but under the Code those syntypes either become isolectotypes (if they belong to the same gathering as the lectotype) or remain syntypes (if they belong to a different gathering). If the lectotype is lost or destroyed, any of the isolectotypes or remaining syntypes is eligible as the replacement lectotype.

\section{HISTORICAL BACKGROUND}

In the protologue of the name of a new taxon at the rank of species or below published on or after 1 January 1958 there will generally be a single element, normally a speci- 
men, explicitly designated as the type, i.e. the holotype. A name published before that date, however, may have more than one specimen designated as types (i.e. syntypes), or more than one specimen cited but none designated as a type (again, these are syntypes), or no specimens cited at all (Fig. 5, p. 37). In the last case, the name may lack any of the kinds of types defined above (pp. 70-71), but it may well have original material, which can include uncited specimens and cited and uncited illustrations. In all these cases where no holotype exists, the name may be typified by designating a lectotype or, where permitted, a neotype.

It was common practice for 18th-century authors to give a statement of provenance such as "Habitat in India orientali" (it dwells in eastern India), and less common to cite a collector or give further details pertaining to an actual specimen or gathering. A statement of provenance alone does not constitute citation of a specimen or gathering; concrete evidence is needed, such as a collector's name, number, or date (see Art. 40 Note 1). For names with no cited specimens or gatherings, i.e. with no syntypes, it is very important to know where the author's herbarium and types are now located (use Taxonomic literature, ed. 2 or "TL-2"; see pp. 151 and 154) and to look for original material that could provide a potential lectotype, i.e. uncited specimens that were or could have been in the author's possession before the name was published and that bear annotations by the author linking the specimen to the name (Fig. 17, p. 76). I strongly recommend Order out of chaos (Jarvis, 2007) as the definitive guide to typifying Linnaean names. The methods described therein are often relevant to the typification of names published by other 18th- and early-19th-century authors.

In the 19th century, authors frequently cited collectors' names in a protologue (Fig. 6, p. 38), often with collecting numbers, less often specifying a herbarium. These should be regarded as gatherings, comprising an undetermined number of specimens, unless there is evidence that individual specimens were being cited. Consulting the actual specimens, examining their annotations and features, often helps to determine which ones the author used and cited. Bear in mind that specimens may have been lost, destroyed, or moved to other herbaria since the author used them. They may even have been discarded or given away by the author (e.g. Linnaeus did this; see Jarvis, 2007: 170).

In the 20th century, citation of specimens became more and more detailed and precise, with specimens explicitly designated as types. Remember that the type concept, although dating back to the latter half of the 19th century, was not formally accepted internationally until the V International Botanical Congress, held in Cambridge in 1930. The 1958 starting date in Art. 40.1, requiring that a type be indicated for the name of a new taxon at the rank of genus or below, reflects that indicating types had become general practice by that time. The rules are even stricter for names published on or after 1 January 1990, when the type must be explicitly designated using the word "typus", "holotypus", or an equivalent in a modern language (or an abbreviation, e.g. "holo."), and the single herbarium where the type is conserved must be specified. 
Regardless of the date of publication of a name, if a single specimen in a specified herbarium is explicitly designated as the type, using that word or an equivalent, this is the holotype, i.e. "the one specimen ... indicated by the author(s) as the nomenclatural type" (Art. 9.1). For names published before 1990, however, it is often uncertain if a holotype exists and, if it does, in which herbarium it is located. McNeill (2014) outlined the rules on holotype recognition and made suggestions for best practice.

\section{THE TYPIFICATION PROCESS}

If a name never had a holotype, or if the holotype has been lost or destroyed, or if the holotype is found to consist of more than one taxon, a lectotype may be designated (Art. 9.11). The same applies if a previously designated lectotype has been lost or destroyed or is found to consist of more than one taxon.

Lecto-, neo-, or epitypification is achieved by effective publication (Art. 7.10), and the first author who designates a lectotype, neotype, or epitype in accordance with the rules must be followed (Art. 9.19 and 9.20). The type must be definitely accepted as such by the author and it must be clearly indicated by direct citation including the word "type" or an equivalent (Art. 7.11).

The Code requires a strict procedure in lectotype designation (Art. 9.12). This can be best expressed by the flow chart in Fig. 16 (p. 74).

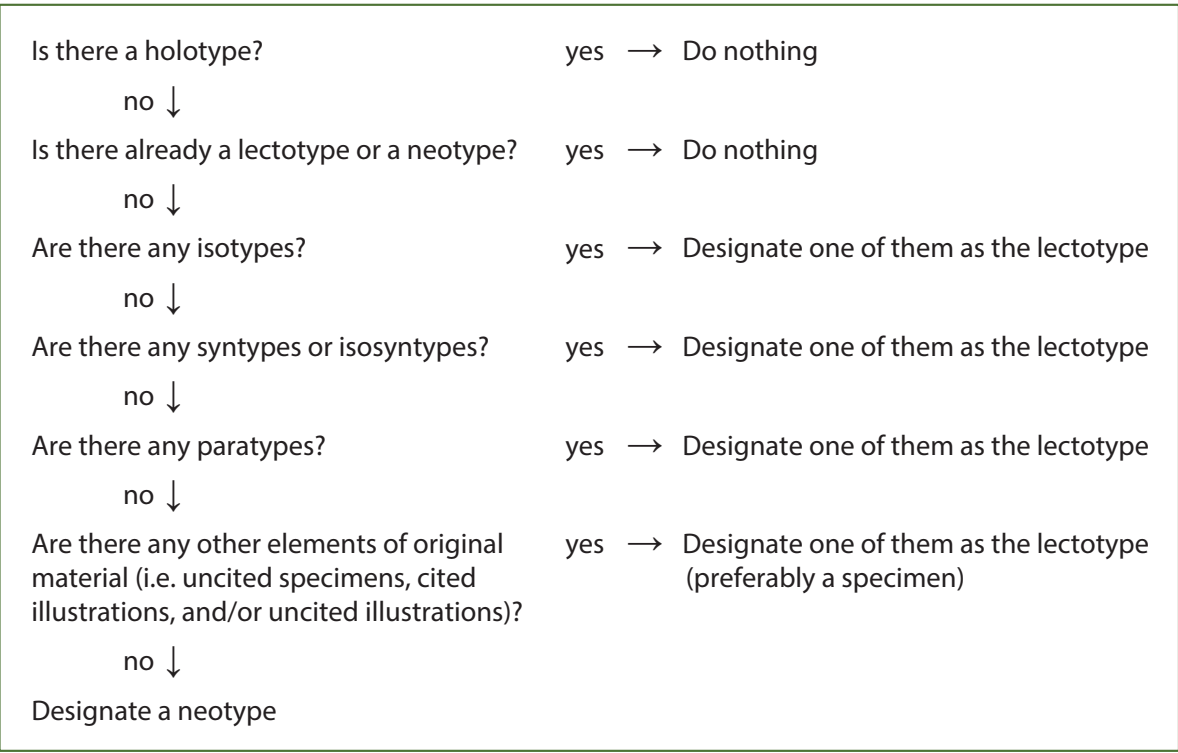

Fig. 16. Typification flow chart. 
If a name has no extant original material, a neotype may be designated (Art. 9.13). If any original material exists, a neotype may not be designated, except under two special circumstances. The first is under Art. 9.16, i.e. to preserve the usage established by a holotype or lectotype that was lost or destroyed when all the remaining original material differs taxonomically from the destroyed type. The second is under Art. 9.19(c), i.e. to supersede a lectotype that is in serious conflict with the protologue when no other, non-conflicting original material exists.

When material designated as the type (holotype, lectotype, or neotype) is found to belong to more than one taxon, it is actually not a specimen, which is defined (Art. 8.2) as being "of a single species or infraspecific taxon". In such a case, the name must remain attached to the part that complies with the definition of a specimen and corresponds most nearly with the original description or diagnosis (Art. 9.14). This is achieved (Art. 9.11) by designating the appropriate part as the lectotype or, if there is no original material, the neotype.

If the type or all elements eligible as the lectotype of a name are taxonomically ambiguous, then an epitype can be designated to help the interpretation of that type (Art. 9.9). For example, a holotype specimen might be nothing more than a wretched 200-yearold bare twig with degraded DNA; or the only possible lectotype could be a ridiculously oversimplified 17th-century woodcut illustration. When an epitype is designated, the supported holotype, lectotype, or neotype must also be explicitly cited (Art. 9.9).

Sometimes the only element—or all elements—available as the lectotype will be found to conflict with the current usage of a name. There is no taxonomic ambiguity, so an epitype cannot help. In such a case, you can maintain nomenclatural stability by bypassing lectotypification and proposing the name for conservation with a conserved type (see Chapter 8).

There are some additional requirements that come into effect on certain dates. When a lectotype, neotype, or epitype specimen is designated on or after 1 January 1990, the herbarium, collection, or institution in which the material is conserved must be specified (Art. 9.21 and 9.22). The same applies to an unpublished illustration (Art. 9.22). When designating an epitype that is a published illustration, a full and direct bibliographic reference (as defined in Art. 41.5) to that illustration must be provided (Art. 9.21). Furthermore, on or after 1 January 2001, the type designation must include the word "lectotypus", "neotypus", or "epitypus", or its abbreviation (e.g. lecto., LT., neo., NT., epi.), or its equivalent in a modern language (e.g. lectotype, lectotipo) (Art. 9.23) and it must include the phrase "designated here" or an equivalent (Art. 7.11). See Figs. 19 and 20 (pp. 78-79).

Note that many pre-2001 lecto- and neotypifications, often unintended, exist in the literature. An author merely had to write a phrase like "Type: Smith $123(\mathrm{~K})$ " and, if a specimen Smith 123 existed in the Kew herbarium and was eligible as the lectotype 
or neotype, the name was so typified. Today it would be necessary to write "Lectotype designated here: Smith $123(\mathrm{~K}) . "$

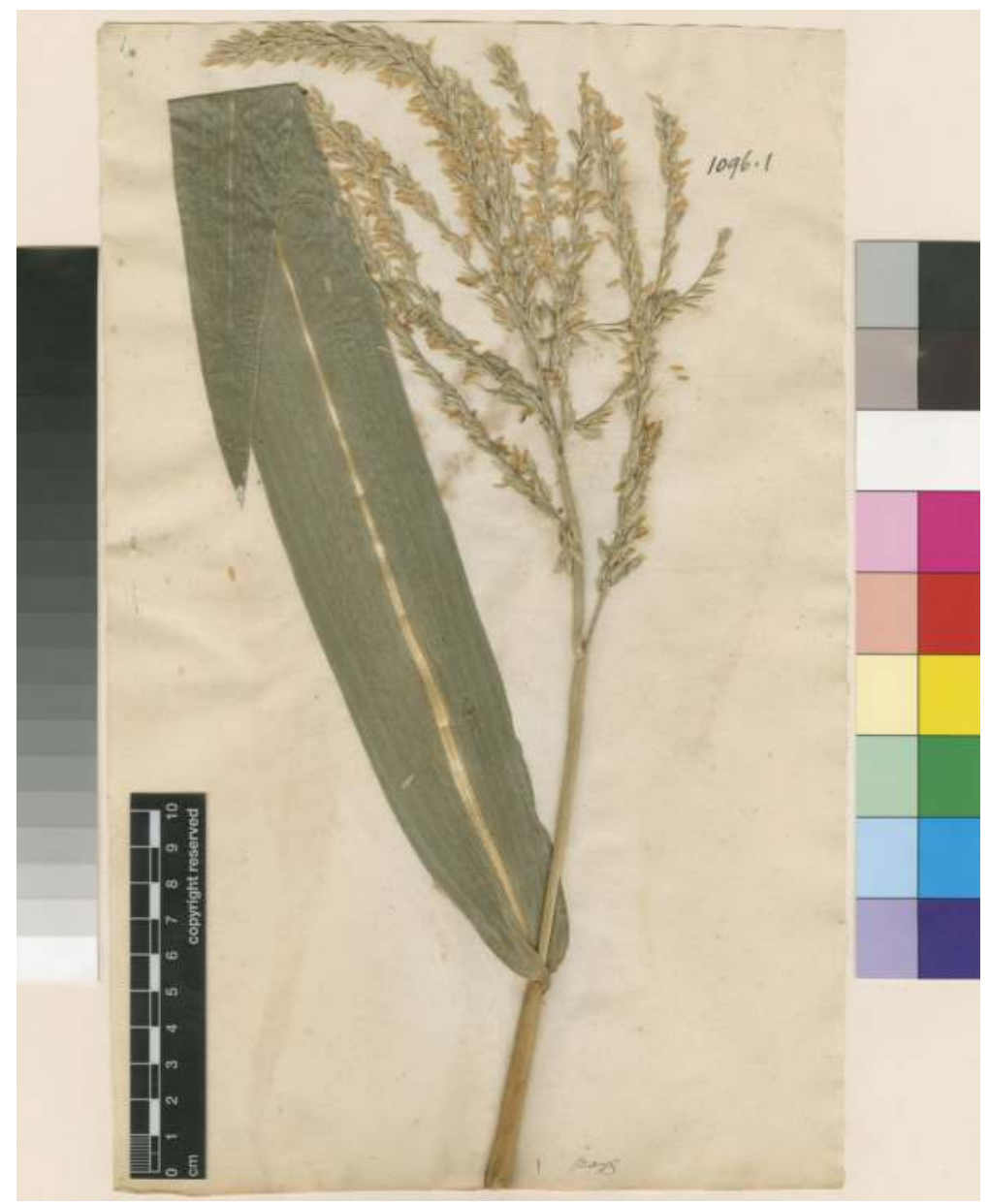

Fig. 17. The lectotype of Zea mays L.: specimen no. 1096.1 in the Linnaean Herbarium (Herb. Linn.) at the Linnean Society of London (LINN). Note the annotations in Linnaeus's handwriting to the right of the stem base: " 1 " is the species number in Species plantarum, and "Mays" is Linnaeus's nomen triviale (i.e. specific epithet); they indicate that in preparing the protologue Linnaeus used this specimen, which is therefore original material. It was designated as the lectotype in a paper in volume 67 of the American Journal of Botany by Iltis \& Doebley (1980: 1001). - Reproduced by permission of the Linnean Society of London (https://www.linnean.org/). 


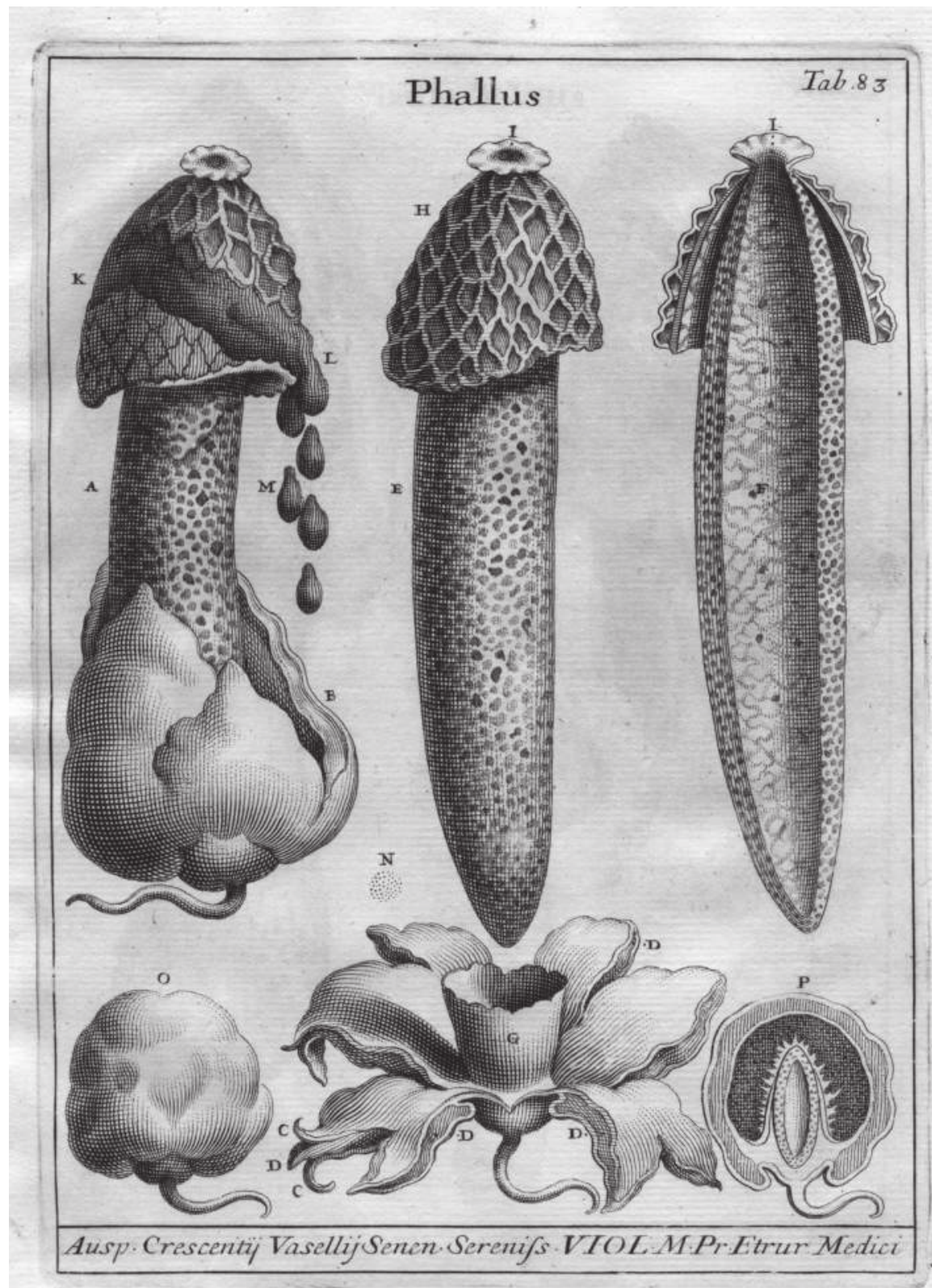

Fig. 18. Lectotype illustration of Phallus impudicus L.: tabula 83 in Micheli's Nova plantarum genera (Micheli, 1729: t. 83). It was designated as the lectotype by Greuter \& Kuyper in the book $A$ list of Linnaean generic names and their types by Jarvis \& al. (1993: 75). See Fig. 5 (p. 37) for the protologue of $P$. impudicus. 
2. Merianthera burlemarxii Wurdack in Phytologia 55: 133134. 1984 - Type: BRAZIL. Espírito Santo: Colatina, Rio Doce, Vila Pancas. Collected in Gardens of Roberto Burle Marx, Rio de Janeiro, 24 Sep 1983, P.C. Hutchison 8472 (lectotype, designated here: US). — Figure 6H-L.

Discussion. - This species shows a lot of variation in leaf pubescence and flower dimensions. However, the poor sample currently available and also the presence of some intermediate specimens does not allow us to split it into intraspecific taxa or even into different species. Further studies and more intensive collections of this species are needed, as well as an

Fig. 19. Lectotypification of Merianthera burlemarxii Wurdack in a paper in volume 61 of the journal Taxon by Goldenberg \& al. (2012: 1047). Lectotypifications and epitypifications of Ulva longissima Gunnerus and U. maxima Gunnerus in another paper in the same volume by Jørgensen (2012: 1094). Reproduced by permission of the International Association for Plant Taxonomy. Components of the typifications are as follows:

- $\quad$ Use of the words "lectotype" and "epitype", as required by Art. 9.23.

- $\quad$ Use of the phrase "designated here", as required by Art. 7.11.

- Specification of the herbaria in which the lectotype and epitype specimens are conserved (US, TRH), as required by Art. 9.22 and 9.21, respectively.

Butyriboletus fechtneri (Velen.) D. Arora \& J.L. Frank, Mycologia 106(3): 466, 2014

= Boletus fechtneri Velen., České houby 4-5: 704, 1922 [basionym]

$=$ Boletus appendiculatus subsp. pallescens Konrad, Bull. Soc. mycol. Fr. 44: 73, 1929

Holoty pe. None designated.

Other original material. Czech Republic, Central Bohemia, Bohemian Karst, Roblín, 1921, leg. F. Fechtner, det. J. Velenovský, preserved in the Department of Botany of Charles University, Prague (PRC 3981). One young fruitbody stored in a glass cylinder filled with preserving liquid (Figs. 12-13), the note "p. 704" refers directly to this page in Velenovskýs České houby.

Le ct oty pe (designated here, MycoBank MBT 381727). Czech Republic, Central Bohemia, Bohemian Karst, Roblín, 1921, leg. F. Fechtner, det. J. Velenovský (PRC 3981) - see above.

Epitype (designated here, MycoBank MBT 381728). Czech Republic, Central Bohemia, Bohemian Karst, Srbsko, Karlštejn National Nature Reserve, Boubová hill, $340 \mathrm{~m}$ a.s.l., under Quercus, Carpinus and Tilia, 8 Aug. 2010, leg. \& det. V. Janda. Epitype deposited in Mycological Department of the National Museum, Prague (PRM 923468), sequence KJ419929 (ITS rDNA, LSU rDNA) deposited in NCBI GenBank (for more details, see Šutara et al. 2014). Isoepitype deposited in the Moravian Museum, Brno (BRNM 805388). Colour photos: Fig. 14 and in Šutara et al. (2014), p. 27, fig. 22. We selected as an epitype herbarium material collected in a characteristic habitat of the Bohemian Karst, thermophilic deciduous forest on calcareous bedrock, which was cited by Velenovský in his original description (see below). Both the site of the collection and the morphological characters of the selected material fit the protologue. 
Fig. 20. Lectotypification and epitypification of Boletus fechtneri Velen. in a paper in volume 71 of the journal Czech Mycology by Janda \& al. (2019: 16). The protologue of Boletus fechtneri (Velenovský, 1922: 704-705) cited no specimens, but there is uncited original material (Art. 9.4(a)), i.e. a specimen collected by František Fechtner in 1921 and determined by Velenovský, which is the only available choice of lectotype. Reproduced by permission of the Czech Scientific Society for Mycology. Components of the typifications are as follows:

- $\quad$ Use of the words "lectotype" and "epitype", as required by Art. 9.23.

- $\quad$ Use of the phrase "designated here", as required by Art. 7.11.

- Specification of the herbaria in which the lectotype and epitype specimens are conserved (PRC, PRM), as required by Art. 9.22 and 9.21, respectively.

- Citation of the identifiers issued for the lecto- and epitypification by the recognized repository, MycoBank ("MBT 381727", "MBT 381728”), as required by Art. F.5.4 in type designations for fungal names from 2019 onward.

- Citation of an isoepitype in the herbarium BRNM.

- Herbarium codes PRC, PRM, and BRNM are followed by numbers identifying the specimens (see Rec. 9C.1)

- $\quad$ Statement (Janda \& al., 2019: 20) explaining in what way the lectotype is ambiguous such that epitypification is necessary (Rec. 9B.2): lacks the colour typical of the species; lacks mature spores; formaldehyde in the preserving liquid prevents DNA extraction.

- Selection of the epitype specimen to have similar locality, habitat, and morphological details to those mentioned in the protologue.

- $\quad$ Because Butyriboletus fechtneri (Velen.) D. Arora \& J.L. Frank and its basionym Boletus fechtneri have the same type (Art. 7.3), both names are lecto- and epitypified here.

- Boletus appendiculatus subsp. pallescens Konrad is a heterotypic synonym and is not therefore typified here.

\section{First- and second-step typifications}

A second-step typification may be invoked when a previously designated lectotype, neotype, or epitype is found to refer to a single gathering but to more than one specimen. In such cases, the first-step lecto-, neo-, or epitypification is accepted, but the choice is further narrowed to a single one of the specimens by a second-step lecto-, neo-, or epitypification (Art. 9.17). 


\section{Superseding a lectotype or neotype}

In almost all cases, the author who first designates a lectotype, neotype, or epitype in accordance with the rules must be followed (Art. 9.19 and 9.20). Only if a lectotype or epitype is lost or destroyed may a different one be designated (Art. 9.11 and 9.20). In addition, an epitype automatically ceases to be an epitype if the type that it supports is lost or destroyed (Art. 9 Note 8). It is also possible, in exceptional circumstances, for an existing lectotype or neotype to be superseded.

A choice of lectotype is superseded if:

- the holotype is rediscovered (Art. 9.19(a));

and it may be superseded if:

- the lectotype was designated contrary to Art. 9.14, i.e. it was designated to replace a taxonomically mixed holotype or lectotype but is not the part that corresponds most nearly with the original description or diagnosis; in this case the superseding lectotype must be the part that most nearly corresponds;

- the lectotype is in serious conflict with the protologue and another element of original material that is not in conflict with the protologue is available to be the superseding lectotype; if no such element is available, a neotype may supersede the lectotype (Art. 9.19(c)). Note that an element cited in the protologue is part of the protologue and cannot therefore conflict with it; hence this rule applies only to uncited specimens and uncited illustrations (Art. 9 Note 7).

A choice of neotype is superseded if:

- any of the original material (including a holotype or previously designated lectotype) is rediscovered (Art. 9.19(a));

and it may be superseded if:

- the neotype was designated contrary to Art. 9.14, i.e. it was designated to replace a taxonomically mixed neotype but is not the part that corresponds most nearly with the original description or diagnosis; in this case the superseding neotype must be the part that most nearly corresponds;

- the neotype is in serious conflict with the protologue and another element that is not in conflict with the protologue is available to be the superseding neotype (Art. 9.19(c)); 
the neotype differs taxonomically from the holotype or lectotype that it was selected to replace, when that holotype or lectotype had been lost or destroyed and it was shown that all the other original material differed taxonomically from the lost or destroyed type (Art. 9.16 and 9.18).

A choice of epitype may not be superseded, but the name may be proposed for conservation with a conserved type if the epitype differs taxonomically from the lectotype or neotype that it supports and if that lectotype or neotype cannot be superseded as described above (Art. 9.20; see Chapter 8). Similarly, a name may be proposed for conservation with a conserved type if its lectotype or neotype conflicts with the current usage of the name and cannot be superseded.

\section{NAMES OF GENERA AND SUBDIVISIONS OF GENERA}

The rules for designating a lectotype or neotype extend also to names of genera and subdivisions of genera and are found in Art. 10. The terms "holotype", "syntype", "lectotype", and "neotype" are often used in this context, by analogy with the typification of names of species and infraspecific taxa, although strictly speaking these terms are not applicable to types of names above the rank of species. For example, if the name of a new genus is published with two or more species names included ("syntypes"), and no "holotype" of the generic name is indicated in the protologue (it would need to be a pre-1958 name in order to be validly published; see Art. 40.1), one of those species names may subsequently be designated as the "lectotype" of the generic name under Art. 10.2. If the name of a new genus is published with no species names included, or, more precisely, with no type of any validly published species name definitely included (see Art. 10.3), a type must otherwise be chosen, i.e. a species name may subsequently be designated as the "neotype", again under Art. 10.2. It is actually the type of the species name that is the type of the generic name, but, as mentioned earlier, for purposes of designation or citation of the type, the species name alone suffices (Art. 10.1).

The only circumstance in which the type of a generic name may be a specimen or illustration that is not the type of a validly published species name is when the generic name is conserved with a conserved type (Art. 10.4; see Art. 14.9). For example, the conserved type of Pseudolarix Gordon (see App. III) is "[specimen] cult. in Anglia, ex Herb. George Gordon (K barcode K000287582)", which is a specimen referable to $P$. amabilis (J. Nelson) Rehder but is not the type of that species name.

In certain cases, typification of the name of a subdivision of a genus is automatic, i.e. when the epithet is the same as, or derived from, the epithet one of the species names included in the protologue (Art. 10.8). For example, the type of Euphorbia subg. Esula Pers. is E. esula L. However, designation of a different type by the original author overrides this automatic typification. 
As with lecto- and neotypifications of names of species and infraspecific taxa, the first author who designates a type for a name of a genus or subdivision of a genus in accordance with the rules must be followed (Art. 10.5). However, if a "neotype" is not conspecific with any of the material associated with the protologue, it is to be superseded (Art. 10.2 last sentence), presumably by a type conspecific with at least some material associated with the protologue.

A choice of type of a name of a genus or subdivision of a genus may also be superseded if it was based on a largely mechanical method of selection (Art. 10.5). It is superseded by any later, different choice that did not use such a method, unless, in the interval, the original choice was affirmed, i.e. adopted in a publication that did not use such a method. The phrase "a largely mechanical method of selection" was not properly defined in previous editions of the Code, but now the Shenzhen Code includes detailed criteria (Art. 10.6 and 10.7) enabling you to determine whether a publication used such a method of selecting types. These are publications that followed the so-called "Philadelphia Code" (Arthur \& al., 1904) or the American Code of Botanical Nomenclature (Arthur \& al., 1907).

\section{Best practice - designating a type}

Some of these suggestions are based on Recommendations in the Code (see Rec. $7 A-10 A$ and $40 A)$.

- Do you really need to designate a type? Designating a type is not always important. A name may have syntypes that are all adequate specimens corresponding with the current usage of that name; perhaps they are duplicates from a single gathering. Such syntypes are serving the intended purpose of types in determining the application of the name. In such a case, designation of one of these syntypes as the lectotype has little or no practical benefit or scientific significance. Writing a paper specially to publish such a typification would normally not be justified, whereas inclusion in a monograph would be appropriate.

- Avoid superfluous type designations. Before typifying a name, make an effort to search the relevant literature (revisions, monographs, Floras) in case the typification has already been made. You can never be sure that you have not missed an existing designation, but it is wise to check at least the most likely publications.

- Choose the type with care. Selecting a lectotype, neotype, or epitype should be done in a way that serves nomenclatural stability. Be aware that duplicate specimens of a single gathering may vary greatly in quality and do not necessarily all belong to the same taxon (mixed gatherings occurl), so never assume anything about duplicates that you have not seen and certainly never designate an unseen specimen as a type. The type should be chosen with a sound understanding of 
the taxonomy of the group concerned, and it should correspond with the current usage of the name. Careless typifications can cause disruptive changes in the application of names, often correctable only through conservation (see Chapter 8).

- Avoid illustrations as types. Designating an illustration as a lectotype, neotype, or epitype when a specimen is available is usually not advisable. In general, a type specimen is far better than a type illustration at unambiguously fixing the application of a name. More information is available from a specimen, and DNA can sometimes be extracted. An exception can be made where both a specimen and an illustration are eligible as a lectotype, and the specimen does not agree with the current usage of the name (it does not belong to the taxon to which the name is normally applied), but the illustration does agree (or at least does not disagree). In that case it would better serve nomenclatural stability to designate the illustration as the lectotype and, if it is demonstrably ambiguous, support it by also designating an epitype specimen.

- Make your type designation obvious. When designating a lectotype, neotype, or epitype, you are required to use the word "lectotypus", "neotypus", or "epitypus", or its abbreviation, or its equivalent in a modern language, and to use the phrase "designated here" (hic designatus) or an equivalent. To make your designation of type obvious to the widest international audience, use one of the Latin words or a modern-language equivalent that uses the Latin alphabet and is cognate with the Latin, e.g. "lectotype désigné ici" (French) or "epitipo designado aquí" (Spanish).

- Specify the herbarium clearly. When designating a specimen as a lectotype, neotype, or epitype, you are required to specify the herbarium, collection, or institution in which it is conserved. The standard method, which should be readily understood internationally, is to cite the herbarium code given in Index Herbariorum (http://sweetgum.nybg.org/science/ih/), e.g. LINN for the Linnean Society of London.

- Refer unambiguously to a single specimen (see Art. 8.2 and 8.3) when designating a lectotype, neotype, or epitype, e.g. by citing a herbarium barcode or other number that permanently identifies the specimen. If you do not, and someone later finds that two or more specimens of the cited gathering exist in the specified herbarium, your typification may be narrowed to one of those specimens by a second-step typification (see p. 79).

- Clearly annotate the lectotype, neotype, or epitype specimen as such, labelling it at least with the name that it typifies, and the type that it supports in the case of an epitype, and your name, and ensure that it is available for examination in the herbarium specified in your type designation. 


\section{CHAPTER 8 | CONSERVATION, PROTEC- TION, REJECTION, SUPPRESSED WORKS, AND BINDING DECISIONS}

This chapter describes the various rules designed to serve nomenclatural stability in exceptional cases where strict adherence to the principle of priority (Art. 11) or the rules on homonymy (Art. 53) or application of a name in the sense of its type (Art. 7) would cause disruption and/or confusion. Put very simply, conservation or protection allows an incorrect or illegitimate name to be used as a correct or legitimate name, or it can change the type of a name, whereas rejection prevents the use of a name, and suppressing a work prevents the use of names in that work. In addition, a binding decision rules whether or not a name is validly published or whether or not names are to be treated as homonyms.

\section{CONSERVATION}

Conservation is dealt with under Art. 14 of the Code. Under Art. 14.1, a conserved name is legitimate even though it may have been illegitimate when published. It is possible to conserve names at the ranks of family, genus, and species; in addition, a name of a subdivision of a genus or infraspecific taxon can be conserved when it is the basionym of a generic or species name that could not continue to be used in its current sense without conservation. Conserved names are listed in the Appendices of the Code: App. IIA and IIB for names of families, App. III for names of genera and subdivisions of genera, and App. IV for names of species and infraspecific taxa. A conserved name may be indicated as such with the abbreviation "nom. cons." (Rec. 50E.1), which stands for nomen conservandum, Latin for "name to be conserved", e.g. Malvaceae Juss., nom. cons., Bambusa Schreb., nom. cons., Galactites tomentosus Moench, nom. cons.

A conserved name at any rank is conserved against all earlier homonyms (Art. 14.10), whether or not those conserved-against, i.e. rejected, homonyms are listed alongside the conserved name in the relevant Appendix. For example, Ipomoea discolor (Kunth) G. Don 1837-1838 is conserved against I. discolor Jacq. 1798, and the latter name is listed alongside the former in App. IV; Blumea DC. 1833 is conserved against Blumea Rchb. 1828-1829 even though the latter name is not listed alongside the former in App. III. Conservation does not make the earlier homonym illegitimate; although unavailable for use, it may serve as a basionym.

A conserved name of a family or genus is conserved against all other names at the same rank based on the same type (homotypic synonyms), whether or not the rejected names are listed alongside the conserved name in the relevant Appendix (Art. 14.4). 
The conserved name is also conserved against those names based on different types (heterotypic synonyms) that are listed as rejected in the entry in App. IIA or III. For example, Corydalis DC. 1805 is listed in App. III as conserved against the earlier homonym Corydalis Medik. 1789, the earlier homotypic synonym Pistolochia Bernh. 1800, and three earlier heterotypic synonyms: Capnoides Mill. 1754, Cysticapnos Mill. 1754, and Pseudo-fumaria Medik. 1789. These five conserved-against names are all rejected in favour of Corydalis DC. However, the three heterotypic synonyms are not rejected under all circumstances; any or all of them may be adopted as correct names if they are considered to apply to genera distinct from Corydalis DC. (Art. 14.6).

A conserved name of a species is conserved against all names listed as rejected in the entry in App. IV, and against all combinations based on the rejected names (Art. 14.4). For example, Cactus cruciformis Vell. 1829 is conserved against the earlier homotypic synonym Cereus squamulosus Salm-Dyck ex DC. 1828 and the three earlier heterotypic synonyms Cereus tenuispinus Haw. 1827, C. myosurus Salm-Dyck ex DC. 1828, and C. tenuis DC. 1828. These four conserved-against names are all rejected in favour of $\mathrm{Cac}$ tus cruciformis. The same applies to all combinations that are based on them. However, under Art. 14.6, any or all of the three heterotypic synonyms may be adopted as correct names if they are considered to apply to species distinct from $C$. cruciformis.

When a species name is conserved against a name that is based on an earlier name, that earlier name may still be used because it is not listed as rejected and it is not a combination based on a rejected name. For example, Lycopersicon esculentum Mill. 1768 is conserved against L. lycopersicum (L.) H. Karst. 1882, which is based on Solanum lycopersicum L. 1753. This conservation does not prevent the use of S. lycopersicum or indeed any name based on it except $L$. lycopersicum.

A name may be conserved with a particular type (Art. 14.9) or to preserve a particular spelling or gender (Art. 14.11). When a type is conserved, it may be different from that determined by the Code or designated by the original author. This is a very useful tool for maintaining nomenclatural stability when an existing type, or an automatic type (e.g. under Art. 7.5 for a name illegitimate under Art. 52.1), or the only element(s) available for designation as the type, conflict with the current usage of the name. You also have the advantage of being able to choose a high-quality, recent specimen with duplicates widely distributed in several herbaria. There is no obligation to "pay homage" by choosing an element connected with the original author(s), although it may be useful to choose a specimen collected near the original type locality.

When a conserved name competes with one or more heterotypic synonyms against which it is not explicitly conserved (i.e. the synonyms are not listed as rejected in the entry in the Appendix), under Art. 14.5 the earliest of the competing names is adopted in accordance with the rules on priority (Art. 11). For example, Mahonia Nutt. 1818 is listed in App. III as conserved, but not explicitly so against any name. If it is united with Berberis L. 1753, the combined genus bears the name Berberis, which has priority. 
There is an exception in Art. 14.5: the conserved family names listed in App. IIB are conserved against all unlisted names. For example, Combretaceae R. Br. 1810 is listed in App. IIB and is therefore conserved against the unlisted earlier heterotypic name Terminaliaceae J. St.-Hil. 1805. For a family circumscribed to include Terminalia L. as well as Combretum Loefl., Terminaliaceae would have priority over Combretaceae if the latter were not conserved.

The family names listed in App. IIB are further protected by Art. 14.14, which rules that the places of publication cited are treated as correct in all circumstances and consequently are not to be changed, even when otherwise such a name would not be validly published or when it is a later isonym. If someone digs in the literature and finds an earlier place of valid publication for one of the names in App. IIB, the current entry in the Appendix is protected even though it is a later isonym, which would otherwise have no status under the Code (Art. 6 Note 2).

A rejected name (or a combination based on one) may not be adopted for a taxon that includes the type of the corresponding conserved name (Art. 14.7). To illustrate this, consider Enallagma (Miers) Baill. 1888, conserved against Dendrosicus Raf. 1838, but not against Amphitecna Miers 1868. If all three names are applied to the same genus (so that the genus includes all three types), under Art. 14.5 you might expect the genus to be called Dendrosicus, because that is the earliest name, but in fact it is the second earliest name, Amphitecna, because Dendrosicus cannot be restored for a genus that includes the type of Enallagma. No such restriction applies to Amphitecna, because Enallagma is not conserved against it.

Entries on the lists of conserved names may not be deleted (Art. 14.13), but they may be added to or amended (Art. 14.12); amendment includes changing the listed type or spelling of an already conserved name (Art. 14.8).

\section{Proposing a name for conservation}

To conserve a name, or to amend an existing entry for a conserved name, it is necessary first to submit a proposal to the General Committee (see pp. 143-145), with a detailed but concise statement of the cases both for and against conservation, quantifying how widespread and traditional is the usage of the name compared with the name(s) that threaten it, and citing examples of such usage. Submission of a proposal is by publication in Taxon, the journal of the International Association for Plant Taxonomy. For detailed current guidelines on preparing proposals, see McNeill \& al. (2018).

The General Committee will then refer the proposal to the relevant specialist committee: the Nomenclature Committee for Algae, Bryophytes, Fossils, Fungi, or Vascular Plants. The specialist committee will discuss and vote on the proposal. A qualified majority (at least 60\%) of the members of the committee is needed to make a recommendation, i.e. whether to conserve the name or not conserve the name. 
Reports summarizing each specialist committee's recommendations on proposals are published in Taxon.

The next step is for the General Committee to consider and vote on the specialist committee's recommendation, again requiring at least a $60 \%$ majority of its members to approve or overturn that recommendation. This process is usually straightforward and takes little time. The General Committee then publishes its own report in Taxon. If conservation is recommended, it takes effect non-retroactively on publication of the report (Art. 14.15), but is subject to the decision of a later International Botanical Congress. The name appears in the relevant Appendix (App. IIA, IIB, III, or IV), preceded by an asterisk $\left(^{*}\right)$, which is deleted after approval by a Congress.

The recommendations in the General Committee's report(s) are voted on by the Nomenclature Section of the Congress and are usually approved in a single vote with little or no debate. In the Nomenclature Section, at least a $60 \%$ majority is required to reject one or more recommendations of the General Committee. Until 1950, proposals to conserve and reject names were voted on directly at the Congress, which may seem more democratic but did not allow enough time for adequate debate on each of the names concerned. The Stockholm Congress of 1950 voted to delegate the often very complex debates on proposals to committees that would report to future congresses.

The time that a proposal takes to go through this process is mostly spent in consideration by one of the specialist committees, i.e. from publication of a proposal in Taxon to publication of the relevant committee's report in Taxon. The time can vary from a few months to several years. Many proposals are uncontroversial, with the committees almost unanimously for or against the proposal and reaching a rapid decision, but when opinion is evenly divided, or if complications arise, additional rounds of discussion and voting may be necessary.

\section{PROTECTION}

Protection, which allows submission of lists of names to be treated as conserved, was a new concept introduced at the Melbourne Congress of 2011, but there were no actual protected names until the Shenzhen Congress of 2017, when the scope of protection was also expanded. Protection applies only to names of organisms treated as fungi and is dealt with in Chapter F, under Art. F.2. The concept is essentially the same as conservation, except that the names are submitted in lists and each protected name is treated as conserved against any competing listed or unlisted synonyms or homonyms (including sanctioned names; see Chapter 11). In this respect, protected names behave like the conserved names of families of bryophytes and spermatophytes in App. IIB. The lists are submitted to the General Committee but by publication in IMA Fungus, the journal of the International Mycological Association. The General Committee refers the lists to the Nomenclature Committee for Fungi for examination by subcom- 
mittees established by that Committee in consultation with the General Committee and appropriate international bodies. The voting and approval procedure is the same as for conservation proposals. The protected names appear in the relevant Appendices of conserved names (App. IIA, III, or IV), indicated by "(P)" and, if Congress approval is still pending, preceded by an asterisk $\left(^{*}\right)$. The lists of protected names can be revised by the same process, and conservation under Art. 14 overrides protection under Art. F.2.

\section{REJECTION}

The Code also contains provisions for the formal rejection of any name-at any rankthat would cause a disadvantageous nomenclatural change (Art. 56.1). No name needs to be conserved against such a rejected name. It is rejected in all circumstances and cannot be used; all combinations based on it are likewise rejected. Such names are called nomina utique rejicienda (names to be rejected in any case, suppressed names) and are listed in App. V. A nomen utique rejiciendum may be indicated as such with the abbreviation "nom. utique rej." or (following Rec. 50E.2) "nom. rej.", e.g. Cacalia L., nom. rej., Peziza [unranked] Phialea Pers., nom. rej., Rosa eglanteria L., nom. rej., Actaea spicata var. alba L., nom. rej.

Although such a rejected name becomes unavailable for use, a later homonym of it remains illegitimate (Art. 53 Note 2), so if you want to make a later homonym legitimate, you must conserve it against the earlier homonym.

The procedure for proposing a name for rejection (Art. 56.2), and its journey through the committees to a Congress, is the same as that for conservation. The same guidelines apply (McNeill \& al., 2018). The proposal submitted to Taxon should quantify how widespread and traditional is the usage of the name compared with the name(s) that it threatens. Rejection, if recommended, takes effect non-retroactively on publication of the General Committee's report (Art. 56.3), but is subject to the decision of a later International Botanical Congress. The name appears in App. V, preceded by an asterisk $(*)$, which is deleted after approval by a Congress.

For names of organisms treated as fungi, it is also possible to submit lists of names for rejection under Art. F.7. The procedure parallels that for protection under Art. F.2, and the lists are submitted to the General Committee by publication in IMA Fungus. The rejected names are to be treated as rejected under Art. 56.1, except that they may become eligible for use by conservation under Art. 14. They would presumably be listed in App. V, although to date no lists of names have been submitted for rejection.

Note that even if a proposal to conserve or reject a name is not submitted, the Code provides, under Art. 57.1, protection for a name that has been widely and persistently used for a taxon or taxa not including its type. Such a name is not to be used in a sense that conflicts with current usage unless and until a proposal to deal with it under Art. 14.1 or 56.1 has 
been submitted and rejected. In other words, if a name has had and still has a widespread, traditional usage for a particular taxon, but its type in fact belongs to a different taxon, the usage of the name must not be changed from the traditional sense to the sense of its type, which would be the correct action if Art. 57.1 did not exist. Such a change in usage can only occur if a proposal to conserve or reject the name is submitted and is subsequently rejected, i.e. the General Committee recommends not to conserve or not to reject the name.

\section{SUPPRESSED WORKS}

On rare occasions, a particular publication is found to contain so many disruptive names that it is much simpler to propose the whole publication for suppression under Art. 34.1 than to propose each disruptive name individually for rejection under Art. 56.1. Such publications are called suppressed works, or opera utique oppressa (works suppressed in any case), and are listed in App. I. Names of taxa in specified ranks in a suppressed work are not validly published, e.g. names of species in Gandoger (1883-1891) and names at all ranks in Haller (1753). Suppression also makes any nomenclatural acts in the work ineffective (e.g. lectotypifications; see Art. 34.1 footnote) if they are associated with names at the specified ranks. Suppression is retroactive, so it is as if the works had always been suppressed. Most of the suppressed works listed in App. I are from the 18th century, although one is relatively recent, from the 1990s (Motyka, 1995-1996). The procedure for proposing a work for suppression and the mechanism by which it becomes suppressed and enters App. I are essentially the same as those for conservation and rejection, although more than one specialist committee may consider the proposal if the work covers, e.g., both plants and algae. If suppression is recommended, it takes effect retroactively on publication of the General Committee's report (Art. 34.2), but is subject to the decision of a later International Botanical Congress. The work appears in App. I, preceded by an asterisk $\left(^{*}\right)$, which is deleted after approval by a Congress.

\section{BINDING DECISIONS}

A binding decision provides a ruling in a situation of doubt. It is made by an International Botanical Congress, based on a recommendation by the General Committee, in turn based on a recommendation by one of the specialist committees, resulting from a request from an individual. There are currently two kinds of binding decisions: those on the adequacy of descriptive statements for the purpose of valid publication and those on treating confusingly similar names as homonyms.

\section{Whether or not a descriptive statement satisfies the requirements for valid publication of a name of a new taxon}

As explained in Chapter 5, in order to be validly published, a name of a new taxon must be accompanied by a description or diagnosis or by a reference to one that was 
previously and effectively published (Art. 38.1(a)). A diagnosis is a statement of that which distinguishes the taxon from other taxa in the opinion of the author of the taxon (Art. 38.2). It could mention only one feature, if the author felt it to be diagnostic, e.g. "this species differs from all others in the genus by its white flowers". Indeed, the words "in the opinion of the author" mean that a diagnosis does not have to be a demonstrably correct statement (to continue with the example, the genus could include other white-flowered species of which the author was unaware).

On the other hand, the Code tells us only what a description is not, i.e. statements describing properties such as purely aesthetic features, economic, medicinal or culinary use, cultural significance, cultivation techniques, geographical origin, or geological age (Art. 38.3). Some names have been published with minimal descriptive statements, e.g. "tree", "perennial", "up to $2 \mathrm{~m}$ tall", or "flowers white". They have been called "nomina subnuda" (nearly naked names) and have been regarded by some as validly published but by others as not validly published.

When it is doubtful whether a descriptive statement satisfies the requirement of Art. 38.1(a) for a description or diagnosis, a request for a decision may be submitted to the General Committee (Art. 38.4). The request is published in Taxon. There is no need for a detailed statement of the cases both for and against, as with conservation and rejection proposals, although any notes you might wish to submit with the request may help the committees. For guidelines on how to formulate a request, see McNeill \& Wiersema (2018). The rest of the process essentially matches that for conservation and rejection, except that the specialist committee first decides by a qualified majority (at least 60\%) whether or not a binding decision should be recommended and then decides by a simple majority (more than $50 \%$ ) whether the name is validly published or not validly published. The reason for this is to avoid having to create an entry in the Appendix for every request for a binding decision, because the committee may consider some cases to be self-evident. When a decision by the relevant specialist committee, approved by the General Committee, is finally ratified by an International Botanical Congress, it becomes a binding decision with retroactive effect and the name is listed in App. VI, indicated as either validly or not validly published.

\section{Whether or not names are sufficiently alike to be confused and are to be treated as homonyms}

The other kind of binding decision concerns confusingly similar names, i.e. orthographically similar names at the rank of genus or below that are likely to be confused. Such names, if they are based on different types (so-called "parahomonyms"), are to be treated as homonyms under Art. 53.2 and 53.3. The likelihood of confusion may depend on how similarly they are spelled, and how closely related are the taxa to which they are applied. For example, Cristella Pat. 1887 applies to a fungus and Christella H. Lév. 1915 applies to a pteridophyte; they are hardly likely to be confused, even though they differ by only one letter. On the other hand, Solanum saltiense S. Moore 1895, described from 
Brazil, and S. saltense (Bitter) C.V. Morton 1944, based on Lycianthes saltensis Bitter described from Argentina, are much more likely to be confused because they both apply to South American species of Solanaceae.

Deciding whether or not names are confusable is not always easy, and in doubtful cases a request for a decision may be submitted to the General Committee (Art. 53.4). The procedure and mechanism are the same as for requests for binding decisions on valid publication, except that more than one specialist committee may be involved. The same guidelines apply (McNeill \& Wiersema, 2018). On ratification by an International Botanical Congress, the decision becomes binding with retroactive effect and the names are listed in App. VII, indicated as either "(H)" or "(NH)", i.e. homonyms or not homonyms.

\section{SUMMARY OF APPENDICES I-VII}

The arrangement and contents of the seven Appendices that deal with conserved and rejected names, suppressed works, and binding decisions are given below. Note that, except for the introductions to each Appendix, the texts are in Latin. This may not be immediately obvious, because most of the text consists of scientific names, abbreviated authors' names, and bibliographic references, but you will notice Latin words such as $a d$, icon, and non designatus, and various abbreviations, such as nom. cons., typ. cons., and prim. These and the symbols ${ }^{*},(=),(\equiv),(\mathrm{H}),(\mathrm{NH})$, and $(\mathrm{P})$ are listed in Table 7 (p. 93-94) together with their meanings (they are also included in the list of abbreviations, acronyms, symbols, and Latin words on pp. 166-173).

\section{Appendix I}

Suppressed works, arranged alphabetically by author. Some works are suppressed only for names of taxa in certain ranks, e.g. genera, and this is indicated at the end of each entry.

\section{Appendix IIA}

Conserved and protected names of families, with the rejected names against which they are conserved or protected. The conserved names are arranged alphabetically within each of four parts: algae, fungi (also with protected names), pteridophytes, and fossils.

\section{Appendix IIB}

Conserved names of families, arranged alphabetically within two parts: bryophytes and spermatophytes. Unlike those in App. IIA, names in App. IIB are conserved against all unlisted synonyms and homonyms. In a few cases, which are indicated with cross-references, a name is "superconserved" against another name in App. IIB, which means that when these names are treated as heterotypic synonyms, one name must 
be used and the other is rejected in its favour (e.g. Abietaceae and Pinaceae). Appendix IIB is also unique among the Appendices in that the places of publication cited for the names are treated as correct in all circumstances and are not to be changed, so that if an earlier place of publication of a name is found, or even if a name were found to be not validly published in the publication listed (highly unlikely), the entry in the Appendix cannot be changed.

\section{Appendix III}

Conserved and protected names of genera, with the rejected names against which they are conserved or protected. The conserved names are organized into six parts: algae, fungi (also with protected names), bryophytes, pteridophytes, spermatophytes, and fossils; the bryophytes are further divided into hornworts, hepatics, and mosses, and the spermatophytes into gymnosperms and angiosperms; the names are then listed alphabetically within each group. This is by far the largest Appendix in the Code.

\section{Appendix IV}

Conserved and protected names of species, with the rejected names against which they are conserved or protected. Like App. III, the conserved names are organized into six parts: algae, fungi (also with protected names), bryophytes, pteridophytes, spermatophytes, and fossils, and are arranged alphabetically within each part.

\section{Appendix V}

Suppressed names (names rejected under Art. 56.1), arranged alphabetically within each of six parts: algae, fungi, bryophytes, pteridophytes, spermatophytes, and fossils. If names are ever rejected under Art. F.7, they will presumably also be listed here under fungi.

\section{Appendix VI}

Binding decisions on descriptive statements (see Art. 38.4). These are the so-called "nomina subnuda", names for which it is doubtful whether the descriptive statement is adequate as a description or diagnosis that satisfies the requirement for valid publication of the name. Such names are ruled as either validly published or not validly published.

\section{Appendix VII}

Binding decisions on confusability of names (see Art. 53.4). These are the so-called "parahomonyms", names that are spelled almost, but not exactly, the same. Such names are ruled as either to be treated as homonyms or not to be treated as homonyms. 
Table 7. Symbols, Latin words, and abbreviations of Latin words used in Appendices I-VII of the Code.

\begin{tabular}{|c|c|}
\hline Term & Meaning \\
\hline * & $\begin{array}{l}\text { when preceding an entry indicates a proposal approved by the General } \\
\text { Committee; retention or rejection of the name or suppression of the } \\
\text { publication is authorized subject to the decision of a later International } \\
\text { Botanical Congress }\end{array}$ \\
\hline$(=)$ & heterotypic (i.e. taxonomic) synonym \\
\hline$(\equiv)$ & homotypic (i.e. nomenclatural) synonym \\
\hline$(\mathrm{H})$ & homonym \\
\hline$(\mathrm{NH})$ & not a homonym \\
\hline$(\mathrm{P})$ & protected name, only for names of fungi \\
\hline ad t. & $\begin{array}{l}\text { ad tabulam, at the plate, used when citing a place of publication } \\
\text { associated with an illustration }\end{array}$ \\
\hline ante & before, used when citing a date \\
\hline cancellans & $\begin{array}{l}\text { cancelling, used for a corrected page inserted in a book, replacing the } \\
\text { cancelled page }\end{array}$ \\
\hline deest & it is missing, used for a missing type specimen \\
\hline etiam vide & see also \\
\hline ex & from, used in author citations or to indicate the source of a type specimen \\
\hline gen. fem. cons. & genus femininum conservandum, feminine gender to be conserved \\
\hline $\begin{array}{l}\text { gen. masc. } \\
\text { cons. }\end{array}$ & genus masculinum conservandum, masculine gender to be conserved \\
\hline $\begin{array}{l}\text { gen. neut. } \\
\text { cons. }\end{array}$ & genus neutrum conservandum, neuter gender to be conserved \\
\hline icon & image, i.e. an illustration \\
\hline ined. & ineditus, not published \\
\hline med. & medio, mid, in the middle (in a month or year), used when citing a date \\
\hline nom. alt. & nomen alternativum, alternative name \\
\hline nom. cons. & nomen conservandum, name to be conserved \\
\hline nom. illeg. & nomen illegitimum, illegitimate name \\
\hline nom. rej. & nomen rejiciendum, name to be rejected \\
\hline $\begin{array}{l}\text { nom. utique } \\
\text { rej. }\end{array}$ & $\begin{array}{l}\text { nomen utique rejiciendum, name to be rejected outright, a suppressed } \\
\text { name }\end{array}$ \\
\hline non designatus & not designated \\
\hline orth. cons. & orthographia conservanda, orthography (i.e. spelling) to be conserved \\
\hline post & after, used when citing a date \\
\hline
\end{tabular}




\begin{tabular}{|l|l|}
\hline Term & Meaning \\
\hline prim. & $\begin{array}{l}\text { primo, at the beginning, early (in a month or year), used when citing a } \\
\text { date }\end{array}$ \\
\hline q.v. & quod vide, which see \\
\hline s.ann. & sine anno, without year \\
\hline s.coll. & sine collectore, without collector \\
\hline s.loc. & sine loco, without locality \\
\hline sero & late (in a month or year), used when citing a date \\
\hline sub & under \\
\hline typ. cons. & typus conservandus, type to be conserved \\
\hline typ. des. & typi designatio, designation of type \\
\hline typus & type \\
\hline vide & see (imperative) \\
\hline
\end{tabular}




\section{CHAPTER 9 | HOW TO CITE AUTHORS OF NAMES}

It is not mandatory to cite authors of scientific names. Omitting an author citation has no effect on valid publication, legitimacy, or correctness of a name, nor on the application of a name. In very general terms, scientific publications should use author citations, whereas popular publications should not. Author citations should be included in formal situations where precision is needed and confusion is to be avoided; or, to quote the Code, "In publications, particularly those dealing with taxonomy and nomenclature, it may be desirable, even when no bibliographic reference to the protologue is made, to cite the author(s) of the name concerned" (Art. 46.1), which sounds like a vague recommendation but the Article ends with the actual rule: "In so doing, the following rules apply", so if you do cite authors, you need to follow Art. 46-50.

One potential source of such confusion is homonyms. For example, if I use the name Aster angustifolius, do I mean the Aster angustifolius published by N.J. von Jacquin in 1798 for a species from what is now South Africa, or the Aster angustifolius published by C.C. Chang in 1935 for a species from China? If I cite the authors for both names (and better still the date), precision is thereby achieved, e.g. Aster angustifolius C.C. Chang non Jacq., or Aster angustifolius C.C. Chang 1935 non Jacq. 1798 (in which non is Latin for not).

It is rare to use author citations for suprageneric names, and indeed there is usually no reason to cite them unless you are writing a formal monograph or discussing the place of valid publication of such a name, as when citing a basionym. If you use, e.g., the name Asteraceae, could there be any confusion as to which Asteraceae you mean? There are almost no homonyms above the rank of genus. Citing authors of suprageneric names in general scientific papers, Floras, checklists, etc., is not only unnecessary in most cases, but it often appears overcorrect, and it becomes worse if the author citations are in fact incorrect.

The correct author citation for a scientific name depends on what is termed ascription. Ascription is defined as the direct association of the name of a person or persons with a new name or description or diagnosis of a taxon (Art. 46.3). In the interests of presenting here a reasonably simple guide to author citation, I have avoided using ascription as the basic principle and have omitted rules that apply only in rare cases. The rules on author citation have gradually developed over the years as Code users have encountered ambiguous cases, where authorship could not be determined with certainty, and they have responded by creating additional rules to eliminate the ambiguity. The result is what is today one of the most complex parts of the Code. The guidelines offered here should result in correct author citation in most cases. 


\section{COMMONEST CASES}

In most cases, the correct author citation for a name is simply the author(s) cited immediately following the name, or if no author(s) are cited thus, the author(s) of the publication that contains the protologue of the name (see Art. 46 Note 1). That publication might be a book, a chapter of a book, a treatment of a family or genus in a Flora, or a paper in a journal. When the publication is part of a larger work, the relevant authorship is that of the part, not of the larger work (Art. 46.6).

In older works, the author citation is often lacking, e.g. in Linnaeus's Species plantarum (Linnaeus, 1753) you will not find "L.", "Linn.", "Linné", or "Linnaeus" cited after the names, yet Linnaeus is the sole author of the book and is therefore the author of the names therein.

In most modern protologues, a new name is immediately followed by its author citation. For example, "Agrostopoa Davidse, Soreng \& P.M. Peterson, gen. nov." appears in a paper by Davidse, Soreng, and Peterson (Davidse \& al., 2009); "Tainus Torr.-Montúfar, H. Ochot. \& Borsch, gen. nov." appears in a paper by Torres-Montúfar, Borsch, Fuentes, Clase, Peguero, and Ochoterena (Torres-Montúfar \& al., 2017). In these examples, the author citations either exactly match the authorship of the publication or have authors in common. These are uncomplicated cases where you can simply accept the author citation provided.

\section{CITATIONS USING “EX”}

A name, in its protologue, may appear with an author citation that has no person in common with the authorship of the publication that contains the protologue. In most such cases, the correct author citation is not what appears in the publication but may consist of both sets of authors separated by the word "ex", in the format "[author(s) as cited] ex [author(s) of the publication]" (Art. 46.5). Note that citing "[author(s) as cited] ex" is optional, and it is equally correct simply to cite the authors of the publication. For example, Seemann was the sole author of a publication (Seemann, 1865-1873) in which he published the name of a new species, ascribing it to Nuttall, thus: "G[ossypium]. tomentosum, Nutt. mss." The correct citation is either Gossypium tomentosum Nutt. ex Seem. or Gossypium tomentosum Seem., but not "Gossypium tomentosum Nutt." When "ex" is used, it separates what might be called an "honorary" author (Nuttall) from the actual author who validly published the name (Seemann).

Authors of publications often cite such honorary authors when they feel some credit for the new name is due, e.g. the name was first used in an annotation of a herbarium specimen or in correspondence (i.e. it was not effectively published), or it was effectively but not validly published previously. 
You will often see these "ex" citations actually used in protologues. If you are publishing a new name and wish to ascribe it to someone else, you yourself can use an "ex" citation, i.e. "[his/her name] ex [your name]" (Art. 46.10).

A useful rule to remember is that the same author cannot correctly appear on both sides of an "ex" citation. When a cited authorship and the authorship of the publication have at least one person in common, the cited authorship is always accepted as correct (Art. 46.2 last sentence). For example, the authorship of Tainus, mentioned above (p. 96), cannot be "Torr.-Montúfar, H. Ochot. \& Borsch ex Torr.-Montúfar \& al."

\section{CITATIONS USING “IN"}

When a name is cited with its author and a full bibliographic citation, sometimes the authorship of the publication as a whole may differ from the correct author citation of the name. In that case, both may be cited, separated by the word "in" (Art. 46 Note 2). For example, Carex continua C.B. Clarke in Hooker, Fl. Brit. India 6: 717. 1894, where Clarke is the author of both the name, which appears as "C. continua, C. B. Clarke", and the treatment of the Cyperaceae in The Flora of British India, indicated by "CYPERACEÆ. (C. B. Clarke)" at the top of the page, whereas Hooker is the general author of the Flora (Hooker, 1872-1897), indicated by "by Sir J. D. Hooker" on the title pages of the volumes.

Note that the authorship following "in" is part of a bibliographic citation and is not part of the authorship of the name; it is therefore omitted unless a full bibliographic citation follows, and then it is preferably not abbreviated. For example, you would not write "Carex continua C.B. Clarke in Hooker" by itself nor "Carex continua C.B. Clarke in Hook., Fl. Brit. India 6: 717. 1894”.

When a journal is involved, the authors of the publication, i.e. the whole paper, are usually omitted, e.g. Cleretum clavatum (Haw.) Klak in Taxon 61: 304. 2012, not "Cleretum clavatum (Haw.) Klak in Klak \& Bruyns, Taxon 61: 304. 2012", where Klak is the sole author of the name in a paper jointly authored by Klak and Bruyns in the journal Taxon (Klak \& Bruyns, 2012). 


\section{Is it "ex" or "in"?}

How do you know when to use "ex" and when to use "in"? The two examples, given here, of Gossypium tomentosum and Carex continua seem similar. But who is the author of the publication in each case? Or, more precisely, who is the author of the validating description or diagnosis of the name? For G. tomentosum it is Seemann and for C. continua it is Clarke. Remember that the publication may be part of a larger work, e.g. Clarke's treatment of the Cyperaceae in Hooker's The Flora of British India. The author of the validating description or diagnosis is the author of the publication, unless it is explicitly stated otherwise, which is rare (Art. 46 Note 5). So when Seemann wrote "G. tomentosum, Nutt. mss.", he ascribed the name to someone (Nuttall) who was not an author of the validating description or diagnosis (himself), and the name is therefore cited as G. tomentosum Nutt. ex Seem. (or just G. tomentosum Seem.) (Art. 46.5). When Clarke wrote "C. continua, C. B. Clarke", he ascribed the name to the author of the validating description or diagnosis (himself), and the name is therefore cited as C. continua C.B. Clarke (Art. 46.2) or, in a full bibliographic citation, C. continua C.B. Clarke in Hooker, Fl. Brit. India 6: 717. 1894 (Art. 46 Note 2).

\section{PARENTHETICAL (BASIONYM) AUTHOR CITATIONS}

For a new combination or name at new rank, the author of the basionym is cited in parentheses immediately before the author of the new name (Art. 49.1). For example, Smith is the author of the name at new rank, Drynaria (Bory) J. Sm., and Bory is the author of its basionym, Polypodium subg. Drynaria Bory. Or in the example above (p. 97), Klak is the author of the new combination, Cleretum clavatum (Haw.) Klak, and Haworth is the author of its basionym, Mesembryanthemum clavatum Haw. Such parenthetical authors are cited only when a name has a basionym, hence the alternative term, basionym author.

It follows, then, that for a replacement name the author of the replaced synonym is not cited in parentheses. For example, Ziziphus jujuba Mill., which is a replacement name for Rhamnus zizyphus L., is not cited as $Z$. jujuba "(L.) Mill." The same applies to a replacement name that re-uses the final epithet of its replaced synonym (explicitly permitted under Art. 58.1), e.g. Calandrinia polyandra Benth. is a replacement name for Talinum polyandrum Hook. 1855, which is an illegitimate later homonym of T. polyandrum Ruiz \& Pav. 1798; the author citation of C. polyandra is Benth., not "(Hook.) Benth."

Moreover, parenthetical authors are not cited for suprageneric names (Art. 49.2). For example, even though Illiciaceae A.C. Sm. 1947 was validly published by reference to Illicieae DC. 1824, and is a name at new rank, it is not cited as Illiciaceae "(DC.) A.C. Sm." 


\section{Standard author citations}

Whether one cites, e.g., "L.", "Linn.", "Linné", or "Linnaeus" is a matter of personal preference or editorial style. If you commonly abbreviate authors' names, you should follow the standard forms provided via the Author Query of the International Plant Names Index (IPNI), at https://www.ipni.org/ipni/authorsearchpage.do, which was originally based on Authors of plant names (Brummitt \& Powell, 1992) but has been extensively updated over the last 20 years. The index includes authors of fungal and algal names too. These standard forms are used in author citation throughout the Code (Rec. 46A Note 1). Note that these are not always abbreviations, hence standard forms, not "standard abbreviations".

If you do not abbreviate authors' names, adopting as a standard the main spelling given by IPNI is good practice. Remember that spellings vary, particularly when transcribed from, e.g., Cyrillic script or Chinese ideographs into the Latin alphabet. For example, consider the author who lived from 1864 to 1932 and for whom IPNI gives the main spelling as "Nicolai Ivanowicz Kusnezow" and the standard (abbreviated) form as "Kusn." IPNI also gives four alternative spellings for his family name: "Kusnetzou", "Kusnezov", "Kuznetzov", and "Kuznezov", and one alternative spelling for his patronym: "Ivanovitch". If you cite him in abbreviated form, you should write "Kusn."; if you spell out his family name, you should write "Kusnezow". 


\section{CHAPTER 10 | HOW TO SPELL NAMES}

It is often said that the "devil is in the details" and this certainly applies to orthography and gender, which seem to be the aspects of biological nomenclature that cause the most trouble for scientists. This is perhaps because they have practically nothing to do with science or the theoretical framework of nomenclature, but much to with linguistics. Indeed, orthography and gender have generated more than their fair share of proposals to amend the Code at previous International Botanical Congresses.

The rules on orthography and gender exist to promote correct and standardized spellings of new names and to facilitate correction and standardization, where needed, of existing names. Standardization of spellings (irrespective of linguistic correctness) has become very important over the last 25 years or so because of the advent of many large databases. Having the same name spelled in several different ways in a database could result in multiple records, thereby distorting statistics. Trying to merge databases involves linking the same names between the databases, but if they are spelled differently they will not readily link and this may have to be done manually, which can be extremely time consuming. Searching for names in a database requires you to know in advance the spelling, or at least the approximate spelling. Variations in spelling can be difficult to predict, and your search could fail to find a name even though it exists in the database.

Knowledge of the Latin language is no longer required in order to publish a name validly (because English is now permitted as an alternative to Latin for a validating description or diagnosis; Art. 39.2). Nevertheless, scientific names are largely derived from Latin (or Greek) and it therefore helps to develop a basic understanding of the linguistic elements involved in formulating scientific names. Two kinds of words are used: nouns and adjectives. These words are inflected, i.e. the terminations (endings) change, according gender, number, and case. There are three genders: masculine, feminine, and neuter; two numbers: singular and plural; and two cases that are used in scientific names: nominative and genitive. Understanding these basic elements will greatly help you follow the rules of the Code in formulating new names and in determining whether already published names are spelled correctly. The definitive work on the use of Latin in the scientific names of algae, fungi, and plants is William T. Stearn's Botanical Latin (Stearn, 1992), whereas if you are not already familiar with botanical Latin, a less formal introduction is A primer of botanical Latin with vocabulary (Short \& George, 2013).

Remember that a name can be validly published with an incorrect spelling. Errors in orthography and gender do not prevent effective or valid publication of names and do not affect the legitimacy, priority, or taxonomic application of names. Because creating new errors is worse than failing to correct existing ones, attempting to correct perceived orthographical errors is unwise unless you are confident that you understand the relevant rules. 


\section{The "golden rule" of orthography}

If there is a golden rule of orthography, it is that the original spelling of a name or epithet must be retained (Art. 60.1), except for the correction of typographical or orthographical errors and the standardizations imposed by the other rules on orthography. Original spelling means the spelling used in the protologue of the name or that of its basionym if it has one (Art. 60.2), disregarding typography (e.g. use of boldface, italics, upper- or lower-case letters, or different fonts). You should use the liberty of correcting a name with reserve, especially if the change affects the first syllable and, above all, the first letter of the name (Art. 60.3). In other words, only correct a spelling when the Code requires it.

\section{THE OTHER RULES ON ORTHOGRAPHY}

- Alphabet and form. Strictly speaking this is not orthography and it does affect valid publication: a name must be composed only of letters of the Latin alphabet and have a form that complies with the provisions of Art. 16-27 (Art. 32.1). These provisions are the rules on the formation of names discussed on pp. 48-54.

- Letters and ligatures foreign to classical Latin (Art. 60.4). The letters $k, w$, and $y$ are permissible in scientific names, but other letters and ligatures are to be transcribed (e.g. German $\beta$ to ss).

- Letters $u / v$ or $i / j$ used interchangeably or in any other way incompatible with modern typographical or nomenclatural practices (Art. 60.5 and 60.6). Such letters are to be transcribed in conformity with modern nomenclatural usage, e.g. "Vredo pustvlata" is to be spelled Uredo pustulata. When the diphthong ey (в) derived from Greek words is transcribed as $e v$, this is treated as an error correctable to eu, e.g. "Evonymus" is to be spelled Euonymus. When names or epithets of Latin but not Greek origin include the letter $i$ as a semi-vowel (followed by another vowel), this is treated as an error correctable to $j$, e.g. Brachypodium "iaponicum" is to be spelled Brachypodium japonicum.

- Diacritical signs and ligatures (Art. 60.7). Diacritical signs are not used in scientific names and are to be transcribed (e.g. $\ddot{a} \rightarrow a e ; \ddot{o} \rightarrow o e ; \ddot{u} \rightarrow u e ; e ́, \grave{e}, \hat{e} \rightarrow e$;

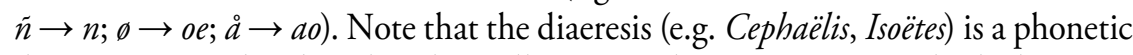
device not considered to alter the spelling; as such, its use is optional. The ligatures $a$ and $\alpha$ are to be replaced by the separate letters $a e$ and $o e$.

- Terminations (endings) (Art. 32.2). If a name has Latin or transcribed Greek termination that is against the rules, it is to be corrected without change of the author citation or date of the name (Art. 32.2). This includes suprageneric names 
with improper terminations (Art. 16.3, 18.4, and 19.7) and, among other errors, an adjectival epithet that does not agree in gender with the generic name (Art. 21.2, 23.5, and 24.2). For example, Aster "nigromontana" is correctable to A. nigromontanus because the generic name Aster is masculine. Also a correctable error is usage of the word element -cola as an adjective (Art. 23.5), e.g. Erigeron "alpicolus" is correctable to E. alpicola.

- Terminations of epithets honouring people (Art. 60.8 and Rec. 60C.1). The use of a termination (for example-i, -ii, -ae, -iae, -anus, or -ianus) contrary to Art. 60.8 is to be corrected to conform with it. However, terminations of epithets formed in accordance with Rec. 60C.1 are not to be corrected. For example, the epithet of Quercus michauxii was formed in accordance with Art. 60.8 and is not therefore to be changed. However, the epithet of Rhododendron "potanini" is contrary to Art. 60.8 and was not formed in accordance with Rec. 60C.1; it is therefore to be corrected to potaninii. On the other hand, the epithet of Phoenix theophrasti was formed in accordance with Rec. 60C.1 and is not therefore to be changed to "theophrastii" or anything else. See More on terminations of epithets honouring people, pp. 103-108.

- Intentional latinizations (Art. 60.9). The essence of this rule, and there are some exceptions, is that intentional latinizations of personal, geographical, or vernacular names are to be preserved. For example, Abies alcoquiana commemorates "Rutherford Alcock Esq.", implying an intentional latinization of Alcock to Alcoquius. The spelling must not be changed to "alcockiana".

- Compound epithets (Art. 60.10 and Rec. 60G.1). An adjectival epithet combining elements derived from two or more Greek or Latin words that is not formed in accordance with Art. 60.10 is to be corrected to conform with it (with some exceptions). For example, the epithet "cannaefolia" must be changed to cannifolia. See More on compound epithets, pp. 108-109.

- Hyphens (Art. 60.11 and 60.12). In a compound epithet, a hyphen is treated as an error to be corrected by deletion of the hyphen, e.g. Acer "pseudo-platanus" and Scirpus sect. "Pseudo-eriophorum" are to be spelled Acer pseudoplatanus and Scirpus sect. Pseudoeriophorum. A hyphen is permitted only when the epithet is formed of words that usually stand independently, e.g. Vitis novae-angliae (of New England), or when the letters before and after the hyphen are the same, e.g. Athyrium austrooccidentale. Note that if an epithet consists of two or more words, Art. 23.1 rules that they are to be united or hyphenated in accordance with Art. 60.11, e.g. Coix "lacryma jobi", originally published with a space but no hyphen, in which the two words usually stand independently (Job's tears), is to be spelled Coix lacryma-jobi. When a generic name is published with a hyphen, the hyphen is to be retained (Art. 60 Note 6), unless it is the name of a fossil-genus, when the hyphen is always to be deleted (Art. 60.12). 
- Apostrophes, quotation marks, and full stops (periods) (Art. 60.13). When an apostrophe or quotation mark is used in an epithet, it is to be deleted, e.g. $L y$ cium "o'donellii" is to be spelled Lycium odonellii. However, if it follows the letter $m$ to represent the patronymic prefix $\mathrm{Mc}_{\mathrm{c}}$ or $\mathrm{M}^{c}$, it is replaced by the letter $c$, e.g. "Stobaea M"Kenii" is to be spelled Stobaea mckenii. When a full stop is used in an epithet that is derived from a personal or geographical name that contains this full stop, the epithet is to be expanded (see Abbreviations, below) or, if nomenclatural tradition does not support expansion, the full stop is to be deleted, e.g. Nesoluma "St.-Johnianum" is to be spelled Nesoluma st-johnianum.

- Abbreviations (Art. 60.14). Abbreviated names and epithets are to be expanded in conformity with nomenclatural tradition, e.g. Allium "a.-bolosii" is to be spelled Allium antonii-bolosii.

- Epithets of fungal names (Art. F.9.1). When derived from the generic name of an associated organism, epithets are to be spelled in accordance with the accepted spelling of the name of that organism. For example, Phyllachora "anonicola" is to be corrected to Phyllachora annonicola because the accepted spelling of the name of the associated organism is Annona, not "Anona".

\section{MORE ON TERMINATIONS OF EPITHETS HONOURING PEOPLE}

Article 60.8, concerning terminations of epithets that honour people, can be explained as follows: When a specific or infraspecific epithet that is derived from a personal name is formed in accordance with Art. 60.8, it cannot be changed. When it is contrary to Art. 60.8, it must be corrected so that it accords, unless it was formed in accordance with Rec. 60C.1, in which case, again, it cannot be changed.

Article 60.8 concerns the formation of specific and infraspecific epithets that are derived from unlatinized personal names. For example, michauxii and potaninii derive from the unlatinized personal names Michaux and Potanin. Two kinds of epithets are possible: substantival ones, i.e. nouns, in the genitive case (michauxii, potaninii) and adjectival ones, in the nominative case (michauxianus, potaninianus). Substantival epithets must agree in gender and number with the persons being honoured (masculine or feminine, singular or plural), whereas adjectival epithets must agree in gender with the generic name (masculine, feminine, or neuter, singular). This agreement is achieved by using the appropriate Latin termination. Both kinds of epithets are formed by adding a termination to the unlatinized personal name, with or without minor modifications depending on whether the personal name ends in $-a$, another vowel $(-e,-i,-o,-u,-y)$, -er, or a consonant (but not -er). These rules are set out in Art. 60.8, but may also be "keyed out" as follows: 


\section{Key to forming epithets honouring people who have unlatinized personal names}

1a. Epithet is an adjective:

2a. Personal name ends in a consonant:

3a. Gender of generic name is masculine: add -ianus

3b. Gender of generic name is feminine: add -iana

3c. Gender of generic name is neuter: add -ianum

2b. Personal name ends in a vowel:

4a. Personal name ends in - $a$ :

5a. Gender of generic name is masculine: add -nus

5b. Gender of generic name is feminine: add -na

5c. Gender of generic name is neuter: add -num

4b. Personal name ends in $-e,-i,-0,-u$, or $-y$ :

6a. Gender of generic name is masculine: add -anus

6b. Gender of generic name is feminine: add -ana

6c. Gender of generic name is neuter: add -anum

1b. Epithet is a noun in the genitive case:

7a. Personal name ends in a consonant (but not -er):

8a. One person is being honoured:

9a. Person is male: add -ii

9b. Person is female: add -iae

8b. Two or more people are being honoured:

10a. At least one person is male: add -iorum 
10b. All people are female: add -iarum

7b. Personal name ends in a vowel or -er:

11a. Personal name ends in $-a$ :

12a. One person is being honoured (male or female): add -e

12b. Two or more people are being honoured (male or female): add -rum

11b. Personal name ends in $-e,-e r,-i,-0,-u$, or $-y$ :

13a. One person is being honoured:

14a. Person is male: add $-i$

14b. Person is female: add -ae

13b. Two or more people are being honoured:

15a. At least one person is male: add -orum

15b. All people are female: add -arum

The epithet of Quercus michauxii is derived from the personal name, Michaux, as a genitive noun. The key above gives michauxii (1b, 7a, 8a, 9a). The termination -ii is in accordance with Art. 60.8 and is not therefore to be changed. Similarly, Rhododendron "potanini" is derived from the personal name, Potanin. The key above would give potaninii (again, $1 \mathrm{~b}, 7 \mathrm{a}, 8 \mathrm{a}, 9 \mathrm{a}$ ). The termination $-i$ is contrary to Art. 60.8 and is therefore treated as an error to be corrected.

Not all epithets derived from personal names are to be formed according to Art. 60.8, though. If a personal name is already in Greek or Latin, or if it possesses a well-established latinized form, Rec. 60C.1 applies and that name should be given its appropriate Latin genitive to form a substantival epithet. For example, the personal names Linnaeus and Theophrastus are already in Latin (nominative case), so Rec. 60C.1 applies to them. They are given their appropriate Latin genitive to form substantival epithets: linnaei and theophrasti. When considering whether an epithet such as theophrasti requires correction, remember that according to Art. 60.8 terminations of epithets formed in accordance with Rec. 60C.1 are not to be corrected.

Elisabeth and Martin are examples of personal names possessing a well-established latinized form, i.e. Elisabetha and Martinus, respectively. When their appropriate Latin 


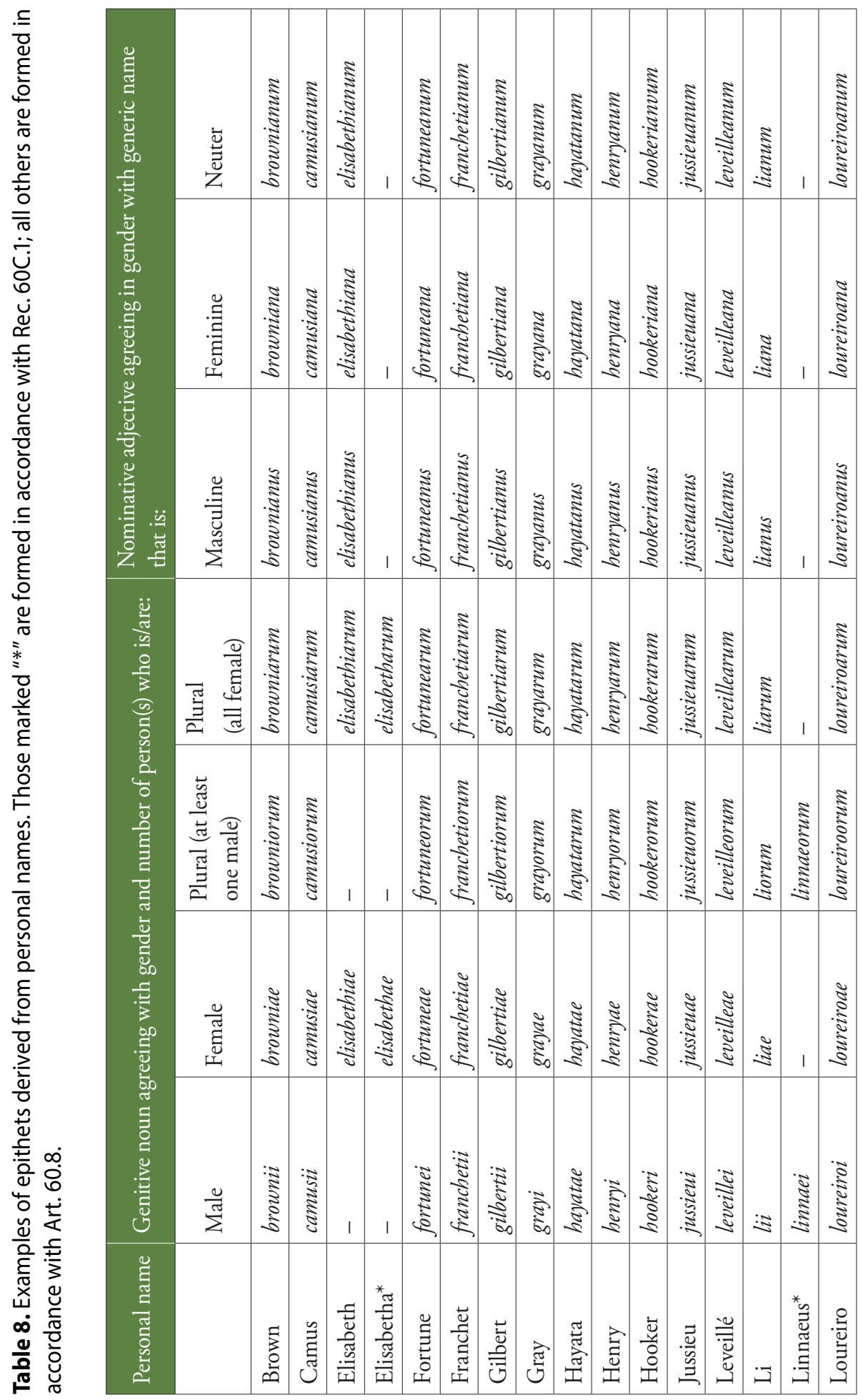




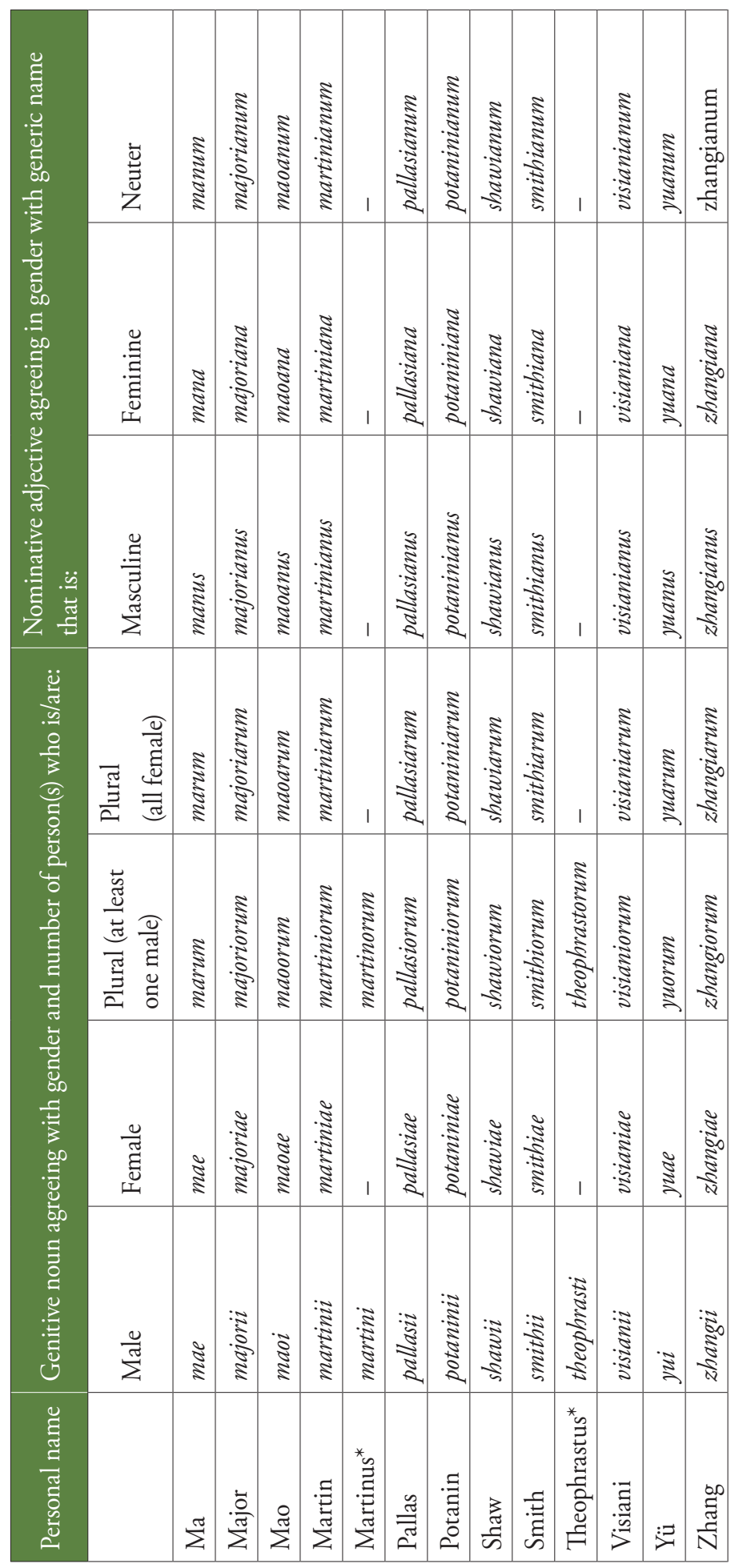


genitives are used to form substantival epithets under Rec. 60C.1, the result is elisabethae and martini. Again, the terminations of epithets formed in accordance Rec. 60C.1 are not to be changed.

On the other hand, if the epithets were published as elisabethiae and martinii, they could not have been formed in accordance with Rec. 60C.1 (because "Elisabethia" and "Martinius" do not exist) and they would not be contrary to Art. 60.8. Therefore, once again, Art. 60.8 would not permit them to be changed. It is confusing, but any of the epithets martini, martinii, elisabethae, and elisabethiae can be correct.

Table 8 (pp. 106-107) gives several examples of epithets derived from personal names and formed in accordance with either Art. 60.8 or Rec. 60C.1.

Finally, beware of some epithets that may appear to be derived from personal names but in fact are not. In these cases, Art. 60.8 does not apply at all. Examples include $A s-$ paragus tamaboki Yatabe 1893, where the epithet is derived from a Japanese vernacular name "tamaboki"; Paeonia emodi Wall. ex Royle 1834, where emodi is the genitive of Emodus, the name by which the Romans and Greeks knew the Himalaya; and Uladendron codesuri Marc.-Berti 1971, which is derived from an acronym, CODESUR (Comisión para el Desarrollo del Sur de Venezuela).

\section{MORE ON COMPOUND EPITHETS}

Article 60.10 concerns the formation of adjectival epithets that combine elements derived from two or more Greek or Latin words. Epithets not formed in accordance with this rule must be corrected to conform with it, unless Rec. 60G applies (see Pseudocompounds, p. 109). Remember that Art. 60.10 concerns only epithets (not generic names), and only adjectival epithets, and applies only when the elements are derived from Greek or Latin words. For example, in Andromeda polifolia L., the epithet is actually a noun (the pre-Linnaean generic designation "Polifolia"); it is not therefore to be changed to "poliifolia". This is not apparent without analysis of the protologue. You should always check the protologue in case the derivation is not as you initially assume. The epithet in Tetragonia tetragonoides (Pall.) Kuntze is derived from a noun (the generic name Tetragonia) and a suffix (-oides), not from two Greek or Latin words (a suffix is not a word); it is not therefore to be changed to "tetragonioides".

A regular compound epithet contains a noun or adjective in a non-final position, e.g. aquilegiifolia, which means Aguilegia-leaved. Aquilegia is a noun in a non-final position. The case ending, -ae, of the genitive singular, Aquilegiae, is removed, giving aquilegi-, to which is added a connecting vowel, $-i$-, and the ending, -folia.

The connecting vowel is only used before a consonant and is $-i$ - when the elements of the compound are Latin or -o- when they are Greek. Mixed compounds, with one 
element Latin and the other Greek are discouraged (Rec. 23A.3(c)) but are not errors to be corrected, e.g. we cannot correct the epithet of Chomelia grandicarpa, which compounds Latin for large and Greek for fruit, to the all-Greek macrocarpa.

\section{Pseudocompounds}

A pseudocompound contains a noun or adjective in a non-final position as the whole word inflected with a case ending (Rec. 60G.1(b)). For example, the epithet albomarginatus means margined with white. Here album (white) is a noun in a non-final position. It appears as the whole word in the ablative case, albo (implying "with white"), followed by the adjective marginatus (margined).

Under Art. 60.11, the use in a pseudocompound of the genitive singular case ending of a Latin first-declension noun instead of a connecting vowel is treated as an error to be corrected, unless it makes a semantic distinction. For example, the pseudocompound epithet tubaeformis is derived from tuba (trumpet), a Latin first-declension noun, of which the genitive singular is tubae. The regular compound under Art. 60.10 would be tubiformis, but that would be identical with the regular compound tubiformis derived from tubus (tube, genitive singular tubi). Because the epithet tubaeformis makes a semantic distinction between tuba and tubus, it is not an error to be corrected. On the other hand, the genitive singular of Aquilegia, another Latin first-declension noun, is Aquilegiae, which would give "aquilegiaefolia" in a pseudocompound. Because in this case no semantic distinction is being made, the epithet must be corrected to the regular compound form, aquilegiifolia.

\section{ORTHOGRAPHICAL VARIANTS}

Orthographical variants are dealt with under Art. 61. They are defined in Art. 61.2 as the various spelling, compounding, and inflectional forms of a name or its final epithet (including typographical errors) when only one nomenclatural type is involved. Only one orthographical variant of any one name is treated as validly published: the form that appears in the original publication, i.e. the protologue (Art. 61.1); all the others are to be corrected to the validly published form of that name and treated as if they appeared in that corrected form (Art. 61.4). Of course, the orthographical variant that appears in the original publication may itself be subject to corrections in spelling as discussed under orthography above, or its spelling may require correction to match that of the basionym (see Art. 6.10) or, for a fungal name, that in the sanctioning work (Art. F.3.2). It is also possible to conserve a name under Art. 14.11 to preserve a particular spelling (see Chapter 8).

Orthographical variants can appear to be separate names when published at different times by different authors, but under the Code the later variants are merely later usages of the earlier name and have no nomenclatural status. They may be cited in quotation 
marks, appropriate to their status as a designation rather than a name (i.e. not validly published), and are sometimes cited (though not in the Code) as "orth. var." Confusingly similar names based on the same type are treated as orthographical variants (Art. 61.5). For example, Nelumbo Adans. 1763 and "Nelumbium" (Jussieu, 1789: 68) are spelling forms of a generic name based on Nymphaea nelumbo L., and are treated as orthographical variants. Even if Jussieu's "Nelumbium" had been intended as a new name, it was confusingly similar to Nelumbo and was based on the same type; hence it is treated as an orthographical variant. In effect, Jussieu used Adanson's name, albeit with a correctable spelling mistake.

Occasionally the original publication may contain more than one orthographical variant. In such cases, Art. 61.3 rules on which one is to be retained: the one that conforms to the rules and best suits the recommendations of Art. 60. However, if the variants conform and suit equally well, a nomenclatural act decides which variant is to be retained, i.e. the first choice appearing in an effectively published text, in which an author explicitly adopts one of the variants and rejects the other(s).

\section{GENDER}

All generic names have a gender: masculine, feminine, or neuter. This is significant because adjectival epithets in the names of subdivisions of genera, species, and infraspecific taxa must agree in gender with the generic name (Art. 21.2, 23.5, and 24.2). If they do not, the names are validly published but the terminations of the epithets are to be corrected without change of the author citation or date of the name (Art. 32.2). Of course, it is quite possible for there to be no adjectival epithets among the names of the subordinate taxa of some small genera.

There are some general trends that are worth remembering. Names ending in -us (e.g. Agaricus, Astragalus) tend to be masculine, unless they are names of trees, in which case they tend to be feminine (Aesculus, Prunus, Quercus, Ulmus). Names ending in - $a$ and -is are nearly always feminine (Rosa, Yucca; Cannabis, Orchis), unless they end in -ma, in which case they tend to be neuter (Alisma, Melastoma). Names ending in -um are always neuter (Allium, Lilium).

The rules on gender are in Art. 62 of the Code. The basic rule is Art. 62.1, which states that a generic name retains the gender assigned by nomenclatural tradition. The gender of nomenclatural tradition usually, but not always, coincides with the classical gender of the corresponding Greek or Latin word, if any, e.g. Quercus L. 1753 is feminine in nomenclatural tradition and the classical gender of the Latin word quercus (oak) is also feminine. If the classical usage of the name or the author's original usage of the name is different, it does not override the nomenclatural tradition. If there is no nomenclatural tradition, the generic name retains the gender assigned by its original author (also Art. 62.1). 
Arbitrarily formed generic names, vernacular names used as generic names, or adjectives used as generic names also take the gender assigned by the original author (Art. 62.3). If that author did not indicate the gender, a subsequent author may choose a gender, and the first such choice, if effectively published, is a nomenclatural act and must be followed.

There are exceptions, which comprise the remaining rules of Art. 62. Compound generic names take the gender of the last word in the nominative case in the compound (Art. 62.2), e.g. the gender of Parasitaxus de Laub. 1972 is feminine because the gender of Taxus L. 1753 is feminine. There are also certain endings of generic names that always take either masculine, feminine, or neuter gender. These are listed in Table 9 alongside the relevant Article numbers.

It is also possible to conserve a name under Art. 14.11 to preserve a particular gender (see Chapter 8).

Table 9. Endings of generic names that always take a particular gender.

\begin{tabular}{|l|l|l|l|l|l|}
\hline Masculine & Article & Feminine & Article & Neuter & Article \\
\hline -anthos & $62.2(\mathrm{c})$ & -achne & $62.2(\mathrm{~b})$ & -ceras & $62.2(\mathrm{c})$ \\
\hline -anthus & $62.2(\mathrm{c})$ & -anthes & 62.4 & -dendron & $62.2(\mathrm{c})$ \\
\hline -botrys & $62.2(\mathrm{a})$ & -chlamys & $62.2(\mathrm{~b})$ & -nema & $62.2(\mathrm{c})$ \\
\hline -cheilos & $62.2(\mathrm{c})$ & -daphne & $62.2(\mathrm{~b})$ & -stigma & $62.2(\mathrm{c})$ \\
\hline -chilos & $62.2(\mathrm{c})$ & -glochin & $62.2(\mathrm{~b})$ & -stoma & $62.2(\mathrm{c})$ \\
\hline -chilus & $62.2(\mathrm{c})$ & -mecon & $62.2(\mathrm{~b})$ & & \\
\hline -codon & $62.2(\mathrm{a})$ & -odes & 62.4 & & \\
\hline -gaster & $62.2(\mathrm{~b})$ & -oides & 62.4 & & \\
\hline -ites & 62.4 & -osma & $62.2(\mathrm{~b})$ & & \\
\hline -myces & $62.2(\mathrm{a})$ & & & & \\
\hline -odon & $62.2(\mathrm{a})$ & & & & \\
\hline -panax & $62.2(\mathrm{a})$ & & & & \\
\hline -phycos & $62.2(\mathrm{c})$ & & & & \\
\hline -phycus & $62.2(\mathrm{c})$ & & & & \\
\hline -phykos & $62.2(\mathrm{c})$ & & & & \\
\hline -pogon & $62.2(\mathrm{a})$ & & & & \\
\hline -stemon & $62.2(\mathrm{a})$ & & & & \\
\hline
\end{tabular}




\section{CHAPTER 11 | NAMES OF ALGAE, FUNGI, FOSSILS, AND HYBRIDS, AND OF GROUPS NOT COVERED BY THE CODE}

The following three sections discuss the rules and recommendations of the Code that apply only to algae, fungi, and fossils. Table 10 (pp. 114-116) summarizes some of the more important rules and compares them with the corresponding rules for plants.

\section{ALGAE}

\section{Blue-green algae (Cyanobacteria)}

The blue-green algae (Cyanobacteria, Cyanophyta, cyanoprokaryotes) present problems, because their nomenclature is covered not only by the International Code of Nomenclature for algae, fungi, and plants but also by the International Code of Nomenclature of Prokaryotes. For further details, see p. 128.

\section{Starting-points}

The nomenclatural starting-points for algae (Art. 13.1(e)) are as follows:

- All groups, except those listed below, 1 May 1753, Species plantarum, ed. 1 (Linnaeus, 1753).

- Desmidiaceae (s.l.), 1 January 1848, The British Desmidieae (Ralfs, 1848).

- Nostocaceae heterocysteae, 1 January 1886, "Révision des Nostocacées hétérocystées" (Bornet \& Flahault, 1886-1888). The four parts are treated as having been published simultaneously on 1 January 1886. The Nostocaceae heterocysteae relate to groups of Cyanobacteria, essentially the Nostocales.

- Nostocaceae homocysteae, 1 January 1892, "Monographie des Oscillariées" (Gomont, 1892-1893). The two parts are treated as having been published simultaneously on 1 January 1892. The Nostocaceae homocysteae relate to groups of Cyanobacteria, essentially the Oscillatoriales.

- Oedogoniaceae, 1 January 1900, "Monographie und Iconographie der Oedogoniaceen" (Hirn, 1900). 


\section{Formation of names}

The formation of algal names above the rank of family differs in two cases from that of plant and fungal names. The name of a class ends in -phyceae and that of a subclass ends in -phycidae (Art. 16.3; see Table 5, p. 51). Names not in accordance with these terminations are to be corrected, unless they are published with a non-Latin termination, in which case they are not validly published.

\section{Language of validating description or diagnosis}

The algae have different dates to fungi and plants for the implementation of the rules concerning the language of the validating description or diagnosis. For a name of a new taxon of non-fossil algae published before 1958, the description or diagnosis may be in any language. Between 1 January 1958 and 31 December 2011, inclusive, the description or diagnosis must be in Latin (Art. 44.1). On and after 1 January 2012, algae joined all other taxonomic groups treated under the Code in requiring the description or diagnosis to be in either Latin or English (Art. 39.2).

\section{Validating illustration}

For valid publication of a name of a new taxon of non-fossil algae of specific or lower rank published on or after 1 January 1958, an illustration is required (Art. 44.2) in addition to a description or diagnosis. The name must be accompanied by an illustration or figure that shows the distinctive morphological features, or by a reference to a previously and effectively published illustration or figure that shows the distinctive morphological features.

\section{Type}

Valid publication requires indication of the type for all names of new taxa at the rank of genus or below published on or after 1 January 1958 (Art. 40.1); this applies in all groups, not only algae. For names of new species or infraspecific taxa published before 2007, it was permitted for that type to be a specimen or an illustration. A specimen could be, e.g., a microscopic preparation, a dried culture, or a specimen collected from nature. For such names published on or after 1 January 2007, the type-i.e. the holotype-must be a specimen (Art. 40.4) and not an illustration. An exception is made for names of microscopic algae, for which the holotype may be an effectively published illustration if there are technical difficulties of preservation or if it is impossible to preserve a specimen that would show the features attributed to the taxon by the author of the name (Art. 40.5). Note that for names of fossil-taxa, including fossil algae (but excluding diatoms), the type must always be a specimen (Art. 8.5).

Even though the type of a name may not be a living organism or culture, the type of an algal name may be a culture provided that it is preserved in a metabolically inactive state, e.g. by lyophilization or deep-freezing to remain alive in that inactive state (Art. 
Table 10. Comparison of important rules that apply differently to algae, fungi, plants, and fossils.

\begin{tabular}{|c|c|c|c|c|}
\hline & Algae & Fungi & Plants & Fossils \\
\hline 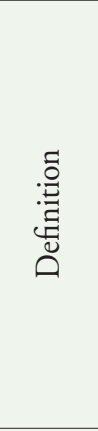 & $\begin{array}{l}\text { Including blue- } \\
\text { green algae and } \\
\text { photosynthetic } \\
\text { protists with their } \\
\text { taxonomically } \\
\text { related non- } \\
\text { photosynthetic } \\
\text { groups; diatoms } \\
\text { are included }\end{array}$ & $\begin{array}{l}\text { All organisms } \\
\text { traditionally } \\
\text { treated as fungi, } \\
\text { including } \\
\text { lichen-forming } \\
\text { fungi, chytrids, } \\
\text { oomycetes, and } \\
\text { slime moulds; } \\
\text { Microsporidia are } \\
\text { excluded }\end{array}$ & $\begin{array}{l}\text { Vascular plants } \\
\text { (spermatophytes } \\
\text { and pteridophytes) } \\
\text { and bryophytes } \\
\text { (mosses, liver- } \\
\text { worts, and horn- } \\
\text { worts) }\end{array}$ & $\begin{array}{l}\text { Fossils of algae, } \\
\text { fungi, or plants; } \\
\text { diatoms are ex- } \\
\text { cluded }\end{array}$ \\
\hline 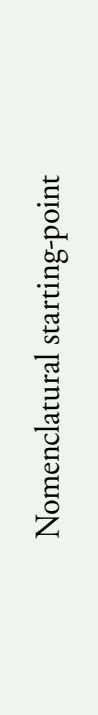 & $\begin{array}{l}1 \text { May 1753; } \\
\text { exceptions: } 1 \\
\text { January } 1848 \text { for } \\
\text { Desmidiaceae (s.l.); } \\
1 \text { January } 1886 \\
\text { for Nostocaceae } \\
\text { heterocysteae; } 1 \\
\text { January } 1892 \\
\text { for Nostocaceae } \\
\text { homocysteae; } 1 \\
\text { January } 1900 \text { for } \\
\text { Oedogoniaceae } \\
\text { (Art. 13.1(e); see } \\
\text { p. 112) }\end{array}$ & $\begin{array}{l}1 \text { May } 1753 \text { (Art. } \\
\text { F.1.1; see p. } 117 \text { ) }\end{array}$ & $\begin{array}{l}1 \text { May 1753; } \\
\text { exceptions: } 4 \\
\text { August } 1789 \\
\text { for suprageneric } \\
\text { names of vascular } \\
\text { plants and certain } \\
\text { bryophytes } \\
\text { (Sphagnaceae } \\
\text { and Hepaticae, } \\
\text { including } \\
\text { Anthocerotae); } \\
1 \text { January } 1801 \\
\text { for all names of } \\
\text { mosses (except } \\
\text { Sphagnaceae) (Art. } \\
\text { 13.1(a-c); see p. } \\
\text { 130) }\end{array}$ & $\begin{array}{l}31 \text { December } \\
1820 \text { (Art. 13.1(f); } \\
\text { see p. 122) }\end{array}$ \\
\hline 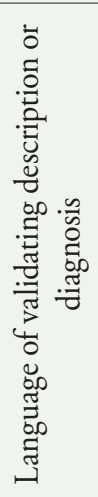 & $\begin{array}{l}\text { For names of new } \\
\text { taxa published } \\
\text { 1753-1957: any } \\
\text { language (Art. } \\
\text { 44.1) } \\
\text { 1958-2011: Latin } \\
\text { (Art. 44.1) } \\
2012 \text { onward: } \\
\text { Latin or English } \\
\text { (Art. 39.2) }\end{array}$ & $\begin{array}{l}\text { For names of new } \\
\text { taxa published } \\
\text { 1753-1934: any } \\
\text { language (Art. } \\
\text { 39.1) } \\
\text { 1935-2011: Latin } \\
\text { (Art. 39.1) } \\
\text { 2012 onward: } \\
\text { Latin or English } \\
\text { (Art. 39.2) }\end{array}$ & Same as for fungi & $\begin{array}{l}\text { For names of new } \\
\text { taxa published } \\
\text { 1753-1995: any } \\
\text { language (Art. } \\
\text { 43.1) } \\
1996 \text { onward: } \\
\text { Latin or English } \\
\text { (Art. 43.1) }\end{array}$ \\
\hline
\end{tabular}




\begin{tabular}{|c|c|c|c|c|}
\hline & Algae & Fungi & Plants & Fossils \\
\hline 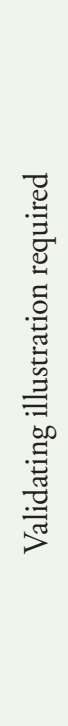 & $\begin{array}{l}\text { For names of } \\
\text { new species and } \\
\text { infraspecific taxa } \\
\text { published } 1958 \\
\text { onward (Art. } \\
44.2 \text { ) }\end{array}$ & Never & Never & $\begin{array}{l}\text { For names of new } \\
\text { fossil-genera and } \\
\text { lower-ranked fos- } \\
\text { sil-taxa published } \\
1912 \text { onward } \\
\text { (Art. 43.2) } \\
\text { For names of new } \\
\text { fossil-species and } \\
\text { infraspecific fos- } \\
\text { sil-taxa published } \\
2001 \text { onward: at } \\
\text { least one validat- } \\
\text { ing illustration } \\
\text { must be identified } \\
\text { as representing } \\
\text { type specimen } \\
\text { (Art. 43.3) }\end{array}$ \\
\hline 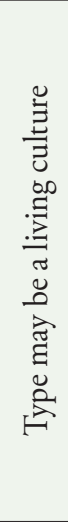 & $\begin{array}{l}\text { Only if preserved } \\
\text { in metabolically } \\
\text { inactive state (Art. } \\
8.4 \text { ) } \\
\text { This must } \\
\text { be stated in } \\
\text { protologue of } \\
\text { names of new } \\
\text { species and } \\
\text { infraspecific taxa } \\
\text { published 2019 } \\
\text { onward (Art. 40.8) }\end{array}$ & $\begin{array}{l}\text { Only if preserved } \\
\text { in metabolically } \\
\text { inactive state (Art. } \\
8.4 \text { ) } \\
\text { This must be } \\
\text { stated in proto- } \\
\text { logue of names of } \\
\text { new species and } \\
\text { infraspecific taxa } \\
\text { published } 2019 \\
\text { onward (Art. } \\
40.8 \text { ) }\end{array}$ & Never & Not possible \\
\hline 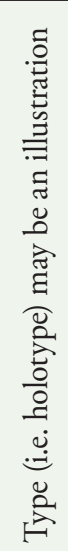 & $\begin{array}{l}\text { For names of } \\
\text { new species and } \\
\text { infraspecific taxa } \\
\text { published } 1753- \\
2006 \text { (Art. } 40.4 \text { ) } \\
2007 \text { onward only } \\
\text { under special cir- } \\
\text { cumstances (Art. } \\
40.5 \text {; see p. } 113 \text { ) }\end{array}$ & $\begin{array}{l}\text { For names of new } \\
\text { species and infra- } \\
\text { specific taxa pub- } \\
\text { lished 1753-2006 } \\
\text { (Art. 40.4) } \\
2007 \text { onward only } \\
\text { under special cir- } \\
\text { cumstances (Art. } \\
40.5 \text {; see p. 118) }\end{array}$ & $\begin{array}{l}\text { Only for names of } \\
\text { new species and } \\
\text { infraspecific taxa } \\
\text { published 1753- } \\
2006 \text { (Art. 40.4) }\end{array}$ & Never (Art. 8.5) \\
\hline
\end{tabular}




\begin{tabular}{|c|c|c|c|c|}
\hline & Algae & Fungi & Plants & Fossils \\
\hline 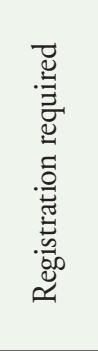 & $\begin{array}{l}\text { Not under } \\
\text { Shenzhen Code }\end{array}$ & $\begin{array}{l}\text { For all new names } \\
\text { published } 2013 \\
\text { onward (Art. } \\
\text { F.5.1) } \\
\text { For type designa- } \\
\text { tions published } \\
2019 \text { onward (Art. } \\
\text { F.5.4) }\end{array}$ & $\begin{array}{l}\text { Not under Shen- } \\
\text { zhen Code }\end{array}$ & $\begin{array}{l}\text { Fossil fungi: same } \\
\text { as for fungi } \\
\text { Fossil algae and } \\
\text { fossil plants: not } \\
\text { under Shenzhen } \\
\text { Code }\end{array}$ \\
\hline 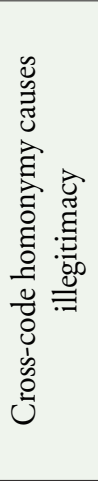 & $\begin{array}{l}\text { Only under Art. } \\
54.1 \text { (see pp. } \\
128-129 \text { ) }\end{array}$ & $\begin{array}{l}\text { New names of } \\
\text { fungi published } \\
2019 \text { onward are } \\
\text { illegitimate if } \\
\text { later homonyms } \\
\text { of prokaryotic or } \\
\text { protozoan names } \\
\text { (Art. F.6.1) } \\
\text { Art. } 54.1 \text { also } \\
\text { applies (see pp. } \\
\text { 128-129) }\end{array}$ & $\begin{array}{l}\text { Only under Art. } \\
54.1 \text { (see pp. } \\
128-129 \text { ) }\end{array}$ & $\begin{array}{l}\text { Fossil fungi: same } \\
\text { as for fungi } \\
\text { Fossil algae and } \\
\text { fossil plants: only } \\
\text { under Art. 54.1 } \\
\text { (see pp. 128-129) }\end{array}$ \\
\hline
\end{tabular}

8.4). Living cultures derived from such a preserved type are referred to as "ex-type" (Rec. 8B.2). For names of new species or infraspecific taxa published on or after 1 January 2019, if the type is a culture, the protologue must include a statement that the culture is preserved in a metabolically inactive state (Art. 40.8).

\section{Registration}

Registration is not yet mandatory for names of algae, although a mechanism is in place (Art. 42) for nomenclatural repositories to become recognized under the Code (see pp. $47-48$.

\section{FUNGI}

Major changes were made to the Code at the Shenzhen Congress of 2017 with respect to the nomenclature of organisms treated as fungi. The two main changes were the decision to move all the provisions of the Code that deal solely with names of fungi to a separate section, Chapter F. The second was that the provisions of Chapter F can be amended only by an International Mycological Congress (IMC), whereas the provisions of the rest of the Code can be amended (as before) only by an International Botanical Congress (IBC). The decisions of the IMC are binding on the subsequent IBC, except that the Editorial Committee can make editorial adjustments (see Chapter 13). 
If you are working in mycology, do remember that Chapter $\mathrm{F}$ consists of those provisions of the Code that deal solely with names of fungi. But most of the other provisions of the Code deal with names of fungi just as much as they do with names of algae and plants. Therefore, never think that you only need to learn Chapter F. The introduction to Chapter $\mathrm{F}$ includes this emphatic reminder as well as an annotated list of particularly relevant provisions in other parts of the Code.

IMCs are held every four years, e.g. 2018, 2022, and 2026, whereas IBCs are held every six years, e.g. 2017, 2023, and 2029. Therefore, one or two IMCs are held between consecutive IBCs. Changes to Chapter F resulting from an IMC that has been held since the previous IBC are shown in the online version of the Code, incorporated in such a way that it is clear that they originated from a specific IMC. A revised version of Chapter $\mathrm{F}$ is also published separately in IMA Fungus. The key changes resulting from the San Juan IMC of 2018 were summarized by May \& al. (2018) and are also included in the present guide.

\section{Lichens}

Lichens are fungi for nomenclatural purposes, in that names given to lichens apply to their fungal component (Art. F.1.1). A lichen is a fungus containing algae or blue-green algae (Cyanobacteria), or both, and those partners have separate scientific names.

\section{Starting-point}

The nomenclatural starting-point for fungi (Art. F.1.1) is now 1 May 1753, i.e. Species plantarum, ed. 1 (Linnaeus, 1753), but prior to the Sydney Congress of 1981 later dates were used for certain groups. Note that names in certain fungal groups are sanctioned (see pp. 119-120).

\section{Formation of names}

The formation of fungal names above the rank of family differs somewhat from that of plant and algal names. The name of a division or phylum ends in -mycota, that of a subdivision or subphylum in -mycotina, that of a class in -mycetes, and that of a subclass in -mycetidae (Art. 16.3; see Table 5, p. 51). Names not in accordance with these terminations are to be corrected, unless they are published with a non-Latin termination, in which case they are not validly published.

\section{Type}

Valid publication requires indication of the type for all names of new taxa at the rank of genus or below published on or after 1 January 1958 (Art. 40.1); this applies in all groups, not only fungi. For names of new species or infraspecific taxa published before 2007, it was permitted for that type to be a specimen or an illustration. A specimen 
could be, e.g., a microscopic preparation, a dried culture, or a specimen collected from nature. For such names published on or after 1 January 2007, the type-i.e. the holotype-must be a specimen (Art. 40.4) and not an illustration. An exception is made for names of microfungi, for which the holotype may be an effectively published illustration if there are technical difficulties of preservation or if it is impossible to preserve a specimen that would show the features attributed to the taxon by the author of the name (Art. 40.5). Note that for names of fossil-taxa, including fossil fungi, the type must always be a specimen (Art. 8.5).

Even though the type of a name may not be a living organism or culture, the type of a fungal name may be a culture provided that it is preserved in a metabolically inactive state, e.g. by lyophilization or deep-freezing to remain alive in that inactive state (Art. 8.4). Living cultures derived from such a preserved type are referred to as "ex-type" (Rec. 8B.2). For names of new species or infraspecific taxa published on or after 1 January 2019, if the type is a culture, the protologue must include a statement that the culture is preserved in a metabolically inactive state (Art. 40.8).

\section{Registration}

New names of fungi published on or after 1 January 2013 must be registered in order to be validly published (Art. F.5.1). Registration is achieved by citing in the protologue the identifier issued for the name by a recognized repository (see Fig. 4, p. 36). This requirement applies to names of new taxa, new combinations, names at new ranks, and replacement names of all organisms treated as fungi, including fossil fungi and lichen-forming fungi, at all ranks.

Under Art. F.5.3, a "recognized repository" is one appointed by the Nomenclature Committee for Fungi (see pp. 143-145). The Committee also has the power to cancel such an appointment or even to set aside the requirements for registration should the system cease to function. These decisions are subject to ratification by a subsequent International Mycological Congress. A repository is defined as one or more localized or decentralized, open and accessible electronic repositories to accession the information required by Art. F.5.2 and issue the identifiers required by Art. F.5.1. An identifier is an identification number or code associated with the record of a particular name in a nomenclatural database, often called a Life Science Identifier (LSID).

There are currently three recognized repositories: MycoBank (http://www.mycobank. org/), Index Fungorum (http://www.indexfungorum.org/), and Fungal Names (http:// www.fungalinfo.net/).

Type designations published on or after 1 January 2019 will also have to be registered in order to be effective (Art. F.5.4). This means designations of lectotypes, neotypes, epitypes, and their equivalents for the names of genera and subdivisions of genera, but not type designations in the protologues of names of new taxa (e.g. holotypes), which 
are covered already by Art. F.5.1. The registration procedure is similar to that for new names: the identifier issued for the typification by the recognized repository must be cited with the type designation (see Fig. 20, p. 78).

Should you cite an identifier incorrectly, it can in some cases be treated as a correctable error, not affecting valid publication of a name or designation of a type (Art. F.5.6-F.5.8, added to Chapter F at the San Juan Congress of 2018).

\section{Homonyms}

A name of a taxon treated as a fungus published on or after 1 January 2019 is illegitimate if it is a later homonym of a prokaryotic or protozoan name (Art. F.6.1). You can check if your proposed new fungal name could be a later homonym by searching an inter-kingdom database such as the Catalogue of Life (http://www.catalogueoflife.org). A simple web search can also help to find if a name has already been published.

\section{Sanctioning}

Fungal names in certain groups are protected by sanctioning, which is covered under Art. F.3. Sanctioning was introduced into the Code at the Sydney Congress of 1981 as a nomenclatural device to avoid name changes that might otherwise have occurred when a system of later starting-points was abandoned. Sanctioned names are treated as if conserved against earlier homonyms and competing synonyms.

The core rule is Art. F.3.1, which specifies which names are sanctioned, i.e. those in Uredinales, Ustilaginales, and Gasteromycetes (s.l.) adopted by Persoon in Synopsis methodica fungorum (Persoon, 1801) and names of other fungi (excluding slime moulds) adopted by Fries in Systema mycologicum, vol. 1-3, with additional Index (Fries, 18211832) and in Elenchus fungorum, vol. 1-2 (Fries, 1828). These works contain the sanctioning treatments of the sanctioned names. A sanctioning treatment behaves rather like a "supplementary protologue", although the actual protologue remains the place of valid publication of the sanctioned name.

The other main rules and recommendations for sanctioned names can be summarized as follows:

- Sanctioned names are treated as if conserved against earlier homonyms and competing synonyms (Art. F.3.2).

- The spelling used by a sanctioning author is treated as conserved, except for changes mandated by Art. 60 and F.9 (Art. F.3.2).

- A sanctioned name is illegitimate if it is a later homonym of another sanctioned name (Art. F.3.3). 
- An earlier homonym of a sanctioned name is not made illegitimate by that sanctioning; although unavailable for use, the earlier homonym may serve as a basionym (Art. F.3.4).

- When two or more sanctioned names compete, the rules on priority (Art. 11.3 or 11.4) govern the choice of the correct name (Art. F.3.5 and F.3.6).

- The date of sanctioning does not affect the date of valid publication and therefore priority (Art. F.3 Note 1).

- Conservation (Art. 14), protection (Art. F.2), and explicit rejection (Art. 56 and F.7) override sanctioning (Art. F.3.8).

- The lectotype of a sanctioned name (or its equivalent under Art. 10) may be selected from among the elements associated with the name in the protologue and/or the sanctioning treatment (Art. F.3.9 and 10.2(b)). Elements from the context of the protologue are original material, whereas those from the context of the sanctioning work are considered as equivalent to original material for the purpose of typification (Art. F.3 Note 2).

- Finally, a Recommendation: in a formal citation, the status of a sanctioned name may be indicated by adding "nom. sanct." (nomen sanctionatum, sanctioned name) after the author(s), e.g. Boletus piperatus Bull., nom. sanct. (Rec. F.3A.1). The former system of indicating sanctioned status by adding ": Fr." or ": Pers." to the author citation is no longer recommended by the Code (since the San Juan Congress of 2018).

\section{Protection and rejection}

Lists of names proposed for protection or rejection may be submitted to the General Committee under Art. F.2 or F.7, respectively. After review and approval by the Nomenclature Committee for Fungi and the General Committee, the protected names are added to the Appendices (App. IIA, III, or IV) and are treated as conserved against any competing listed or unlisted synonyms or homonyms (including sanctioned names); the rejected names are added to App. V and are to be treated as rejected under Art. 56.1. Conservation under Art. 14 overrides this protection or rejection. See Chapter 8 for further details.

\section{Fungi with a pleomorphic life cycle}

For more than a century, special rules have applied to certain groups of fungi with life history phases involving one or more mitotic asexual states (anamorphs) and a meiotic sexual state (teleomorph); such fungi are said to have a pleomorphic life cycle. The states are morphologically different, and may be found growing separately, so that they often came to be given separate names before it was realized they were part of 
the life cycle of a single species. In addition, it is often the case that only one state is encountered in nature, and for some fungi only the sexual state is known in artificial culture, whereas others have lost the ability to form the sexual state at all. Before the advent of molecular methods, connections were established by critical studies of pure cultures, especially when a colony of an asexual state could be grown from a single spore from a sexual state. However, even in the absence of a sexual state, molecular data can unequivocally demonstrate where an asexual state should be placed phylogenetically. Under pre-Melbourne editions of the Code, the asexual and sexual states of the same species in the largest groups of fungi were required to have separate names, and the name used for the species when considered in all its states (the holomorph) had to have a sexual type. As new data from cultures and molecular analysis linked more and more asexual states with their corresponding sexual states, some mycologists considered as early as 1991 that the need for this "dual nomenclature" had passed and, after numerous debates and discussions, the mycological community became increasingly in favour of abandoning it, culminating in a formal decision to that effect at the Melbourne Congress of 2011. Thus the system of dual nomenclature came to an end on 30 July 2011, when the final plenary session of the Congress voted to accept the decisions of the Nomenclature Section. A fungal taxon at the rank of family or below with a particular circumscription, position, and rank can now bear only one correct name, i.e. following the same rules as names of other organisms treated under the Code (Art. 11.1). Importantly, dual nomenclature has not only been abandoned, but its abandonment is retroactive to 1753 , so it is now as if it had never existed. This means that all names, regardless of the date of valid publication and whether the type be asexual or sexual, compete whenever they apply to the same taxon. As you might guess, this has the potential to result in considerable nomenclatural disruption, with widely and/or traditionally used names becoming incorrect and little-used and/or ambiguous names becoming correct.

With the above concerns in mind, the Melbourne Congress also introduced a mechanism for submitting lists of fungal names for en masse protection (Art. F.2) or rejection (Art. F.7) to serve nomenclatural stability. Note that these provisions apply not only to names of fungi with a pleomorphic life cycle but to names of all organisms treated as fungi. The provisions were extended in their scope at the Shenzhen Congress of 2017, not only to include names of lichen-forming fungi (which were initially excluded), but also so that protected names are treated as conserved against competing unlisted synonyms or homonyms as well as listed ones. See Chapter 8 for more information.

The Melbourne Congress also introduced a rule to prevent a name published for a particular sexual state of a fungus from being illegitimate under Art. 52, if it was nomenclaturally superfluous when published because the protologue included a type referable to a different sexual state. If the name is otherwise legitimate, it competes for priority regardless of whether the type is asexual or sexual. This rule (Art. F.8.1) applies only to names of non-lichen-forming Ascomycota and Basidiomycota published before 2013. 


\section{Author citation}

A new method of author citation for fungal names was introduced at the San Juan Congress of 2018 (Art. F.10.1 and Rec. 10A.1). The identifier issued for the name by a recognized repository may be used, subsequent to the protologue, in place of an author citation, e.g. Astrothelium meristosporoides (P. M. McCarthy \& Vongshew.) Aptroot \& Lücking may instead be cited as Astrothelium meristosporoides [MB\#816706]. Both methods of author citation are permitted.

\section{FOSSILS}

\section{Definition}

Fossil material is distinguished from non-fossil material by stratigraphic relations at the site of original occurrence. The Code establishes non-fossil as the default state in that a name is treated as pertaining to a non-fossil taxon unless its type is fossil in origin. The provisions for non-fossil taxa apply in cases of doubtful stratigraphic relations, as well as for all diatoms. These rules are all in Art. 13.3. The term "fossil-taxon" (hyphenated thus) is defined as a taxon (diatom taxa excepted) the name of which is based on a fossil type and one that consists of the remains of one or more parts of the parent organism, or one or more of their life history stages, in one or more preservational states, as indicated in the original or any subsequent description or diagnosis of the taxon (Art. 1.2).

\section{Diatoms}

Note that diatoms are always treated as non-fossil taxa under the Code, even if they are found in a fossil context. The provisions for fossil-taxa do not therefore apply to diatoms. The provisions for algae, on the other hand, do apply to diatoms (see pp. 112-116).

\section{Starting-point}

The nomenclatural starting-point for fossil organisms in all groups (Art. 13.1(d)) is 31 December 1820, i.e. Versuch ... der Flora der Vorwelt, Heft 1 (Sternberg, 1820).

\section{Priority}

Names of fossil-taxa compete for priority only with names based on a fossil type (Art. 11.7); they do not compete with names based on a non-fossil type. Names based on a non-fossil type are treated as having priority over names at the same rank based on a 
fossil type where these names are treated as synonyms for a non-fossil taxon (Art. 11.8). To illustrate this, Platycarya Siebold \& Zucc. 1843 is the name of a non-fossil genus and Petrophiloides Bowerb. 1840 is the name of a fossil-genus. Both names may be correct, unless they are treated as heterotypic synonyms applying to the same non-fossil genus, in which case the name Platycarya is correct, even though Petrophiloides is the earlier name.

These rules do not affect homonymy. Regardless of whether the types of homonyms are fossil, non-fossil, or both, each later homonym is illegitimate (Art. 11 Note 5). For example, Cornus paucinervis Hance 1881, based on a non-fossil type, is an illegitimate later homonym of C. paucinervis Heer 1859, based on a fossil type.

\section{Language of validating description or diagnosis}

Fossil-taxa have different dates to non-fossil taxa for the implementation of the rules concerning the language of the validating description or diagnosis. For a name of a new fossil-taxon published before 1996, the description or diagnosis may be in any language, but on or after 1 January 1996 it must be in either Latin or English (Art. 43.1).

\section{Validating illustration}

For valid publication of a name of a new fossil-genus or lower-ranked fossil-taxon published on or after 1 January 1912, an illustration is required (Art. 43.2) in addition to a description or diagnosis. The name must be accompanied by an illustration or figure that shows the essential characters, or by a reference to a previously and effectively published illustration or figure that shows the essential characters. For this purpose, in the case of a name of a fossil-genus or subdivision of a fossil-genus, citation of, or reference to, a name of a fossil-species validly published on or after 1 January 1912 will suffice. In addition, a name of a new fossil-species or infraspecific fossil-taxon published on or after 1 January 2001 is not validly published unless at least one of these validating illustrations is identified as representing the type specimen (Art. 43.3).

\section{Type}

The type of the name of a fossil-taxon at the rank of species or below is always a specimen (Art. 8.5). This means the holotype, lectotype, neotype, or conserved type. Epitypes are excepted from this rule and may be either specimens or illustrations.

The holotype or lectotype of a name of a fossil-species or infraspecific fossil-taxon is a specimen that is the basis of the validating illustration(s). If, in the protologue of such a name published before 2001, a type specimen is indicated but not identified among the validating illustrations, a lectotype must be designated from among the specimens illustrated in the protologue. This choice is superseded if it can be demonstrated that the original type specimen corresponds to another validating illustration (Art. 9.15). 


\section{Registration}

Note also that the fungal registration requirements of Art. F.5 apply also to fossil fungi, i.e. that an identifier (an identification number or code) issued by a recognized repository must be cited in the protologue of all new names published on or after 1 January 2013 (Art. F.5.1) or with all type designations published on or after 1 January 2019 (Art. F.5.4; see pp. 118-119). If this identifier is not cited, the new name is not validly published or the type designation is not effective. Type designations here mean those made subsequent to the protologue of the name, i.e. lectotypes, neotypes, epitypes, and their equivalents for the names of genera and subdivisions of genera.

Registration is not yet mandatory for names of fossil algae or fossil plants, although a mechanism is in place (Art. 42) for nomenclatural repositories to become recognized under the Code (see pp. 47-48).

\section{Morphotaxa}

Although the nomenclatures used for fossil-taxa and non-fossil taxa do not differ substantially, the two types of taxa are fundamentally different in nature. This is because most fossils represent only parts or individual life-cycle stages of organisms and may be preserved in various ways that reveal different levels of taxonomic information. Palaeontologists therefore tend to recognize taxa of the fragmentary fossils; only very rarely are taxa of the whole macrofossil organisms recognized. To try to reflect this, prior to the Melbourne Code, a fossil could be treated as a morphotaxon, which for nomenclatural purposes consisted of only the one part, life-history stage, or preservational state represented by the corresponding nomenclatural type. Moreover, for purposes of priority, names of morphotaxa competed only with names based on a fossil type representing the same part, life-history stage, or preservational state. This system was problematic in that nomenclatural regulations were impinging on what should have been purely taxonomic decisions. The Melbourne Congress therefore decided to abandon morphotaxa and introduce a new concept of a "fossil-taxon" (which can be, e.g., a fossil-genus, fossil-species, or infraspecific fossil-taxon, hyphenated thus). Like a morphotaxon, a fossil-taxon can represent a different part, life-history stage, or preservational state, but it differs from a morphotaxon in that its circumscription is not limited to that one part, stage, or state. If a taxonomic decision is made to combine fossil-taxa representing different parts (e.g. pollen and flowers) or different preservational states (e.g. compression fossils and petrifactions), then so be it. If that taxonomic decision is made, the different names compete for priority in the usual way under Art. 11. However, there is no requirement for those fossil-taxa to be united if taxonomy is better served by retaining their independence. For instance, even if pollen was found in a fossil flower, it would be justified to unite the pollen fossil-species and flower fossil-species only if it could be demonstrated beyond reasonable doubt that the type of the pollen fossil-species came only from the same biological species represented by the type of the flower fossil-species. It might be decided best to maintain the separation of 
the pollen and flower fossil-species if, for example, it could be shown that the pollen fossil-species was produced in different flower fossil-species or maybe even different flower fossil-genera. These are taxonomic decisions to be made by palaeontologists, and not by the Code.

\section{HYBRIDS}

A hybrid individual contains genetic material inherited from both parents, as in other sexually produced individuals, but in this case those parents are considered to belong to different taxa. Many taxa are interpreted as hybrids by some scientists but are considered to be non-hybrid taxa by others. Hybridization can be part of the process of evolution, where polyploid hybrids that are able to reproduce eventually lose their extra chromosomes and become diploid species. Such hybrids, which essentially behave like "normal" species, are quite different from the rare occurrences of hybrid individuals in nature, where the parent species coexist, and from artificial hybrids created in cultivation by deliberate crossing of parent species.

The Code provides for hybrids to be expressed in two ways. One is by means of a hybrid formula, e.g. Agrostis $\times$ Polypogon, Agrostis stolonifera $\times$ Polypogon monspeliensis, and Polypodium vulgare subsp. prionodes $\times P$. vulgare subsp. vulgare. The other way is by means of a hybrid name, e.g. $\times$ Agropogon, $\times$ Agropogon littoralis, and Polypodium vulgare nothosubsp. mantoniae (which correspond with the aforementioned three hybrid formulae, respectively). The provisions for naming hybrids had been placed in Appendix I in several previous editions of the Code, but in the Shenzhen Code they form Chapter H.

Be aware of an important rule (Art. H.3.2): a hybrid taxon cannot be designated unless at least one parent taxon is known or can be postulated. If you have a new taxon that you suspect may be a hybrid, but you cannot postulate even one parent, you cannot describe it as a hybrid taxon. You can, however, describe it as a regular, non-hybrid taxon.

Some of the rules for naming hybrids apply primarily to cultivated organisms, e.g. hybrids between three or more genera (especially common in the Orchidaceae). Names of hybrid genera need only be effectively published with a statement of parentage, and no validating description or diagnosis or type is required. The rules become more complex when naming hybrids between subdivisions of genera or infraspecific taxa, especially when the (putative) parents are taxa at different ranks.

My own preference is to refrain from publishing hybrid names unless the hybrid occurs frequently in nature and is repeatedly produced by its parents crossing or is itself able to reproduce. Publishing a hybrid name when only one or a few individuals are known, especially if the hybrid is unable or unlikely to reoccur or reproduce or exists only in cultivation, seems unnecessary to me, perhaps even unscientific. A hybrid formula, although somewhat more cumbersome, avoids the need to comply with the often com- 
plex rules on publishing hybrid names, and it is anyway more informative because it communicates the known or postulated parentage.

A brief summary of the main rules on names of hybrids is provided below. Full details can be found in Chapter $\mathrm{H}$.

- Indicating a hybrid. A hybrid is indicated by use of the multiplication sign $(x)$ or by addition of the prefix "notho-" or "n-" (from Greek vó日os, nothos, hybrid) to the rank-denoting term of the taxon (Art. H.1.1), e.g. nothovar., nothosubsp., nothosect.

- Ranks of nothotaxa. The principal ranks of nothotaxa (hybrid taxa) are nothogenus and nothospecies. These ranks are the same as genus and species (Art. 3.2). The subordinate ranks of nothotaxa are the same as the subordinate ranks of non-hybrid taxa, except that nothogenus is the highest rank permitted (Art. 4.4). The appropriate rank of a nothotaxon is that of its parent taxa, or, if their ranks are unequal, it is the lowest of those ranks (Art. H.5).

- Hybrid formulae. A hybrid may be expressed by means of a hybrid formula in which a multiplication sign $(x)$ is placed between the names of the parent taxa (Art. H.2.1). Formulae designating hybrids are not to be regarded as species names (Art. 23.6(d)).

- Hybrid names. Alternatively, a hybrid may receive a name (Art. H.3.1), which must be validly published.

- Nothogenera and subdivisions of nothogenera. In order to be validly published, the name of a nothotaxon at the rank of genus or subdivision of a genus must be effectively published with a statement of the names of the parent genera or subdivisions of genera (Art. H.9.1). No description or diagnosis is necessary, nor is a type necessary. The name or epithet is termed a "condensed formula", which combines elements from two or more generic names or subdivisional epithets that are correct for the parent taxa, e.g. ×Agropogon for hybrids between Agrostis and Polypogon, or Ptilostemon nothosect. Platon for hybrids between P. sect. Platyrhaphium and P. sect. Ptilostemon (Art. H.6-H.8).

- Nothospecies and infraspecific nothotaxa. In order to be validly published, the name of a nothotaxon at the rank of species or below must comply with the same rules as names of non-hybrid taxa of the same rank (Art. 32.4 and H.10.1). In addition, at least one parent taxon must be known or postulated (Art. H.3.2).

- Priority. Names given to hybrids are subject to the same rules on priority as are those of non-hybrid taxa of equivalent rank (Art. 11.9). 
- Homonymy and synonymy between hybrids and non-hybrids. For purposes of homonymy and synonymy the multiplication sign and the prefix "notho-" are disregarded (Art. H.3.3), e.g. $\times$ Hordelymus Bachteev \& Darevsk. 1950 is a later homonym of Hordelymus (Jess.) Harz 1885; the names apply to a nothogenus and a non-hybrid genus, respectively. Note that the first name is a condensed formula (Art. H.6), but the latter is not. Just because a generic name resembles a condensed formula does not necessarily mean it is a nothogeneric name.

- Transfer between hybrid and non-hybrid categories. When a taxon at the rank of species or below is transferred from the non-hybrid category to the hybrid category of the same rank, or vice versa, the author citation remains unchanged but may be followed by an indication in parentheses of the original category, e.g. Stachys xambigua Sm. (pro sp.), Salix glaucops Andersson (pro hybr.), where the abbreviations stand for pro specie and pro hybrida, "as species" and "as hybrid", respectively (Art. 50.1).

\section{GROUPS NOT COVERED BY THE CODE}

For precision while discussing several codes in this section, and to avoid having to repeat its long title, I will refer to the International Code of Nomenclature for algae, fungi, and plants as the Shenzhen Code.

\section{Which groups are covered by the Shenzhen Code?}

The Melbourne Congress of 2011 changed the title of the International Code of Botanical Nomenclature to the International Code of Nomenclature for algae, fungi, and plants, reflecting the view, held especially among mycologists, that the words "botanical", "botanist", "botany", and "plant" are ambiguous and could imply that only vascular plants, bryophytes, and perhaps green algae were covered, but not fungi and the various other lineages of algae, which had traditionally been included with "plants" under earlier editions of the Code. Preamble 8 now makes it clear that the Code applies to all organisms traditionally treated as algae, fungi, or plants, whether fossil or non-fossil, including blue-green algae (Cyanobacteria), chytrids, oomycetes, slime moulds, and photosynthetic protists with their taxonomically related non-photosynthetic groups (but excluding Microsporidia).

The nomenclature of special forms (formae speciales), i.e. parasites (especially fungi) characterized by their adaptation to different hosts, is not governed by the Shenzhen Code (Art. 4 Note 4).

\section{Which codes cover the groups not covered by the Shenzhen Code?}

The nomenclature of animals (including Microsporidia) is covered by the International Code of Zoological Nomenclature (International Commission on Zoological Nomencla- 
ture, 1999); that of prokaryotes (bacteria etc.) by the International Code of Nomenclature of Prokaryotes (Parker \& al., 2019); that of viruses by the International Code of Virus Classification and Nomenclature (International Committee on Taxonomy of Viruses, 2018); and that of cultivars and other special categories of organisms in agriculture, forestry, and horticulture by the International Code of Nomenclature for Cultivated Plants (Brickell \& al., 2016).

\section{Taxa originally, but not currently, assigned to groups not covered by the Shenzhen Code}

Note that the Shenzhen Code applies to taxa that are currently treated as algae, fungi, or plants even if those taxa were originally assigned to other groups that are currently covered by other codes (Principle I). A name of a taxon originally assigned to one of those other groups, but now treated as an alga, fungus, or plant, is validly published provided that the original publication meets the requirements for valid publication under the Shenzhen Code. But in some cases these requirements are not met. Some extra latitude is allowed when a taxon originally assigned to one of those other groups is treated as belonging to the algae or fungi: in this case, the name need satisfy only the requirements of the relevant other Code for a status equivalent to valid publication under the Shenzhen Code. For example, Petalodinium Cachon \& Cachon-Enj. was published for a genus of dinoflagellates (Cachon \& Cachon, 1969: 16). Under the International Code of Zoological Nomenclature, the name is available, i.e. the status equivalent to validly published. When the genus is treated as belonging to the algae, the name is validly published under the Shenzhen Code, even though the original publication lacks a description or diagnosis in Latin (see Art. 45 for further details).

\section{Blue-green algae (Cyanobacteria)}

The blue-green algae (Cyanobacteria, Cyanophyta, cyanoprokaryotes) present problems, because their nomenclature is covered not only by the Shenzhen Code but also by the International Code of Nomenclature of Prokaryotes (ICNP), in which the Note under General Consideration 5 states "Prokaryotes' covers those organisms that are variously recognized as e.g. Schizomycetes, [...] Schizophycetes, Cyanophyceae and Cyanobacteria”. Furthermore, Art. 45.1 of the Shenzhen Code (see previous paragraph) has not yet been reciprocated in the ICNP. Because the two codes work in different ways, the result is a chaotic situation. This has been discussed by, e.g., Oren \& Tindall (2005) and Oren \& al. (2009).

\section{Cross-code homonymy}

The rules on illegitimate later homonyms in the Shenzhen Code do not consider names of organisms covered by the other codes. For example, the plant generic name Pieris D. Don 1804 (Ericaceae) is a later homonym of the animal generic name Pieris Schrank 1801 (Lepidoptera), but it is not illegitimate for that reason. However, the following exceptions exist: 
- Later homonyms of names of taxa once treated as algae, fungi, or plants are illegitimate, even when those taxa have been reassigned to a different group of organisms to which the Shenzhen Code does not apply (Art. 54.1(a)).

- A name applied to an organism covered by the Shenzhen Code and validly published under it, but originally published for a taxon other than an alga, fungus, or plant, i.e. under another Code, is illegitimate if it

o is unavailable for use under the other Code, usually because of homonymy (Art. 54.1(b)(1)), or

- becomes a later homonym of an algal, fungal, or plant name when the taxon to which it applies is first treated as a alga, fungus, or plant (Art. 54.1(b)(2)).

- A name of a genus is treated as an illegitimate later homonym if it is spelled identically with previously published graft hybrid "name" established under the International Code of Nomenclature for Cultivated Plants (Art. 54.1(c)). Currently only ten such "names" are known to have been established; they were listed by McNeill $\&$ al. (2016).

- A name of a taxon treated as a fungus published on or after 1 January 2019 is illegitimate if it is a later homonym of a prokaryotic or protozoan name (Art. F.6.1). Conversely, Rule 51b(4) of the International Code of Nomenclature of Prokaryotes states that a prokaryotic name is illegitimate if it is a later homonym of a name of a taxon of prokaryotes, fungi, algae, protozoa, or viruses.

\section{Cultivated plants}

When it is considered appropriate to treat a taxon under the International Code of Nomenclature for Cultivated Plants (ICNCP), epithets in names published for that taxon under the Shenzhen Code are retained as cultivar epithets. They are not written with "cv." (cultivar), as if that were a rank-denoting term; instead, they are included in single quotation marks (Art. 28 Note 4) and with initial capital letters unless linguistic custom demands otherwise, e.g. Mahonia japonica DC., when treated as a cultivar, becomes Mahonia 'Japonica', not "Mahonia cv. japonica"; Taxus baccata var. variegata Weston becomes Taxus baccata 'Variegata', not "Taxus baccata cv. variegata".

The ICNCP also provides for the establishment of epithets differing markedly from epithets provided for under the Shenzhen Code (Art. 28 Note 5), e.g. Camellia 'Shōjōno-mai', Cedrus libani subsp. atlantica 'Mt St Catherine', Geranium pratense 'Mrs Kendall Clark', and Helianthus annuus 'E9730LM'. 


\section{CHAPTER 12 | IMPORTANT DATES IN THE CODE}

\section{May 1753}

Nomenclatural starting-point for algae (with exceptions; Art. 13.1(e)), bryophytes (Sphagnaceae and Hepaticae, including Anthocerotae; Art. 13.1(c)), fungi (Art. F.1.1), and vascular plants (Art. 13.1(a)). Species plantarum, ed. 1 (Linnaeus, 1753). No names published before a nomenclatural starting-point are validly published.

\section{August 1789}

Nomenclatural starting-point for suprageneric names of vascular plants (Art. 13.1(a)) and certain bryophytes (Sphagnaceae and Hepaticae, including Anthocerotae; Art. 13.1(c)). Genera plantarum (Jussieu, 1789).

\section{January 1801}

Nomenclatural starting-point for bryophytes (Musci, except Sphagnaceae; Art. 13.1(b)). Species muscorum frondosorum (Hedwig, 1801).

\section{December 1820}

Nomenclatural starting-point for fossils (Art. 13.1(f)). Versuch ... der Flora der Vorwelt, Heft 1 (Sternberg, 1820).

\section{January 1848}

Nomenclatural starting-point for certain algae (Desmidiaceae; Art. 13.1(e)). The British Desmidieae (Ralfs, 1848).

\section{January 1886}

Nomenclatural starting-point for certain algae (Nostocaceae heterocysteae; Art. 13.1(e)). “Révision des Nostocacées hétérocystées” (Bornet \& Flahault, 1886-1888).

\section{January 1887}

Indication of suprageneric rank. The termination of a suprageneric name published on or after 1 January 1887 is acceptable as an indication of the rank (Art. 37.2) (e.g. -aceae indicates the rank of family, -eae that of tribe), although any explicitly 
designated rank takes precedence and the rules on rank sequence (Art. 5.1 and 37.6-37.8) apply. Before 1887, such terminations cannot indicate rank.

\section{January 1890}

Variety is default infraspecific rank. If a publication before 1890 uses only one infraspecific rank, that rank is considered to be variety unless the author indicates otherwise. It was common in these early publications to cite infraspecific taxa without using a rank-denoting term, e.g. " $\beta$. glabra", " $\gamma$. intermedia" (Art. 37.4). Publications from 1890 onward generally indicate the rank; if they do not, the names are validly published but unranked (but only before 1 January 1953 , see there).

\section{January 1892}

Nomenclatural starting-point for certain algae (Nostocaceae homocysteae; Art. 13.1(e)). "Monographie des Oscillariées" (Gomont, 1892-1893).

\section{January 1900}

Nomenclatural starting-point for certain algae (Oedogoniaceae; Art. 13.1(e)). "Monographie und Iconographie der Oedogoniaceen" (Hirn, 1900).

\section{January 1908}

Illustration with analysis. Certain names of new taxa published before 1908 may be validly published even if only accompanied by an illustration with analysis, i.e. without a written description or diagnosis or reference to such (Art. 38.7 and 38.8; for analysis see Art. 38.9 and 38.10). Such names published on or after 1 January 1908 are not validly published.

\section{January 1912}

Latin technical terms as generic names. The name of a new genus published before 1912 may coincide with a Latin technical term in use in morphology at the time of publication (e.g. Radicula, Tuber), provided that it was accompanied by a species name published in accordance with the binary system of Linnaeus (Art. 20.2), i.e. a binomial species name. Such names published on or after 1 January 1912 are not validly published.

Validating illustration for names of fossil-taxa. A validating illustration, or reference to such, is required for valid publication on or after 1 January 1912 of a name of a new fossil-taxon at the rank of genus or below (Art. 43.2). A validating illustration is an illustration or figure showing the essential characters. 


\section{January 1921 and 1 January 1935}

Largely mechanical method of type selection. A publication that appeared before 1921 has adopted a largely mechanical method of type selection if any of the criteria given in Art. 10.7(c-f) apply; likewise for a publication that appeared before 1935 if either of the criteria given in Art. 10.7( $\mathrm{a}$ and $\mathrm{b})$ applies; but if the authors specifically stated that they did not use such a method, that statement is to be accepted.

\section{January 1935-31 December 2011}

Latin requirement for names offungi and plants. A name of a new taxon of fungi or plants (not of algae or fossils) published between 1 January 1935 and 31 December 2011, inclusive, is not validly published unless accompanied by a Latin description or diagnosis or by a reference to such (Art. 39.1). That reference may be indirect prior to 1953 but must be full and direct on or after 1 January 1953 (see there).

\section{January 1953}

Effective publication. The following kinds of material issued on or after 1 January 1953 are not effectively published: indelible autograph (Art. 30.5), trade catalogues and non-scientific newspapers (Art. 30.7), printed matter accompanying specimens (Art. 30.8), and certain theses submitted to a university or other institute of education for the purpose of obtaining a degree (Art. 30.9).

Alternative names. Alternative names published on or after 1 January 1953 are not validly published (Art. 36.3). In this sense, they are defined as two or more different names based on the same type and accepted as alternatives simultaneously for the same taxon by the same author in the same publication. This is a different sense to the alternative family names authorized by Art. 18.6.

Indication of rank. A name published on or after 1 January 1953 is not validly published unless there is a clear indication of the rank of the taxon concerned (Art. 37.1). Such a name published before 1953 is validly published but unranked (Art. 37.3).

Full and direct reference to basionym or replaced synonym. A new combination, name at new rank, or replacement name published on or after 1 January 1953 is not validly published unless the reference to the basionym or replaced synonym is full and direct (Art. 41.5, see also Art. 41.6 and 41.8), whereas for names published before 1953 the reference may be either direct or indirect (Art. 41.3, see also Art. 41.4).

Full and direct reference to earlier description or diagnosis. When the protologue of a name of a new taxon includes no description or diagnosis of the taxon, it may instead refer to a previously and effectively published description or diagnosis (Art. 38.1(a)). If the name is published on or after 1 January 1953, that reference must 
be full and direct, otherwise the name is not validly published, whereas for names published before 1953 the reference may be either direct or indirect (Art. 38.13).

\section{January 1954}

Determining date of conservation or protection of a name. Before 1954, conservation of a name takes effect on the date of the decision on the conservation proposal by the relevant International Botanical Congress (Art. 14.15, for the dates see Art. 14 Note 4). On or after 1 January 1954, conservation or protection of a name takes effect on the date of effective publication of the General Committee's approval of the conservation or protection proposal (Art. 14.15).

\section{January 1958}

Indication of type. A name of a new taxon at the rank of genus or below published on or after 1 January 1958 is not validly published unless the type of the name is indicated (Art. 40.1).

Validating illustration for names of algae. A validating illustration, or reference to such, is required for valid publication on or after 1 January 1958 of a name of a new taxon of algae (except fossils) at the rank of species or below (Art. 44.2). A validating illustration is an illustration or figure showing the distinctive morphological features.

\section{January 1958-31 December 2011}

Latin requirement for names of algae. A name of a new taxon of algae (except fossils) published between 1 January 1958 and 31 December 2011, inclusive, is not validly published unless accompanied by a Latin description or diagnosis or by a full and direct reference to such (Art. 44.1).

\section{January 1973}

Effective publication. Seed-exchange lists issued on or after 1 January 1973 are not effectively published (Art. 30.7).

Requirements for valid publication not simultaneously fulfilled. For a name to be validly published on or after 1 January 1973 without simultaneous fulfilment of all the relevant requirements of the Code for valid publication, a full and direct reference must be given to the places where these requirements were previously fulfilled (Art. 33.1). Before 1973, such a name is validly published when the last of these requirements is fulfilled. 


\section{January 1990}

Writing "typus" or "bolotypus". Indication on or after 1 January 1990 of the type of a name of a new taxon at the rank of genus or below must include one of the words "typus" or "holotypus", or its abbreviation, or its equivalent in a modern language (Art. 40.6). Otherwise the name is not validly published.

Specifying herbarium of holotype. Indication on or after 1 January 1990 of a specimen or unpublished illustration as the holotype of a name of a species or infraspecific taxon must specify the single herbarium, collection, or institution in which the type is conserved (Art. 40.7). Otherwise the name is not validly published.

Specifying herbarium of lectotype, neotype, or epitype. Designation on or after 1 January 1990 of a specimen or unpublished illustration as the lectotype or neotype of a name of a species or infraspecific taxon must specify the herbarium, collection, or institution in which the type is conserved (Art. 9.22). The same applies to an epitype (Art. 9.21), which entered the Code at the Tokyo Congress of 1993. Failure to comply with these rules results in an ineffective type designation.

\section{January 1996}

Latin or English requirement for names of fossil-taxa. A name of a new fossil-taxon published on or after 1 January 1996 is not validly published unless accompanied by a Latin or English description or diagnosis or by a full and direct reference to such (Art. 43.1).

\section{January 2001}

Writing "lectotypus", “neotypus", or "epitypus". Designation on or after 1 January 2001 of the lectotype, neotype, or epitype of a name of a species or infraspecific taxon must use the word "lectotypus", "neotypus", or "epitypus", its abbreviation, or its equivalent in a modern language (Art. 9.23). Otherwise the type designation is ineffective.

Writing “designated here”. Designation on or after 1 January 2001 of a lectotype, neotype, or epitype must include the phrase "designated here" (bic designatus) or an equivalent (Art. 7.11). The same applies to the equivalent designation of the type of a name of a genus or subdivision of a genus; it does not apply to indicating the type of a name of a new taxon. Failure to comply with this rule results in an ineffective type designation.

Identifying validating illustrations as the type. A name of a new fossil-taxon at the rank of species or below published on or after 1 January 2001 is not validly published unless at least one of the validating illustrations is identified as representing the type specimen (Art. 43.3). When, before 2001, a type specimen is indicated in the pro- 
tologue but not identified among the validating illustrations, a lectotype must be designated from among the specimens illustrated in the protologue (Art. 9.15).

\section{January 2007}

Illustrations as types. The type of a name of a new taxon (except fossils) at the rank of species or below published before 2007 may be an illustration. For such a name to be validly published on or after 1 January 2007 , the type must be a specimen (except under certain circumstances for non-fossil microscopic algae and non-fossil microfungi) (Art. 40.4 and 40.5).

Citing the basionym or replaced synonym. A new combination, name at new rank, or replacement name published on or after 1 January 2007 is not validly published unless its basionym or replaced synonym is cited (Art. 41.5). This means the basionym or replaced synonym must actually appear in the text; merely indicating it, e.g. by citing only its author and place of publication, is not enough.

\section{January 2012}

Latin or English requirement now universal. A name of a new taxon (of algae, fungi, or plants, whether fossil or non-fossil) published on or after 1 January 2012 is not validly published unless accompanied by a Latin or English description or diagnosis or by a full and direct reference to such (Art. 39.2). (Already the case for names of fossil-taxa from 1 January 1996.)

Effective electronic publication. Electronic material distributed on or after 1 January 2012 is effectively published provided that it is in Portable Document Format (PDF) in an online publication with an International Standard Serial Number (ISSN) or an International Standard Book Number (ISBN) (Art. 29.1). Electronic material distributed before 2012 is not effectively published (Art. 29 Note 1).

\section{January 2013}

Registration of names of fungi. Names of organisms treated as a fungi (including fossil fungi) published on or after 1 January 2013 are not validly published unless the identifier (i.e. an identification number or code) issued for the name by a recognized repository is cited in the protologue (Art. F.5.1). This includes names of new taxa, new combinations, names at new ranks, and replacement names.

Names of fungi with a pleomorphic life cycle. A name of non-lichen-forming Ascomycota or Basidiomycota published before 2013 for a particular sexual state of a fungus is protected from being illegitimate under Art. 52, if it was nomenclaturally superfluous when published because the protologue included a type referable to a different sexual state (Art. F.8.1). 


\section{January 2019}

Cultures as types. The type specimen of an algal or fungal name may be a culture, provided it is preserved in a metabolically inactive state (Art. 8.4). A name of a new species or infraspecific taxon published on or after 1 January 2019 with such a type is not validly published unless the protologue includes a statement that the culture is preserved in a metabolically inactive state (Art. 40.8).

Registration of type designations for fungal names. Designation on or after 1 January 2019 of the lectotype, neotype, or epitype of a name of an organism treated as a fungus (including fossil fungi) must cite the identifier issued for the typification by a recognized repository (Art. F.5.4). The same applies to the equivalent designation of the type of a name of a genus or subdivision of a genus. Failure to comply with this rule results in an ineffective type designation.

Fungal homonyms. A name of a taxon treated as a fungus (including fossil fungi) published on or after 1 January 2019 is illegitimate if it is a later homonym of a prokaryotic or protozoan name (Art. F.6.1). 


\section{CHAPTER 13|HOWTOCHANGETHECODE}

The nomenclature of algae, fungi, and plants is essentially democratic, involving internationally collaborative decision-making. The Code derives its authority from international consensus, in which a majority of users worldwide voluntarily agrees to follow the rules. It is then appropriate that a similarly democratic process be used when the Code is amended. The Code contains detailed rules on how it may be amended, called "governance of the Code" and forming its Division III. The following sections describe the processes: who may propose amendments to the Code, how are they proposed, and what happens to them; the International Botanical Congress, its Nomenclature Section (Fig. 21, p. 139), and its Bureau of Nomenclature; the International Mycological Congress, its Fungal Nomenclature Session, and its Fungal Nomenclature Bureau; and the roles of the various nomenclature committees. To help readability and minimize repetition, I have omitted references to the specific provisions of Div. III in this chapter and have used the following acronyms:

IBC - International Botanical Congress

IMC - International Mycological Congress

Two international organizations in particular give logistical and financial support to the Code. The International Association for Plant Taxonomy provides the vehicle for publishing nomenclatural papers, proposals, and reports in its journal, Taxon; helps with preparations for the Nomenclature Section of the IBC, e.g. the preliminary guiding vote; supports travel by the Bureau of Nomenclature to the IBC; supports the meeting of the Editorial Committee following the IBC; supports transcription of the audio recordings of the Nomenclature Section and their subsequent editing and publication as proceedings; and publishes the Code itself. The International Mycological Association provides the vehicle for publishing fungal nomenclatural papers, proposals, and reports in its journal, IMA Fungus, and supports the IMC including the Fungal Nomenclature Session.

The actual people working for the Code, i.e. the members of the Bureau of Nomenclature, the Fungal Nomenclature Bureau, the nine Permanent Nomenclature Committees, and any Special-purpose Committees appointed by an IBC or an IMC, are botanists, mycologists, and phycologists offering their time on a voluntary basis. These individuals are elected or appointed (see Bureaus of Nomenclature, p. 142). If you are not already part of this nomenclatural community, and would like to become more actively involved, I encourage you to consider any of the following:

- Join the International Association for Plant Taxonomy (https://www.iaptglobal. org/) or the International Mycological Association (http://www.ima-mycology.org/) 
- Publish material that will positively impact biological nomenclature

- Attend an IBC including its Nomenclature Section or an IMC including its Fungal Nomenclature Session

- Volunteer to serve on a Special-purpose Committee established by an IBC or an IMC

- Tell a member of the Bureau of Nomenclature, the Fungal Nomenclature Bureau, or the Secretary of the Nominating Committee at a (Fungal) Nomenclature Section/Session that you are able and willing to serve on one of the Permanent Nomenclature Committees

\section{PROPOSALS TO AMEND THE CODE}

Anyone may submit proposals to amend the Code to the journal Taxon or proposals to amend Chapter $\mathrm{F}$ to the journal IMA Fungus. The published proposals are voted on by the international nomenclature user community, ultimately by an IBC or an IMC. The Code (except Chapter F) may be modified only by action of a plenary session of an IBC on a resolution moved by the Nomenclature Section of that IBC. Chapter F may be modified only by action of a plenary session of an IMC on a resolution moved by the Fungal Nomenclature Session of that IMC.

At least three years before the IBC, a notice is placed in Taxon announcing that the column "Proposals to amend the Code" is open (for the Shenzhen IBC, see Turland \& Wiersema, 2013). These proposals are not subject to peer-review, but the column editors, who in recent years have been the Rapporteur-général and Vice-rapporteur, work closely with the proposers to edit proposals, ensuring that they are logical, and pointing out any consequences that the proposers may not have foreseen. Proposals may be withdrawn by the proposers if, during the editorial process, unwanted consequences become apparent. The closing date for proposals is about one year before the IBC. After the last of the proposals has been published, the Rapporteur-général and Vice-rapporteur compile a synopsis of proposals, including their comments, also published in Taxon (for the Shenzhen IBC, see Turland \& Wiersema, 2017). A preliminary guiding vote is held early in the year of the IBC. In order to participate in the guiding vote, you must be either (1) an author of at least one proposal to amend the Code, or (2) an individual member of the International Association for Plant Taxonomy, or (3) a member of one of the Permanent Nomenclature Committees. The purpose of the guiding vote is to advise the Nomenclature Section of the IBC of the level of support for the proposals, and the results of the vote are made available to the Section (e.g. by publication in Taxon, see Turland \& al., 2017a).

When preparing a proposal, you should be careful to distinguish between what the Code actually says and what you think it should say. There will normally be a differ- 
ence, and this will be the basis of your proposal. Think carefully about the logic of your proposal, and try to anticipate all side-effects; deal with the side-effects appropriately. Remember that changes to the Code are retroactive to 1753 unless limited by date (Principle VI). In other words, a new rule will behave as if it had always been in the Code (and the Code behaves as if it had existed since 1753). Be concise in your arguments. Lengthy justifications may need to be published in a separate (and peer-reviewed) paper in Taxon. Be realistic as to whether the international scientific community is likely to agree with you. Members of that community tend to be conservative when contemplating changes to the rules of nomenclature. If your proposal is radical, you will need to be very persuasive indeed — or make it less radical. Not only does it have to avoid receiving $75 \%$ or more "no" votes in the preliminary guiding vote, but it must survive discussion and be accepted at the Nomenclature Section.

\section{NOMENCLATURE SECTION OF THE IBC}

The format of recent IBCs has been a main week of plenary lectures, symposia, workshops, etc., with the Nomenclature Section taking place in the immediately preceding week. Whereas thousands of people might attend the main week of the IBC, typically only 100-300 attend the Nomenclature Section. In order to be a member of the Nomenclature Section with the right to vote on proposals, you need to be a registered member of the IBC (no qualifications are required, just a fee) and to attend in person.

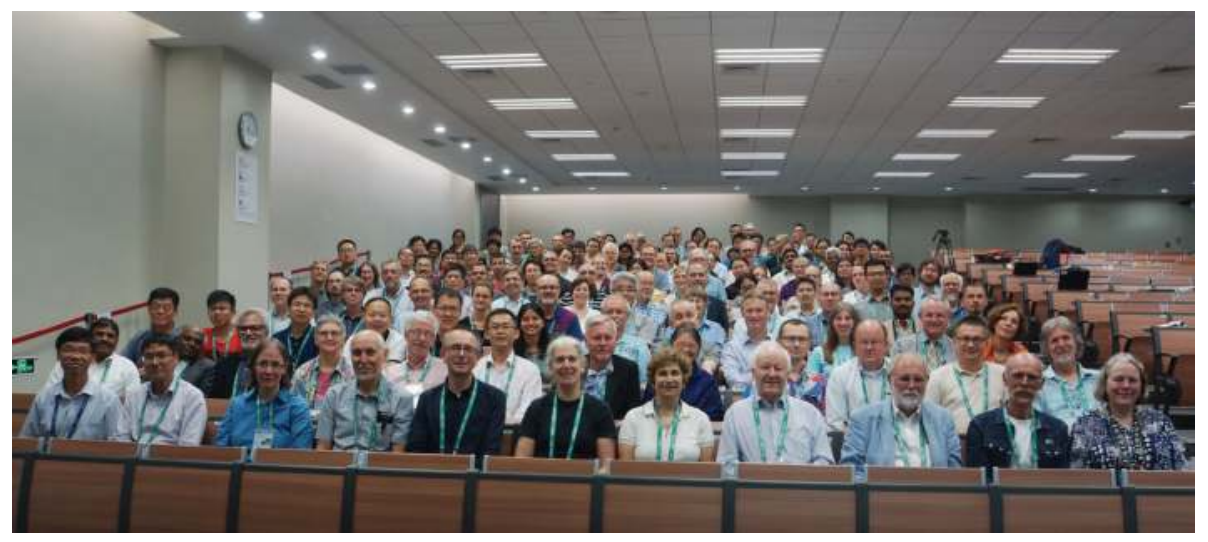

Fig. 21. The Nomenclature Section of the XIX International Botanical Congress, Shenzhen, China, 20 July 2017. The decisions of this Section, ratified by the final plenary meeting of the Congress, resulted in the Shenzhen Code. The Bureau of Nomenclature is seated on the front row (left to right): Li Zhang, Yun-Fei Deng (Recorders), Anna M. Monro (Recorders' Assistant), John H. Wiersema (Vice-rapporteur), Nicholas J. Turland (Rapporteur-général), Sandra Knapp (President), Renée H. Fortunato, John McNeill, Werner Greuter, Gideon F. Smith, and Karen L. Wilson (Vice-presidents). — Reproduced by permission of the photographer, Li Zhang, Fairy Lake Botanical Garden. 
The Nomenclature Section is run by the Bureau of Nomenclature, which consists of the President of the Nomenclature Section, up to five Vice-presidents, the Rapporteur-général, the Vice-rapporteur, and the Recorder. The President chairs the proceedings, the Vice-presidents serve in place of the President if requested, the Rapporteur-général and Vice-rapporteur provide the expertise on the Code, and the Recorder handles logistics and ensures that the discussions and decisions are recorded in detail. These officers are either elected or appointed: the President is elected by the General Committee, the Vice-presidents are appointed by the Bureau of Nomenclature, the Rapporteur-général is elected by the previous IBC, the Vice-rapporteur is appointed by the Rapporteur-général and approved by the General Committee, and the Recorder is appointed by the Organizing Committee of the IBC.

The main task of the Nomenclature Section is to discuss, amend if necessary, and vote on proposals to amend the Code. In addition, the recommendations of the General Committee on the previous six years of proposals to conserve, protect, or reject names, to suppress works, and requests for binding decisions are subject to approval by the Section.

Each member has one personal vote and may also carry up to 14 institutional votes. Institutions are each allocated between one and seven institutional votes, which may be exercised at the Nomenclature Section by the member who is the authorized delegate of the institution(s). The number of votes allocated to an institution depends on its level of taxonomic activity, e.g. number of active staff, size of collections, and current publications. The list of institutions and numbers of allocated votes is revised prior to each IBC by the Committee on Institutional Votes, subject to approval by the General Committee. An institution wishing to vote for the first time, or to increase or decrease its allocated votes, may contact the Rapporteur-général (who serves as chair of the Committee on Institutional Votes) with relevant information on taxonomic activity.

A qualified majority (at least 60\%) of votes cast at the Nomenclature Section is required to accept a proposal or refer it to the Editorial Committee, and thereby effect a change to the Code. Recommendations of the General Committee can be rejected by the same qualified majority; otherwise they are accepted. The Section may also refer proposals to a Special-purpose Committee (see p. 145). Proposals that receive $75 \%$ or more "no" votes in the preliminary guiding vote are automatically rejected, and proposals that concern only Examples or the Glossary are automatically referred to the Editorial Committee, although in both cases a proposal may be reintroduced for discussion. Proposals may also be amended during discussion.

The Nomenclature Section also elects a Nominating Committee at the proposal of the President. The Nominating Committee prepares a report proposing the Rapporteur-général for the next IBC and the members of the Permanent Nomenclature Committees to serve until the next IBC (except the Nomenclature Committee for Fungi, which is elected by the IMC). 
The decisions of the Nomenclature Section become a resolution of the IBC, ratified at a plenary session (normally the closing ceremony on the last day of the IBC), at which point the Section's decisions become official and the rules of the new Code take effect unless expressly limited by date. After the IBC, a report is published in Taxon detailing all the decisions and appointments made by the Section (that for the Shenzhen IBC was published 16 days after the closing ceremony, Turland $\&$ al., 2017b).

The audio recordings of the discussions of the Nomenclature Section are transcribed into text and then edited, with the help of the published report and written records made at the Section, to produce a full report of the nomenclature proceedings of the IBC. The full reports for the Vienna and Melbourne IBCs were published online, as open-access volumes of PhytoKeys (Flann \& al., 2014, 2015). That for the Shenzhen IBC is currently being prepared.

\section{FUNGAL NOMENCLATURE SESSION OF THE IMC}

As mentioned earlier, Chapter F of the Code may be modified only by an IMC, whereas the rest of the Code may be modified only by an IBC. The procedure for modifying Chapter $\mathrm{F}$ is very similar to that described above, but the timetable is tighter because the IMC is held every four years, while the IBC is held every six years. Proposals to amend Chapter $\mathrm{F}$ are submitted to and published in the journal IMA Fungus. There is a synopsis of proposals (May \& Redhead, 2018) and a preliminary guiding vote (May \& Miller, 2018). The IMC has a Fungal Nomenclature Session (not "Section"). This took place during one day at the San Juan IMC of 2018. The much shorter duration was possible because there were far fewer proposals to consider (only 18 compared with 397 at the Shenzhen IBC). There is a Fungal Nomenclature Bureau consisting of the Chair, Deputy Chairs, Secretary, Deputy Secretary, and Recorder (Chair and Secretary are equivalent to President and Rapporteur-général, respectively). The Rapporteur-général for the next IBC is invited to attend the Session as a non-voting advisor. There are no institutional votes. The Session considers and votes on proposals to amend Chapter F and can authorize Special-purpose Committees. The Session does not vote on recommendations of the General Committee; this is done only at the IBC. The Session elects the Secretary for the next IMC and the members of the Nomenclature Committee for Fungi, who have been proposed by the Nominating Committee of the Fungal Nomenclature Session. After the IMC, a report is published in IMA Fungus detailing the decisions and appointments made by the Fungal Nomenclature Session (for the San Juan IMC, see May \& al., 2018). The San Juan IMC established an ad hoc Editorial Committee for Fungi to prepare the new edition of Chapter $\mathrm{F}$ and work with the regular Editorial Committee to finalize and approve it before publication. 


\section{Bureaus of Nomenclature}

The Bureau of Nomenclature of the International Botanical Congress consists of the following officers:

- $\quad$ President (of the Nomenclature Section, not of the whole Congress). Elected before the Congress by the General Committee. Presides over the Nomenclature Section, moderating the meeting, calling the votes, etc. Presents a resolution to a plenary session of the main Congress that the decisions and appointments of the Nomenclature Section be approved.

- Vice-presidents (up to five). Appointed by the Bureau of Nomenclature. Serve in place of the President if and when requested.

- Rapporteur-général (usually simply called the Rapporteur). Elected by the Nomenclature Section of the previous Congress. Edits, compiles into a synopsis, and presents the proposals to amend the Code, explaining the consequences of acceptance or rejection of the proposals, etc. Chairs the Committee on Institutional Votes. Chairs the Editorial Committee that produces the new edition of the Code.

- Vice-rapporteur. Appointed by the Rapporteur-général and approved by the General Committee no later than three years before the Congress. Assists and, if necessary, serves in place of the Rapporteur-général. Co-edits proposals to amend the Code and co-authors the synopsis. Serves as Secretary of the Editorial Committee.

- Recorder. Appointed before the Congress by the Organizing Committee of the Congress in consultation with the Rapporteur-général. Responsible for all local facilities needed by the Nomenclature Section. Records the discussion and outcome of each proposal, including the wording of amendments, collects written versions of members' comments, and ensures that an audio recording of the sessions is made.

The Fungal Nomenclature Bureau of the International Mycological Congress consists of the following officers, who have parallel roles to their counterparts in the International Botanical Congress:

- Chair (of the Fungal Nomenclature Session). Elected before the Congress by the Nomenclature Committee for Fungi in consultation with the General Committee.

- Deputy Chairs. Appointed by the Fungal Nomenclature Bureau.

- Secretary. Elected by the Fungal Nomenclature Session of the previous Congress. 
- Deputy Secretary. Appointed by the Secretary and approved by the Nomenclature Committee for Fungi in consultation with the General Committee no later than three years before the Congress.

- Recorder. Appointed before the Congress by the Organizing Committee of the Congress in consultation with the Secretary.

\section{PERMANENT NOMENCLATURE COMMITTEES}

A significant portion of the work in managing the Code, including considering proposals to conserve, protect, or reject names, and the actual editing of the Code, is delegated to Permanent Nomenclature Committees. They are as follows:

- General Committee

- Nomenclature Committee for Vascular Plants

- Nomenclature Committee for Bryophytes

- Nomenclature Committee for Fungi

- Nomenclature Committee for Algae

- Nomenclature Committee for Fossils

- Committee on Institutional Votes

- Registration Committee

- $\quad$ Editorial Committee

These Committees can be contacted through their secretaries. The current members and officers of each Committee are listed on the website of the International Association for Plant Taxonomy (https://www.iaptglobal.org/committee-and-reports) and the members of the Editorial Committee are also listed in the preliminary pages of the Code. Contact details for these individuals can usually be found in Index Herbariorum (http://sweetgum.nybg.org/science/ih/).

The General Committee is effectively the Committee with overall authority to govern the Code in the six-year period between IBCs. Its actions are mandated by a previous IBC and its recommendations are subject to approval by a future IBC. 
The main task of the five specialist committees (i.e. those for Vascular Plants, Bryophytes, Fungi, Algae, and Fossils) is to consider and make recommendations on proposals to conserve, protect, or reject names, proposals to suppress works, and requests for binding decisions. These specialist committees publish reports in Taxon making recommendations on the proposals and requests that fall within their authority. The General Committee then considers each recommendation, either approving it, overturning it, or referring it back to the specialist committee(s) for further consideration. The Nomenclature Committee for Fungi also has various functions connected with the Fungal Nomenclature Session of the IMC.

The Committee on Institutional Votes maintains and updates the list of institutions and their allocated votes for the upcoming International Botanical Congress. This includes considering applications from institutions wishing to be added to the list or to adjust their number of votes. The list must be approved by the General Committee and published prior to the Congress.

The Registration Committee considers applications from nomenclatural repositories (for organisms other than fungi) that wish to become recognized under the Code. It also assists in the design and implementation of such repositories, monitors the functioning of existing ones, and makes recommendations to the General Committee.

The Editorial Committee is responsible for producing the new Code according to the decisions made at the Nomenclature Section and approved by the IBC. The Committee may change the meaning of the Code only when an IBC decision mandates such a change, but it has freedom to editorially adjust the wording and arrangement of rules and recommendations so long as the meaning remains the same, and it may add or delete Examples. Proposals referred to the Editorial Committee by the IBC may be dealt with at the Committee's discretion; they may be accepted into the Code more or less unchanged, extensively modified, or omitted altogether. The Committee normally meets about six months after the IBC at the institution of one of its members, e.g. after the Shenzhen IBC it met at the Botanischer Garten und Botanisches Museum Berlin. The meeting generally lasts for five full working days, during which a draft version of the new Code, prepared in advance by the Rapporteur-général and other Committee members, is carefully read, discussed, and edited, with attention to the existing text as well as the amendments from the IBC. The Committee also provides new Examples to illustrate rules that are new or lack Examples or to replace defective Examples. The meeting ends with a revised version of the new Code, which is then repeatedly read and improved by the Committee in the months following the meeting. Finally, the new edition of the Code is published, usually in the year following the IBC, both in print and online. The Shenzhen Code was published on 26 June 2018, just under 11 months after the closing ceremony of the Shenzhen IBC (29 July 2017). The online edition, hosted by the International Association for Plant Taxonomy, was made available on 27 June 2018 (https://doi.org/10.12705/Code.2018). 
The Melbourne IBC of 2011 voted to give the Editorial Committee the option of publishing the Appendices of the Code in electronic form only. Although the Appendices of the Melbourne Code were published in print (Wiersema \& al., 2015a), an online database was also developed by John H. Wiersema (Wiersema \& al., 2015b, 2017), which provides not only any part or all of the Appendices on demand, but also gives the full history of all proposals to conserve or reject names, to suppress works, and requests for binding decisions, even when they were rejected and did not result in changes to the Appendices. The database is hosted by the Smithsonian National Museum of Natural History (https://naturalhistory2.si.edu/botany/codes-proposals/).

\section{SPECIAL-PURPOSE COMMITTEES}

The Nomenclature Section of an IBC can authorize Special-purpose Committees to investigate and discuss complex issues. This may stem from a particular proposal or set of proposals that cannot be resolved at the Section. The General Committee appoints the membership of the Special-purpose Committee, which (if all goes well) eventually reports with proposed solutions to the Nomenclature Section of the next IBC, often by publishing in Taxon a report and/or proposals to amend the Code. For example, three consecutive Special-purpose Committees to investigate electronic publication were established at the Tokyo, Saint Louis, and Vienna IBCs. The proposals of the first two Committees were rejected by the Saint Louis IBC in 1999 and the Vienna IBC in 2005, but those of the third were accepted by the Melbourne IBC in 2011, permitting certain electronic material to be effectively published under the Code. Two of the Special-purpose Committees established at the Melbourne IBC resulted in the new Division III of the Shenzhen Code and greater autonomy in the governance of fungal nomenclature, i.e. the creation of Chapter F and the authority of the Fungal Nomenclature Session of the IMC to amend it. The Special-purpose Committees established by the Shenzhen IBC, together with their mandates and members, were announced by Wilson (2019). The Fungal Nomenclature Session of an IMC also has the power to authorize Special-purpose Committees, which are appointed by the Nomenclature Committee for Fungi. Two were established by the San Juan IMC of 2018. 


\section{CHAPTER 14 | A VERY BRIEF HISTORY OF THE CODE}

This account is only the briefest of outlines of the development of the Code. For a very detailed account, up until the VIII International Botanical Congress held in Paris in 1954, see Nicolson (1991). For the remainder of the 20th century, see McNeill (2000).

\section{THE 18TH AND 19TH CENTURIES}

Linnaeus himself drew up a set of 365 principles that dealt to some extent with biological nomenclature, the Fundamenta botanica (Linnaeus, 1735), but these mostly died with their creator and are now forgotten. Early in the following century, Augustin Pyramus de Candolle put forward the principle of priority in his Théorie élémentaire de la botanique (Candolle, 1813). However, a formal set of rules for the nomenclature of algae, fungi, and plants did not come into being until more than half a century later when Alphonse de Candolle, son of Augustin Pyramus, published his Lois de la Nomenclature Botanique (Candolle, 1867). Candolle's Lois (Laws) were prepared at the request of the Organizing Committee of the International Botanical Congress held in Paris in 1867, to serve as a basis for discussions on controversial issues in nomenclature.

\section{SCHISM AND RECONCILIATION (1905-1930)}

The next set of rules, based on Candolle's Lois, were the Règles Internationales de la Nomenclature Botanique (International Rules of Botanical Nomenclature) produced at the II International Botanical Congress, held in Vienna in 1905 (Briquet, 1906). However, trouble was brewing. In the first decade of the 20th century, many scientists in the United States became frustrated by what they perceived as their European colleagues' sluggishness in adopting the type method, and were unhappy at what they saw as the arbitrariness of permitting so many exceptions to the rules through the conservation of numerous generic names at the Vienna Congress of 1905 (see Briquet, 1906: 72-93). They therefore decided to take a separate path and adopt their own set of rules, first the so-called "Philadelphia Code" (Arthur \& al., 1904) and then the American Code of Botanical Nomenclature (Arthur \& al., 1907). The next Congress, held in Brussels in 1910, produced a new edition of the Règles (Briquet, 1912), but the schism between it and the American Code persisted. The London Congress scheduled for 1915 was cancelled because of World War I. At the next Congress, held in Ithaca in 1926, J.I. Briquet, the Rapporteur-général at the Vienna and Brussels Congresses, introduced a round-table discussion on nomenclature (Section for Taxonomy, 1929) and A.S. Hitchcock made suggestions for reconciliation in a paper on the relevance of nomenclature to taxonomy 
(Hitchcock, 1929). The schism between much of the United States and the rest of the world ended in 1930, when the Cambridge Congress adopted the type method and produced the International Rules of Botanical Nomenclature (Briquet, 1935).

\section{DECREASINGLY AMBIGUOUS AND INCREASINGLY DETAILED}

The Amsterdam Congress of 1935 did not produce an official revised set of International Rules, but there were unofficial "Brittonia Rules" (Camp \& al., 1947) and a belated supplement to the previous Cambridge Rules (Sprague, 1950). The first International Code of Botanical Nomenclature (ICBN) was adopted by the Stockholm Congress of 1950 (Lanjouw \& al., 1952). Since then, there have been ten further decreasingly ambiguous and increasingly detailed editions of the International Code of Botanical Nomenclature, followed by two editions of the International Code of Nomenclature for algae, fungi, and plants, each Code adopted by each subsequent Congress and superseding all previous editions. 


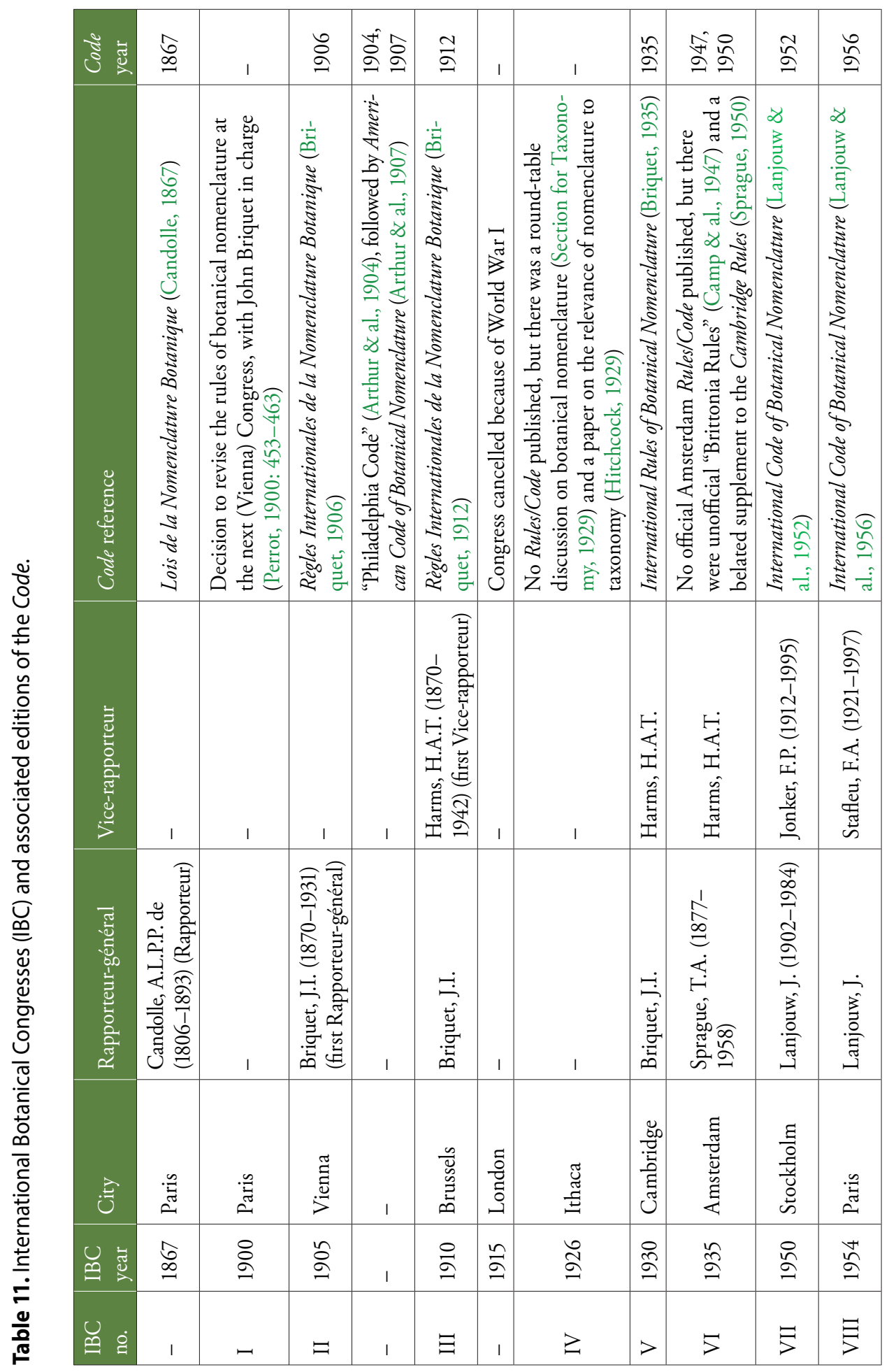




\begin{tabular}{|c|c|c|c|c|c|c|c|c|c|c|c|c|}
\hline 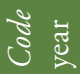 & Бొ & 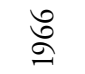 & $\stackrel{\widetilde{N}}{\approx}$ & $\stackrel{\infty}{\stackrel{2}{\Xi}}$ & $\stackrel{\mathscr{2}}{\varrho}$ & $\begin{array}{l}\infty \\
\stackrel{0}{\beth}\end{array}$ & $\stackrel{\varpi}{\check{\Xi}}$ & 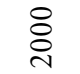 & ঃ্ণ & 룩 & $\stackrel{\infty}{\stackrel{\sim}{\sim}}$ & 1 \\
\hline 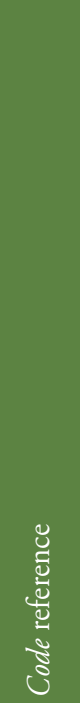 & 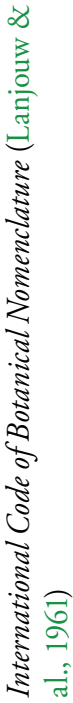 & 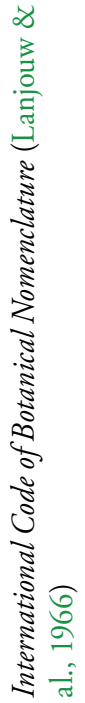 & 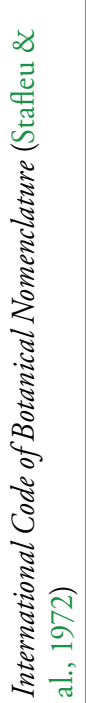 & 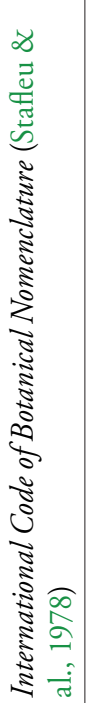 & 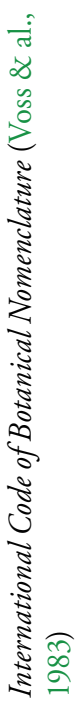 & 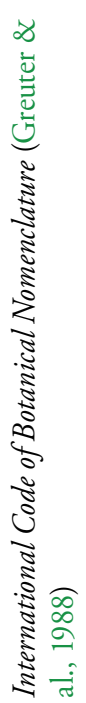 & 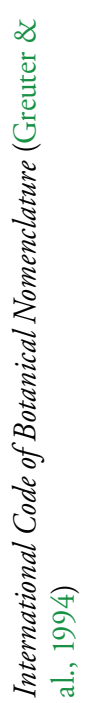 & 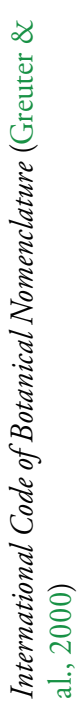 & 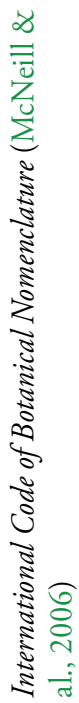 & 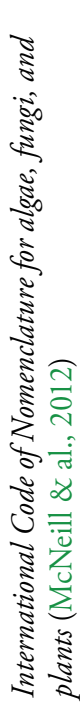 & 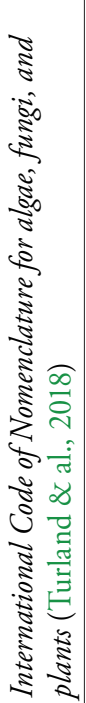 & \\
\hline 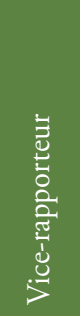 & 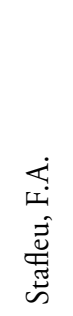 & 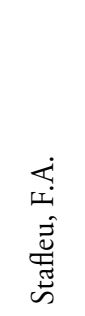 & 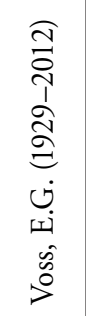 & $\begin{array}{l}\dot{0} \\
\text { بj } \\
\hat{0} \\
0\end{array}$ & 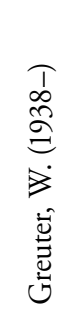 & 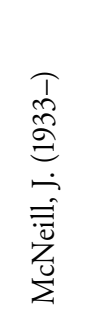 & 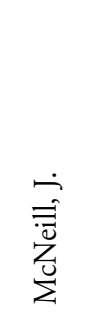 & 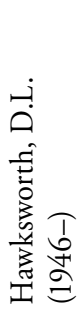 & 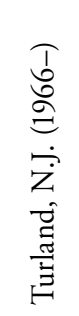 & 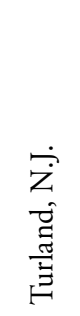 & 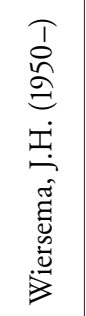 & 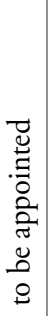 \\
\hline 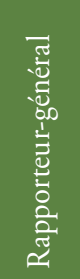 & 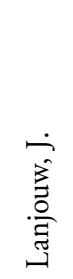 & $\stackrel{\dot{3}}{\stackrel{\dot{0}}{\frac{0}{\tilde{\sigma}}}}$ & 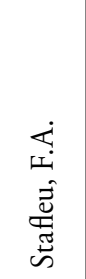 & 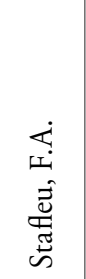 & 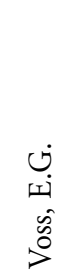 & 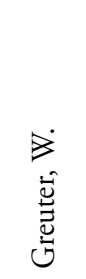 & 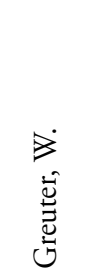 & 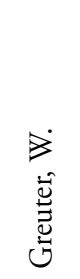 & 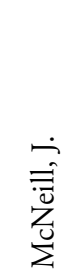 & $\begin{array}{l}\stackrel{\dot{\vec{J}}}{\overrightarrow{\vec{\Delta}}} \\
\stackrel{\vec{\Delta}}{\Sigma}\end{array}$ & $\begin{array}{l}\dot{\vec{Z}} \\
\dot{\vec{\Xi}} \\
\stackrel{\vec{\Xi}}{\Xi} \\
\vec{\Xi}\end{array}$ & 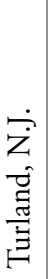 \\
\hline 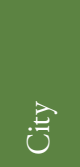 & $\begin{array}{l}\bar{\Xi} \\
\stackrel{\Xi}{ \pm} \\
\stackrel{0}{0}\end{array}$ & 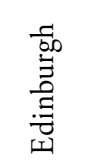 & $\begin{array}{l}\stackrel{U}{E} \\
\stackrel{\vec{J}}{\omega}\end{array}$ & 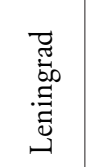 & 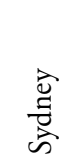 & $\stackrel{\Xi}{\Xi}$ & 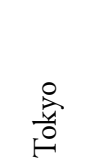 & 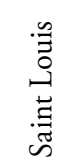 & 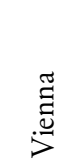 & 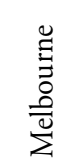 & 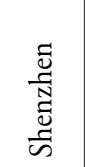 & 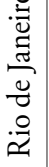 \\
\hline 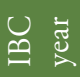 & $\widehat{\approx}$ & 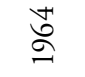 & ఏ & $\stackrel{n}{\widehat{\Omega}}$ & $\stackrel{\infty}{\varrho}$ & 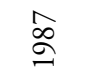 & 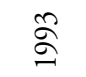 & Әे & 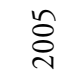 & 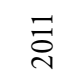 & $\widehat{\widehat{े}}$ & گి \\
\hline $\mathscr{\theta}$ & ג & $x$ & $\bar{x}$ & $\ddot{\bar{x}}$ & 釜 & 至 & 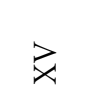 & $\sum$ & $\underset{x}{ }$ & $\underset{叉}{\Xi}$ & 爻 & $\sqrt[x]{x}$ \\
\hline
\end{tabular}




\section{CHAPTER 15 |RESOURCES FOR BIOLOGI- CAL NOMENCLATURE}

In this chapter I provide a selection of printed and online resources that should be useful—or even indispensable — to anyone engaged in the systematics of algae, fungi, or plants, but in particular their nomenclature. The list is not comprehensive. I have probably overlooked major resources in languages other than English, although the list is by no means restricted to English content. I have deliberately focused on nomenclatural and bibliographic resources, and have generally avoided those primarily concerned with phylogeny, taxonomy, biodiversity, genetics, or information technology.

\section{PRINTED}

Most of the books that traditionally have been the mainstay of biological nomenclature are now freely available online, and these are dealt with on pp. 152-155. This is, of course, immensely convenient for users with adequate access to the internet. Paper books are often expensive for institutions or individuals to purchase or they may require long-distance visits to specialist libraries.

International Code of Nomenclature for algae, fungi, and plants or Shenzhen Code (Turland \& al., 2018). Obviously the primary book is the current edition of the Code itself. The printed version is published by Koeltz Botanical Books (http:// www.koeltz.com/product.aspx?pid=212180), the online version is hosted by the International Association for Plant Taxonomy (see p. 152).

Other books of great utility include the following (arranged alphabetically by title):

A primer of botanical Latin with vocabulary (Short \& George, 2013). Although Botanical Latin has been the standard reference work for more than 50 years, it is not an easy starting point for those without prior knowledge of Latin. This primer, which is cross-referenced to Botanical Latin, has a more informal style, including sections on grammar, exercises, translating, and a 175 -page vocabulary of Latin and English words; you can supplement it with Botanical Latin when you want to know even more.

Botanical Latin, now in its 4th edition (Stearn, 1992), with a Spanish translation, Latin botánico (Stearn, 2006), contains practically everything one could ever need to know about the use of the Latin language in systematics. It will enable the reader to translate Latin descriptions and diagnoses of taxa into English (or Spanish), and vice versa, and it contains an extensive Latin and English (and Spanish) vocabulary that reveals the meaning of many technical terms and descriptive epithets of scientific names. 
Botanico-periodicum-buntianum, ed. 2. Whereas TL-2 (see below) deals with books, journals are dealt with by BPH-2, or Botanico-periodicum-huntianum, ed. 2 (Bridson \& al., 2004). The entries provide a comprehensive listing of almost all "periodicals with botanical content", a standard abbreviation for each journal title, the ranges of volume numbers and dates of the journals, and any preceding or superseding titles in a series. BPH-2 consists of two volumes (A-M and N-Z) and is also available online (see p. 154).

Fossilium catalogus II: Plantae. The index for plant fossils, a serial publication running from Pars 1 in 1913 to the most recent Pars 114 in 2016. It remains at present in printed form only, except for Pars $I$ to Pars $X$, which are available online (see p. 153).

Index kewensis. Printed catalogues of scientific names have largely been replaced by online databases in recent years. For example, the Index kewensis (Jackson, 1895) and its 21 supplements up to Supplement XXI (Challis \& Davies, 2002) include most names of genera and species of seed plants published between 1753 and 2000. Finding names in these catalogues could be a slow process because it was often necessary to check several volumes, e.g. if you were publishing the name of a new species and wanted to be sure that name had never been used before. Today all of this information is searchable online via the International Plant Names Index (IPNI; see p. 153), which should be used in preference to the printed catalogues because not only is the database much more up to date but the information is fuller and very many errors have been corrected.

Order out of chaos. A profoundly useful book is Order out of chaos: Linnaean plant names and their types (Jarvis, 2007). The first part of the book provides a very detailed account of Linnaeus's materials and methods and explains the process of choosing types to enable the precise application of Linnaean names. The second part is a catalogue of the 9000 or so names of species and varieties published by Linnaeus, with their types. The catalogue is also available online (see p. 154), with links to images of many of the type specimens.

Taxonomic literature, ed. 2 and its supplements, commonly called "TL-2", includes a huge amount of information on thousands of works published between 1753 and 1940 (including some pre-Linnaean materials). It is arranged by author, giving standard abbreviations of titles, precise dates of publication, location of copies, authors' biographical details and location of their herbarium specimens including types. The first seven volumes (Stafleu \& Cowan, 1976-1988) cover authors from A to Z; then eight supplementary volumes (Stafleu \& Mennega, 1992-2000; Dorr \& Nicolson, 2008-2009) provide additional information on authors from A to G. TL-2 is also available online (see p. 154). 


\section{ONLINE}

\section{The Code}

International Code of Nomenclature for algae, fungi, and plants or Shenzhen Code (Turland \& al., 2018), open-access version: https://doi.org/10.12705/Code.2018; in addition, members of the International Association for Plant Taxonomy can download a PDF version: https://www.iaptglobal.org/the-code-pdf

Appendices of the Shenzhen Code, a database providing any part or all of the Appendices of the Code on demand; also including the full history of all proposals to conserve or reject names, to suppress works, and requests for binding decisions, even when they were rejected and did not result in changes to the Appendices. Hosted by the Smithsonian National Museum of Natural History: https://naturalhistory2. si.edu/botany/codes-proposals/

Translations of the Shenzhen Code, at the time of writing (February 2019), French, bilingual French/English, Portuguese, and Spanish translations have been published, more languages are on the way: https://www.iaptglobal.org/shenzhen-code

Previous editions of the Code and their translations: https:/www.iaptglobal.org/ previous-codes

Overview of editions of the Code, by Paul van Rijckevorsel. All editions of the Code going back to the Lois de la Nomenclature Botanique (Candolle, 1867). Cross-references between provisions are hyperlinked, provisions are linked between consecutive editions, and bibliographic citations in the Shenzhen Code are linked to those publications online: https://www.iapt-taxon.org/historic/index.htm

\section{The other codes of nomenclature}

Draft BioCode (2011) (Greuter \& al., 2011): http://www.bionomenclature.net/ (see pp. 13-14).

International Code of Nomenclature for Cultivated Plants (ICNCP or Cultivated Plant Code), 9th edition (Brickell \& al., 2016), PDF version: https://www.ishs. org/sites/default/files/static/ScriptaHorticulturae_18.pdf (see also https:/www. ishs.org/scripta-horticulturae/international-code-nomenclature-cultivated-plantsninth-edition).

International Code of Nomenclature of Prokaryotes (Parker \& al., 2019): https:// doi.org/10.1099/ijsem.0.000778

International Code of Phylogenetic Nomenclature or PhyloCode, version 4c (Cantino \& Queiroz, 2010): https://www.ohio.edu/phylocode/ (see p. 14).

International Code of Virus Classification and Nomenclature (International Committee on Taxonomy of Viruses, 2018): https://talk.ictvonline.org/information/w/ ictv-information/383/ictv-code

International Code of Zoological Nomenclature (ICZN), 4th edition (International Commission on Zoological Nomenclature, 1999): http://www.nhm.ac.uk/hostedsites/iczn/code/ 


\section{Nomenclatural indexes, repositories, and other databases}

International Plant Names Index (IPNI), combining Index kewensis, for seed plants, Index filicum, for pteridophytes, the Gray Card Index, from the Harvard University Herbaria, and the Australian Plant Names Index (APNI): https://www.ipni.org/. It also includes a database of authors, with standard forms based on and much updated since Authors of plant names (Brummitt \& Powell, 1992): https:/www.ipni.org/ ipni/authorsearchpage.do. There is also a comprehensive database of publications with standard abbreviations: https://www.ipni.org/ipni/publicationsearchpage.do

Tropicos, the Missouri Botanical Garden's online database, incorporating Index of Mosses and Index to Plant Chromosome Numbers (IPCN). It includes names, with data on taxonomic acceptance and synonymy, types, specimens, images, publications, and much more: http://www.tropicos.org/

Index Hepaticarum, for names of liverworts and hornworts (Marchantiophyta and Anthocerotophyta): http://www.ville-ge.ch/musinfo/bd/cjb/hepatic/index.php

Fungal Names, Index Fungorum, and MycoBank are the three currently recognized nomenclatural repositories for organisms treated as fungi, providing the registration of names and types mandatory under Art. F.5 (see pp. 118-119): Fungal Names: http://www.fungalinfo.net/, Index Fungorum: http://www. indexfungorum.org/, MycoBank: http://www.mycobank.org/

AlgaeBase (http://www.algaebase.org/) and DiatomBase (http://www.diatombase. org/) are databases of taxonomic, nomenclatural, and distributional information on algae worldwide.

Index Nominum Algarum, for names of algae: http://ucjeps.berkeley.edu/INA.html PhycoBank, voluntary registration of nomenclatural acts (new names and types) of algae: https://www.phycobank.org/

Catalogue of Life, an inter-kingdom database allowing simultaneous searches of other data sources covering algae, fungi, plants, animals, prokaryotes, and viruses. It claims to be the most comprehensive and authoritative global index of species currently available, holding information on the names, relationships, and distributions of over 1.8 million species (February 2019): http://www.catalogueoflife.org/

Fossilium catalogus II: Plantae (see p. 151), Pars I (1913) to Pars X (1922) are available online through the Biodiversity Heritage Library: https:/www.biodiversitylibrary. org/bibliography/146191\#/summary

International Fossil Plant Names Index, voluntary registration of names and types for all fossil-taxa covered by the Code, publications containing them, and authors of such publications: https://fossilplants.info/

Plant Fossil Names Registry, a database of fossil plant names, types, works, and authors, offering voluntary registration of names and types (fossil fungi, diatoms, and presumably other fossil algae are excluded): https://www.fossilplantnames.org/

Index Nominum Genericorum (ING), for generic names of algae, fungi, and plants, including fossils: https:/naturalhistory2.si.edu/botany/ing/

Indices Nominum Supragenericorum Plantarum Vascularium, for names of vascular plants above the rank of genus (e.g. tribes, families, orders, etc.): http://www. plantsystematics.org/reveal/pbio/fam/allspgnames.html

The Linnaean database, from the Linnaean Plant Name Typification Project at the 
Natural History Museum, London, is the online catalogue of Linnaean algal, fungal, and plant names and their types, published also in book form in Order out of chaos (see p. 151): http://www.nhm.ac.uk/our-science/data/linnaean-typification/ databasehome.html

\section{Bibliography}

Botanico-periodicum-huntianum, ed. 2 (BPH-2; Bridson \& al., 2004; for details see p. 151): http://www.huntbotanical.org/databases/show.php?1

Taxonomic literature, ed. 2 (TL-2; Stafleu \& Cowan, 1976-1988; Stafleu \& Mennega, 1992-2000; Dorr \& Nicolson, 2008-2009; for details see p. 151): http://www. sil.si.edu/digitalcollections/tl-2/index.cfm

\section{Digital libraries}

Biblioteca Digital del Real Jardín Botánico de Madrid, containing numerous publications that are not included in Biodiversity Heritage Library: http://bibdigital. rjb.csic.es/spa/index.php

Biodiversity Heritage Library, containing ca. 145,000 titles (in January 2019) of scanned literature mostly published before 1924, i.e. material in the public domain in the United States, although material published from 1924 onward is included where permitted under copyright law; also providing links to material in the Biblioteca Digital del Real Jardín Botánico de Madrid: https://www.biodiversitylibrary.org/

Gallica, the digital library project of the Bibliothèque Nationale de France, especially rich in French-language publications: https://gallica.bnf.fr/

JSTOR, a digital archive of scholarly journals. A paid subscription is necessary for full access, but you can read up to six articles each month for free if you register for a free "MyJSTOR" account: https://www.jstor.org/

Seed lists (indices seminum), a guide to the species descriptions published in seed lists from Botanic Gardens for the period 1800-1900, with many scanned seed lists from the 19th century, from the Naturalis Biodiversity Center, Leiden: https:// seedlists.naturalis.nl/home.htm

Google Books (https://books.google.com/) and the Internet Archive (https://archive. org/) may be useful for finding titles that are not available through the above resources.

\section{Library catalogues}

Many major scientific institutions, as well as national libraries and archives, have placed their library catalogues online for searching and browsing. They are not listed here, but can be searched for online. The following resource, however, is useful for its global coverage. 
Karlsruher Virtueller Katalog (Karlsruhe Virtual Catalogue), a powerful search interface for books, serials, and digital media in library and trade catalogues worldwide, with a particular focus on German-speaking countries and other European countries: https://kvk.bibliothek.kit.edu/

WorldCat, enabling simultaneous searching for books and other materials in thousands of library catalogues worldwide: https://www.worldcat.org/

\section{Herbaria}

Many of the world's herbaria have been digitized, at least in part, and made available online. They are not listed here, but can be searched for online. The following two resources have a more general scope.

Index Herbariorum, with details of the world's herbaria, the standard herbarium codes used for citing them (e.g. B, KUN, MEXU), their collections, and their current staff, with contact details and research interests: http://sweetgum.nybg.org/ science/ih/

JSTOR Global Plants, digitized type specimens from a large number of participating herbaria worldwide. A paid subscription is necessary to access the images, although the metadata (and thumbnail images) are open access: https://plants.jstor.org/

\section{Handwriting}

Auxilium ad Botanicorum Graphicem, providing images of handwriting. These samples are useful for evaluating annotations on herbarium specimens in ordewr to recognize potential types: http://www.ville-ge.ch/musinfo/bd/cjb/auxilium/index.php

\section{Latin language tools}

A Grammatical Dictionary of Botanical Latin, a work still in progress, but now mostly complete: http://www.mobot.org/mobot/LatinDict/search.aspx

William Whitaker's Words, an accurate and comprehensive online Latin-English and English-Latin dictionary, which usefully includes all inflected forms of words (different cases, numbers, conjugations, tenses, etc.): http://archives.nd.edu/words.html

\section{Glossary}

Terms used in bionomenclature (Hawksworth, 2010), is a comprehensive glossary of terms used in all disciplines of biological nomenclature, i.e. botanical, cultivated organismal, mycological, phycological, phylogenetic, phytosociological, prokaryotic, viral, and zoological nomenclature. In printed and PDF versions, the PDF available at: https://www.gbif.org/document/80577 


\section{REFERENCES}

Arthur, J.C., Barnhart, J.H., Britton, N.L., Brown, S., Clements, F.E., Cook, O.F., Coulter, J.M., Coville, F.V., Earle, F.S., Evans, A.W., Hazen, T.E., Hollick, A., Howe, M.A., Knowlton, F.H., Moore, G.T., Morris, E.L., Murrill, W.A., Rusby, H.H., Shear, C.L., Trelease, W., Underwood, L.M., White, D. \& Wight, W.F. 1904. Code of Botanical Nomenclature. Bull. Torrey Bot. Club 31: 249-261. https://doi.org/10.2307/2478576

Arthur, J.C., Barnhart, J.H., Britton, N.L., Clements, F.E., Cook, O.F., Coville, F.V., Earle, F.S., Evans, A.W., Hazen, T.E., Hollick, A., Howe, M.A., Knowlton, F.H., Moore, G.T., Rusby, H.H., Shear, C.L., Underwood, L.M., White, D. \& Wight, W.F. 1907. American Code of Botanical Nomenclature. Bull. Torrey Bot. Club 34: 167-178. https://doi.org/10.2307/2479237

Barkley, T.M., DePriest, P., Funk, V., Kiger, R.W., Kress, W.J., McNeill, J., Moore, G., Nicolson, D.H., Stevenson, D.W. \& Wheeler, Q.D. 2004. A review of the International Code of Botanical Nomenclature with respect to its compatibility with phylogenetic classification. Taxon 53: 159-161. https://doi.org/10.2307/4135502

Bornet, E. \& Flahault, C. 1886-1888. Révision des Nostocacées hétérocystées contenues dans les principaux herbiers de France. Ann. Sci. Nat., Bot., ser. 7, 3: 323-381; 4: 343-373; 5: 51-129; 7: 177-262. https://biodiversitylibrary.org/page/43093059

Brickell, C.D., Alexander, C., Cubey, J.J. David, J.C., Hoffman, M.H.A., Leslie, A.C., Malécot, V. \& Jin, X.-B. (eds.) 2016. International Code of Nomenclature for Cultivated Plants (ICNCP or Cultivated Plant Code) incorporating the Rules and Recommendations for naming plants in cultivation, 9th ed., Adopted by the International Union of Biological Sciences International Commission for the Nomenclature of Cultivated Plants. Scripta Horticulturae 18. Leuven: International Society for Horticultural Science. https://www.ishs.org/sites/default/files/static/ScriptaHorticulturae_18.pdf

Bridson, G.D.R., Townsend, S.T., Polen, E.A. \& Smith, E.R. 2004. BPH-2: Periodicals with botanical content; Constituting a second edition of Botanico-Periodicum-Huntianum, 2 vols. Pittsburgh: Hunt Institute for Botanical Documentation, Carnegie Mellon University.

Briquet, J. 1906. Règles Internationales de la Nomenclature Botanique adoptées par le Congrès International de Botanique de Vienne 1905. Jena: Gustav Fischer.

Briquet, J. 1912. Règles Internationales de la Nomenclature Botanique adoptées par le Congrès International de Botanique de Vienne 1905 deuxième édition mise au point d'après les décisions du Congrès International de Botanique de Bruxelles 1910. Jena: Gustav Fischer. https://doi.org/10.5962/bhl.title.33717

Briquet, J. 1935. International Rules of Botanical Nomenclature: Adopted by the International Botanical Congresses of Vienna, 1905, and Brussels, 1910; Revised by the International Botanical Congress of Cambridge, 1930. Jena: Gustav Fischer. 
Brummitt, R.K. \& Powell, C.E. 1992. Authors of plant names: A list of authors of scientific names of plants with recommended standard forms of their names, including abbreviations. Kew: Royal Botanic Gardens, Kew.

Cachon, J. \& Cachon, M. 1969: Contribution à l'étude des Noctilucidae Saville-Kent. Évolution morphologique, cytologie, systématique. II. Les Leptodiscinae Cachon J. et M. Protistologica 5: 11-32.

Camp, W.H., Rickett, H.W. \& Weatherby, C.A. 1947. International Rules of Botanical Nomenclature: Formulated by the International Botanical Congresses of Vienna, 1905, Brussels, 1910, and Cambridge, 1930; Adopted and revised by the International Botanical Congress of Amsterdam, 1935, unofficial special edition, issued as a service to the members of the American Society of Plant Taxonomists. Brittonia 6(1). New York: New York Botanical Garden and American Society of Plant Taxonomists.

Candolle, A.P. de 1838-1839. Prodromus systematis naturalis regni vegetabilis, sive enumeratio contracta ordinum, generum, specierumque plantarum huc usque cognitarum, juxta methodi naturalis normas digesta, vol. 7 [part 1, 1838; part 2, 1839]. Parisiis: Sumptibus Sociorum Treuttel et Würtz. https://doi.org/10.5962/bhl.title.286

Candolle, A. de 1867. Lois de la Nomenclature Botanique adoptées par le Congrès International de Botanique tenu à Paris en août 1867 suivies d'une deuxième édition de l'introduction historique et du commentaire qui accompagnaient la rédaction préparatoire présentée au Congrès. Genève et Bale [Basel]: H. Georg; Paris: J.-B. Baillière et fils. https:/gallica.bnf.fr/ark:/12148/bpt6k981450

Candolle, A.P. de 1813. Théorie élémentaire de la botanique. Paris: Déterville. https:// doi.org/10.5962/bhl.title.39705

Cantino, P.D. \& Queiroz, K. de 2010. International Code of Phylogenetic Nomenclature, version 4c. https://www.ohio.edu/phylocode/

Challis, K.M. \& Davies, R.A. 2002. Index kewensis, suppl. 21, Names of seed-bearing plants at the rank of family and below published between January 1996 and the end of 2000 with some omissions from earlier years. Kew: Royal Botanic Gardens, Kew. https://www.biodiversitylibrary.org/bibliography/66820\#/summary

Crantz, H.J.N. 1769. Classis cruciformium emendata cum figuris aeneis in necessarium instit. rei herbariae supplementum. Lipsiae: Impensis Ioannis Pauli Kraus. http:// bibdigital.rjb.csic.es/ing/Libro.php?Libro=4074

David, J., Garrity, G.M., Greuter, W., Hawksworth, D.L., Jahn, R., Kirk, P.M., McNeill, J., Michel, E., Knapp, S., Patterson, D.J., Tindall, B.J., Todd, J.A., Tol, J. van \& Turland, N.J. 2012. Biological nomenclature terms for facilitating communication in the naming of organisms. ZooKeys 192: 67-72. https://doi.org/10.3897/ zookeys.192.3347

Davidse, G., Soreng, R.J. \& Peterson, P.M. 2009. Agrostopoa (Poaceae, Pooideae, Poeae, Poinae), a new genus with three species from Colombia. Novon 19: 32-40. https:// doi.org/10.3417/2007132

Dorr, L.J. \& Nicolson, D.H. 2008-2009. Taxonomic literature: A selective guide to botanical publications and collections with dates, commentaries and types, 2nd ed., suppls. 7-8. Regnum Vegetabile 149, 150. Ruggell: Gantner. http://www.sil.si.edu/ DigitalCollections/tl-2/index.cfm 
Flann, C., McNeill, J., Barrie, F.R., Nicolson, D.H., Hawksworth, D.L., Turland, N.J. \& Monro, A.M. 2015. Report on botanical nomenclature-Vienna 2005. XVII International Botanical Congress, Vienna: Nomenclature Section, 12-16 July 2005. PhytoKeys 45: 1-341. https://doi.org/10.3897/phytokeys.45.9138

Flann, C., Turland, N.J. \& Monro, A.M. 2014. Report on botanical nomenclatureMelbourne 2011. XVIII International Botanical Congress, Melbourne: Nomenclature Section, 18-22 July 2011. PhytoKeys 41: 1-289. https://doi.org/10.3897/ phytokeys.41.8398

Fries, E. 1821-1832. Systema mycologicum, sistens fungorum ordines, genera et species, huc usque cognitas, quas ad normam methodi naturalis determinavit, disposuit atque descripsit. 3 vols. [with additional Index in vol. 3]. Lundae: Ex Officina Berlingiana [vols. $1 \& 2$ ]; Gryphiswaldae: Sumtibus Ernesti Mauritii [vol. 3]. https://doi. org/10.5962/bhl.title.5378

Fries, E. 1828. Elenchus fungorum, sistens commentarium in systema mycologicum. 2 vols. Gryphiswaldiae: Sumptibus Ernesti Mauritii. http://bibdigital.rjb.csic.es/ing/ Libro.php?Libro=3065; http://bibdigital.rjb.csic.es/ing/Libro.php?Libro=3066

Gandoger, M. 1883-1891. Flora Europae terrarumque adjacentium sive enumeratio plantarum per Europam atque totam regionem mediterraneam cum insulis atlanticis sponte crescentium, novo fundamento instauranda. 27 vols. Parisiis: F. Savy; Londini: Bernard Quaritch, Williams and Norgate; Neoboraci: Westermann and Co.; Mediolani: Ulrico Hoepli; Berolini: Friedländer und Sohn [publishers vary between volumes].

Gledhill, D. 2008. The names of plants, 4th ed. Cambridge, U.K. \& New York: Cambridge University Press. https://doi.org/10.1017/CBO9780511550898

Goldenberg, R., de Fraga, C.N., Fontana, A.P., Nicolas, A.N. \& Michelangeli, F.A. 2012. Taxonomy and phylogeny of Merianthera (Melastomataceae). Taxon 61: 1040-1056. https://www.jstor.org/stable/41679349

Gomont, M. 1892-1893. Monographie des Oscillariées (Nostocacées homocystées). Ann. Sci. Nat., Bot., ser. 7, 15: 263-368; 16: 91-264. https://biodiversitylibrary. org/page/43357141

Greuter, W., Burdet, H.M., Chaloner, W.G., Demoulin, V., Grolle, R., Hawksworth, D.L., Nicolson, D.H., Silva, P.C., Stafleu, F.A., Voss, E.G. \& McNeill, J. (eds.) 1988. International Code of Botanical Nomenclature: Adopted by the Fourteenth International Botanical Congress, Berlin, July-August 1987. Regnum Vegetabile 118. Königstein: Koeltz Scientific Books.

Greuter, W., Barrie, F.R., Burdet, H.M., Chaloner, W.G., Demoulin, V., Hawksworth, D.L., Jørgensen, P.M., Nicolson, D.H., Silva, P.C., Trehane, P. \& McNeill, J. (eds.) 1994. International Code of Botanical Nomenclature (Tokyo Code): Adopted by the Fifteenth International Botanical Congress, Yokohama, August-September 1993. Regnum Vegetabile 131. Königstein: Koeltz Scientific Books. https://archive.bgbm.org/ iapt/nomenclature/code/tokyo-e/default.htm

Greuter, W., Hawksworth, D.L., McNeill, J., Mayo, M.A., Minelli, M., Sneath, P.H.A., Tindall, B.J., Trehane, P. \& Tubbs, P. (eds.) 1998. Draft BioCode (1997): The prospective international rules for the scientific names of organisms. Taxon 47: 127-150. https://doi.org/10.2307/1224030 
Greuter, W., McNeill, J., Barrie, F.R., Burdet, H.M., Demoulin, V., Filgueiras, T.S., Nicolson, D.H., Silva, P.C., Skog, J.E., Trehane, P., Turland, N.J. \& Hawksworth, D.L. (eds.) 2000. International Code of Botanical Nomenclature (Saint Louis Code): Adopted by the Sixteenth International Botanical Congress St Louis, Missouri, JulyAugust 1999. Regnum Vegetabile 138. Königstein: Koeltz Scientific Books. https:// archive.bgbm.org/iapt/nomenclature/code/SaintLouis/0000St.Luistitle.htm

Greuter, W., Garrity, G., Hawksworth, D.L., Jahn, R., Kirk, P.M., Knapp, S., McNeill, J., Michel, E., Patterson, D.J., Pyle, R. \& Tindall, B.J. (eds.) 2011. Draft BioCode (2011): Principles and Rules Regulating the Naming of Organisms. Taxon 60: 201-212. https://www.jstor.org/stable/41059835

Haller, A. von 1753. Enumeratio plantarum horti regii et agri gottingensis. Göttingen: apud Viduam Abrami Vandenhoeckii. https://doi.org/10.5962/bhl.title.47075

Hawksworth, D.L. 2010. Terms used in bionomenclature: The naming of organisms (and plant communities); Including terms used in botanical, cultivated plant, phylogenetic, phytosociological, prokaryote (bacteriological), virus, and zoological nomenclature. Copenhagen: Global Biodiversity Information Facility. https:/www.gbif.org/document/80577

Hedwig, J. 1801. Species muscorum frondosorum descriptae et tabulis aeneis lxxvii coloratis illustratae. Lipsiae: sumtu Joannis Ambrosii Barthii; Parisiis: apud Amand Koenig. https://doi.org/10.5962/bhl.title.26

Hirn, K. E. 1900. Monographie und Iconographie der Oedogoniaceen. Acta Soc. Sci. Fenn. 27. https://biodiversitylibrary.org/page/14098280

Hitchcock, A.S. 1929. The relation of nomenclature to taxonomy. Pp. 1434-1439 in: Duggar, B.M. (ed.), Proceedings of the International Congress of Plant Sciences, Ithaca, New York, August 16-23, 1926. Menasha, Wisconsin: George Banta Publishing Company.

Hooker, J.D. 1872-1897. The flora of British India. 7 vols. London: L. Reeve \& Co. https://doi.org/10.5962/bhl.title.678

Iltis, H.H. \& Doebley, J.F. 1980. Taxonomy of Zea (Gramineae). II. Subspecific categories in the Zea mays complex and a generic synopsis. Amer. J. Bot. 67: 994-1004. https://doi.org/10.1002/j.1537-2197.1980.tb07731.x

International Commission on Zoological Nomenclature 1999. International Code of Zoological Nomenclature, 4th ed., Adopted by the International Union of Biological Sciences. London: International Trust for Zoological Nomenclature. http://www. nhm.ac.uk/hosted-sites/iczn/code/

International Committee on Taxonomy of Viruses 2018. The International Code of Virus Classification and Nomenclature. October 2018. Published at https://talk.ictvonline. org/information/w/ictv-information/383/ictv-code

Jackson, B.D. 1895. Index kewensis plantarum phanerogamarum: Nomina et synonyma omnium generum et specierum a Linnaeo usque ad annum MDCCCLXXXV complectens nomine recepto auctore patria unicuique plantae subjectis, 2 vols. Oxford: Clarendon Press. https://doi.org/10.5962/bhl.title.66720

Jacquin, N.J. 1804. Plantarum rariorum horti caesarei schoenbrunnensis descriptiones et icones, vol. 4. Viennae: apud C. F. Wappler; Londini: apud B. et J. White; Lugduni Batavorum: apud S. et J. Luchtmans. https://doi.org/10.5962/bhl.title.332 
Janda, V., Kř́ž, M. \& Kolařík, M. 2019. Butyriboletus regius and Butyriboletus fechtneri: typification of two well-known species. Czech Mycol. 71: 1-32. http://www. czechmycology.org/_cmo/CM71101.pdf

Jarvis, C. 2007. Order out of chaos: Linnaean plant names and their types. London: Linnean Society of London \& the Natural History Museum.

Jarvis, C.E., Barrie, F.R., Allan, D.M. \& Reveal, J.L. (eds.) 1993. A list of Linnaean generic names and their types. Regnum Vegetabile 127. Königstein: Koeltz Scientific Books.

Jeffrey, C. 1989. Biological nomenclature, 3rd ed. London: Edward Arnold.

Jørgensen, P.M. 2012. New names in Gunnerus's Flora Norvegica, and their typification. Taxon 61: 1088-1095. https://www.jstor.org/stable/41679352

Jussieu, A.L. de 1789. Genera plantarum secundum ordines naturales disposita juxta methodum in horto regio parisiensi exaratum, anno M. DCC. LXXIV. Parisiis: apud Viduam Herissant et Theophilum Barrois. https://doi.org/10.5962/bhl.title.284

Klak, C. \& Bruyns, P.V. 2012. Phylogeny of the Dorotheantheae (Aizoaceae), a tribe of succulent annuals. Taxon 61: 293-307. https://www.jstor.org/stable/23210522

Knapp, S., Lamas, G., Nic Lughadha, E. \& Novarino, G. 2004. Stability or stasis in the names of organisms: the evolving codes of nomenclature. Philos. Trans., Ser. B 359: 611-622. https://doi.org/10.1098/rstb.2003.1445

Kuntze, O. 1891. Revisio generum plantarum vascularium omnium atque cellularium multarum secundum leges nomenclaturae internationales cum enumeratione plantarum exoticarum in itinere mundi collectarum, pars 1. Leipzig: Arthur Felix; London: Dulau \& Co.; Milano: U. Hoepli; New-York: Gust. E. Stechert; Paris: Charles Klincksieck. https://doi.org/10.5962/bhl.title.327

Lanjouw, J., Baehni, C., Merrill, E.D., Rickett, H.W., Robyns, W., Sprague, T.A. \& Stafleu, F.A. (eds.) 1952. International Code of Botanical Nomenclature: Adopted by the Seventh International Botanical Congress, Stockholm, July 1950. Regnum Vegetabile 3. Utrecht: International Bureau for Plant Taxonomy and Nomenclature of the International Association for Plant Taxonomy.

Lanjouw, J., Baehni, C., Robyns, W., Rollins, R.C., Ross, R., Rousseau, J., Schulze, G.M., Smith, A.C., Vilmorin, R. de \& Stafleu, F.A. (eds.) 1956. International Code of Botanical Nomenclature: Adopted by the Eighth International Botanical Congress, Paris, July 1954. Regnum Vegetabile 8. Utrecht: International Bureau for Plant Taxonomy and Nomenclature of the International Association for Plant Taxonomy.

Lanjouw, J., Baehni, C., Robyns, W., Ross, R., Rousseau, J., Schopf, J.M., Schulze, G.M., Smith, A.C., Vilmorin, R. de \& Stafleu, F.A. (eds.) 1961. International Code of Botanical Nomenclature: Adopted by the Ninth International Botanical Congress Montreal, August 1959. Regnum Vegetabile 23. Utrecht: International Bureau for Plant Taxonomy and Nomenclature of the International Association for Plant Taxonomy.

Lanjouw, J., Mamay, S.H., McVaugh, R., Robyns, W., Rollins, R.C., Ross, R., Rousseau, J., Schulze, G.M., Vilmorin, R. de \& Stafleu, F.A. 1966. International Code of Botanical Nomenclature: Adopted by the Tenth International Botanical Congress Edinburgh, August 1964. Regnum Vegetabile 46. Utrecht: International Bureau for Plant Taxonomy and Nomenclature of the International Association for Plant Taxonomy. 
Linnaeus, C. 1735 ["1736"]. Fundamenta botanica quae majorum operum prodromi instar theoriam scientiae botanices per breves aphorismos tradunt. Amstelodami: apud Salomonem Schouten. http://bibdigital.rjb.csic.es/ing/Libro.php?Libro=2308

Linnaeus, C. 1753. Species plantarum, exhibentes plantas rite cognitas, ad genera relatas, cum differentiis specificis, nominibus trivialibus, synonymis selectis, locis natalibus, secundum sytema sexuale digestas, 2 vols. Holmiae: Impensis Laurentii Salvii. https:// doi.org/10.5962/bhl.title.669

Linnaeus, C. 1758-1759. Systema naturae per regna tria naturae, secundum classes, ordines, genera, species, cum characteribus, differentiis, synonymis, locis, 10th ed., vol. 1 [1758] and vol. 2 [1759]. Holmiae: Impensis Direct. Laurentii Salvii. https://doi. org/10.5962/bhl.title.542

Luch, R.M. \& Lücking, R. 2018. The genus Halegrapha new to Hawaii, with the new and potentially endemic species $H$. paulseniana and an updated checklist of Hawaiian lirellate Graphidaceae (Ascomycota: Ostropales). - Willdenowia 48: 415-423. https://doi.org/10.3372/wi.48.48311

May, T.W. \& Miller, A.N. 2018. XI International Mycological Congress: Guiding Vote on nomenclature proposals to amend Chapter F of the International Code of Nomenclature for algae, fungi, and plants. IMA Fungus 9: (xv)-(xxi). https://link. springer.com/article/10.1007/BF03449447

May, T.W. \& Redhead, S.A. 2018. Synopsis of proposals on fungal Nomenclature: a review of the proposals concerning Chapter F of the International Code of Nomenclature for algae, fungi, and plants submitted to the XI International Mycological Congress, 2018. IMA Fungus 9: (ix)-(xiv). https://link.springer.com/article/10.1007/ BF03449482

May, T.W., Redhead, S.A., Lombard, L. \& Rossman, A.Y. 2018. XI International Mycological Congress: report of Congress action on nomenclature proposals relating to fungi. IMA Fungus 9: (xxii)-(xxvii). https://link.springer.com/article/10.1007/ BF03449448

McNeill, J. 2000. Naming the groups: Developing a stable and efficient nomenclature. Taxon 49: 705-720. https://doi.org/10.2307/1223972

McNeill, J. 2014. Holotype specimens and type citations: General issues. Taxon 63: 1112-1113. https://doi.org/10.12705/635.7

McNeill, J., Barrie, F.R., Burdet, H.M., Demoulin, V., Hawksworth, D.L., Marhold, K., Nicolson, D.H., Prado, J., Silva, P.C., Skog, J.E., Wiersema, J.H. \& Turland, N.J. (eds.) 2006. International Code of Botanical Nomenclature (Vienna Code): Adopted by the Seventeenth International Botanical Congress Vienna, Austria, July 2005. Regnum Vegetabile 146. Ruggell: Gantner. https:/www.iapt-taxon.org/icbn/main.htm

McNeill, J. \& Wiersema, J.H. 2018. Guidelines for requests for binding decisions on application of the Code. Taxon [without volume, 2 pp.]: https://www.iaptglobal. org/taxon-guidelines

McNeill, J., Barrie, F.R., Buck, W.R., Demoulin, V., Greuter, W., Hawksworth, D.L., Herendeen, P.S., Knapp, S., Marhold, K., Prado, J., Prud'homme van Reine, W.F., Smith, G.F., Wiersema, J.H. \& Turland, N.J. (eds.) 2012. International Code of Nomenclature for algae, fungi, and plants (Melbourne Code): Adopted by the Eighteenth In- 
ternational Botanical Congress Melbourne, Australia, July 2011. Regnum Vegetabile 154. Königstein: Koeltz Scientific Books. https://www.iapt-taxon.org/melbourne/main.php McNeill, J., Redhead, S.A. \& Wiersema, J.H. 2018. Guidelines for proposals to conserve or reject names. Taxon [without volume, 4 pp.]: https://www.iaptglobal.org/ taxon-guidelines

McNeill, J., Shaw, J.M.H. \& Wiersema, J.H. 2016. (390) Proposal to preclude homonymy of generic names with names of intergeneric graft-hybrids (chimaeras). Taxon 65: 1198-1199. https://doi.org/10.12705/655.39

Micheli, P.A. 1729. Nova plantarvm genera ivxta Tovrnefortii methodvm disposita Quibus Plantae MDCCCC recensentur, scilicet fere MCCCC nondum observatae, reliquae suis sedibus restitutae; quarum vero figuram exhibere visum fuit, eae ad DL aeneis Tabulis CVIII. graphice expressae sunt; Adnotationibus, atque Observationibus, praecipue Fungorum, Mucorum, affiniumque Plantarum sationem, ortum, \& incrementum spectantibus, interdum adiectis. Florentiae: Typis Bernardi Paperinii. https:// doi.org/10.5962/bhl.title. 49380

Miller, P. 1768. The gardeners dictionary: Containing the best and newest methods of cultivating and improving the kitchen, fruit, flower garden, and nursery; As also for performing the practical parts of agriculture: including the management of vineyards, with the methods of making and preserving wine, according to the present practice of the most skilful vignerons in the several wine countries in Europe. Together with directions for propagating and improving, from real practice and experience, all sorts of timber trees, the eighth edition, revised and altered according to the latest system of botany; and embellished with several copper-plates, which were not in some former editions. London: printed for the author. https://doi.org/10.5962/bhl.title.541

Moench, C. 1794. Methodus plantas horti botanici et agri Marburgensis, a staminum situ describendi. Marburgi Cattorum: in officina nova libraria academiae. https://doi. org/10.5962/bhl.title.304

Morison, R. 1680. Plantarum historiae universalis oxoniensis pars secunda seu herbarum distributio nova, per tabulas cognationis \& affinitatis ex libro naturae observata \& detecta. Oxonii: e Theatro Sheldoniano. http://bibdigital.rjb.csic.es/ing/Libro.php?Libro=5551

Motyka, J. 1995-1996. Porosty (Lichenes). Rodzina Lecanoraceae. 4 vols. Lublin: Lubelskie Towarzystwo Naukowe.

Nicolson, D.H. 1991. A history of botanical nomenclature. Ann. Missouri Bot. Gard. 78: 33-56. https://doi.org/10.2307/2399589

Oren, A. \& Tindall, B.J. 2005. Nomenclature of the Cyanophyta/Cyanobacteria/cyanoprokaryotes under the International Code of Nomenclature of Prokaryotes. Algol. Stud. 117: 39-52. https://doi.org/10.1127/1864-1318/2005/0117-0039

Oren, A., Komárek, J. \& Hoffmann, L. 2009. Nomenclature of the Cyanophyta/Cyanobacteria/Cyanoprokaryotes - What has happened since IAC Luxembourg? Algol. Stud. 130: 17-26. https://doi.org/10.1127/1864-1318/2009/0130-0017

Ortiz, S. \& Zinnecker-Wiegand, U. 2011. Valid publication of names in Astereae originally proposed in 1990 in a University of Munich dissertation. Taxon 60: 11941198. https://www.jstor.org/stable/41317339 
Parker, C.T., Tindall, B.J. \& Garrity, G.M. (eds.) 2019. International Code of Nomenclature of Prokaryotes. Prokaryotic Code (2008 revision). Int. J. Syst. Evol. Microbiol. 69(1A): S1-S111. https://doi.org/10.1099/ijsem.0.000778

Peralta, I.E., Spooner, D.M. \& Knapp, S. 2008. Taxonomy of wild tomatoes and their relatives (Solanum sect. Lycopersicoides, sect. Juglandifolia, sect. Lycopersicon; Solanaceae). Syst. Bot. Monogr. 84: 1-186. https://www.jstor.org/stable/i25027970

Perrot, E. (ed.) 1900. Actes du $1^{\text {er }}$ Congrès International de Botanique. Tenu à Paris à l'occasion de l'Exposition Universelle de 1900. Lons-le-Saunier: Lucien Declume.

Persoon, C.H. 1801. Synopsis methodica fungorum. Sistens enumerationem omnium huc usque delectarum specierum cum brevibus descriptionibus nec non synonymis et obeservationibus selectis. Gottingae: apud Henricum Dieterich. http://bibdigital.rjb.csic.es/ ing/Libro.php?Libro=3134; http://bibdigital.rjb.csic.es/ing/Libro.php?Libro=3136

Ralfs, J. 1848. The British Desmidieae. London: Reeve, Benham, and Reeve. https://doi. org/10.5962/bhl.title.14791

Royle, J.F. 1833-1840. Illustrations of the botany and other branches of the natural history of the Himalayan mountains and of the flora of Cashmere, 2 vols. London: Wm. H. Allen and Co. https://doi.org/10.5962/bhl.title.449

Section for Taxonomy 1929. Round-table discussion: Botanical nomenclature. Pp. 1556-1570 in: Duggar, B.M. (ed.), Proceedings of the International Congress of Plant Sciences, Ithaca, New York, August 16-23, 1926. Menasha, Wisconsin: George Banta Publishing Company.

Seemann, B. 1865-1873. Flora vitiensis: A description of the plants of the Viti or Fiji islands with an account of their history, uses, and properties. London: L. Reeve and Co. https://doi.org/10.5962/bhl.title.455

Short, E. \& George, A. 2013. A primer of botanical Latin with vocabulary. Cambridge: Cambridge University Press. https://doi.org/10.1017/CBO9781139525268

Spencer, R., Cross, R. \& Lumley, P. 2007. Plant names: A guide to botanical nomenclature, 3rd ed. Collingwood: CSIRO Publishing; Wallingford: CABI.

Sprague, T.A. 1950. International rules of botanical nomenclature supplement embodying the alterations made at the Sixth International Botanical Congress, Amsterdam, 1935. Pp. 63-87 in: Lanjouw, J. (ed.), Botanical nomenclature and taxonomy: A symposium organized by the International Union of Biological Sciences with support of UNESCO at Utrecht, the Netherlands, June 14-19, 1948. Chronica Botanica 12(1-2). Waltham: Chronica Botanica.

Stafleu, F.A. \& Cowan, R.S. 1976-1988. Taxonomic literature: A selective guide to botanical publications and collections with dates, commentaries and types, 2nd ed., vols. 1-7. Regnum Vegetabile 94, 98, 105, 110, 112, 115, 116. Utrecht/Antwerpen: Bohn, Scheltema \& Holkema; The Hague/Boston: dr. W. Junk b.v., Publishers. http://www.sil.si.edu/DigitalCollections/tl-2/index.cfm

Stafleu, F.A. \& Mennega, E.A. 1992-2000. Taxonomic literature: A selective guide to botanical publications and collections with dates, commentaries and types, 2nd ed., suppls. 1-6. Regnum Vegetabile 125, 130, 132, 134, 135, 137. Königstein: Koeltz Scientific Books. http://www.sil.si.edu/DigitalCollections/tl-2/index.cfm 
Stafleu, F.A., Bonner, C.E.B., McVaugh, R., Meikle, R.D., Rollins, R.C., Ross, R., Schopf, J.M., Schulze, G.M., Vilmorin, R. de \& Voss, E.G. (eds.) 1972. International Code of Botanical Nomenclature: Adopted by the Eleventh International Botanical Congress Seattle, August 1969. Regnum Vegetabile 82. Utrecht: A. Oosthoek's Uitgeversmaatschappij for the International Association for Plant Taxonomy.

Stafleu, F.A., Demoulin, V., Greuter, W., Hiepko, P., Linczevski, I.A., McVaugh, R., Meikle, R.D., Rollins, R.C., Ross, R., Schopf, J.M. \& Voss, E.G. (eds.) 1978. International Code of Botanical Nomenclature: Adopted by the Twelfth International Botanical Congress, Leningrad, July 1975. Regnum Vegetabile 97. Utrecht: Bohn, Scheltema \& Holkema.

Stearn, W.T. 1992. Botanical Latin: History, grammar, syntax, terminology and vocabulary, 4th ed. Newton Abbot: David \& Charles.

Stearn, W.T. 2006. Latín botánico: Historia, gramática, sintaxis, terminología y vocabulario, trans. Joan Manuel del Llano; trans. chapter XXV Neus Villegas, Jaume Vaqué. Barcelona: Ediciones Omega.

Sternberg, K. 1820. Versuch einer geognostisch-botanischen Darstellung der Flora der Vorwelt, Heft 1: 1-24, t. 1-13. Leipzig und Prag: in Kommission im Deutschen Museum; in Leipzig bei Fr. Fleischer. https://doi.org/10.5962/bhl.title.154066

Torres-Montúfar, A., Borsch, T., Fuentes, S., Clase, T., Peguero, B. \& Ochoterena, H. 2017. The new Hispaniolan genus Tainus (Rubiaceae) constitutes an isolated lineage in the Caribbean biodiversity hotspot. Willdenowia 47: 259-270. https:// doi.org/10.3372/wi.47.47309

Turland, N.J. 2013. The Code Decoded. A user's guide to the International Code of Nomenclature for algae, fungi, and plants. Regnum Vegetabile 155. Königstein: Koeltz Scientific Books.

Turland, N.J. \& Wiersema, J.H. 2013. Procedures and timetable for proposals to amend the International Code of Nomenclature for algae, fungi, and plants. Taxon 62: 1071-1072. https://doi.org/10.12705/625.8

Turland, N.J. \& Wiersema, J.H. 2017. Synopsis of Proposals on Nomenclature - Shenzhen 2017: A review of the proposals concerning the International Code of Nomenclature for algae, fungi, and plants submitted to the XIX International Botanical Congress. Taxon 66: 217-274. https://doi.org/10.12705/661.36

Turland, N.J., Kempa, M., Knapp, S., Senková, E. \& Wiersema, J.H. 2017a. XIX International Botanical Congress: Preliminary guiding mail vote on nomenclature proposals. Taxon 66: 995-1000. https://doi.org/10.12705/664.25

Turland, N.J., Wiersema, J.H., Monro, A.M., Deng, Y.-F. \& Zhang, L. 2017b. XIX International Botanical Congress: Report of Congress action on nomenclature proposals. Taxon 66: 1234-1245. https://doi.org/10.12705/665.16

Turland, N.J., Wiersema, J.H., Barrie, F.R., Greuter, W., Hawksworth, D.L., Herendeen, P.S., Knapp, S., Kusber, W.-H., Li, D.-Z., Marhold, K., May, T.W., McNeill, J., Monro, A.M., Prado, J., Price, M.J. \& Smith, G.F. (eds.) 2018. International Code of Nomenclature for algae, fungi, and plants (Shenzhen Code) adopted by the Nineteenth International Botanical Congress Shenzhen, China, July 2017. Regnum Vegetabile 159. Glashütten: Koeltz Botanical Books. https://doi.org/10.12705/Code.2018 
Velenovský, J. 1920-1922. České houby. V Praze [in Prague]: Nákladem “České Botanické Společnosti” v Praze. https://doi.org/10.5962/bhl.title.3881

Voss, E.G., Burdet, H.M., Chaloner, W.G., Demoulin, V., Hiepko, P., McNeill, J., Meikle, R.D., Nicolson, D.H., Rollins, R.C., Silva, P.C. \& Greuter, W. (eds.) 1983. International Code of Botanical Nomenclature: Adopted by the Thirteenth International Botanical Congress, Sydney, August 1981. Regnum Vegetabile 111. Utrecht/ Antwerpen: Bohn, Scheltema \& Holkema; The Hague/Boston: Dr. W. Junk, Publishers.

Wang, L., Ma, X.-J. \& Yang, C.-P. 2012. Two new infraspecific taxa of Orychophragmus violaceus (Brassicaceae) in northeast China. Novon 22: 109-113. https://doi. org $/ 10.3417 / 2009133$

Watts, D. 2000. Elsevier's dictionary of plant names and their origin. Amsterdam: Elsevier Science B.V.

Wei, Z. \& Pedley, L. 2010. Craspedolobium Harms. P. 189 in: Wu, Z.-Y., Raven, P.H. \& Hong, D.-Y. (eds.), Flora of China, vol. 10 (Fabaceae). Beijing: Science Press; St. Louis: Missouri Botanical Garden Press. http://flora.huh.harvard.edu/china/mss/ volume10/index.htm (Millettieae).

Wiersema, J.H., McNeill, J., Turland, N.J., Barrie, F.R., Buck, W.R., Demoulin, V., Greuter, W., Hawksworth, D.L., Herendeen, P.S., Knapp, S., Marhold, K., Prado, J., Prud'homme van Reine, W.F. \& Smith, G.F. (eds.) 2015a. International Code of Nomenclature for algae, fungi, and plants (Melbourne Code) adopted by the Eighteenth International Botanical Congress Melbourne, Australia, July 2011. Appendices II-VIII. Regnum Vegetabile 157. Königstein: Koeltz Scientific Books.

Wiersema, J.H., McNeill, J., Turland, N.J., Orli, S.S. \& Wagner, W.L. 2015b. The foundation of the Melbourne Code Appendices: Announcing a new paradigm for tracking nomenclatural decisions. Taxon 64: 1021-1027. https://doi.org/10.12705/645.11

Wiersema, J.H., May, T.W. \& Turland, N.J. 2017. Report on corrections and future considerations for Appendices II-VIII of the International Code of Nomenclature for algae, fungi, and plants. Taxon 66: 772-775. https://doi.org/10.12705/663.38

Wilson, K.L. 2019. Report of the General Committee: 21. Taxon 68: 160-162. https:// doi.org/10.1002/tax.12011

Xue, B., Su, Y.C.F., Thomas, D.T. \& Saunders, R.M.K. 2012. Pruning the polyphyletic genus Polyalthia (Annonaceae) and resurrecting the genus Monoon. Taxon 61: 1021-1039. https://www.jstor.org/stable/41679348 


\section{ABBREVIATIONS, ACRONYMS, SYMBOLS, AND LATIN WORDS}

The following list includes all the abbreviations used in the Code, as well as several other abbreviations, acronyms, symbols, and Latin words generally used in biological nomenclatural contexts. The various Latin words used in Appendices I-VII (which, apart from their introductions, are in Latin) are also included. Whole Latin words (but not their abbreviations) are shown in italics. The Code consistently uses a particular style for certain abbreviations, e.g. "t.", not "tab.", for tabula, and "subg.", not "subgen.", for subgenus. In such cases, both forms are listed, with the form used by the Code indicated accordingly. Some of the terms given here are not used in the Code at all, e.g. "nom. ambig.", but absence of a term from the Code does not by itself mean that the term is incorrect and should not be used. A much fuller list relevant to the biological sciences in general may be found in the Symbols and Abbreviations chapter (Chapter XXIV) in William T. Stearn's Botanical Latin (Stearn, 1992: 350-358).

The Code includes a Glossary, which is deliberately closely linked with the main text of the Code, so that the definitions given in the Glossary refer to, and use essentially the same wording as, the relevant rules and recommendations in the Code. Several additional terms used in the Code, but not defined there, are included and defined in the Glossary, whereas terms not used in the Code are omitted from the Glossary, even if they are otherwise used in biological nomenclature. For a much broader glossary that includes such additional terms, see Hawksworth's Terms used in bionomenclature (Hawksworth, 2010). With these two up-to-date glossaries available, it seems quite superfluous to provide yet another glossary here.

Note that a short sequence of one to seven uppercase letters, especially in specimen citations, may be one of the standard codes of herbaria as given in Index Herbariorum (http://sweetgum.nybg.org/science/ih/), e.g. K for the Royal Botanic Gardens, Kew; MO for the Missouri Botanical Garden; and PERTH for the Western Australian Herbarium.

Bear in mind that the custom of abbreviating titles of books and journals, names of people and places, and many other words dates back to a time when the high cost of paper and printing was an incentive to keep text as concise as possible. With electronic publications, there is no longer a need for such thriftiness, although using abbreviations and acronyms can reduce the kind of repetition that might interfere with readability. If there is any possibility of ambiguity or simply not being understood, it is good practice to spell out abbreviations and acronyms in full, at least on their first occurrence in a text, with the abbreviation or acronym cited in parentheses and used thereafter. 
! - used to indicate that a specimen has been seen, e.g. Smith $123(\mathrm{~K}$ !)

* - when preceding an entry in the Appendices indicates a proposal approved by the General Committee; retention or rejection of the name or suppression of the publication is authorized subject to the decision of a later International Botanical Congress

${ }^{*}$ Ex. - voted Example (see Art. $7^{*}$ Ex. 16 footnote)

$\&$ al., et al. - et alii, and others (the Code uses $\&$ al.); et aliorum, and of others

$\&$, et - and (the Code uses \&)

$x$ - indicates a hybrid

$=,(=)-$ heterotypic (i.e. taxonomic) synonym

$\equiv,(\equiv)$ - homotypic (i.e. nomenclatural) synonym

$(\mathrm{H})$ - homonym, used in the Appendices

$(\mathrm{NH})$ - not a homonym, used in the Appendices

(P) - protected name, used in the Appendices, only for names of fungi

A

ad t. - ad tabulam, at the plate, used when citing a place of publication associated with an illustration

aff. - affinis (affine), akin to, related to

an - can it be (that) ... ?, often seen preceding a doubtful synonym, mostly in pre-20th-century works

ante - before, used when citing a date

ap. - see apud

App. - Appendix

apud, ap. - with, in the work of (equivalent to in, q.v.)

Art. - Article

auct. - auctorum, of authors, used for a misapplied name

auct. non - auctorum non ..., of authors, not ..., used for a misapplied name, inserted before the name(s) of the original author(s), e.g. "Ficus exasperata" auct. non Vahl

B

BPH-2 - Botanico-periodicum-huntianum, ed. 2

c., ca. - circa, circiter, about

cancellans - cancelling, used for a corrected page inserted in a book, replacing the cancelled page

cf. - confer, compare (imperative)

cl. - classis, class; or in some old works it could mean clarissimus, "most illustrious", preceding a person's name

comb. \& stat. nov., comb. et stat. nov. - combinatio et status novi, new combination and name at new rank

comb. in stat. nov. - combinatio in statu novo, "combination in new rank"; uncommon, apparently an invention of Werner Greuter, used when the same combination has been published previously at a different rank, and a different combination has been 
published previously at the same rank, and all three combinations are homotypic (see Art. 6 Ex. 13)

comb. inval. - combinatio invalida, "invalid combination", i.e. not validly published comb. nov. - combinatio nova, new combination

corr. - correxit, he/she has corrected

cv. - cultivar, but this term is not used when writing a cultivar name (see p. 129)

D

deest - it is missing, used for a missing type specimen

det. - determinavit, he/she has determined, followed by a person's name and date in the annotation of a specimen

Div. - Division

DOI - digital object identifier, often cited as a URL, e.g. https://doi.org/10.12705/ Code. 2018

E

e.g. - exempli gratia, for example

ed. - editio, edition

emend. - emendavit, he/she has emended, used when the diagnostic characters or circumscription of a taxon are altered without exclusion of the type

epi. - epitypus, epitype

et - see \&

et al. - see $\&$ al.

etc. - et cetera, and the rest

etiam vide - see also

ex - from, out of, e.g. ex typo, ex-type, used for a living isolate obtained from a algal or fungal type culture permanently preserved in a metabolically inactive state; also used in author citation, e.g. Benth. ex Rchb. (see pp. 96-97)

Ex. - Example

excl. gen. - excluso genere (exclusis generibus), with genus (genera) excluded, used when the circumscription of a taxon is altered (without exclusion of the type)

excl. sp. - exclusa specie (exclusis speciebus), with species excluded

excl. specim. - excluso specimine (exclusis speciminibus), with specimen(s) excluded

excl. var. - exclusa varietate (exclusis varietatibus), with variety (varieties) excluded

$\mathbf{F}$

f. - forma, form; or filius, son; also figura, figure (but the Code uses fig.)

f. nov. - forma nova, new form

fam. - familia, family

fam. nov. - familia nova, new family

fide - by the faith, by the assurance (of), i.e. according to

fig. - figura, figure

fil. - filius, son (but the Code uses f.)

fo. - forma, form (but the Code uses f.) 
gen. - genus, genus; or gender

gen. fem. cons. - genus femininum conservandum, feminine gender to be conserved

gen. masc. cons. - genus masculinum conservandum, masculine gender to be conserved gen. neut. cons. - genus neutrum conservandum, neuter gender to be conserved

gen. nov. - genus novum, new genus

H

herb. - herbarium, herbarium

holo., HT. - holotypus, holotype

hort. - hortorum, of gardens, or hortulanorum, of gardeners, sometimes seen in author citations

HT. - see holo.

HTML - hypertext markup language

I

i.e. $-i d$ est, that is

IAPT - International Association for Plant Taxonomy

ib., ibid. - ibidem, in the same place

IBC - International Botanical Congress

ICBN - International Code of Botanical Nomenclature

ICN - International Code of Nomenclature for algae, fungi, and plants (but not used in the Shenzhen Code and best avoided because it could refer to any one of five biological codes)

ICNCP - International Code of Nomenclature for Cultivated Plants

ICNP - International Code of Nomenclature of Prokaryotes

icon, ic. - image, i.e. an illustration

ICZN - International Code of Zoological Nomenclature

idem - the same

IMA - International Mycological Association

IMC - International Mycological Congress

in - in, used in bibliographic citation, e.g. Hance in J. Bot., R. Br. in Aiton, Hort.

Kew., ed. 2 (see p. 97)

in herb. - in herbario, in herbarium

in litt. - in litteris, in letters, in correspondence

in sched. - in scheda (schedis), in schedula (schedulis), on label (labels), i.e. on herbarium sheet(s) or label(s)

in syn. - in synonymia, in synonymy; or in synonymis, among synonyms

incertae sedis - literally, "of uncertain seat", i.e. of uncertain (taxonomic) position

incl. - including

ined. - ineditus, unpublished

IPNI - International Plant Names Index (https://www.ipni.org/)

iso. - isotypus, isotype, a duplicate of a holotype

isoepi. - isoepitypus, isoepitype, a duplicate of an epitype 
isolecto. - isolectotypus, isolectotype, a duplicate of a lectotype

isoneo. - isoneotypus, isoneotype, a duplicate of a neotype

isosyn. - isosyntypus, isosyntype, a duplicate of a syntype

$\mathbf{L}$

1.c. - see loc. cit.

lecto., LT. - lectotypus, lectotype

leg. - legit, he/she has gathered

loc. cit., l.c. - loco citato, in the cited place

LT. - see lecto.

\section{M}

m. - mibi, literally "to me", used in the past when an author ascribed a name to himself or herself; also metre(s); also manu, in/by the hand(writing of); also mons, mountain, in Latin text indicating geographical provenance

med. - medio, mid, in the middle (in a month or year), used when citing a date

MS., ms. - manuscriptum, manuscript

MSS., mss. - manuscripta, manuscripts

mut. char. - mutatis characteribus, with changed characters, used when the diagnostic characters or circumscription of a taxon are altered without exclusion of the type

$\mathbf{N}$

n. - see no., nob., notho-, and nov.

n.s. - new series, in a bibliographic context, e.g. of a journal

n.v. - non vidi, I have not seen; or non visus $(-a,-u m)$, not seen

nec - and not, nor

neo., NT. - neotypus, neotype

nm. - nothomorph, an obsolete rank-denoting term for a hybrid taxon, now treated as variety (Art. H.12.2)

no., n., nr. - numero, number

nob., n. - nobis, "to us", used in the past when authors ascribed names to themselves

nom. alt. - nomen alternativum, alternative name

nom. ambig. - nomen ambiguum, ambiguous name, of ambiguous application

nom. confus. - nomen confusum, confused name, of confused application

nom. cons. - nomen conservandum, name to be conserved

nom. cons. prop. - nomen conservandum propositum, name proposed to be conserved

nom. dub. - nomen dubium, doubtful name, of dubious application

nom. illeg. - nomen illegitimum, illegitimate name

nom. illeg. superfl. - nomen illegitimum superfluum, name that is illegitimate because

it was nomenclaturally superfluous when published

nom. inval. - nomen invalidum, "invalid name", i.e. not validly published

nom. legit. - nomen legitimum, legitimate name

nom. non rite publ. - nomen non rite publicatum, name not properly (i.e. validly) pub-

lished 
nom. nov. - nomen novum, literally "new name", i.e. replacement name

nom. nud. - nomen nudum, naked name, i.e. without a validating description or diagnosis or reference to such

nom. obsc. - nomen obscurum, obscure name, of obscure application

nom. prov. - nomen provisorium, provisional name

nom. rej. - nomen rejiciendum, name to be rejected

nom. rej. prop. - nomen rejiciendum propositum, name proposed to be rejected

nom. sanct. - nomen sanctionatum, sanctioned name

nom. subnud. - nomen subnudum, nearly naked name, i.e. a name for which the description or diagnosis is considered by some to be inadequate for the purposes of valid publication

nom. superfl. - nomen superfluum, superfluous name

nom. utique rej. - nomen utique rejiciendum, name to be rejected in any case, suppressed name

non - not

non designatus - not designated

notho-, n- - prefix indicating a hybrid taxon, e.g. nothogenus, nothospecies, nothosubsp., nsubsp.

nov., n. - novus, nova, novum, new, e.g. comb. nov., nom. nov., sp. nov., stat. nov. (q.v.) nr. - see no.

NT. - see neo.

obs. - observatio, observation

op. cit. - opere citato, in the cited work

ord. - ordo, order

orth. cons. - orthographia conservanda, orthography (i.e. spelling) to be conserved

orth. var. - orthographical variant

p. - pagina, page

PDF - portable document format

p.p. - pro parte, in part

para. - paratypus, paratype

post - after, used when citing a date

Pre. - Preamble

prim. - primo, at the beginning, early (in a month or year), used when citing a date

pro hybr. - pro hybrida, as a hybrid

pro sp. - pro specie, as a species

pro syn. - pro synonymo, as a synonym

pro var. - pro varietate, as a variety

Prov. - Provision (in Division III) 
q.v. - quod vide, which see

quoad - as to, as regards, with respect to

$\mathbf{R}$

Rec. - Recommendation

recte - rightly, correctly

\section{S}

s.ampl. - sensu amplo, in a large (ample) sense; or sensu amplificato, in an enlarged (amplified) sense

s.ann. - sine anno, without year

s.coll. - sine collectore, without collector

s.d. - sine die, without day, i.e. undated

s.l., s.lat. - sensu lato, in a broad/wide sense (the Code uses s.l.); could also mean sea

level in statements of geographical provenance

s.loc. - sine loco, without locality

s.n. - sine numero, without number, used for an unnumbered gathering, e.g. Wallich

s.n.; also series nova, new series (equivalent to n.s., q.v.)

s.str., s.s. - sensu stricto, in a strict/narrow sense (the Code uses s.str.)

sec. - secundum or secus, following, after, according to

sect. - sectio, section

sensu - in the sense/opinion (of), followed by a person's name; see also s.ampl., s.l., and

s.str.

ser. - series, series, i.e. the rank; may also mean a series of a journal, e.g. ser. 2

sero - late (in a month or year), used when citing a date

sine - without

sp. - species, species

sp. nov. - species nova, new species

spec. - specimen, specimen; also species, species

sphalm. - sphalmate, by mistake, mistakenly

ssp. - see subsp.

stat. nov. - status novus, name at new rank

sub- - prefix used in rank-denoting terms, e.g. subfamily, subspecies; also sub, under

subcl. - subclassis, subclass

subf. - subforma, subform

subfam. - subfamilia, subfamily

subg., subgen. - subgenus (the Code uses subg.)

subord. - subordo, suborder

subsect. - subsectio, subsection

subser. - subseries, subseries

subsp., ssp. - subspecies, subspecies (the Code uses subsp.)

subtr. - subtribus, subtribe

subvar. - subvarietas, subvariety 
syn. - synonymum, synonym; also syntypus, syntype

syn. nov. - synonymum novum, new synonym, i.e. a taxonomic act when a name is first treated as a heterotypic synonym, or a nomenclatural act when a name is typified so that it becomes a homotypic synonym

$\mathbf{T}$

T. - typus, type

t., tab. - tabula, tablet, i.e. plate, illustration (the Code uses t.)

teste - by the witness (of), i.e. according to

TL-2 - Taxonomic literature, ed. 2

tr. - tribus, tribe

trans. nov. - translatio nova, new transfer, i.e. new combination at the same rank (the

Code uses comb. nov.)

typ. cons. - typus conservandus, type to be conserved

typ. des. - typi designatio, designation of type

typus - type

U

URL - uniform resource locator, e.g. an internet address

V

v.s. - vidi siccam, I have seen (a/the) dry (plant), i.e. a herbarium specimen

v.v. - vidi vivam, I have seen (a/the) living (plant)

var. - varietas, variety

var. nov. - varietas nova, new variety

vel - or

vide - see (imperative)

vidi - I have seen 


\section{INDEX TO SUBJECTS}

! [exclamation mark] 32-33, 58-59

* [asterisk], in Appendices 87-89, 93

*Ex. 24

$\times$ [multiplication sign], see Hybrids

$=$ [equality sign $] 22,93$

三 [identity sign] 22, 93

A

A Grammatical Dictionary of Botanical Latin 155

A primer of botanical Latin with vocabulary 100,150

Algae 112-116, see also Blue-green algae

definition 114

language of validating description or diagnosis $\quad 113-114$

names, formation of 113

registration 116

starting-points $44,112,114,130-131$

types $113,115-116$

validating illustration 113,115

AlgaeBase 153

American Code of Botanical Nomenclature 82, 146, 148

Appendices 23, 91-92, 145

online 145,152

Appendix I 91

Appendix IIA 91

Appendix IIB 91

Appendix III 92

Appendix IV 92

Appendix V 92

Appendix VI 92

Appendix VII 92

Articles 15

Asterisk (*)

in Appendices 93

indicating voted Example ( ${ }^{*}$ Ex.) 24

auct. (auctorum) 56

Australian Plant Names Index 153

Authors of names

abbreviation (standard form) 99

ascription 95 
basionym (parenthetical) 98

"ex", use of 96-98

fungal names, citing identifier in place of authors 122

how to cite 95-99

“in", use of 97-98

parentheses, use of 98

standard citation (standard form) 99

suprageneric names 98

why to cite 95

Autograph, indelible 27, 132

Automatically typified

by basionym 69

by replaced synonym 69

name above rank of family $\quad 49,70$

name of a family or subdivision of a family 70

name of a subdivision of a genus 81

Autonym(s) 54

definition 20-21

priority 59

type 68

Auxilium ad Botanicorum Graphicem 155

Avowed substitute 22, see also Replacement name

B

Bacteria, Code, see International Code of Nomenclature of Prokaryotes

Basionym

automatically typified by 69

definition 21

legitimacy 22

BHL, see Biodiversity Heritage Library

Biblioteca Digital del Real Jardín Botánico de Madrid 154

Binding decision 89

on homonymy 90-91, see also Appendix VIII

on valid publication $89-90$, see also Appendix VII

Binomial 11

BioCode, Draft 13-14

online 152

Biodiversity Heritage Library 154

Blue-green algae 112,128

Botanical Latin

A Grammatical Dictionary of 155

A primer of, with vocabulary 100,150

Stearn's 100, 150

Botanical Code, see Code 
Botanico-periodicum-huntianum, ed. 2 151, 154

BPH-2, see Botanico-periodicum-huntianum, ed. 2

Brittonia Rules 147-148

Bureau of Nomenclature 139-140, 142, see also Fungal Nomenclature Bureau

President 142

Rapporteur-général 142

Recorder 142

Vice-presidents 142

Vice-rapporteur 142

C

Catalogue of Life 119, 153

Chair (of Fungal Nomenclature Session) 142

Deputy 142

Chapter F, see Fungi

Chapter H, see Hybrids

Choice (as nomenclatural act)

between names of equal priority 59-60

between orthographical variants 110

of gender 111

Circumscription 19, 55, 57-58, 60, 63, 124

definition 19, 60

in determining correct name 60

Classification 11

Code

amend, see here changes

Appendices 23, 91-92, 145

changes 137-139

editions 148-149, 152

Editorial Committee 143-145

governance 137-138

groups covered 12,127

groups not covered $12,127-129$

history 146-149

organization 23-24

proposals to amend 138-141

provisions, see here organization

rank-based 14

rules

binding, see Articles; Notes; Examples, voted

optional, see Recommendations

sequence of items 24

structure, see here organization

subdivisions, see here organization 
translations 152

Codes (other), see also Draft BioCode; PhyloCode

bacteriological, see International Code of Nomenclature of Prokaryotes

cultivated plants, see International Code of Nomenclature for Cultivated Plants

prokaryotes, see International Code of Nomenclature of Prokaryotes

viruses, see International Code of Virus Classification and Nomenclature

zoological, see International Code of Zoological Nomenclature

comb. nov., see New combination

Combination, see also New combination

definition 19

Combinatio nova, see New combination

Committee(s)

Editorial 143-145

General 143-144

Nominating 140-141

on Bionomenclature, International 13-14

on Institutional Votes 143-144

Permanent Nomenclature 143-145

for Algae 143

for Bryophytes 143

for Fossils 143

for Fungi 143

for Vascular Plants 143

Registration 143-144

Special-purpose 145

specialist 144

Common names 10-11

problems 10-11

vs. scientific 10-11

Compound epithets 102, 108-109

pseudocompounds 109

regular compounds 108

Conservation 84-87, see also Appendix IIA, IIB, III, IV, V; Sanctioning of fungal names

date of 133

of gender 85

of spelling 85

of type 85

proposal $86-87$

with conserved type 85

Correct name, see Name(s)

"Cotype" 72

Cultivated Plant Code, see International Code of Nomenclature for Cultivated Plants

Cultivated plants 129 
Cyanobacteria 112,128

Cyanophyta 112,128

Cyanoprokaryotes 112,128

D

Databases (online resources) 153-154

Dates of importance , see also Nomenclatural starting-points

1 May 1753 44, 112, 114, 117, 130

4 August 1789 114, 130

1 January $1801 \quad 114,130$

31 December $1820 \quad 114,122,130$

1 January $1848 \quad 112,114,130$

1 January 1886 112, 114, 130

1 January $1887 \quad 130$

1 January $1890 \quad 131$

1 January $1892 \quad 112,114,131$

1 January $1900 \quad 112,114,131$

1 January 1908 45, 131

1 January $1912 \quad 45,51,123,131$

1 January $1921 \quad 132$

1 January 1935132

1 January 1935-31 December $2011 \quad$ 45, 132

1 January $1953 \quad 45,132$

1 January 1954133

1 January 1958 17, 46, 69, 72, 113, 117, 133

1 January 1958-31 December $2011 \quad 46,113,133$

1 January 1973 46, 133

1 January $1990 \quad 46,72-73,75,134$

1 January 1996 46, 123, 134

1 January $2001 \quad 72,75,123,134$

1 January 2007 47, 69, 113, 118, 135

1 January 2012 18, 25-26, 47, 113, 135

1 January $2013 \quad 47,118,124,135$

1 January 2019 47, 116, 118-119, 124, 129, 136

alternative names $\quad 45,132$

basionym or replaced synonym

citing 47, 135

reference to $45-46,132$

conservation 133

effective electronic publication 26, 135

effective publication $\quad 132-133,135$

full and direct reference 46, 132

fungal homonyms of prokaryotic or protozoan names 136

fungal superfluous names, protection from illegitimacy 135 
identifying validating illustrations as the type 134

illustrations as types 47,135

illustration with analysis 45, 131

indication of rank 45, 130-132

indication of type 46-47, 133-134, 136

Latin or English requirement

names of fossil-taxa 46,134

names of all new taxa 47,135

Latin requirement

names of algae 46,133

names of fungi and plants 45,132

Latin technical terms as generic names 45, 131

protection 133

publications adopting largely mechanical method of type selection $\quad 132$

registration

of names of fungi 135

of type designations for fungal names 136

requirements for valid publication not simultaneously fulfilled 46,133

specifying herbarium

of holotype 46, 134

of lectotype, neotype, or epitype 134

stating that type culture is preserved in metabolically inactive state $\quad 47,136$

validating illustration

names of algae 133

names of fossil-taxa 131

writing "designated here" 134

writing "lectotypus", "neotypus", or "epitypus" 134

writing "typus" or "holotypus" 46, 134

Description, see also Binding decision; Descriptive statement

definition 18

Descriptive statement 90

for valid publication $89-90,92$

Designation 56, see also Tautonym

definition 18

Diagnosis, see also Binding decision, on valid publication definition 18

DiatomBase 153

Diatoms 122

Digital libraries 154

Draft BioCode 13-14

online 152

"Dual nomenclature" for fungi with a pleomorphic life cycle $\quad 120-121$

Duplicate, definition 16 
Editorial Committee 143-145

Effective publication 25-29

"best practice" 27-28

date of 28-29

definition 17, 26

electronic material 26-27, 135

content 25, 27

corrections 25, 27

date 26,135

ineffective publication $\quad 26-27,135$

pagination 25,28

preliminary vs. final version $25,27-28$

Version of Record 28

handwriting 27

indelible autograph 27,132

labels, etc. 27

microfilm 27

printed matter 26

date 26, 132-133

ineffective publication $\quad 132-133$

public meeting 27

Epithet 19, 102-109

adjectival 102, 108-110, see also Orthography, compound epithets agreement in gender with generic name 52, 102-103, 110

cultivar 129

definition 19-20

Epitype $71,75,78-80,123$

superseding 81

when to designate 65,75

Epitypification, see also Epitype

first- and second-step 79

procedure $74-75,78-79$

Equality sign (=) 22, 93

Error to be corrected

in citing identifier (fungi) 119

in orthography $101-110$

hyphens 102

terminations of epithets honouring people 102-108

in typification 72

Examples 15

voted 24

Exclamation mark (!) 33, 59 
Forma, see Infraspecific taxa

Formae speciales 127

Formation of names, see Name(s)

Fossilium Catalogus II: Plantae 151, 153

Fossils 122-125

definition 15,122

language of validating description or diagnosis 114,123

morphotaxa 124-125

priority $122-123$

registration of fossil fungi 116,124

starting-point $114,122,130$

types 115,123

validating illustration $\quad 115,123$

Fossil-taxon 15

Fundamenta botanica 146

Fungal Names (nomenclatural repository) 118, 153

Fungal Nomenclature Bureau 142-143

Chair 142

Deputy Chairs 142

Deputy Secretary 143

Recorder 143

Secretary 142

Fungal Nomenclature Session 141

Fungi 116-122, see also Lichens

author citation 122

definition 114

homonyms 116, 119

names, formation of 117

pleomorphic life cycle 120-121, 135

protection 120

registration of names and types 116, 118-119

rejection 120

sanctioning 119-120

starting-point $44,114,117,130$

types $115,117-118$

G

Gallica 154

Gathering

citation of 71,73

definition 16,70

single $43,79,82$

Gender 110-111, see also Orthography

assigned by author $110-111$ 
assigned by nomenclatural tradition $\quad 110$

choice of 111

determined by ending of generic name 111

of compound generic name 111

rules $110-111$

General Committee 143-144

Genus

formation of name 51

gender of name, see Gender

Glossaries 155, 166

Google Books 154

Graft hybrid name 129

Grammar, see Gender

Gray Card Index 153

Greek(-derived) names 11, 101-102, 105, 108-109

Guiding vote, preliminary $\quad 138-141$

H

(H) 91, 93, see also Homonym

Handwriting (online resource) 155

Holotype $30-36,42-43,46,58-59,66,69-75,80-81,113,115,118,123,134$

Homonym 90-92, 95, see also Homonymy

definition 18

hybrids vs. non-hybrids 127

illegitimate $18,61-63,84,88,119-120,123$

later 42,56

Homonymy, see also Homonym

cross-code $13,116,119,128-129,136$

Hybrid formula 16, 125-126

condensed formula $126-127$

vs. hybrid names $125-126$

Hybrid names 125-126, see also Hybrids

vs. hybrid formula $125-126$

Hybrids 125-127, see also Hybrid formula; Hybrid names

definition 16

homonymy and synonymy with non-hybrids 127

hybrid or non-hybrid taxon 125

indication of 126

multiplication sign $(x) \quad 16,126$

"notho-" prefix 16, 126

nothogenera and subdivisions of nothogenera 126

nothospecies and infraspecific nothotaxa 126

priority 126

ranks of nothotaxa 126 
transfer to non-hybrid categories and vice versa 127

when to describe 125

Hyphens, use of 51-53, 102

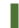

IAPT, see International Association for Plant Taxonomy

IBC, see International Botanical Congress

ICBN, see Code

"ICN" 12, see also Code

ICNCP, see International Code of Nomenclature for Cultivated Plants

ICNP, see International Code of Nomenclature of Prokaryotes

"Iconotype" 72

ICZN, see International Code of Zoological Nomenclature

Identifier (fungi), citation

error to be corrected 119

in place of authors 122

in protologue $36,118,124,135$

in type designation $78-79,118-119,124,136$

Identity sign $(\bigotimes) \quad 22,93$

Illegitimate name, see Name(s)

Illustration, validating $113,115,123,131,133-135$

Indelible autograph 27, 132

Index filicum 153

Index Fungorum 118, 153

Index Hepaticarum 153

Index Herbariorum 43, 59, 83, 143, 155, 166

Index kewensis $42,151,153$

Index Nominum Algarum 153

Index Nominum Genericorum 153

Indices Nominum Supragenericorum Plantarum Vascularium 153

Indices seminum (online resource) 154

Ineffective publication, see Effective publication

Infraspecific taxa, formation of names 53-54, see also Autonym(s)

ING, see Index Nominum Genericorum

Institutional votes $140-141$

Committee on 143-144

International Association for Plant Taxonomy 137-138

International Botanical Congress 137-141, see also Nomenclature Section history 146-149

International Code of Botanical Nomenclature 12, 127, 147-149, see also Code

International Code of Nomenclature for algae, fungi, and plants 12, 14, 112, 127, 147, 149-150, 152, see also Code

International Code of Nomenclature for Cultivated Plants 14, 129

coverage 12,128 
online 152

International Code of Nomenclature of Prokaryotes 14, 112, 129 coverage 12,128

online 152

International Code of Phylogenetic Nomenclature 14

online 152

International Code of Virus Classification and Nomenclature 14 coverage 12,128

online 152

International Code of Zoological Nomenclature 14, 49, 72, 128

coverage 12,127

online 152

International Committee on Bionomenclature 13-14

International Fossil Plant Names Index 48, 153

International Mycological Association 137

International Mycological Congress 137-138, 141

International Plant Names Index 27, 42, 48, 56, 99, 151, 153

International Rules of Botanical Nomenclature 147-148

International Standard Book Number 25-26, 135

International Standard Serial Number 25-26, 135

Internet Archive 154

"Invalid" name 18, see also Designation; Valid publication

vs. illegitimate name 20

IPNI, see International Plant Names Index

ISBN, see International Standard Book Number

Isolectotype 58-59, 71-72

Isoneotype 71

Isonym

definition 21

later $21,42,86$

Isoepitype $71,78-79$

Isosyntype 71,74

Isotype 32-33, 36, 58-59, 71, 74

ISSN, see International Standard Serial Number

$J$

JSTOR 154

Global Plants 69, 155

$\mathbf{K}$

Karlsruher Virtueller Katalog 155

"Kleptotype" 72 
Later homonym 42, 56, 61-63, see also Homonym; Homonymy

Later isonym 21, 42, 86

Latin, see also Gender; Orthography

alphabet $42,48,83,99,101$

description or diagnosis 32-35, 37-38, 45-47, 113-114, 123, 132-135

algae $113-114,133,135$

fossils $114,123,134-135$

fungi or plants $114,132,135$

guides to $100,150,155$

knowledge of 100

rank-denoting terms $16-17,42$

scientific names 11

technical term in use in morphology 45, 51, 131

terms used in nomenclature 166-173

Latinization of personal, geographical, or vernacular names 102

Lectotype $58-59,67-68,71,74-79$

of name of genus or subdivision of genus $\quad 81-82$

of sanctioned name 120

search for existing $\quad 67-69$

superseding 80

when to designate $65-66,74$

Lectotypification, see also Lectotype

"best practice" 82-83

first- and second-step 79

bypassing 75 , see also Conservation

procedure 74-79

Legitimate name, see Name(s)

Library catalogues 154-155

Lichens, treated as fungi 117

Linnaean Plant Name Typification Project, online database 154

Lois de la Nomenclature Botanique 13, 146, 148, 152

M

Misapplied name 56

Morphotaxon 124-125

vs. fossil-taxon 124-125

Multiplication sign ( $x$ ), see Hybrids

MycoBank 36, 78-79, 118, 153

$\mathbf{N}$

Naked name 18,45

Name at new rank, see Name(s)

Name of new taxon, valid publication, see Name(s) 
Name(s), see also Gender; New combination; Orthography; Status novus algae, see Algae

alternative 45, 132

family names $49-50$

at new rank

author citation 98

automatically typified 69

definition 21

valid publication $\quad 39,45-47,132,135$

common 10-11

problems 10-11

vs. scientific 10-11

conserved 84-87, 91-92

correct

below rank of genus $\quad 56-58$

definition 19

determination key 57

how to find 55-64

more than one 60

priority 55-60

rank of family to genus $55-56$

definition 15

equal priority 59-60

formation $48-54$

fossils, see Fossils

fungi, see Fungi

Greek(-derived) 11, 101-102, 105, 108-109

hybrids, see Hybrids

illegitimate 61-64

based on illegitimate generic name 64

definition 18, 61

later homonym 61-63

superfluous $62-64,121,135$

vs. invalid 20

vs. legitimate 19

in Current Use 14

"invalid", see Designation; see also Valid publication

vs. illegitimate 20

later homonym 42, 56, 61-63, see also Homonym; Homonymy

legitimate 61-64

definition 19

vs. illegitimate 19

vs. valid(ly published) 20

misapplied 56 
naked 18,45

new taxon 32-38

definition 21

valid publication $\quad 30-31,44-47,132-135$

not validly published, see Designation; see also Valid publication

vs. illegitimate 20

orthography, see Orthography

provisional 44

protected $87-88,91-92,120$

rejected $88-89,91-92,120$

replacement $40-41$

author citation 98

automatically typified 69

definition 21

valid publication $39,45-47,132,135$

scientific 10-11

history 11

vs. common 10-11

superfluous

becoming correct 64

definition 19

illegitimacy $18,41,61-64,121,135$

suppressed, see here rejected

trivial, see Nomen triviale

validly published, see also Valid publication

vs. legitimate 20

vernacular, see here common

vs. taxon 15

Naming

clades 14, 16, 49, see also PhyloCode

organisms, purpose of 10

NCU (Names in Current Use) 14

Neotype 71, 74-76

search for existing 67-69

superseding 80-81

when (not) to designate 65,75

Neotypification, see also Neotype

first- and second-step 79

procedure $74-76$

New combination $\quad 40-41$

author citation 98

automatically typified 69

definition 21

valid publication $39,45-47,132,135$ 
New species, new taxon, etc., see Name(s), new taxon

(NH) 91, 93, see also Homonym

nom. alt., see Nomen alternativum

nom. cons., see Nomen conservandum

nom. illeg., see Name(s), illegitimate

nom. inval., see Nomen invalidum

nom. nov., see Nomen novum

nom. nud., see Nomen nudum

nom. prov., see Nomen provisorium

nom. rej., see Nomen utique rejiciendum

nom. sanct., see Nomen sanctionatum

nom. subnud., see Nomen subnudum

Nomen alternativum $\quad 49-50$

Nomen conservandum 84

Nomen illegitimum, see Name(s), illegitimate

Nomen invalidum 18, see also Designation

Nomen novum 22, see also Replacement name

Nomen nudum $18,45,56$

Nomen provisorium 44

Nomen sanctionatum 120

Nomen specificum legitimum 37

Nomen subnudum (nomina subnuda) 90,92

Nomen triviale $11,37,76$

Nomen utique rejiciendum 88

Nomenclatural act, definition 22

Nomenclatural novelty, definition 22

Nomenclatural stability, maintaining/serving 75, 82-85, 121

Nomenclatural starting-points

algae 44, 112, 114, 130

algae (Desmidiaceae) 112, 114, 130

algae (Nostocaceae heterocysteae) 112, 114, 130

algae (Nostocaceae homocysteae) 112, 114, 131

algae (Oedogoniaceae) 112, 114, 131

bryophytes (Musci, except Sphagnaceae) 114, 130

bryophytes (Sphagnaceae and Hepaticae, including Anthocerotae) 44, 114, 130

fossils $114,122,130$

fungi $44,114,117,130$, see also Sanctioning of fungal names

suprageneric names of bryophytes (Sphagnaceae and Hepaticae, including Anthocerotae) 114,130

suprageneric names of vascular plants 114,130

vascular plants $44,114,130$

Nomenclature, see also Nomenclature Section

binary system, see here binomial system

binomial system $\quad 11,131$ 
binominal system, see here binomial system

Committees 143-145

definition $11-12$

development 11

harmonizing (Draft BioCode) 13-14

history 11

how to become involved $\quad 137-138$

rank-based 14

rules $12-13$, see also Code

$$
\text { purpose } 12
$$

Section 139-141

Session, Fungal 141

vs. taxonomy 11-12

Nomenclature Section 139-141, see also Nomenclature Session, Fungal

Bureau of Nomenclature 139-140, 142

Committees 143-145

institutional votes $140-141$

personal votes 140

preliminary guiding vote $\quad 138-141$

Special-purpose Committees 145

voting on proposals 140

Nomenclature Session, Fungal 141

Fungal Nomenclature Bureau $\quad 142-143$

Nominating Committee 140

of the Fungal Nomenclature Session 141

Non-fossil taxon, definition 15

Notes 15

Nothogenera and subdivisions of nothogenera, see Hybrids; Nothotaxon

Nothospecies and infraspecific nothotaxa, see Hybrids; Nothotaxon

Nothotaxon (-taxa), see also Hybrids definition 16

ranks 126

Opera utique oppressa 89, 91, see also Appendix I

Order out of chaos $\quad 67,73,151$

Original material $\quad 65,70-75,80-81$

definition 71

of sanctioned name 120

Orthographical variants 109-110

choice between 110

citation $109-110$

definition 109

status 109 
validly published 109

which to retain $109-110$

Orthography, see also Gender

abbreviations 103

adjectival compound $\quad 102,108-109$

apostrophes 103

compound epithets 102, 108-109

pseudocompounds 109

regular compounds 108

diacritical signs 101

diaeresis 101

endings, see terminations

errors 100

eu/ev, use of 101

formation of names $\quad 48-54$

full stops 103

fungal names, epithets 103

hyphens 102

$\mathrm{i} / \mathrm{j}$, use of 101

importance of standardization $\quad 100$

Latin 100

alphabet 101

latinizations 102

letters and ligatures foreign to classical Latin 101

ligatures 101

original spelling, retention 101

periods 103

quotation marks 103

rules $101-103$

terminations 101-102

of epithets honouring people $\quad 102-108$

of generic names with particular gender 111

of suprageneric names $\quad 49-51,113,117$

$\mathrm{u} / \mathrm{v}$, use of 101

(P) 93, see also Protection

Parahomonym 62, 90, 92

Paralectotype 72

Paratype 34-35, 71, 74

PDF, see Portable Document Format

"Philadelphia Code" 82, 146, 148

PhycoBank 48, 153

PhyloCode 14 
online 152

Plant Fossil Names Registry $\quad 48,153$

Plants, definition 114

Pleomorphic life cycle, fungi with a 120-121, 135

Portable Document Format 25-26, 135

Position 19, 55, 57-58, 60

definition 19,60

in determining correct name 60

Preliminary guiding vote $138-141$

President (of Nomenclature Section) 142

Priority 55-60

autonym 59-60

competing for 55-60

conserved names 85

definition 19

equal 59-60

hybrids 126

names of fossil-taxa $\quad 122-124$

sanctioned names 120

typifications 68, 74

pro hybr. (pro hybrida) 127

pro sp. (pro specie) 127

pro syn. (pro synonymo) 44

Prokaryotes, Code, see International Code of Nomenclature of Prokaryotes

Proposals to amend the Code 138-141

preliminary guiding vote $138-141$

preparation $138-139$

synopsis 138,141

Proposals to conserve or reject names $86-87,140,143-144$

history and results of (Appendices online) $\quad 145,152$

Protection 87-88, 120-121

date of 133

Protologue, definition 18

Provisional name 44

Provisions (Division III) 23

Publication

effective, see Effective publication

valid, see Valid publication

Publications, see Resources for biological nomenclature

Quotation marks, use of 103

double 56

single 129 
$\mathbf{R}$

Rank-denoting terms $16-17,20,42,51,53,126,131$ abbreviations 16-17, 42

Rank-denoting terminations 49-51, 113, 117

$\operatorname{Rank}(\mathrm{s}) \quad 16,55-61$

consecutive and subordinate $\quad 16,60$

definition 16, 60-61

in determining correct name $\quad 60-61$

indication of 45, 130-132

Rapporteur-général 142

Recommendations 15

Recorder

of Fungal Nomenclature Session 143

of Nomenclature Section 142

Registration 14,116

Committee 143-144

names

algae $47-48,116,153$

fossils $116,124,135,153$

fungi $116,118-119,135,153$

plants $47-48,116$

typifications 136

Règles Internationales de la Nomenclature Botanique $\quad 146,148$

Rejection 88-89, 92, 120-121, see also Suppressed works; Appendix I, IIA, IIB, III, IV, V

Replaced synonym

automatically typified by 69

definition 21

Replacement name $40-41$

author citation 98

automatically typified 69

definition 21-22

valid publication $39,45-47,132,135$

Repository, nomenclatural 36, 47-48, 78-79, 116, 118-119, 122, 124, 135-136, 144,153

Requests for binding decisions 89-91, 140, 144

history and results of (Appendices online) 145, 152

Resources for biological nomenclature 150-155

bibliography 154

codes of nomenclature 152

databases 153-154

digital libraries 154

glossary 155

handwriting 155 
herbaria 155

indices 153

Latin 155

library catalogues 154-155

Linnaean names and types 154

online $\quad 152-155$

printed 150-151

repositories 153

Retroactive 12-13, 89-91, 121, 139

\section{S}

Sanctioning of fungal names $119-120$

Secretary (of Fungal Nomenclature Session) 142

Deputy 143

Sections, see Subdivisions of genera

Seed lists (online resource) 154

Series, see Subdivisions of genera

Shenzhen Code, see Code

Special forms 127

Special-purpose Committees 145

Specialist committees 144

Species, formation of names 52-53

Specific epithet 11, 19

Specimen, definition 16

Standard form in citing authors 99

Starting-points, see Nomenclatural starting-points

stat. nov. (status novus) 21, see also Name(s), at new rank

Stearn's Botanical Latin 100, 150, 166

Subdivisions of genera, formation of names 51-52, see also Autonym(s)

Subgenera, see Subdivision of genera

Subspecies, see Infraspecific taxa

Substitute, avowed, see Replacement name

Superfluous name, see Name(s)

Suppressed names, see Name(s), rejected

Suppressed works 89, 91, see also Appendix I

Suprageneric taxa, formation of names 49-51, 113, 117

Synonym(s)

definition 22

heterotypic, definition 22

homotypic, definition 22

hybrids vs. non-hybrids 127

indication 22

nomenclatural, see here homotypic

replaced 
automatically typified by 69

definition 21

taxonomic, see here heterotypic

Syntype $43,65-66,71,74,82$

Systematics, see Taxonomy

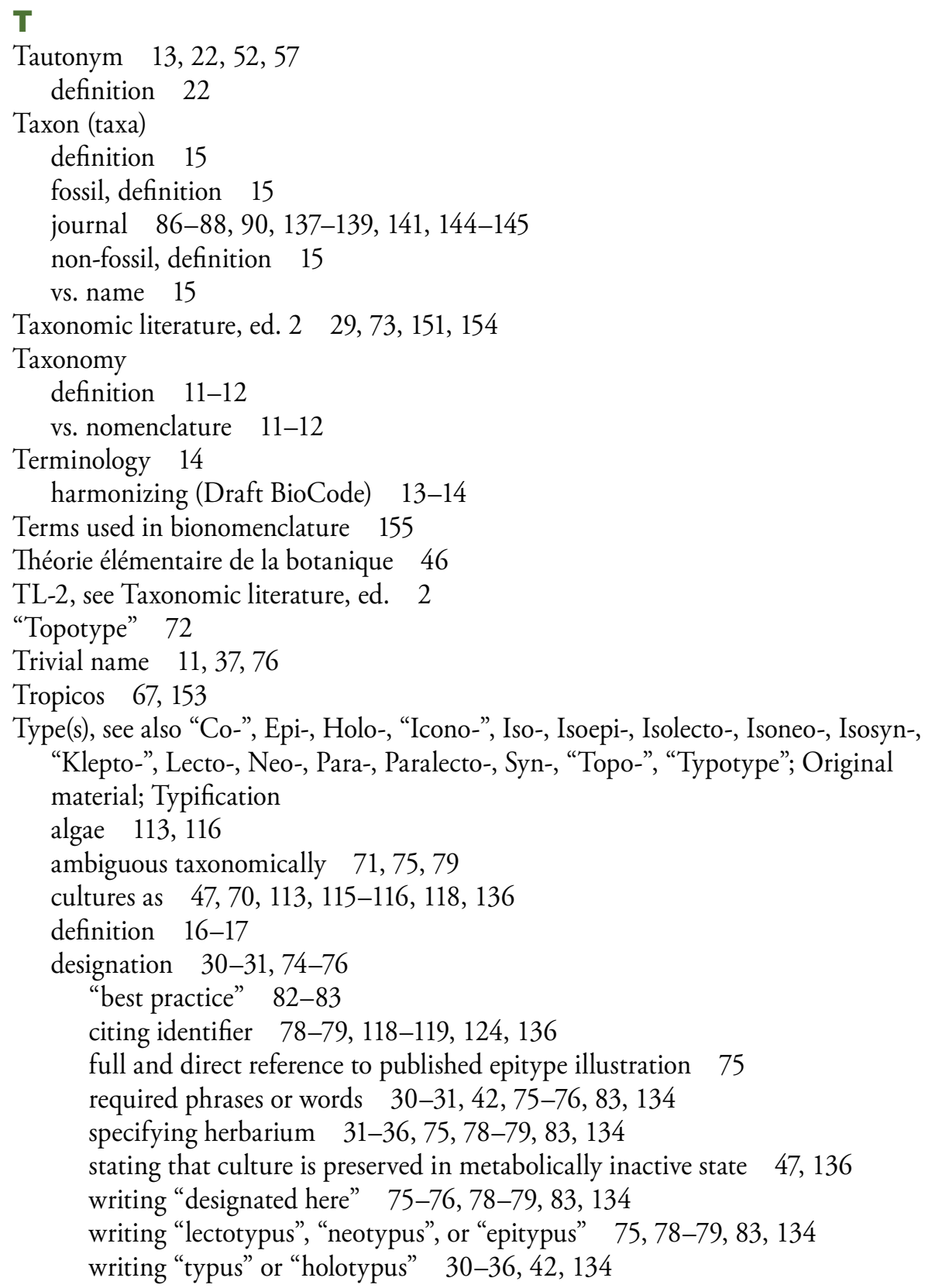


fossils 115,123

fungi $115,117-118$

illustration 69

kinds 70-71

living organisms as types 70

name above rank of family 70

name of genus or subdivision of genus 69

name of family or subdivision of family 70

name of species or infraspecific taxon 69

obsolete/unofficial terms 72

representing more than one taxon 75

search for existing 67-69

specimen 69

superseding $80-81$, see also Lectotype; Neotype

when to indicate or designate $\quad 65-66,74-75,82$

why to designate 65

Typification, see also Type

automatic 49, 69-70, 81

"best practice" 82-83

error to be corrected 72

first- and second-step 79

flow chart 74

history $72-74$

18th century 73

19th century 73

20th century 73

largely mechanical method of type selection $\quad 82,132$

names of genera and subdivisions of genera $\quad 81-82$

statement of provenance 73

"Typotype" 72

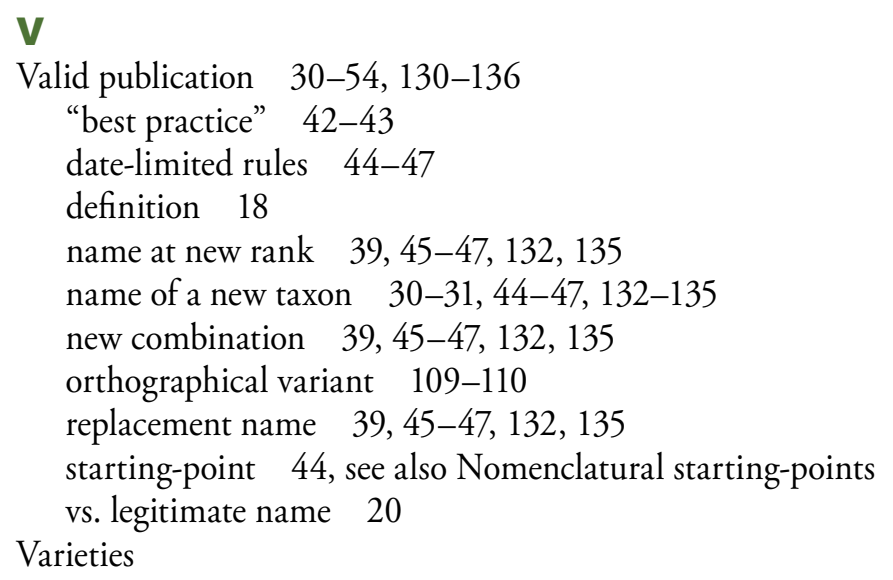


formation of names, see Infraspecific taxa

Variety as default infraspecific rank 131

Vernacular names, see Common names

Vice-presidents (of Nomenclature Section) 142

Vice-rapporteur 142

Viruses, Code, see International Code of Virus Classification and Nomenclature Voting

at Nomenclature Section 140

institutional votes $140-141$

personal votes 140

preliminary guiding vote $\quad 138-141$

W

Websites, see Resources for biological nomenclature

William Whitaker's Words 155

Works, suppressed 89, 91, see also Appendix I

WorldCat 155

Z

Zoological Code, see International Code of Zoological Nomenclature 